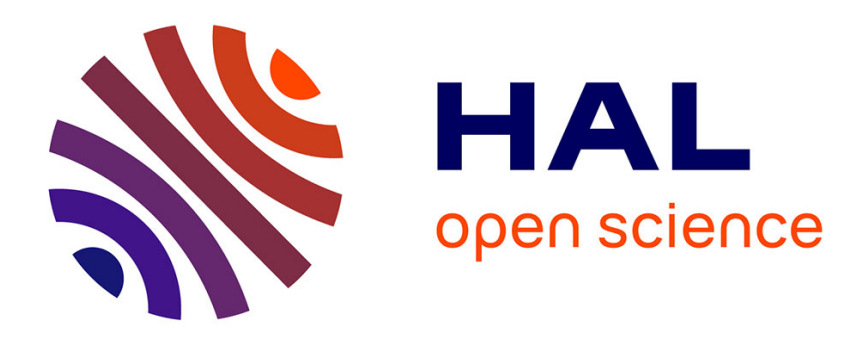

\title{
Antarctic atmospheric river climatology and impacts Jonathan Wille
}

\section{To cite this version:}

Jonathan Wille. Antarctic atmospheric river climatology and impacts. Climatology. Université Grenoble Alpes [2020-..], 2021. English. NNT : 2021GRALU003 . tel-03276308

\section{HAL Id: tel-03276308 \\ https://theses.hal.science/tel-03276308}

Submitted on 2 Jul 2021

HAL is a multi-disciplinary open access archive for the deposit and dissemination of scientific research documents, whether they are published or not. The documents may come from teaching and research institutions in France or abroad, or from public or private research centers.
L'archive ouverte pluridisciplinaire HAL, est destinée au dépôt et à la diffusion de documents scientifiques de niveau recherche, publiés ou non, émanant des établissements d'enseignement et de recherche français ou étrangers, des laboratoires publics ou privés. 
THÈSE

Pour obtenir le grade de

\section{DOCTEUR DE L'UNIVERSITÉ GRENOBLE ALPES}

Spécialité : Sciences de la Terre et de l'Univers et de l'Environnement

Arrêté ministériel : 25 mai 2016

Présentée par

\section{Jonathan WILLE}

Thèse dirigée par Vincent FAVIER, Enseignant-chercheur et codirigée par Francis CODRON, LOCEAN

préparée au sein du Laboratoire Institut des Géosciences de l'Environnement dans l'École Doctorale Sciences de la Terre de I'Environnement et des Planètes

Climatologie et impacts des rivières atmosphériques en Antarctique

\section{Antarctic atmospheric river climatology and impacts}

Thèse soutenue publiquement le 15 janvier 2021, devant le jury composé de :

\section{Monsieur VINCENT FAVIER}

PHYSICIEN ADJOINT, UNIVERSITE GRENOBLE ALPES, Directeur de thèse

Monsieur JOHN KING

DOCTEUR EN SCIENCES, BRITISH ANTARTIC SURVEY, Rapporteur Madame MASA KAGEYAMA

DIRECTRICE DE RECHERCHE, CNRS DÉLÉGATION ÎLE-DE-FRANCE SUD, Rapporteure

Monsieur JEAN-LOUIS DUFRESNE

DIRECTEUR DE RECHERCHE, CNRS DÉLÉGATION ÎLE-DE-FRANCE SUD, Examinateur

Madame SANDRINE ANQUETIN

DIRECTRICE DE RECHERCHE, CNRS DÉLÉGATION ALPES,

Présidente

Monsieur FRANCIS CODRON

PROFESSEUR DES UNIVERSITES, UNIVERSITE PARIS 6 -PIERRE \& MARIE CURIE, Co-directeur de thèse 


\section{Résumé}

En raison de l'augmentation de la pression de vapeur saturante avec la température, les précipitations en Antarctique sont censées augmenter au cours du prochain siècle. Cela conduirait à un accroissement de l'accumulation de neige sur le continent, atténuant ainsi en partie l'augmentation future du niveau des mers. Les tendances récentes de température et d'accumulation de neige en Antarctique ne reflète pas clairement ce processus. Le rôle joué par les intrusions d'humidité dans la variabilité des températures et des précipitations pourrait expliquer en partie ce paradoxe. Jusqu'à présent, seuls des événements épars de très forte intensité avaient été analysés. Une étude de 2014 portant sur la région de Dronning Maud Land avait montré la concordance des intrusions intenses avec l'occurrence de rivières atmosphériques (RA). Dans cette thèse, nous développons un algorithme de détection des rivières atmosphériques adapté aux régions polaires et créons une climatologie de ces événements à l'échelle de l'Antarctique. En utilisant les sorties du modèle à aire limitée MAR (Modèle Atmosphérique Régional), nous évaluons les impacts de rivières atmosphériques sur la fonte, la stabilité des plateformes de glace de la Péninsule Antarctique et sur les précipitations neigeuses en surface de la calotte.

Chaque point de la calotte est concerné par des rivières trois jours par an en moyenne. Cette valeur est plus faible encore à l'intérieur du continent. Pourtant, les rivières contrôlent les processus de fonte de surface sur l'Antarctique de l'ouest et la variabilité des précipitations sur l'Antarctique de l'Est. A l'ouest, les RA qui pénètrent à l'intérieur du continent provoquent des anomalies positives du rayonnement de grande longueur d'onde incident et de vent, accompagné d'effet foehn marqué le long des pentes situées sous le vent. Entre 1979 et 2017, les rivières provoqué 40\% de la fonte estivale sur la plateforme de Ross (près de $100 \%$ à plus haute altitude sur Marie Byrd Land) et 40 à $80 \%$ de la fonte hivernale le long des plateformes de la péninsule 
Antarctique. En été, ces RA contribuent aussi à la fonte des plateformes de glace de Larsen situées à l'est de la Péninsule. Les RA provoquent 60 à $80 \%$ des événements de fonte/ruissellement les plus intenses ainsi que les extrêmes de chaleur. Cette fonte est amplifiée par l'effet Foehn et par les anomalies positives des flux radiatifs incidents provoqués à l'Est de la Péninsule. L'eau de fonte s'accumule alors dans des lacs et des crevasses en surface des plateformes, étape préliminaire à la désintégration d'une plateforme par phénomène de fracturation hydraulique. Les RA repoussent aussi la glace de mer loin de la côte permettant à la houle d'abîmer les marges des plateformes de glace, permettant de déclencher leur désintégration. En particulier, la présence de RA a été découverte lors de la désintégration des plateformes de Larsen A fin janvier 1995 et de Larsen B fin février/début mars 2002. Dans l'ensemble, depuis 2000, 12 des 20 derniers événements de vêlage ou d'effondrement le long des plateformes de Larsen ont été précédés (dans la limite de 5 jours) par l'arrivée d'une RA. Enfin, les RA sont responsables de la majorité des précipitations les plus intenses en Antarctique. A l'Est, elles provoquent 20 à 30\% de l'accumulation de neige et contrôlent les tendances et la variabilité interannuelle précipitations neigeuses sur cette partie du continent. Ce contrôle s'étend même à la majeure partie de la calotte glaciaire entre 1980 et 2018.

En définitive, les RA jouent un rôle important du climat de l'Antarctique. Une évolution des conditions de blocage atmosphérique autour de l'Antarctique au cours du 21ème siècle engendrerait des changements du bilan de masse de surface de l'Antarctique. De telles évolutions sont actuellement ignorées dans le cadre des projections d'impact du changement climatique. 


\section{Abstract}

Due to the increased ability of the air to hold moisture with temperature, precipitation in Antarctica is expected to increase significantly over the next century. This process will undoubtedly lead to an increase in snow accumulation on the continent, thereby partially mitigating future sea level rise. However, recent observed trends in temperature and snow accumulation in Antarctica are insignificant and paradoxical. The role played by moisture intrusions in temperature and precipitation variability could partly explain this phenomenon. These events are known to transport warm air masses from the oceans to the Antarctic continent, but only individual and unrelated intrusion events have been described so far. In an earlier study of the Dronning Maud Land region, the description of atmospheric rivers (ARs) provided an innovative view to describe high intensity moisture intrusions. In this thesis, we develop an atmospheric river detection algorithm adapted to the polar regions, in order to create a climatology of these events at the Antarctic scale. Using the outputs of the regional climate model, MAR (Regional Atmospheric Model), we evaluate the impacts of atmospheric rivers on the melting in West Antarctic, ice-shelf stability on the Antarctic Peninsula ice shelves, and on snowfall across the Antarctic ice sheet.

Atmospheric rivers are infrequent events with coastal areas of Antarctica experiencing AR conditions around only three days per year on average and this value is even lower in Antarctic interior. However, ARs control surface melting processes on West Antarctica and precipitation variability on East Antarctica. In the west, ARs entering the interior of the continent cause positive anomalies in downward longwave radiation via highly liquid-laden clouds and wind, resulting in a marked foehn effect along leeward slopes. Between 1979 and 2017, rivers were thus associated with about $40 \%$ of the summer melt on the Ross Ice Shelf (nearly $100 \%$ at higher altitudes on Marie Byrd Land) and 40-80\% of the winter melt along the ice shelves of the Antarctic 
Peninsula. In summer, these rivers also contribute to the melting of the Larsen ice shelves located east of the Peninsula. Their direct contribution to cumulative melting is more limited than in winter because the intense solar radiation in summer allows daily melting to occur. However, ARs caused $60-80 \%$ of the most intense melt/runoff events as well as high temperature extremes. This melting is linked to the Foehn effect and the positive longwave radiative fluxes anomalies over the eastern Peninsula during AR passages. The melt water accumulates in lakes and crevasses on the ice shelf surface, a preliminary step in ice shelf disintegration by hydraulic fracturing. ARs also push sea ice away from the coast, allowing swells to hit and apply strain to the ice-shelf margins. ARs can thus trigger the final disintegration of ice shelves. In particular, ARs were present during the disintegration of the Larsen A ice shelf in late January 1995 and the Larsen B ice shelf in late February/early March 2002. Overall, since 2000, 12 of the last 20 calving or collapse events along the Larsen Ice Shelves have been preceded (within 5 days) by the arrival of an AR. Finally, atmospheric rivers are responsible for the majority of the most intense precipitation in Antarctica. In eastern Antarctica, 20-30\% of the snow accumulation occurred during of AR landfalls. Although this value remains modest, we observe that AR activity controls the trends and interannual variability of snowfall in this part of the continent. This control even extends to most of the ice sheet between 1980 and 2018 .

Ultimately, ARs play an important role in the Antarctic surface mass balance. Therefore, a change in atmospheric blocking conditions around Antarctica during the 21 st century would lead to changes in the Antarctic surface mass balance. Such changes are currently ignored in climate change impact projections. 


\section{Acknowledgments}

I sat down to write a paragraph about thanking those who helped me complete my thesis and instead I thanked everybody who help me along my life journey.

Going from the elementary school weatherboy to becoming a Doctor in Meteorology would not have been possible without the guidance and support of family, friends, and colleagues on this long path. I must first thank my parents, Mindy and Douglas, who never could say no to their children's strangest career paths. They tolerated my constant insistence to watch The Weather Channel on the family TV and helped direct me down the good path towards a quality meteorology education. Really everybody in my family and childhood friends including my brother David, sister-inlaw Emily, sister Jennifer, brother-in-law Mike, my aunt Barbara and uncle Phillip, my grandmother Leona, and Leah never once suggested that I should pursue something a bit more mainstream and profitable.

Attending the University of Oklahoma transformed my naïve love of weather into some actual meteorological skills, and I am so grateful to my professors. Especially to Dr. Cavallo and Dr. Basara who first drew me into polar meteorology and atmospheric rivers respectively. I will also always remember my time in Reading, England where Austin, Lindsay, Nicole, and myself somehow found time to learn some weather while also learning that living in Europe is pretty sweet. I want to thank my brothers in AEPI and other friends like Ryan, Bekah, Evilsizer, Kalman, Yoni, Carly, Rose who made this Jersey boy feel more at home in Oklahoma.

I became emersed into the world of Antarctic research when I did my master's at The Ohio State University. I am very thankful to my supervisor, Dr. David Bromwich who accepted a student who was rejected from every other university and could barely locate Antarctica on a map when he started. My teammates, Aaron, Sheng-Hung, Wes, Jerry, and Julien helped me develop my research and coding skills 
and made me look like a passable researcher. When responding to a roommate advertisement shortly after arriving in Columbus, I met Josh who felt guilty about selling me his decrepit former room and so invited me for some beers to watch a basketball game. Josh and his roommates Colin and Adam would become my lifelong friends who I am so grateful for getting me past some of the tougher days while going on some truly random adventures. I must also thank my other friends from the Columbus Jewish life like Katya, Stacie, Randi, and Jacob who made transplanting into a new city a bit easier.

After finishing school in Ohio, I took my suburban mind and body to Antarctica. I would have frozen over and became penguin food very quickly if it wasn't for the much more experienced and patient coworkers who became my ice family. Thank you, Tony, Francis, Beth, Kat, Ben, Marc, Fritz, and all the other talented and amazing people from the United States Antarctic Program and Antarctic Logistics and Expeditions who taught me about the ice life and helped me fully appreciate the wonders of Antarctica.

Now it is time to stop beating around the bush and discuss those in France who helped me raise my thesis baby. First, I must thank my supervisor, Vincent, who convinced me to make my $\mathrm{PhD}$ in France. I had a very fruitful PhD through his support, research network of collaborators, and desire to teach me the ways of the mountains and Génépi. I don’t recall Vincent complaining or questioning once when I basically changed the research project and said, "Well, what about atmospheric rivers? Those seem interesting." My co-supervisor, Francis, helped with many of the technical details of my research. Within the IGE, I want to thank Nicolas, Julien, Jai, Jordi, and Ambroise for basically teaching me Python from scratch and bouncing ideas around over a café, beer, or ski tour in the mountains. I must thank the MAR group (Xavier, Christoph, Cécile, and Charles) for explaining and providing the data from MAR that was crucial for my research. And thank you to Irina for teaming up as we uncovered all those atmospheric rivers in Antarctica. Outside of the lab, I had the love of an amazing group of friends who we shared so many unforgettable moments together. From exploring the streets of Copacabana, Brazil with my favorite Greek person, Foteini, to learning every detail about Vienna, Berlin, and especially the Berlin Pride with Mario and Eugenie, to being peer pressured into swimming in a frozen stream with 
Ugo, and discovering the pride and energy of an Italian Nonna with Erika and Zeno. There is of course the Sometimes Injured, Sometimes Employed, Sometimes Not Injured, Sometimes Unemployed, and Sometimes Chouffed Climbers Group (SISESNISUSCCG) consisting of Felix, Jakes, Camille, Michael, Amber, Nate, Line, Louise. Thank you so much for all the moments of pure mayhem and shenanigans whether it was in the Basse Terre, in the mountains, or a party where a certain American themed bathing suit made an appearance. And finally, I could never forget to thank my partner Isabelle, who gave me enough smiles, hugs, motivational speeches, love, and adventures to make this PhD happen. I am truly blessed. Thank you everybody.

On a different note, beyond the scientific rational for studying the impacts of atmospheric rivers over the Antarctic Ice Sheet, there is also a personal story behind this research that I would like to share. In the austral summer of 2015-2016, I was working as a weather observer for the United States Antarctic Program and was stationed out of the remote West Antarctic Ice Sheet Divide (WAIS Divide) field camp. Located about a mile above sea level (1,800 meters), WAIS Divide was formerly an ice core drilling site that now serves as a regional science logistics hub. This was my first time visiting Antarctica and constantly found myself awestruck by the harshness of an icy continent once described by Robert Scott as, "Great God! this is an awful place and terrible enough for us to have laboured to it without the reward of priority." During my time at WAIS Divide, I would become familiar with the rolling ice fogs, clouds that would make the horizon indistinguishable, and flat light that made tripping over sastrugi a daily exercise. However in early January, the weather turned in a way that even the most seasoned ice people found bizarre. The clouds transformed from light and crystal-like to low, dark and laden with liquid moisture. And the temperatures that generally ranged from $-30^{\circ} \mathrm{C}$ to $-10^{\circ} \mathrm{C}$ were hovering around $0^{\circ} \mathrm{C}$ (Figure 1). As a result, the snow surface became increasing sticky making aircraft operations difficult while snow melted next to any object optically dark enough to absorb radiation. During this five day or so period, blizzards episodically blew through the camp dumping a heavy, wet snow making shoveling more back breaking than usual.

While camp life became more stressful for the support staff during this period, the atmospheric scientists stationed at the camp measuring and profiling the atmospheric conditions were collecting data that arrived like a late Christmas present. 


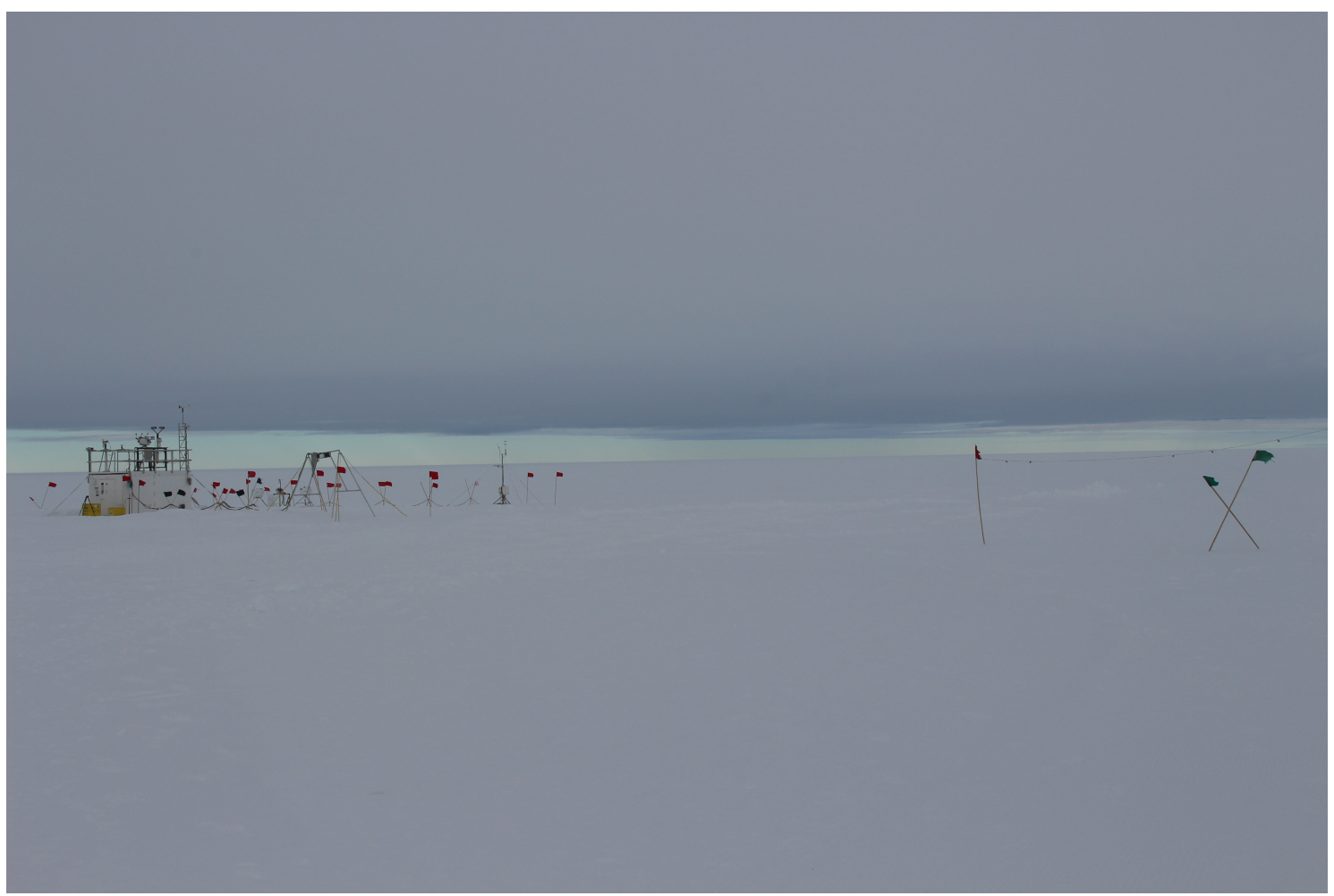

Figure 1: Photo from WAIS Divide Camp, Antarctica taken January 10th, 2016.

The lidars and radiosondes launches revealed an intrusion of warm, moist air more commonly observed with cyclone landfalls at the coastline, not at $79^{\circ} \mathrm{S}$. Meanwhile, the weather forecasters back in civilization were relaying to me that the conditions we were observing at WAIS Divide were at the edge of a highly amplified jet pattern that was leading to widespread melting conditions and storminess across Marie Byrd Land. Again, these conditions were highly foreign to the eyes of the forecasters. To the scientists camped out with us, the data collected was gold and conversations began immediately on trying to understand what just occurred over West Antarctica. After my season on the ice as support staff, I would return to the lab in The Ohio State where I made my masters studies and became involved with the project analyzing what occurred on those early January days. Eventually a paper was written covering the January 2016 West Antarctic melt event (Nicolas et al. [2017]), but I never forgot those alien dark skies that I witnessed. Seeing how quickly the frozen plateau could transform to mush from a few days of warm weather motivated me to continue studying this event and later understand how an atmospheric river was responsible for the extreme temperature surge (Wille et al. [2019]). 


\section{Contents}

Acknowledgments vii

Foreword $\quad$ xiii

1 Introduction: The Antarctic climate system and atmospheric rivers 1

1.1 Antarctic climate features . . . . . . . . . . . . . . . 1

1.1.1 Antarctic Storm Tracks . . . . . . . . . . . . . 2

1.1.2 The Southern Annual Mode . . . . . . . . . . . . . 7

1.1.3 Tropical external forcings . . . . . . . . . . . . . . 11

1.2 Atmospheric rivers . . . . . . . . . . . . . . . 16

1.2.1 Atmospheric river background . . . . . . . . . . . . 16

1.2.2 Atmospheric rivers in Polar Regions . . . . . . . . . . . . . . 21

1.2.3 Thesis context ................... 23

2 Tools and methods $\quad 25$

2.1 Detecting atmospheric rivers . . . . . . . . . . . . . 25

2.1.1 Preceding atmospheric river detection algorithms . . . . . . 25

2.1.2 The development of the polar atmospheric river detection al-

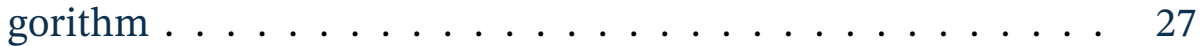

2.2 The MAR . . . . . . . . . . . . . . . . 33

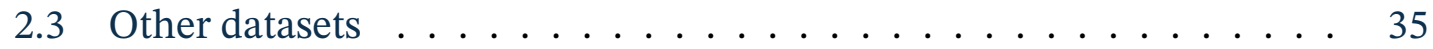

3 Surface melting in West Antarctica and atmospheric rivers 37

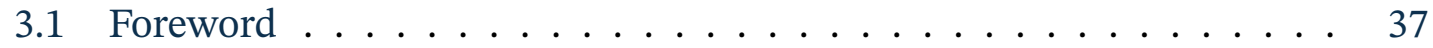

3.2 Article: West Antarctic surface melt triggered by atmospheric rivers . 38

4 The role of atmospheric rivers in ice shelf collapse on the Antarctic 
$\begin{array}{lr}\text { Peninsula } & 47\end{array}$

4.1 Foreword ......................... 47

4.2 Article: The atmospheric river threat to Antarctic Peninsula ice-shelf

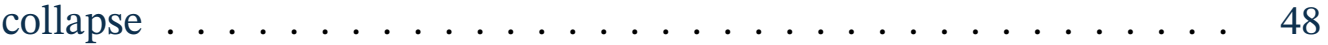

5 An Antarctic atmospheric river climatology 79

5.1 Foreword . . . . . . . . . . . . . . . . . 79

5.2 Article: Antarctic atmospheric river climatology and precipitation impacts ............................ 80

6 Conclusions and perspectives 109

6.1 Conclusions . . . . . . . . . . . . . . . . . . 109

6.2 Perspectives . . . . . . . . . . . . . . . . . 112

$\begin{array}{ll}\text { Bibliography } & 118\end{array}$

$\begin{array}{ll}\text { Appendices } & 152\end{array}$

A Supplementary information and figures to "West Antarctic surface melt $\begin{array}{ll}\text { triggered by atmospheric rivers" } & 155\end{array}$

A.1 Supplementary Text . . . . . . . . . . . . . . . . . . 155

A.2 Supplementary figures and tables . . . . . . . . . . . . . . 162

B Supplementary information and figures to "The atmospheric river threat to Antarctic Peninsula ice-shelf collapse” 179

B.1 Further discussion on ice-shelf disintegration events . . . . . . . . . . 179

B.2 Supplementary figures . . . . . . . . . . . . . . . . . . 187

B.3 Supplementary Tables . . . . . . . . . . . . . . . . . . . . . 196

C Supplementary figures to "Antarctic atmospheric river climatology and $\begin{array}{ll}\text { precipitation impacts” } & 203\end{array}$

D Code for atmospheric river detection algorithm: Wille_v1 221

E Code for atmospheric river detection algorithm: Wille_v2 227 


\section{Foreword}

The anthropogenic warming of our world is already altering landscapes and leaving populations more vulnerable to more frequent natural disasters, drought, flooding, along with the prospect of sea-level rise (IPCC). Accurately predicting the extent of future sea-level rise is essential for coastal communities to begin planning for the eventual consequences of increased coastal flooding and salt-water inundation (Shuang-Ye Wu et al. [2002]. The reasons for the recent sea-level rise is primarily the thermal expansion of the oceans, but the melting glaciers and ice sheets will become the main source of ocean expansion in the near future (Chen et al. [2013]). The melting of the Greenland and Antarctic ice sheets are the biggest concern with the Antarctic ice sheets holding enough land-ice to raise the sea-levels by $58 \mathrm{~m}$ (Fretwell et al. [2013]).

Projecting the potential rise in sea level means calculating the mass balance of the Antarctic ice sheet. The grounded ice mass balance encompasses all the terms that make up the net balance between mass gains by snow accumulation and mass losses through melting both surface and subsurface at the bedrock, and the ice flux towards the ocean above the grounding line (see Fig. 2). The surface mass balance $(\mathrm{SMB})$ reduces the components to the summation of total precipitation, surface sublimation, drifting snow transport which includes erosion, deposition, and sublimation of the snow particles, and the water from melt and rain that drains off the ice surface (Favier et al. [2017]). Overall, the SMB over Antarctica is dominated by the influx of snowfall which are mainly controlled by cyclonic activity. Although surface melting values in Antarctica are less consequential compared to surface melt on the Greenland ice sheet, surface melting can trigger the sudden collapse of ice shelves like observed on the Antarctic Peninsula. These collapses remove the buttressing effect allowing the previously blocked glaciers to freely flow into the ocean and reenforces the importance 


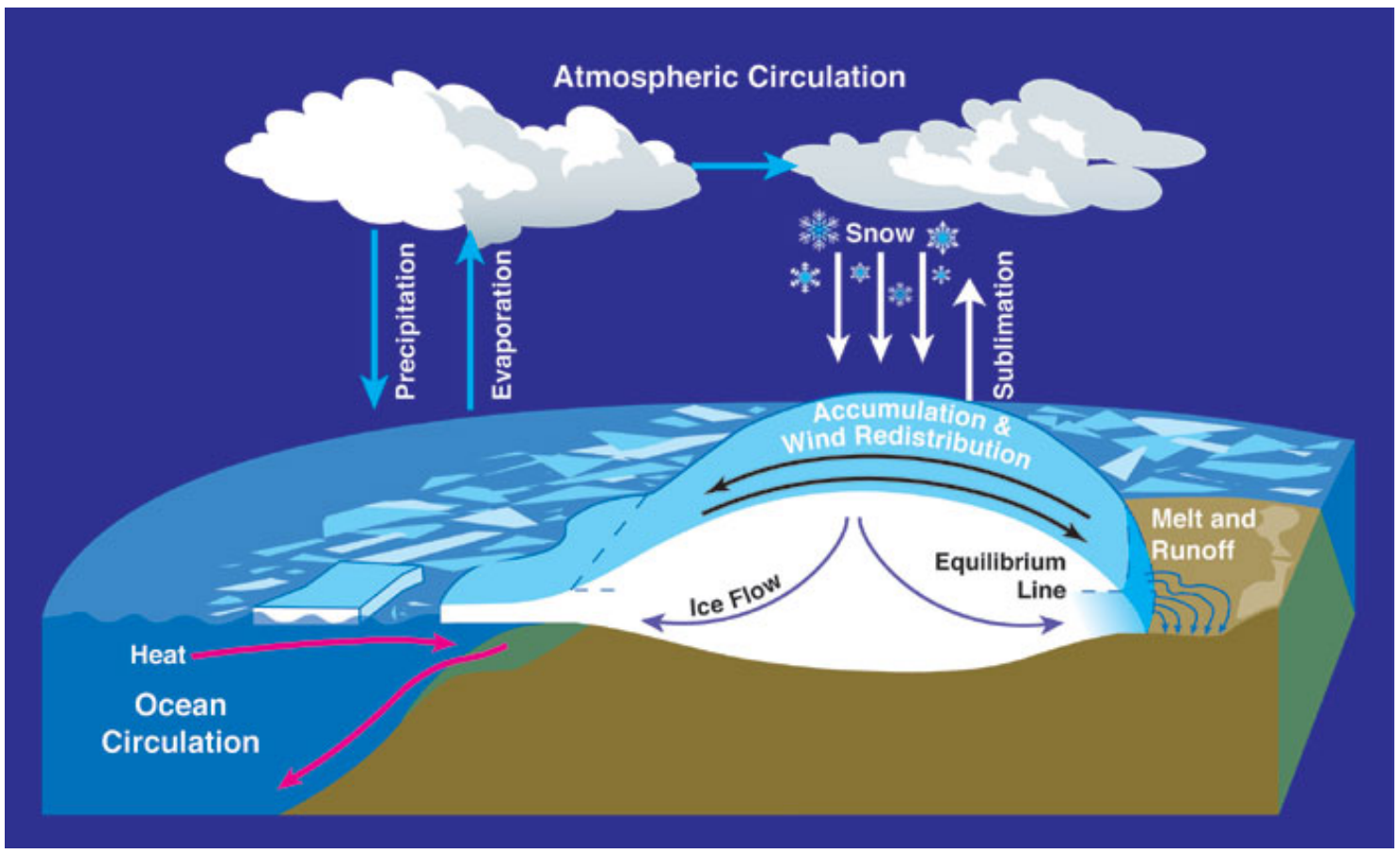

Figure 2: The various components of an ice sheet's mass balance. Source: NASA.

of understanding the full Antarctic mass balance. While it appears simple that storms will bring snowfall while warm, sunny days will cause surface melt, the reality is that intense cyclones can both positively and negatively impact the mass balance. Storms classified as atmospheric rivers (ARs) bring intense warm air and moisture advection to the Antarctic continent and are capable of simultaneously producing heavy snowfall and surface melting that threatens the stability of ice shelves. (Bozkurt et al. [2018]; Gorodetskaya et al. [2014]. Finally, these ARs occur intermittently which drives our desire to quantify how these short-lived, extreme events impact the Antarctic-wide mass balance.

While most the ice on East Antarctica is projected to remain stable during the next century even under the most pessimistic predictions, the West Antarctic Ice Sheet has been losing mass at an increasingly alarming pace of $159 \pm 26 \mathrm{Gt} \mathrm{yr}^{-1}$ while the Antarctic Peninsula is losing mass at a rate of $33 \pm 16 \mathrm{Gt} \mathrm{yr}^{-1}$ (IMBIE [2018]). In total, the possible Antarctic ice sheet contribution to sea-level rise varies from 7.8 to $30.0 \mathrm{~cm}$ by 2100 under a RCP 8.5 climate forcing scenario (Seroussi et al. [2020]). Ice sheet wastage is currently driven by accelerated ice discharge at the ice sheet boundaries (IMBIE [2018]). This acceleration could become more dramatic in a warmer climate (Ritz et al. [2015]; Edwards et al. [2019]) and only partly mitigated by a poten- 
tial precipitation increase from increased atmospheric saturation vapor pressure (e.g. Krinner et al. [2014]).

Recent studies have indicated that parts of Antarctica are warming at rates far exceeding the global average like West Antarctica at $2.4^{\circ} \mathrm{C} \pm 1.2^{\circ} \mathrm{C}$ from $1958-2010$ (Bromwich et al. [2012]) and the South Pole at $0.61^{\circ} \mathrm{C} \pm 0.34^{\circ} \mathrm{C}$ per decade over the past three decades (Clem et al. [2020]). This warming trend has led to an increasing snowfall trend over the Antarctic ice sheet (King and Watson [2020]). However, these snowfall trends are not observed Antarctic-wide and do not match regional warming/cooling trends (Thomas et al. [2015]; Medley and Thomas [2019]).

There is not a clear relationship between temperature and Antarctic snowfall accumulation unlike as simulated by climate models (Fudge et al. [2016]). This implies that variability in atmospheric dynamics in relation to the transport of moisture to the Antarctic ice sheet plays an important role that is missed by most general circulation models. Marine or moist air intrusions have been shown to impact high precipitation events (Kurita et al. [2016]), but the crucial role of extreme precipitation events on interannual precipitation was discovered only recently (Turner et al. [2019]), suggesting a disconnect between temperature and mean annual precipitation across the entirety of Antarctica. Gorodetskaya et al. [2014] was the first to suggest ARs could play a crucial role in these extreme precipitation events. The study described ARs as a mechanism capable of transporting extreme amounts of moisture poleward and significantly and quickly impact the local mass balance. Unlike moist air intrusions, ARs have a clear synoptic definition embedded within the extra-tropical cyclone model. This means their variability is controlled by variations in the atmospheric circulation patterns and we can develop tools for tracking and ultimately, develop a climatology of their impacts on the Antarctic cryosphere.

The manuscript presented here tells the story of the first AR climatology over Antarctica in regards to surface melt, ice-shelf stability, and precipitation. After an introduction describing the state-of-the-art for Antarctic atmospheric circulation and AR dynamics (Chapter 1) and a description of the AR detection algorithm along with other tools (Chapter 2), the results chapters each consist of a manuscript formatted for publication. Chapter 3 describes the relationship between ARs and surface melting in West Antarctica, Chapter 4 describes the relationship between ARs and ice-shelf 
stability on the Antarctic Peninsula, and Chapter 5 provides an overall AR climatology and the relationship between ARs and precipitation patterns across the Antarctic continent. Chapter 6 presents a summary of this $\mathrm{PhD}$ research and perspectives for further Antarctic AR research. 


\section{Chapter 1}

\section{Introduction: The Antarctic climate system and atmospheric rivers}

\subsection{Antarctic climate features}

The underlining motivation behind this thesis is to better understand how the Antarctic surface mass balance (SMB) will change in a warming climate, specifically focusing on how moisture is transported to the Antarctic continent. According the Clausius-Clapeyron equation, an increase in temperature would increase the saturation vapor pressure allowing for the atmospheric to retain more moisture (e.g., Ligtenberg et al. [2013]; Krinner et al. [2014]; Agosta et al. [2013]; Frieler et al. [2015]) In theory, this would increase snow-accumulation in Antarctica (see Favier et al. [2017] for a review), mitigating any potential mass loss through ice dynamics in West Antarctica from destabilizing marine terminating glaciers and ice sheet collapse increasing ice sheet drainage into the Southern Ocean (Bell et al. [2018]; Bintanja et al. [2013]; Favier et al. [2014]. Current ongoing persistent changes in the ice sheet-ocean interactions (see Pattyn [2017]) are controlling present Antarctic mass losses, but Rignot et al. [2019] recently indicated that glacier mass losses decreased along WAIS. This supports more modest projected changes than expected. In that case, SMB change should play a very significant role, and the relationship between temperature and accumulation could be of interest.

However, discerning a clear Clausius Clapeyron relationship is difficult over the 20th Century as snowfall has increased insignificantly over the Antarctic ice sheet 
(King and Watson [2020]). Even over large time scales characterized by large temperature variations, snow accumulation is highly related to the occurrence of moisture intrusions. Then, in spite of clear relationship over the deglaciation (Frieler et al. [2015]), ice core records suggest a complicated and ambiguous relationship over the past 12,000 years, while general circulation models show a more homogenous and highly correlated temperature/precipitation relationship (Fudge et al. [2016]).

This partly reflects that climate models are only partially capturing variations in the atmospheric circulation around Antarctica and that our understanding of accumulation processes on the continent is incomplete. However, there is also the strong natural variability of the Antarctic climate, which leads to a relatively late projected emergence of an anthropogenic climate change signal over the Antarctic continent (Jones et al. [2016]; Mora et al. [2013]), i.e. not before the mid twenty-first century. This slow emergence is a product of the complex and variable interactions with the Southern Ocean, sea ice cover, westerlies, and moisture intrusions linked with blockings. To properly study moisture transport towards Antarctica requires an in-depth understanding of the various components that influence the Antarctic storm track and modes of climate variability. Many of the locations described in the following section are illustrated in Figure 2.2.

\subsubsection{Antarctic Storm Tracks}

\section{Synoptic-scale cyclogenesis}

Before examining the behavior of moisture intrusions into the Antarctic continent, we need a basic understanding of the extra-tropical cyclone climatology around Antarctica. The continent is surrounded by a nearly symmetric circumpolar region of relative low pressure that represents the convergence between ascending branches of the feral and polar cells. Synoptic scale cyclogenesis occurs within this region then the storms are directed towards higher latitudes by the Coriolis force as they reach maturity. When the cyclones reach the Antarctic coastline, they become occluded as baroclinic instability decreases and then dissipate (King and Turner [2007]). Cyclones traversing across the Southern Ocean go through periods of formation and regeneration, as decaying cyclones provide shear vorticity to aid new cyclogenesis. Regardless 


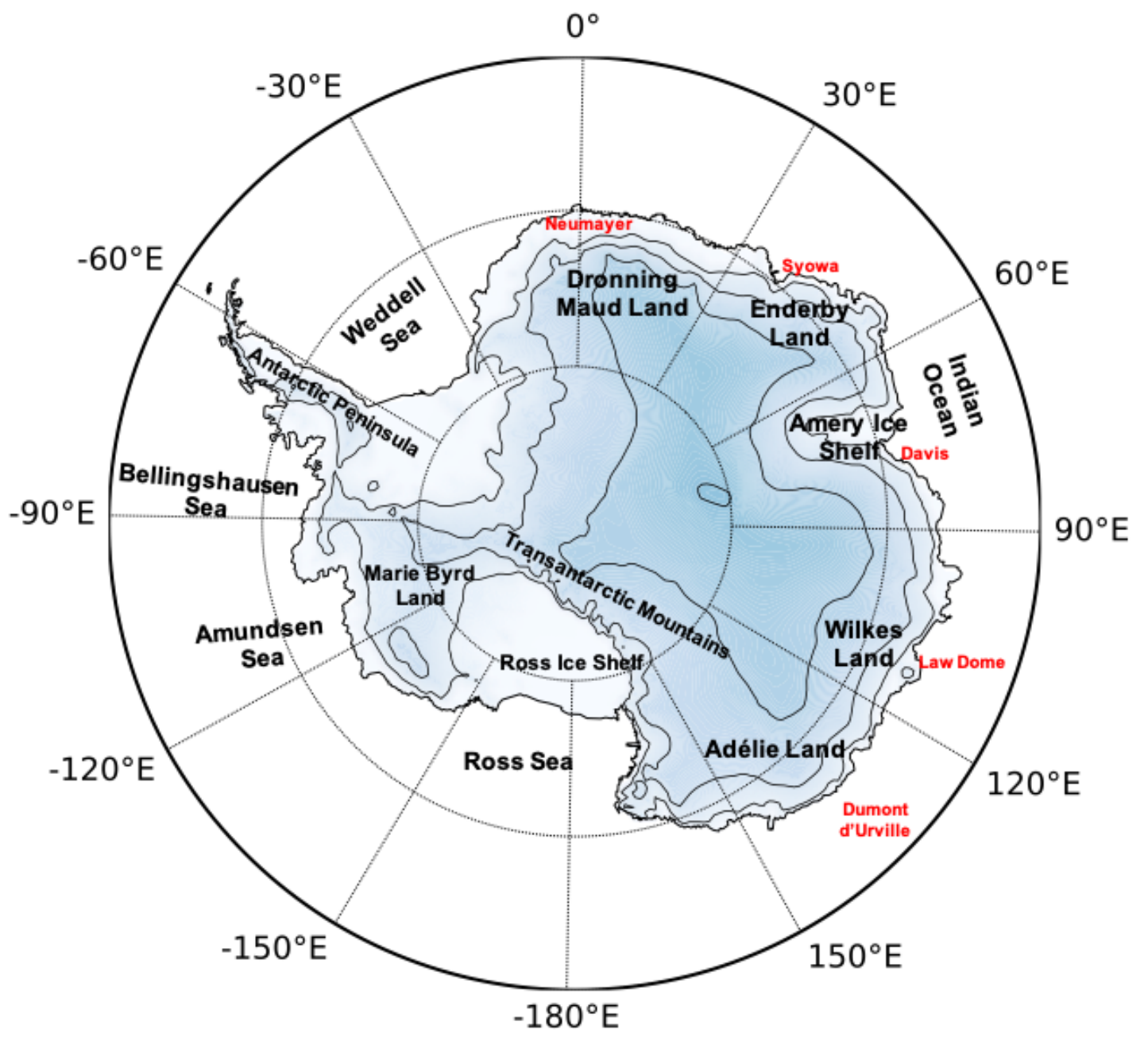

Figure 1.1: Map of Antarctica along with location names often mentioned in this manuscript.

of seasonality, cyclogenesis generally exceeds cyclosis north of $50^{\circ} \mathrm{S}$ while the opposite is true south of $50^{\circ} \mathrm{S}$ (Hoskins and Hodges [2005]). Despite the nearly symmetric circular shape of the circumpolar trough, cyclone activity across the Southern Ocean is not uniform as the highest cyclone density occurs near $60^{\circ} \mathrm{S}$ in the Indian and Atlantic Ocean regions with the South Pacific becoming more active in winter (Fig. 1.2; Simmonds et al. [2003]). These cyclones that form over the Southern Ocean are the main source of large precipitation events along the Antarctic coastline as they advect moist, maritime air masses that are orographically lifted along the steep coastal ice slopes. The location of cyclogenesis is critical to determine where the Southern Ocean cyclones typically strike along the Antarctic coast (Goodwin et al. [2016]; Hosking et al. [2017]; Hoskins and Hodges [2005]). However, the polar anticyclone and the steep slope of the high Antarctic plateau prevents these moist air masses from travel- 

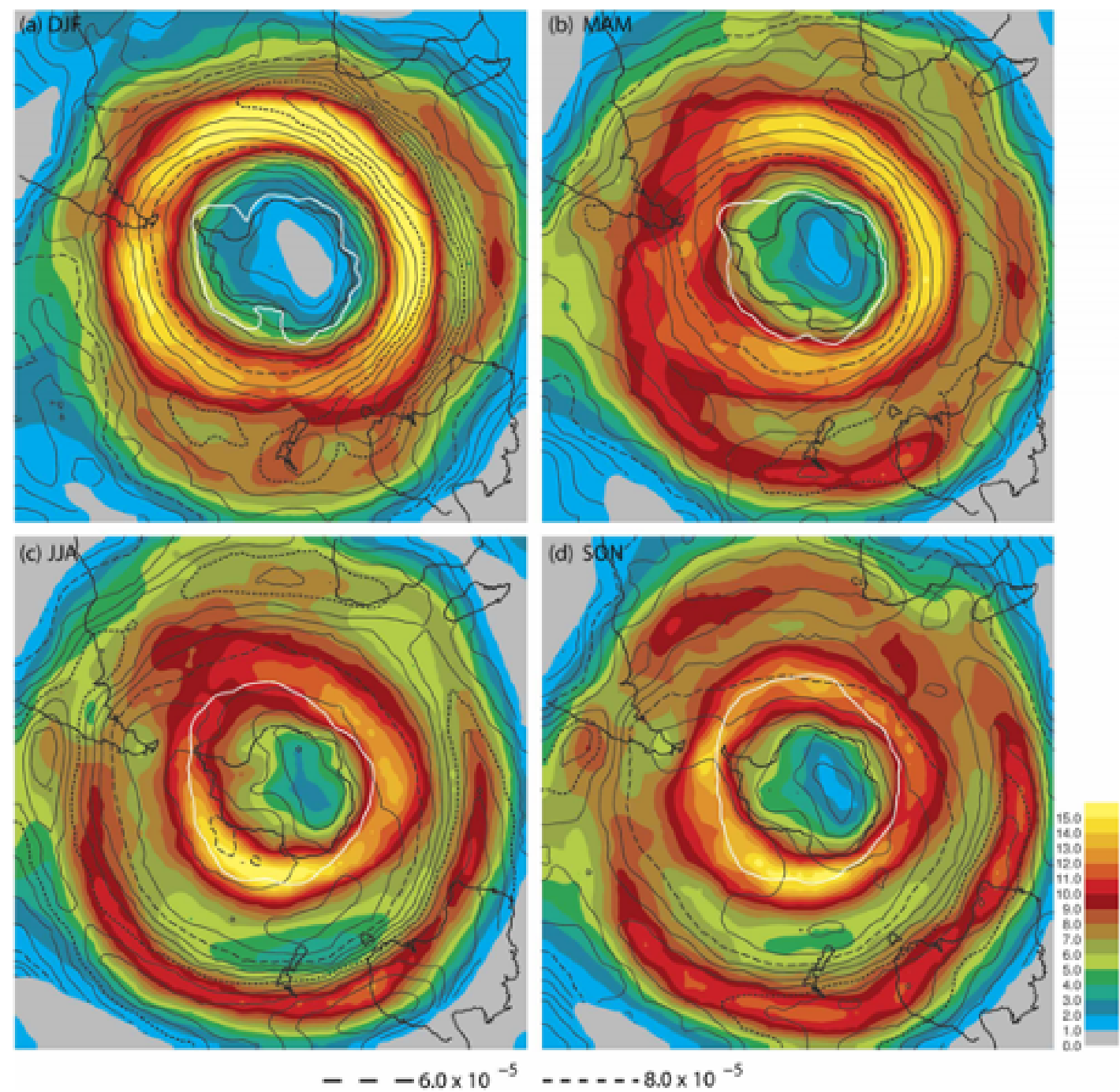

$\cdots \cdot-1.0 \times 10^{-5}$

Figure 1.2: The seasonal cycle of southern hemisphere storm track based the $250 \mathrm{hPa}$ vorticity for (a) DJF, (b) MAM, (c) JJA, and (d) SON. Source: Hoskins and Hodges [2005].

ing far inland due to cyclone decay from topographically induced vorticity compression (Agosta et al. [2019]; Bromwich [1988]; Hobbs [1915]; Kittel et al. [2018]). Away from the influence of maritime cyclones higher up on the Antarctic continent, radiative cooling is the primary source of precipitation, often falling as clear sky ice crystals (Bromwich [1988]; King and Turner [2007]; Picard et al. [2019]; Stenni et al. [2016]).

There are important regions of intense cyclogenesis south of $50^{\circ} \mathrm{S}$ along the Antarctic coastline that are aided by local factors such as katabatic wind, barrier wind jets, and sea ice extent (Bromwich et al. [2011b]; Noone and Simmonds [1998]; Simmonds et al. [2003]). Along the Antarctic coastline, cyclones sometimes interact with the terrain following katabatic winds draining off the Antarctic plateau that create 
regions of increased shear vorticity. This is especially prevalent across Adelie Land where the negatively buoyant katabatic wind funnels down the steep topography creating intense coastal barrier winds. These strong winds near the coast can provide low-level cyclonic vorticity to nearby cyclones or create potential temperature anomalies that reduce the stability of the lower troposphere to aid in lee cyclogenesis with the arrival of upper-level synoptic scale forcing (Bromwich et al. [2011b]). Further into the continent, katabatic winds draining down glaciers and other steep topography generate cyclone vorticity which can lead to mesoscale cyclogenesis like near Byrd Glacier (Carrasco and Bromwich [1993]; O'Connor et al. [1994]). More research is needed to identity the likely many other regions of mesoscale cyclogenesis across the continent.

\section{Moisture intrusions into Antarctica}

As mentioned earlier, synoptic cyclones capable of advecting warm, moist air masses towards the Antarctic coastline are the primary source of precipitation and overall poleward transport of heat and moisture for the continent. When the amplitude of the polar jet increases and blocking anticyclones form in the Southern Ocean, these synoptic cyclones can travel further inland (Hirasawa et al. [2013]; Massom et al. [2004]; Schlosser et al. [2010]). These events are often regarded as "moisture intrusions" and have been described to cause intense temperature increases and high-precipitation events in inland regions normally cold, dry, and stable (Kurita et al. [2016]; Naithani et al. [2002]; Servettaz et al. [2020]). When these moisture intrusions penetrate deep into the continent, they can account for a large portion of the annual precipitation budget in a short time (Bromwich [1988]; King and Turner [2007]; Turner et al. [2019]).

\section{Wavenumber 3 pattern and the Amundsen Sea Low}

A rotating tank experiment with a modelled Antarctica demonstrated that the synoptic cyclonic eddies around Antarctica are topographically forced features (Baines and Fraedrich [1989]). The modelled coastal irregularities yielded a theoretical wavenumber 3 pattern. Reanalysis confirms that within the mean sea level pressure (MSLP) field around Antarctica, there are three semi-permanent climatological low-pressure systems centered nearby $20^{\circ} \mathrm{E}, 90^{\circ} \mathrm{E}$ and $150^{\circ} \mathrm{W}$ that strongly 

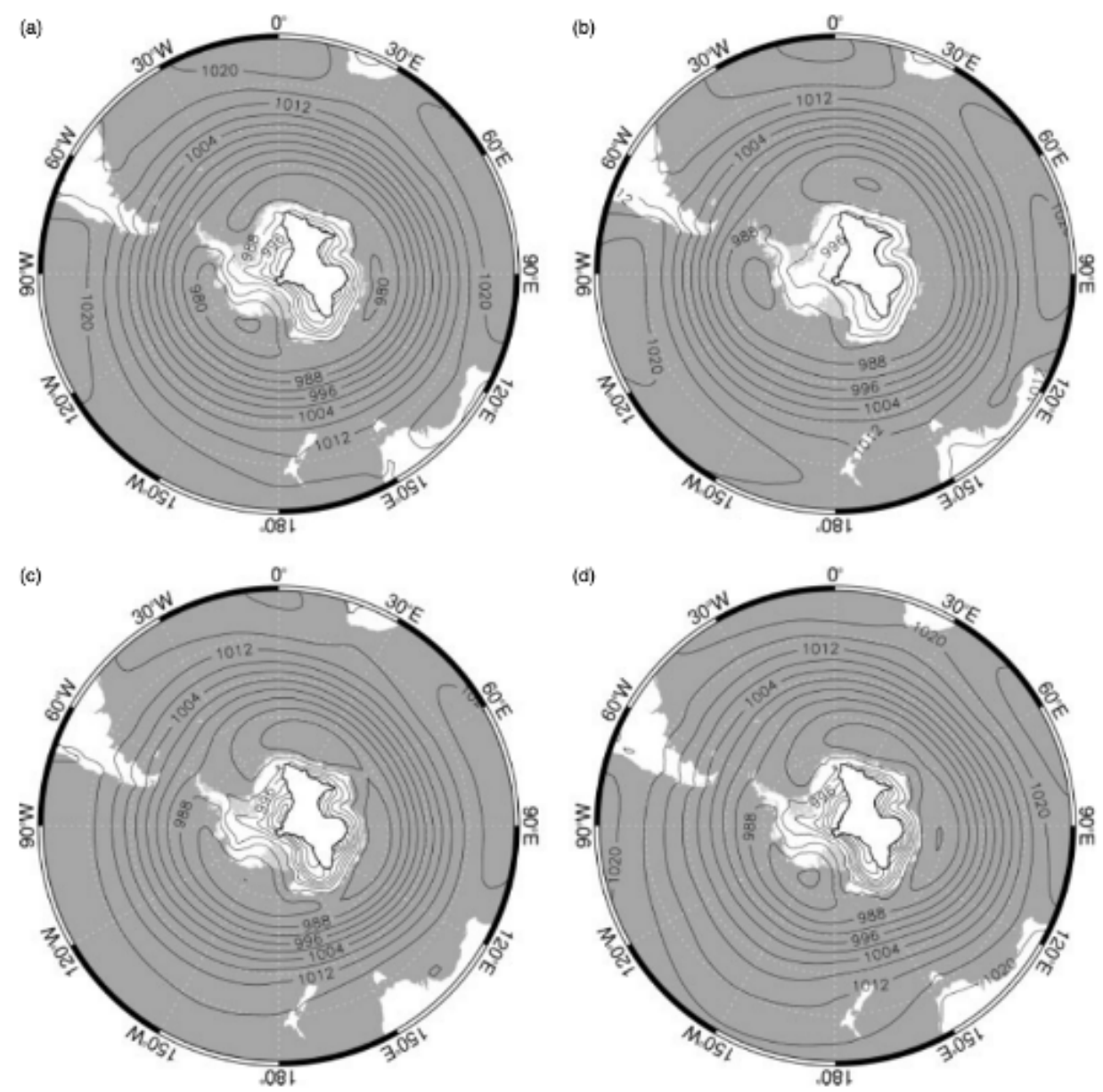

Figure 1.3: The mean MSLP for 1979-2008 from ERA-40 and ECMWF reanalysis for (a) SON, (b) DJF, (c) MAM, and (d) JJA. Source: Turner et al. [2013].

influence moisture fluxes onto the Antarctic continent (Fig. 1.3). One of the climatological lows within the circulation of the circumpolar that strongly influences the climate of West Antarctica is known as the Amundsen Sea Low or the AmundsenBellingshausen Sea Low (ASL). The clockwise flow around this quasi-stationary low centered approximately between $55-75^{\circ} \mathrm{S}$ and $180-90{ }^{\circ} \mathrm{W}$ is an important feature of the West Antarctic and Ross Ice Shelf climatology (Fogt et al. [2012b]; Hosking et al. [2013]; Raphael et al. [2016]; Turner et al. [2013, 2016]). The ASL forms as the strong barotropic flow separates around the coastal extension around $150{ }^{\circ} \mathrm{E}$ and diverges into the Ross Sea region (Baines and Fraedrich [1989]).

A review of the ASL climatology in Turner et al. [2013] demonstrated that the ASL experiences a MSLP maximum in the summer and winter and a minimum in the autumn and spring. Along the eastern edge of the low, north-northwesterly flow advects a warm/moist marine airmass towards the Antarctic Peninsula and Belling- 
hausen Sea while south-southeasterly flow along the western edge advects a cold/dry continental airmass from West Antarctica over the Ross Sea. The meridional location of the ASL is significantly correlated with the upper-level zonal and meridional wind speeds across West Antarctica and the Ross Ice Shelf region. The seasonal MSLP and position of the ASL is influenced by the prevalence of Rossby wave activity during the austral winter (Turner et al. [2013]). This directs the low west towards the Ross Sea in austral winter and east towards east the Antarctic Peninsula in austral summer (Bertler et al. [2004]; Fogt et al. [2012b]). Generally, the ASL migrates westward from $110^{\circ} \mathrm{W}$ to $153^{\circ} \mathrm{W}$ between January to June with the low sliding back to $120^{\circ} \mathrm{W}$ by December. Following the position of the polar jet, the ASL reaches its most southerly position in August (Turner et al. [2013]). The relative low pressure associated with the ASL throughout the troposphere makes the Amundsen-Bellingshausen seas favorable locations for cyclone activity. Regional cyclone system density and central pressures are statistically significantly correlated with the climatological magnitude of the ASL. In addition, the position of the strongest cyclones in the region is correlated with the position of the ASL (Fogt et al. [2012b]). Still the position and intensity of the ASL is sensitive to broader scale teleconnections.

\subsubsection{The Southern Annual Mode}

\section{Definition}

The intensity of the zonal winds, meridional position of the circumpolar westerly wind belt, and overall storm track varies in accordance with the Southern Annual Mode (SAM), the principal component of monthly extratropical climate variability across the southern hemisphere (SH) (Karoly [1990]; Kidson [1975, 1988a, b]; Kiladis and Mo [1998]; Rogers and van Loon [1982]; Shiotani [1990]). Originally referred to as the Southern Oscillation Index, SAM is defined as the difference in zonal MSLP between $40{ }^{\circ} \mathrm{S}$ and $65^{\circ} \mathrm{S}$ (Gong and Wang [1999]). The height anomalies associated with SAM are nearly symmetric around Antarctic with some important exceptions. Using an Empirical Orthogonal Function (EOF), Wilson [2013] shows areas of significant asymmetry in West Antarctica and nearby the Ronnie Ice Shelf. Internal transient eddy forcing helps to maintain the circumpolar winds against friction. These 
synoptic eddies are supported by the shear and circular vorticity associated with the westerly jet and the increased baroclinicty found at higher latitudes supported by the Coriolis force (Karoly [1990]). Therefore, the eddies allow SAM to be an independent mode of tropospheric variability that is not reliant on external forces (Limpasuvan and Hartmann [1999, 2000]).

\section{Link with SH climate variability}

Similar to the North Atlantic Oscillation in terms of dynamics, a SAM+ (SAM-) phase corresponds with increased (decreased) upper level zonal winds and low (high) pressure anomalies across the Antarctic continent (Kidson [1988a]; Thompson and Woodworth [2014]; Thompson and Wallace [2000]). However, the relationship between storm tracks and SAM phase is less clear. A more recent interpretation postulates SAM as a degree of decoupling (SAM+) and coupling (SAM-) between Antarctic and the southern mid-latitudes with more impacts on Antarctic climate variability than the mid-latitudes (Spensberger et al. [2020]).

The phase of SAM has implications for precipitation and temperature patterns across Antarctica, southern Australia, southern Africa, southern South America, and the sub-Antarctic glaciers and ice caps (Cullather et al. [1996]; Favier et al. [2016]; Hendon et al. [2007]; Jomelli et al. [2017]; Reason and Rouault [2005]; Silvestri [2003]; Turner et al. [2005]). Generally, the differences in the SAM polarities have significant impacts on temperatures throughout most of the Antarctic continent (Marshall and Thompson [2016]). According to the Fogt reconstructed SAM index (Fogt et al. [2009]), SAM has been trending more positive since the 1970s and is averaging at its most positive in the past 1,000 years (Abram et al. [2014]). This significant and steady positive phase trend has been linked with significant temperature and precipitation trends across Antarctica, most notably in the Antarctic Peninsula and West Antarctica (Bromwich et al. [2012]; Goodwin et al. [2016]; Nicolas et al. [2017]; Orr et al. [2008]; Skvarca et al. [1998]; Turner et al. [2005]; Thomas et al. [2015]; Medley and Thomas [2019]). A SAM+ trend is responsible for much of the warming occurring in the northeast Antarctic Peninsula. During SAM+, positive significant zonal wind anomalies occur over the northeast peninsula for all seasons. These stronger circumpolar westerlies lead to increased westerly moisture flux resulting in increased 
precipitation along the western Antarctic Peninsula (Fig. 1.4; Marshall et al. [2017]). The mountains along the Antarctic Peninsula trigger orographic precipitation during a moist zonal flow and leading to a dry precipitation shadow in the eastern Antarctic Peninsula. A stronger western zonal wind flow over the Antarctic Peninsula also results in leeside Föhn winds and adiabatic warming (Clem et al. [2016]; Orr et al. [2008]). This warming in the northeast peninsula created large areas of surface melt that likely led to the Larsen B ice shelf collapse and subsequent rapid acceleration of glaciers into the collapsed ice shelf region (Fahnestock et al. [2002]; Scambos [2004]; Scambos et al. [2000]; Vaughan and Doake [1996]). However since the late 1990s, the Antarctic Peninsula has experienced a pronounced cooling trend as cyclonic conditions over the Weddell Sea have favored a colder southeasterly wind especially during the austral summer (Turner et al. [2016]). Moreover, the climatic changes in West Antarctica contradict the prevailing notion that a more SAM+ would enhance cooling over the West Antarctic Ice Sheet. Between 1958 and 2010, temperatures have linearly increased at Byrd Station by $2.4{ }^{\circ} \mathrm{C} \pm 1.2{ }^{\circ} \mathrm{C}$, making West Antarctica one of the fastest warming places in the world (Bromwich et al. [2012]; Jones et al. [2016]). During January 2016, an extensive melt event occurred over parts of the West Antarctic Ice Sheet and the Ross Ice Shelf. For nearly two weeks, a meandering jet pattern advected marine air resulting in large amounts of liquid-water clouds over the melt region. This event occurred despite SAM+ conditions, which demonstrates the relationship between SAM and surface conditions is not a simple correlation (Nicolas et al. [2017]).

While the January 2016 West Antarctic melt event featured a strong blocking ridge during SAM+, other studies support the notion that the SAM phase is connected with blocking likelihoods with SAM- supporting more blocking events (Scott et al. [2019]). The stronger zonal circumpolar flow associated with SAM+ leads to less variance in Antarctic surface temperatures due to decreased atmospheric blocking events (Marshall and Thompson [2016]). Blocking around Wilkes Land is also significantly negatively correlated with the SAM phase (Servettaz et al. [2020]). In this region, blocking situations funnel air masses from the Indian Ocean towards Antarctica leading to moisture intrusions over the East Antarctic Plateau. 
a)

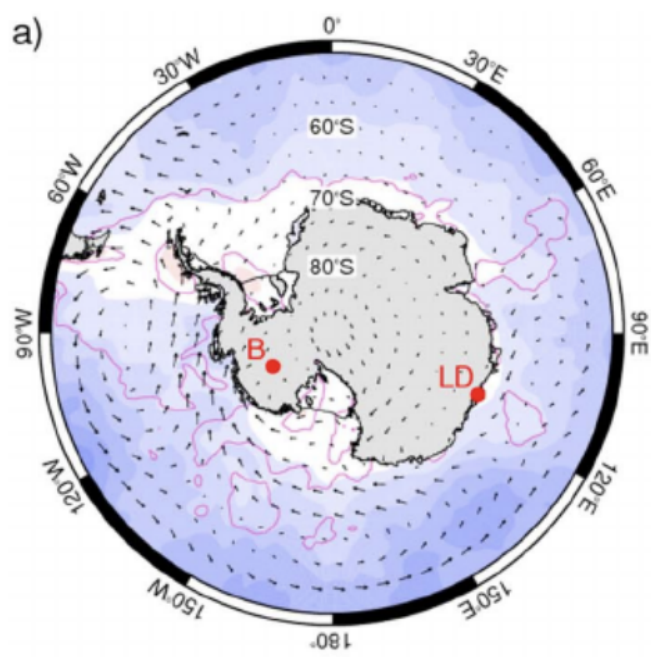

C)

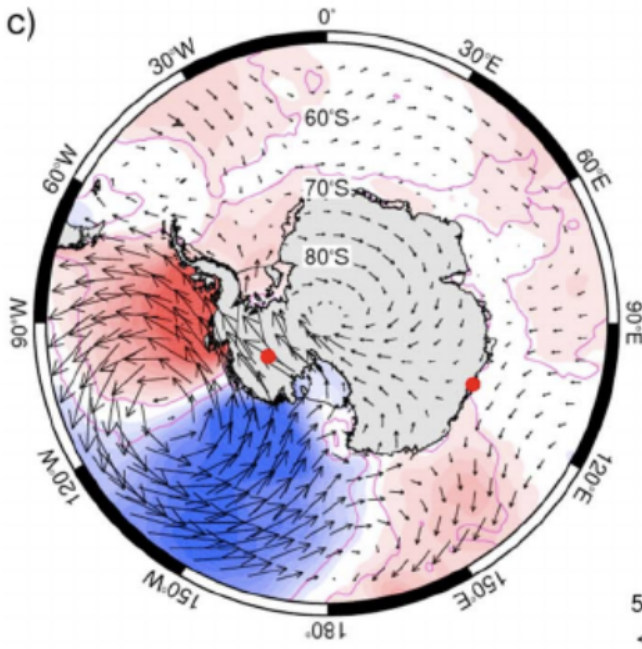

b)

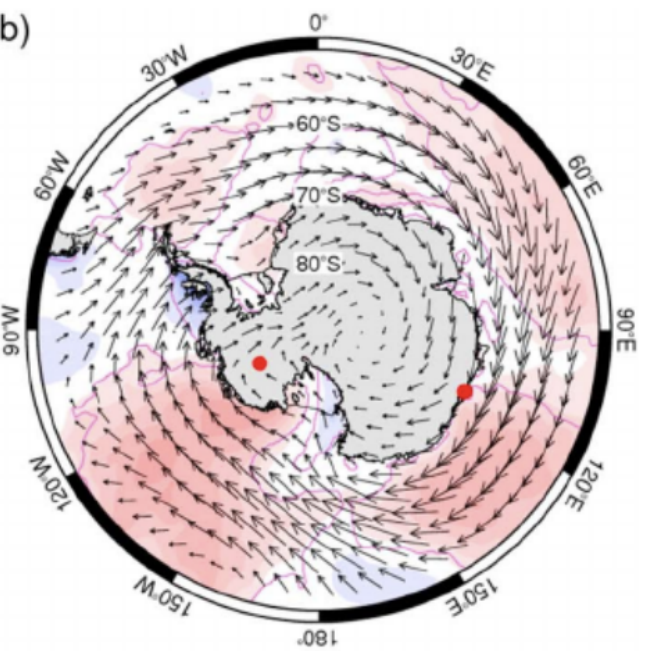

d)

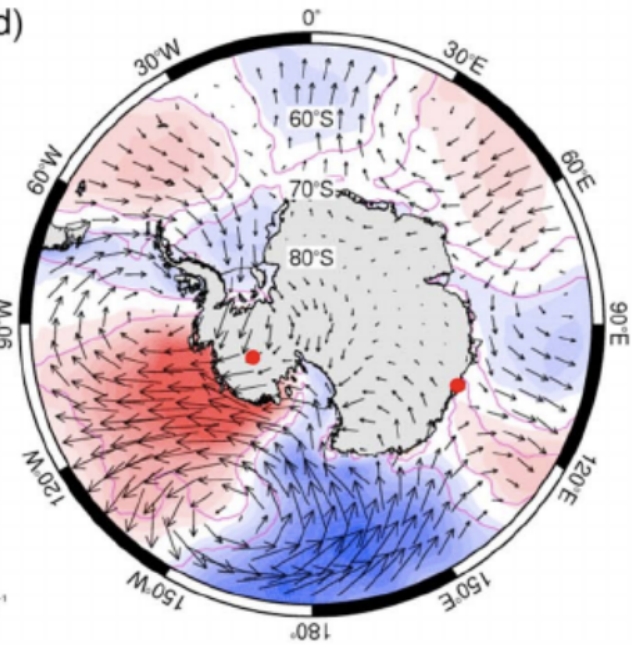

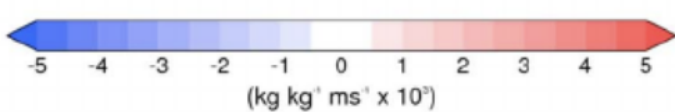

Figure 1.4: The effects between the positive and negative polarities of the (a) BAM, (b) SAM, (c) PSA1 pattern, (d) the PSA2 pattern on the daily $850 \mathrm{hPa}$ meridional moisture flux and near-surface wind anomalies. Source: Marshall et al. [2017]. 


\section{The baroclinic counterpart to SAM}

While SAM is defined as the leading EOF of extratropical southern hemisphere zonal-mean kinetic energy and geopotential, less research has focused on the baroclinic counterpart of the barotropic SAM, the baroclinic southern annual mode (BAM). The BAM is defined as the leading EOF of extratropical eddy kinetic energy. Following the model of energy transfer defined in Thompson and Woodworth [2014], eddy available potential energy is converted to eddy kinetic energy through vertical wave fluxes of heat. The conversion of eddy kinetic energy to zonal-mean kinetic energy, the energy associated with SAM, occurs through eddy fluxes of momentum. Thus, the BAM is associated with the wave fluxes of heat while SAM is related to the wave fluxes of momentum. The peak eddy kinetic energy anomalies occur several days after the peak eddy heat flux anomalies (Thompson and Woodworth [2014]). The peak SAM index generally precedes the momentum flux anomalies by 1-2 days (Lorenz and Hartmann [2001]). In regard with climate consequences, BAM+ is associated with larger wave amplitudes leading to a significant and uniform increase in the poleward moisture transport across the Southern Ocean. This leads to increased precipitation across most of coastal East Antarctica, West Antarctica, and the Antarctic Peninsula (Marshall et al. [2017]).

\subsubsection{Tropical external forcings}

While SAM and BAM act as independent modes of tropospheric variability, there are sensitive to external forcings originating from the tropics.

\section{The ENSO}

The most documented and earliest observed mode of tropical variability is the El Niño-Southern Oscillation (ENSO). ENSO research has progressed significantly since Sir Gilbert Walker discovered the Southern Oscillation in the early 20th century (Walker [1925]), however there is still considerable room for improvement in regard to forecasting and understanding the global effects of ENSO. ENSO describes a coupled system between the ocean (El Niño) and the atmosphere (Southern Oscillation) (Bjerknes [1969]; Philander [1983]; Philander and Rasmusson [1985]). The ocean com- 
ponent is characterized by the variability of anomalous cold and warm SSTs along the Pacific equatorial region. For monitoring purposes, the oceanic Niño index divides the tropical Pacific into four regions ranging from the western Pacific to the South American coast with most attention aimed at the Niño-3 and Niño-3.4 region. An El Niño or La Niña (the cold phase) is declared when a $0.4{ }^{\circ} \mathrm{C}$ SST anomaly is sustained for 6 months or longer in the Niño-3.4 region (Trenberth [1997]).

The atmospheric response typically occurs 1-3 months after an El Niño or La Niña, however predicting the exact timing remains a challenge (Kumar and Hoerling [2003]). The Southern Oscillation Index, a proxy for large scale tropical variability and El Niño, is defined as the sea level pressure differences between Darwin, Australia and Tahiti. An extended period of negative SOI values correlate with the abnormally warm waters in the Eastern Pacific associated with El Niño and vice versa for La Niña. During the formation of El Niño conditions, the easterly trade winds weaken and anomalously switch to the west. This weakening of the trade winds allows warmer ocean water to build along the coastlines of Peru and Ecuador. During El Niño conditions, convective activity shifts eastward following the warmer sea surface temperatures in the central and eastern tropical Pacific. This leads to anomalous convective activity along the same location which then alters the origin of Rossby wave forcing. Through altering the location and intensity of convection along the Pacific equatorial region, ENSO forms a teleconnection with atmospheric circulations in both hemispheres (Fig. 1.5; Fogt et al. [2011]; O'Reilly [2018])

\section{ENSO and SAM}

The ENSO high latitude signals generally manifest in the Antarctic Pacific Ocean regions between the Weddell Sea and the Ross Ice Shelf (Turner [2004]). The Rossby wave train from the resulting tropical convection anomalies associated with ENSO interact with SAM, the ASL, and other circulation patterns around Antarctica. The ENSO/SAM teleconnection is most robust when El Niño (La Niña) is in phase with negative (positive) SAM (Fogt et al. [2011]; Fogt and Bromwich [2006]). When ENSO and SAM are out of phase, their associated anomalous transient eddy momentum fluxes act to oppose one another (Fogt et al. [2011]; Fogt and Bromwich [2006]). This prevents the ENSO signal from reaching the South Pacific during La 
Niña events. When El Niño interacts with positive SAM, the anomalous momentum fluxes are still present in the South Pacific, albeit confined to smaller region. Without the influence of ENSO, SAM displays a zonally symmetric circumpolar circulation around Antarctica. When external tropical forcings like ENSO are evident, SAM exhibits strong anomalies in its zonal symmetry in the South Pacific. From 1957-2009, SAM and ENSO are in phase with one another more often than not as ENSO can sometimes act to drive the phase of SAM, i.e. weak (strong) anticyclonic wave breaking on the equatorward side of the eddy-driven jet associated with El Niño (La Niña) drives SAM- (SAM+) (Gong et al. [2010]; Fogt et al. [2011]).

It is important to note that most of the aforementioned discussion of SAM and ENSO focuses on annual trends and impacts. In fact, there is a strong seasonality to the SAM and ENSO behavior. For instance, in the Pacific Ocean sector asymmetries in the annular SAM structure along with an influence on a two jet pattern are more evident during the austral winter while the connection between ENSO and asymmetries in the SAM structure are seasonally based (Codron [2007]; Fogt et al. [2012a]. This seasonality may influence the connection between these teleconnections and moisture intrusions into the Antarctic continent.

\section{Transmitting the tropical signal to Antarctica}

Determining the mechanisms for transmitting an ENSO signal through the South Pacific is an ongoing discussion. The documented modes of ocean/atmospheric variability that affect SAM in the Southern Pacific Ocean are the El Niño-Southern Oscillation (ENSO) and the Pacific Decadal Oscillation (PDO; Gregory and Noone [2008]; Mantua et al. [1997]). These modes of variability create their teleconnections to the Southern Ocean through their impact on SSTs and the resulting impacts on upper atmosphere wave dynamics. Warm SST anomalies across the equator create additional convection and thus increased upper-level divergence. This upper-level vertical momentum perturbation creates a Rossby-wave train that meridionally propagates across the South Pacific (Hoskins and Karoly [1981]). The Rossby-wave train is referred to as a Pacific South American pattern (PSA) which describes an alternating pattern of positive and negative $500 \mathrm{hPa}$ zonal wind anomalies during the austral winter traversing from the west central equatorial Pacific to Amundsen-Bellingshausen Sea in South 

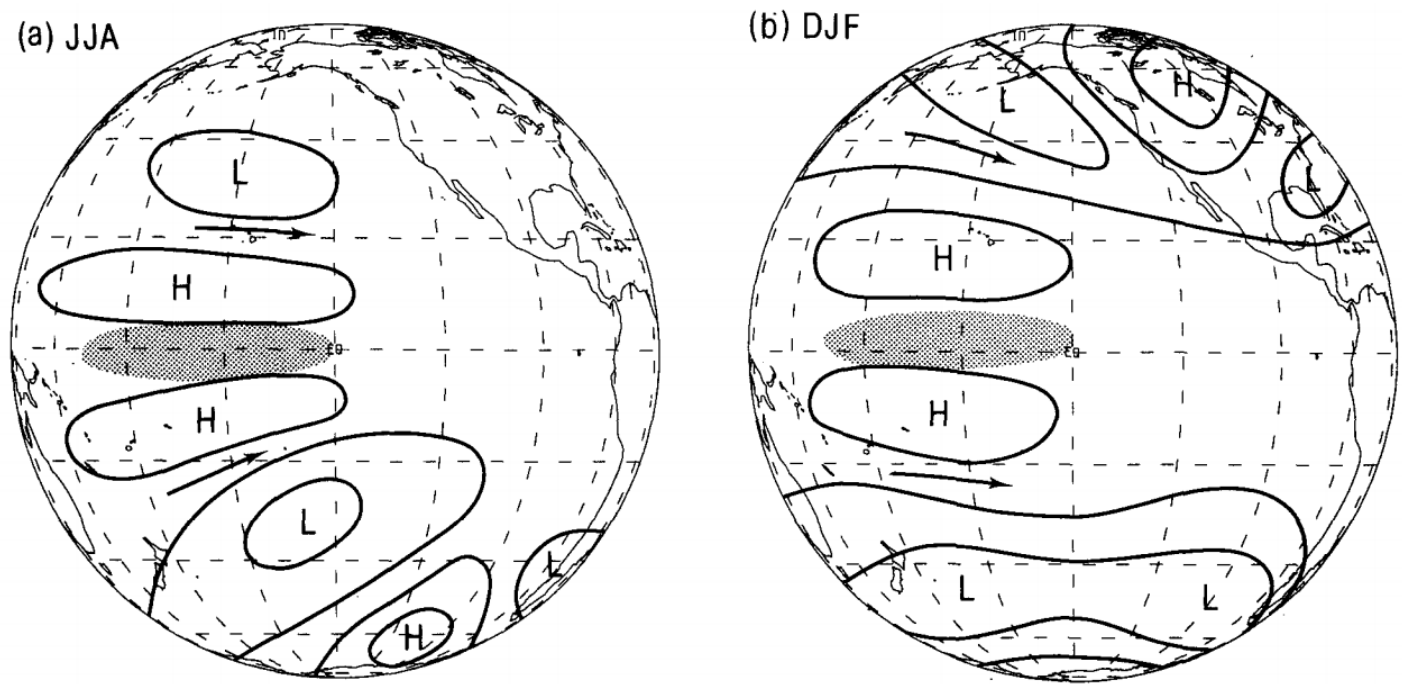

Figure 1.5: The idealized pattern of upper tropospheric height anomalies over the Pacific Ocean in response to (a) the early state of an ENSO event during JJA and (b) the mature stage of an ENSO event during DJF. Source: Karoly [1989].

Pacific (Clem and Renwick [2015]; Ding et al. [2012]; Karoly [1989]; Lachlan-Cope and Connolley [2006]; Mo and Ghil [1987]; Mo and Paegle [2001]; Renwick and Revell [1999]; Wilson [2013]). The PSA contains two structures with PSA1 and PSA2 being defined as the second and third EOFs of extratropical geopotential height after SAM which is the first EOF (Mo and Higgins [1998]).

Another approach to understanding the effects of tropical forcing on SAM is through eddy-driven mean circulation changes. Like Rossby wave teleconnections, transient eddies occur in response to positive SST anomalies in the tropics. Instead of propagating through the upper-levels in wave form, the warm tropics strengthen the poleward edge of the subtropical jet through the thermal wind balance. The strengthened subtropical jet and resulting increased meridional gradient of potential vorticity strengthens the mid-latitude circulation. This results in increased ascent in the ferrel cell but weakens the polar cell through subsidence. The polar front jet weakens in response leading to positive geopotential height anomalies across the Southern Ocean (Seager et al. [2003]; Wilson [2013]). As opposed to Rossby waves, the mechanism for external forcing proposed by Seager et al. [2003] is evident during all seasons.

As discussed in the previous SAM discussion, the PSA1 pattern, eddy-driven mean circulation, and anomalous wave breaking (Gong et al. [2010]) are three proposed methods of atmospheric teleconnection. Goodwin et al. [2016] summarizes that 
altering the position of the South Pacific Convergence Zone (SPCZ) through external tropical forcings is the primary gateway in which tropical climate variability is transmitted to higher latitudes. When positive (negative) SAM is in phase with El Niño (La Niña), the SPCZ shifts southwest (equatorward) generating a transient eddy momentum flux that interacts with the polar front to increase (decrease) cyclonic activity near the Antarctic coast (Chen et al. [1996]; Vincent [1994]). The PSA1+ pattern favors frequent blocking conditions over the Southern Pacific Ocean leading to increased war moisture intrusions and surface melt anomalies over Marie Byrd Land and the Ross Ice Shelf areas (Marshall and Thompson [2016]; Scott et al. [2019]). In these regions, the difference in precipitation between the two polarities of the PSA1 is 2.5 times the mean value of precipitation over the same area, representing a large degree of sensitivity to the PSA1 (Marshall et al. [2017]).

\section{Relation to present manuscript}

The West Antarctic melt event in January 2016 demonstrates that we do not fully understand the relationship between ENSO and SAM. Despite a positive SAM, a large blocking ridge likely associated with El Niño developed in the Amundsen Sea allowing for the advection of warm, marine air over the Ross Ice Shelf and parts of West Antarctica. The zonal winds associated with the circumpolar jet remained strong during the event meaning the magnitude of the El Niño teleconnection overcame the effects of the positive SAM. Nicolas et al. [2017] conducted several simulations with the Community Atmosphere Model (CAM) and determined that a melt event during positive SAM should be a rare event. This event emphasizes that simply understanding the mean climate signals over Antarctic is insufficient to properly understand intense meridional moisture transport towards the continent. These events like the January 2016 melt event can occur even when the SAM and teleconnections would suggest their occurrence to be unlikely. To address this knowledge gap means further studying the dynamics of moisture intrusion events onto the Antarctic continent and looking beyond the mean climate impacts of the observed modes of climate variability. Atmospheric rivers (ARs) are a means of study moisture intrusions under a common dynamical framework. 


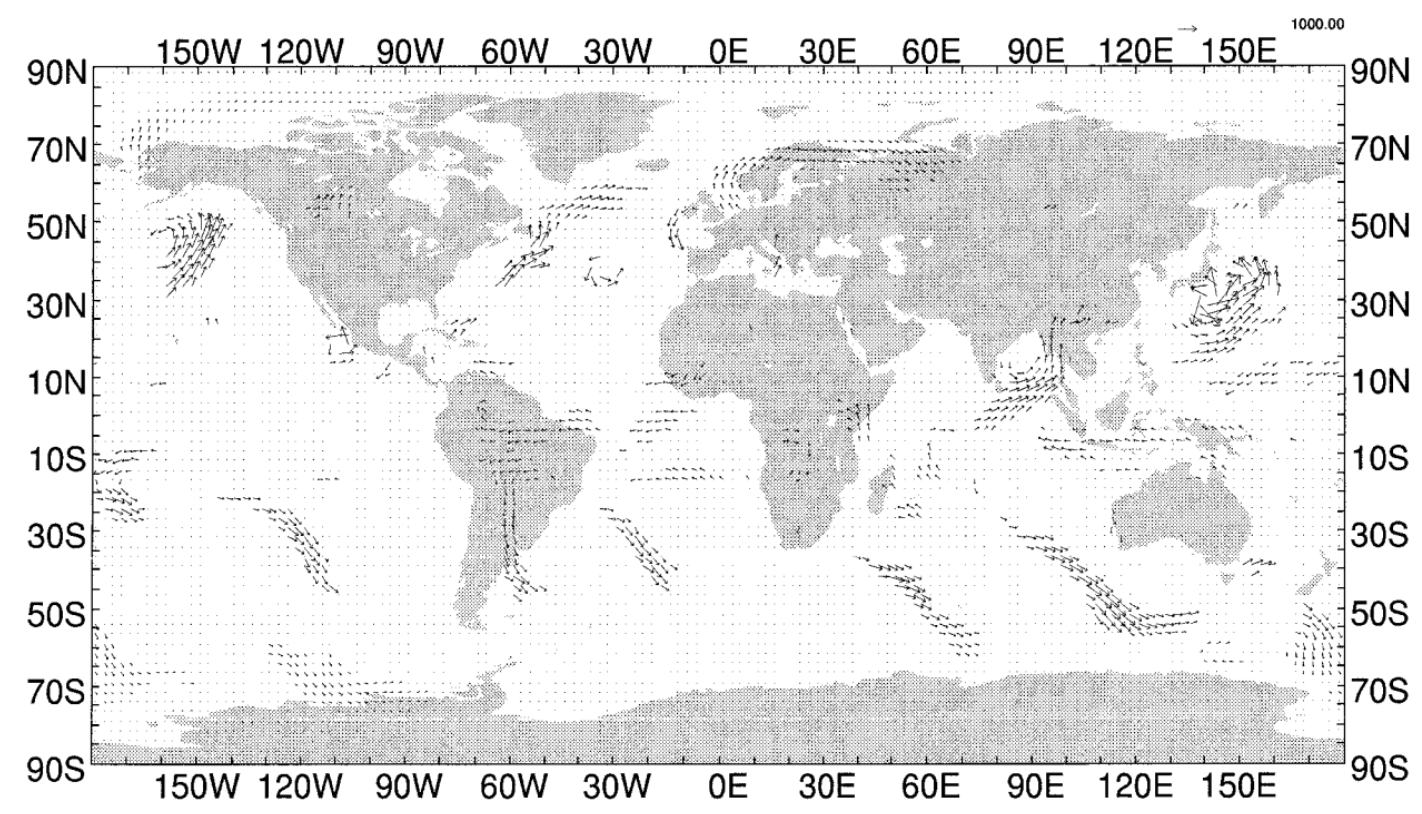

Figure 1.6: Integrated moisture flux $\left(\mathrm{kg} \mathrm{m}^{-1} \mathrm{~s}^{-1}\right)$ observed in detected ARs on 12 October 1991, 1200 UTC using the original atmospheric river detection. Source: Zhu and Newell [1998].

\subsection{Atmospheric rivers}

\subsubsection{Atmospheric river background}

\section{The "discovery" of atmospheric rivers}

The pioneering research on atmospheric rivers (ARs) originally focused on the mid-latitudes many years before interest shifted towards the polar regions. ARs were originally termed "tropospheric rivers" in a study from 1992 that actually was analyzing the transportation of atmospheric carbon monoxide (Newell et al. [1992]). It was the first study to observe narrow plumes of intense vertically integrated water vapor transport (IVT); a variable that would become a bedrock in describing ARs. The term "atmospheric river" was coined in a landmark study in Zhu and Newell [1998] that used reanalysis to identify IVT by grid cell laying the foundation for later AR detection techniques including the one described in this manuscript (Fig. 1.6). A major takeaway from that study was that ARs are responsible for more than $90 \%$ of the meridional moisture transport despite covering $\sim 10 \%$ of the global circumference; a claim reinforced in future studies (Nash et al. [2018]). A field campaign (CALJET) in 1998 was the first to directly measure ARs off the coast of California using dropsondes to 
confirm the strongest moisture transport in an extratropical cyclone was occurring in the lowest parts of the atmospheric within the low-level jet (Ralph et al. [2005]). After the AR characteristics were initially defined and SSMI/R satellites made water vapor tracing and thus AR tracking more feasible (Fig. 1.7; Ralph et al. [2004]), ARs became a more common nomenclature as researchers began focusing on the meteorological forecasting and hydrological challenges posed by ARs in the mid-latitudes. Even the term "Pineapple Express" entered the public's vocabulary as a way for weathercasters to describe ARs reaching from Hawaii to the western US (Dettinger [2004]).

\section{Atmospheric river definition}

Since the "discovery" of ARs in the late 20th/early 21st century, there has been considerable debate over the precise definition for ARs. While it is accepted that the highest moisture transport occurred within the low-level jet ahead of an extratropical cyclone, questions remain whether the moisture plume observed in the lowlevel jet can be distinguished as an AR, the warm conveyor belt (Dacre et al. [2015, 2019]), a tropical moisture export (TME; Knippertz and Wernli [2010]), or a moisture conveyor belt (Bao et al. [2006]). Overall, the definitions of these terms lack precision and overlap in many regards. In 2017, a scientific consensus emerged around a consistent AR definition and was published in the American Meteorological Society (AMS) Glossary of Meteorology, "A long, narrow, and transient corridor of strong horizontal water vapor transport that is typically associated with a low-level jet stream ahead of the cold front of an extratropical cyclone. The water vapor in atmospheric rivers is supplied by tropical and/or extratropical moisture sources. Atmospheric rivers frequently lead to heavy precipitation where they are forced upward-for example, by mountains or by ascent in the warm conveyor belt. Horizontal water vapor transport in the midlatitudes occurs primarily in atmospheric rivers and is focused in the lower troposphere." (Fig. 1.8). Whereas a warm conveyor belt is a cyclonic-specific airflow that ascends along a vertically sloping isentropic surface (Carlson [1980]), an AR is not defined by a relationship with a particular cyclone instead using a Eulerian approach to define discreet regions of integrated water vapor (IWV) and IVT (Ralph et al. [2020]). And while a tropical moisture export can be a shallow moisture transport from a particular level in the tropics, an AR can represent moisture transport from outside the tropics 

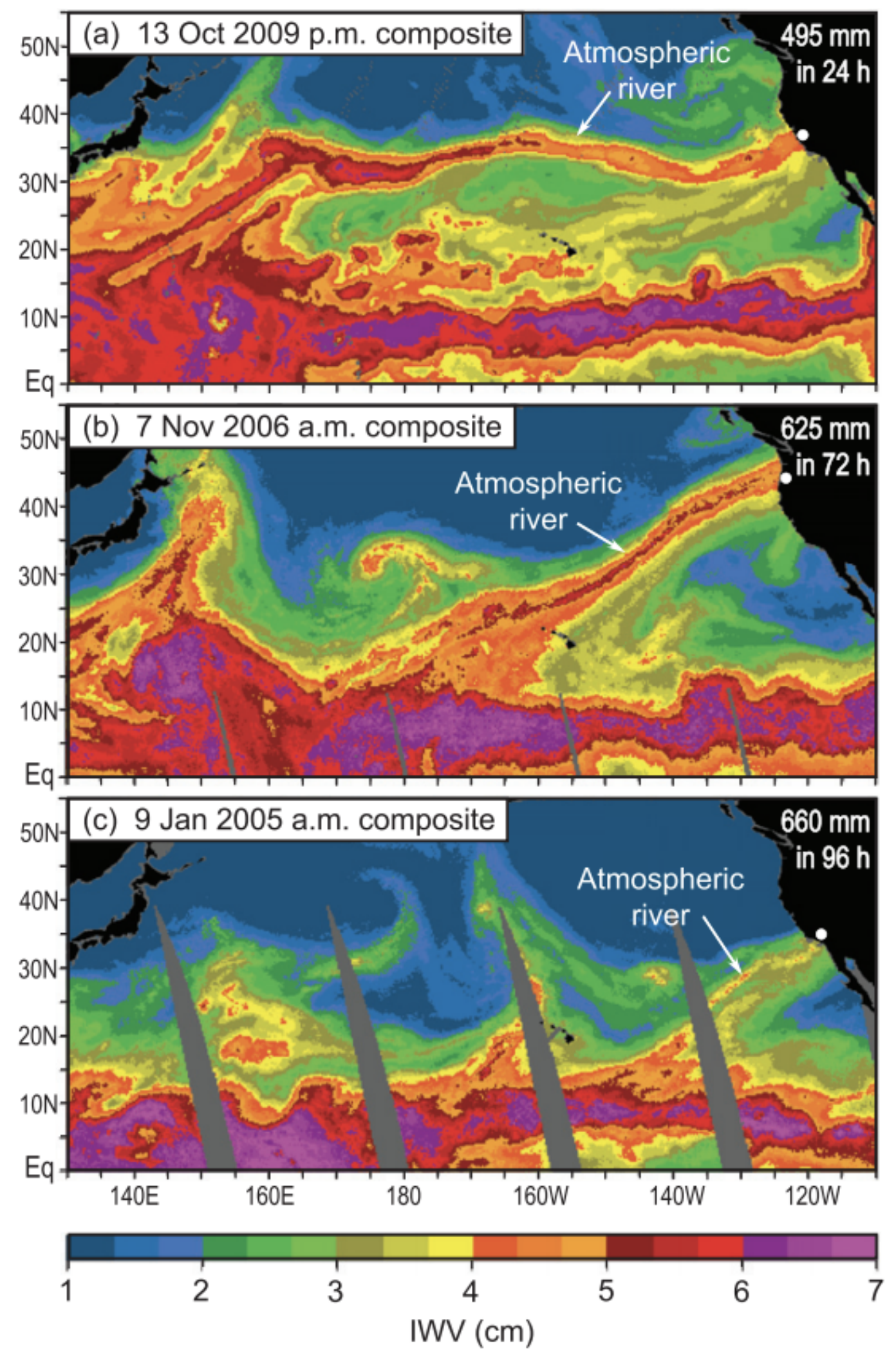

Figure 1.7: AR examples observed from SSM/I satellite imagery that occurred (a) October 13, 2009, (b) November 7, 2006, and (c) January 9, 2005. Source: Ralph et al. [2011]. 
in an vertically coherent structure.

\section{Atmospheric river dynamical life cycle}

The AR life cycle is governed by Rossby wave dynamics where Rossby wave breaking in the exit regions of mid-latitude jet streams may initiate the penetration of mid-latitude troughs into the subtropics and enable the poleward transport of water vapor (Hoskins et al. [1985]). According to quasi-geostrophic (QG) theory, the wave breaking near the jet exit forces upper-tropospheric divergence and upward vertical motion. The subsequent lower-tropospheric convergence acts maintain mass continuity and aids in the generation of cyclonic vorticity along a lower-tropospheric thermal gradient. Following the Norwegian Cyclone Model, the resulting cyclonic vorticity induces the advection of poleward advection of warm air and the equatorward advection of cold air (Bjerknes [1919]). The presence of an IWV reservoir from a previous decayed cyclone or favorable moisture pathway from the subtropics can accelerate the deepening of an extra-tropical low. The poleward transport of heat and moisture releases latent heat through evaporation thus increasing the diabatic heating which enhances vertical motion according the second right-hand side term in the QG omega equation (Bluestein [1992]). When examining this diabatic heating from a potential vorticity (PV) framework (i.e. PV is highest near the poles and lowest near the equator), PV decreases below the diabatic heating maximum, deepening cyclonic circulations, while PV increases above the diabatic heating maximum strengthening anti-cyclonic circulations generating more upstream blocking that encourages poleward moisture transport. This poleward transport of heat and moisture is often represented through ARs and can lead to rapid deepening of an extratropical cyclone when an AR penetrates a cyclonic system (Newell et al. [1992]; Tsuji and Takayabu [2019]). Therefore, while ARs are not a cyclone-relative flow, the two can be mutually beneficial. When looking at an AR visualized by SSM/I satellite imagery, it appears that an $\mathrm{AR}$ is directly transporting moisture from the subtropics to higher latitudes. In reality, the AR loses moisture via precipitation as the air parcels ascend when they move poleward and is replenished from horizontal moisture convergence along the AR (Dacre et al. [2015]). When ARs are connected with deep troughs, they are more likely to transport moisture over further meridional distances compared to smaller cyclones 


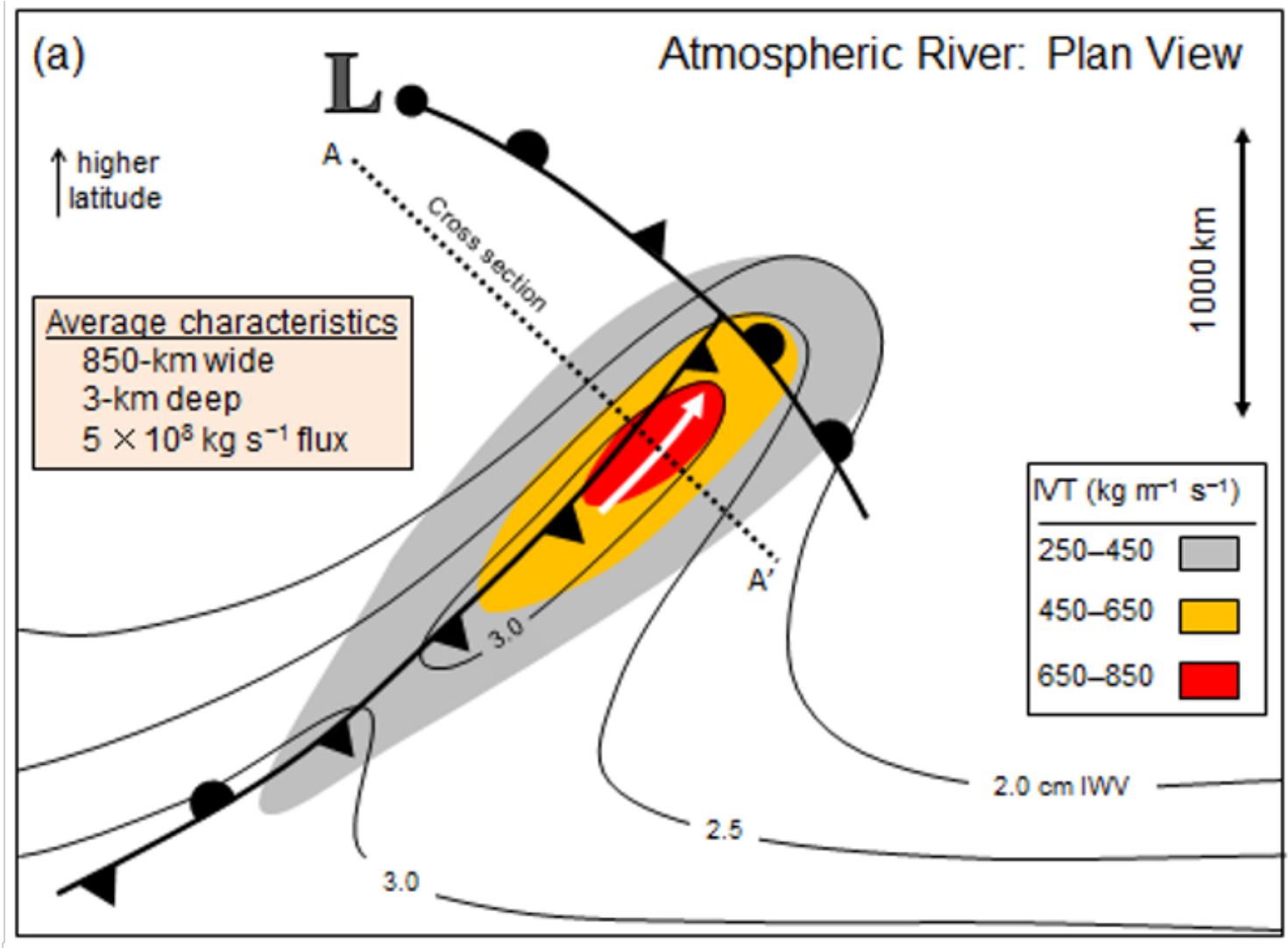

(b) Atmospheric River: Vertical Cross-section

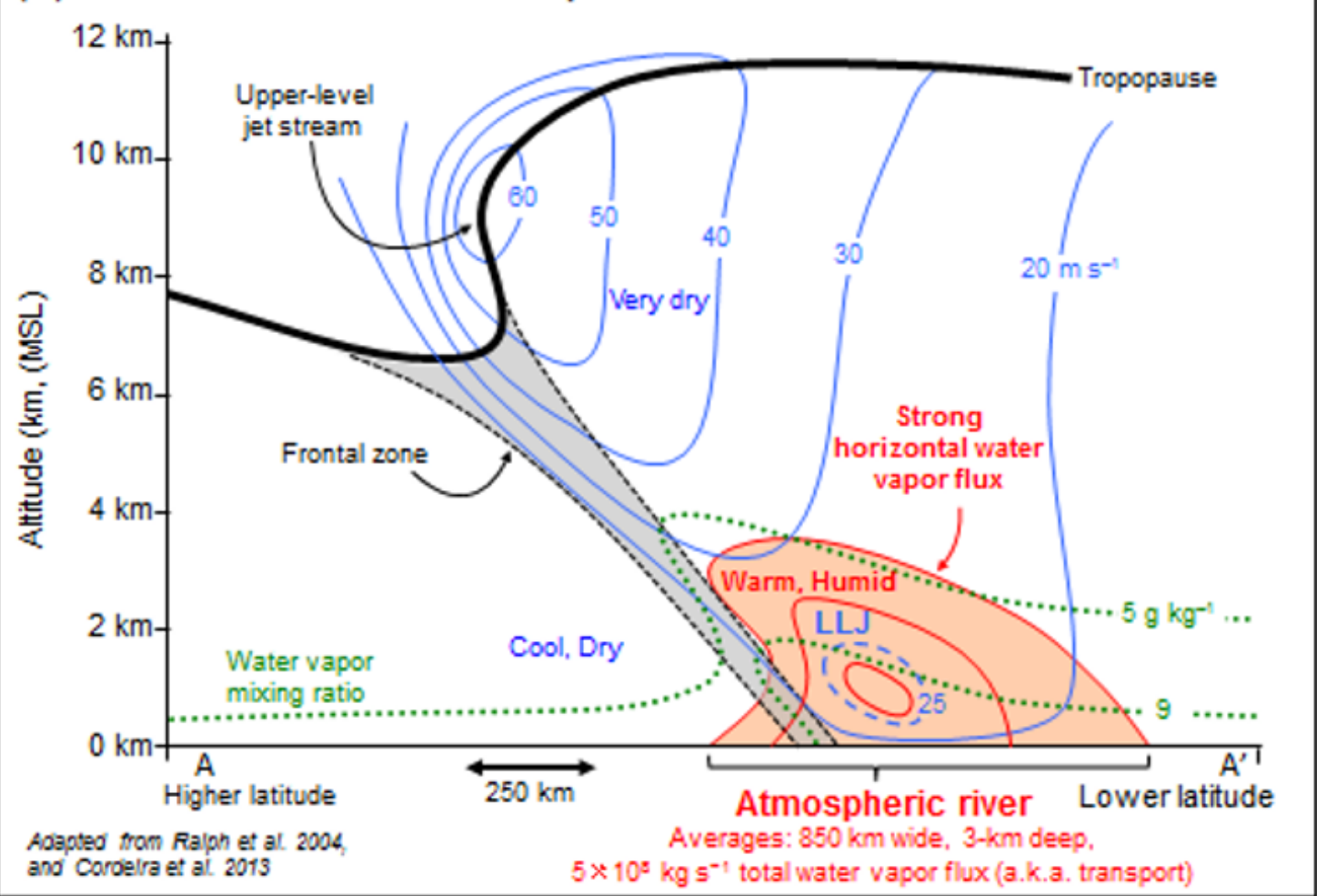

Figure 1.8: An AR schematic displaying the structure and strength based on dropsonde measurements. (a) is an overview of the extratropical structure and observed AR located and (b) is a vertical cross-section of the extratropical structure. Source: American Meteorological Society. 
that have a more local moisture origin (Bonne et al. [2015]). Under conducive atmospheric wave patterns (i.e. high amplitude jet stream and blocking), ARs can persist through multiple cyclones (Sodemann and Stohl [2013]). Under an AR-friendly wave pattern, mesoscale frontal waves can develop small vorticity maxima along an AR's western edge reinforcing moisture convergence and prolonging AR landfalls and their hydrometeorological impacts (Martin et al. [2019]; Neiman et al. [2016]) The aforementioned dynamical processes and AR characterizations were devised around ARs observed in the mid-latitudes and are applicable to ARs in Antarctica, but with some key differences described throughout this manuscript.

\subsubsection{Atmospheric rivers in Polar Regions}

Research on ARs in polar regions is a very recent event with the first papers identifying polar AR being published in 2014 (e.g. Gorodetskaya et al. [2014]; Neffet al. [2014]). The first explicit study of AR structure in Arctic occurred in regard to the 2012 summer Greenland melt episode when nearly $99 \%$ of the Greenland ice sheet surface experienced melt during the month of July (Nghiem et al. [2012]). The warm air and moisture originating over North America and advected to the west coast of Greenland via an atmospheric river led to the formation of liquid water clouds over the highest portions of the ice sheet and subsequent surface melting (Neff et al. [2014]). A highly distorted polar vortex amplified the poleward moisture advection and created a corridor of moisture and heat transport from North American to Greenland. This event occurred just a few months before the same highly amplified jet created an unusually powerful blocking ridge over Greenland that forced hurricane Sandy's westward turn in the Northeast coast of the United States (Mattingly et al. [2015]). Since this initial paper on ARs in Arctic, AR activity over the Greenland ice sheet has been quantified using an AR detection algorithm and found strong AR activity drove high surface mass balance losses throughout the 2000s and early 2010s (Mattingly et al. [2018]).

For the Antarctic, Gorodetskaya et al. [2014] described the first research to address and quantify ARs and was the catalyst for many of the methods and motivation developed in this thesis. Using a novel AR detection algorithm, this study found the anomalously high annual snowfall accumulations at Princess Elisabeth station in 2009 and 2011 could be attributed to just a few AR landfalls (Fig. 2.1). The positive 

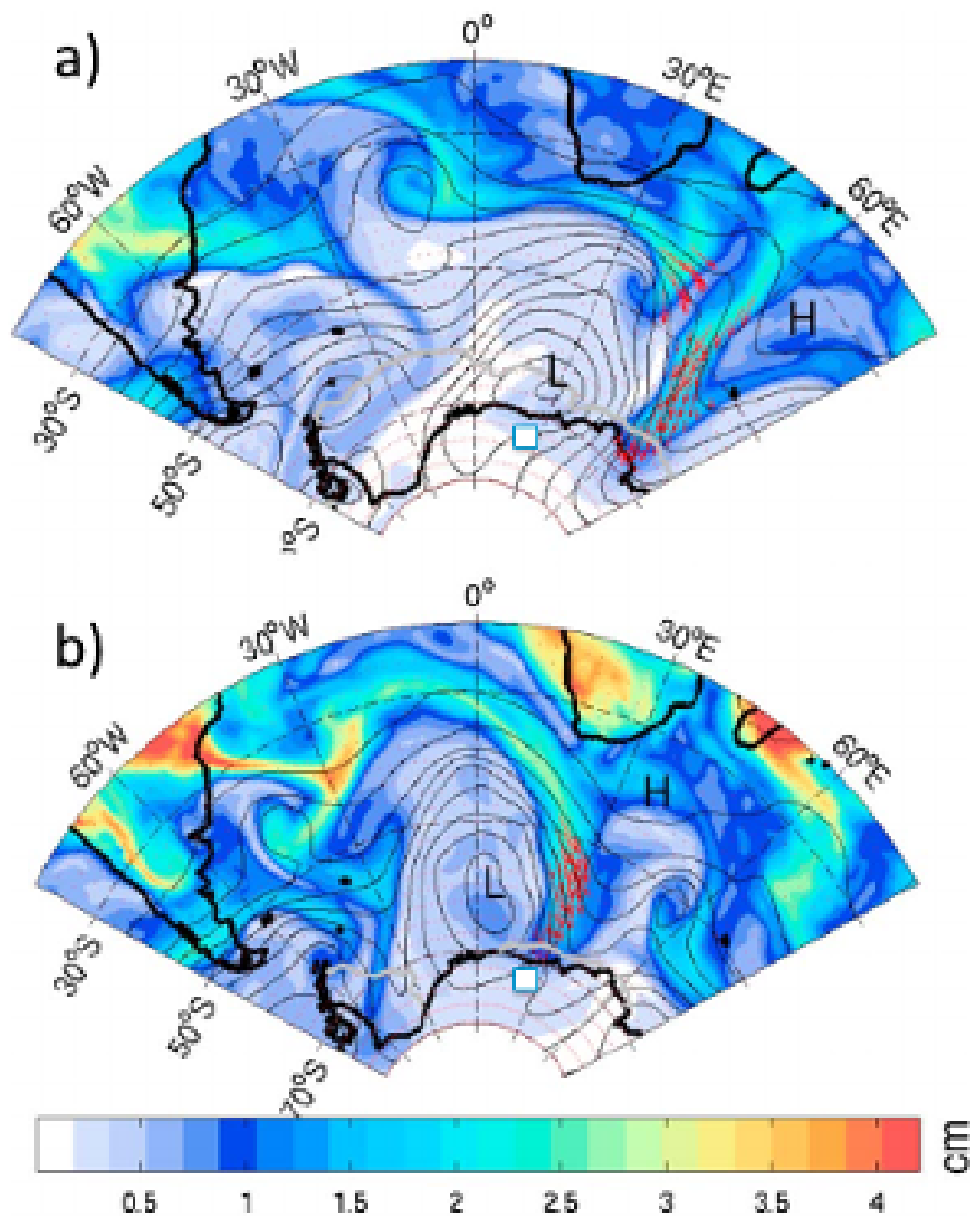

Figure 1.9: Antarctic AR examples as detected by the algorithm described in Gorodetskaya et. al (2014). The maps show the IWV $(\mathrm{cm})$ and the red arrows are the detected AR shapes from (a) May 19, 2009 and (b) February 15, 2011. Source: Gorodetskaya et al. [2014]. 
mass balance anomaly these two years in East Antarctica negated the increased ice discharge from West Antarctica (Boening et al. [2012]). The AR detection algorithm took into account the decreased saturation capacity of the polar troposphere by using a relative IWV threshold for detection instead of an absolute threshold commonly utilized in the mid-latitudes. This study highlighted many of the possible implications of AR activity in Antarctica examined in this thesis such as AR impacts on high precipitation events, interannual variability and trends in Antarctic ice-sheet SMB, and ice core paleoclimatology interpretation.

\subsubsection{Thesis context}

The state-of-the-art presented thus far attempts to summarize the current understanding of Antarctic climate variability and AR science. The prior research conceptualizes a complex network of teleconnections and natural climate variability influencing the mean climate over the Antarctic ice-sheet. However, describing variations in these processes are sometimes insufficient in capturing the variability of the Antarctic SMB. Case studies of moisture intrusion events can describe quick yet significant accumulation events, but lack a common framework to quantify their total contributions to the SMB. Plus events described as moisture intrusions have also demonstrated a capability of triggering surface melting, further complicating the comprehension of their impacts. Therefore, the understanding of moisture intrusions into the Antarctic continent and the atmospheric dynamics that direct them is necessary to accurately reconstruct past climate conditions. ARs offer a promising framework to categorize these moisture intrusions under a common synoptic-scale dynamical definition, but current Antarctic AR research is limited. In the context of this thesis, there is room to expand our understanding of the Antarctic climate system and the SMB of the ice sheet by introducing an AR focus on a continent-wide scale. In the following chapter, we will discuss AR detection algorithms and the development of a polar-oriented detection algorithm. 


\section{Chapter 2}

\section{Tools and methods}

\subsection{Detecting atmospheric rivers}

In this section, I will describe the atmospheric river (AR) detection algorithm that served as the bedrock of this thesis. As the following chapters (chapters 3, 4, and 5) are individual published or submitted papers, they each contain methodology sections that describe the AR detection algorithm as relevant to the specific study. This section will summarize the methodology sections of the three papers and present the development process of the AR detection algorithm.

\subsubsection{Preceding atmospheric river detection algorithms}

As described in section 1.1.1, ARs are defined by the use of Eulerian approaches to define discreet regions of integrated water vapor (IWV) and integrated vapor transport (IVT). The first AR detection algorithm set the standard of identifying areas of enhanced IVT using reanalysis data (Zhu and Newell [1998]). Following research would advance the science of detecting ARs by placing distinct geometry and threshold requirements on the regions of enhanced IWV and IVT. The first criterion that treated ARs as spatial objects as opposed to moisture fluxes like in Zhu and Newell [1998] was developed in a study by Ralph et al. [2004]. Using SSMI/R satellite data and aircraft operations from a field operations, ARs were defined as features $\geq 2,000 \mathrm{~km}$ in length, $\leq 1,000 \mathrm{~km}$ in width, and IWV $>20 \mathrm{~mm}$ (Ralph et al. [2004]). The detection algorithms that followed began to transition towards using IVT as the detection criterion once reanalysis began resolving IVT at an adequate resolution. This would 
be essential for detecting ARs in polar regions where SSMI/R satellite observations are not readily available. Using IVT also favors the detection of ARs that better reflect heavy precipitation processes (Rutz et al. [2014]). Perhaps the most widely recognized and utilized AR detection algorithm nowadays is the algorithm presented in Guan and Waliser [2015]. This global detection combines a relative percentile-based threshold (85th percentile based on location and seasonal IVT climatology) with a minimum IVT threshold (100 $\left.\mathrm{kg} \mathrm{m}^{-1} \mathrm{~s}^{-1}\right)$ to identify ARs (Guan and Waliser [2015]). Along with length and aspect ratio (length/width) requirement, this algorithm is versatile in its global application including polar regions where this algorithm detects very frequent activity in the Southern Ocean (Guan and Waliser [2015]; Ralph et al. [2020]). To summarize the various AR detection algorithms, the introduction of Guan and Waliser [2015] breaks down these algorithms into three distinct categories; (1) observing IVT or IWV values at a single observation or model grid cell with no requirements for AR geometry (Dettinger [2011]; Ralph et al. [2013]), (2) tracking moisture-related fields across a fixed cross-section while examining certain geometric criteria for AR shape (e.g. Lavers et al. [2012]; Nayak et al. [2014]), (3) using a larger spatial domain to identify shapes that meet certain moisture and geometric criteria like what is used in this thesis (e.g. Gorodetskaya et al. [2014]; Guan and Waliser [2015]).

The plethora of AR identification methods and algorithms presents a challenge to the legitimacy of AR science. With so many ways of classifying ARs, they can simply become objects conveniently identified for each study's scientific goal. This has led to a healthy skepticism questioning whether to ARs really are unique features separate from ordinary extra-tropical cyclones. In response to this challenge, the Atmospheric River Tracking Method Intercomparison Project (ARTMIP) was created to compile many various detection algorithms to create a quantitative range to define ARs. Detection algorithms can be classified by their various parameter types and parameter choices (Fig. 2.1; Rutz et al. [2019]). By asking users to test their algorithms on a common reanalysis dataset, it also sets a standard for algorithm developers to meet; something that benefited the development of the Antarctic detection algorithm described in this thesis. One important early result from the first ARTMIP publication suggests that the global detection algorithm in Guan and Waliser [2015] is very permissive when detecting ARs in the higher latitudes of the Southern Hemisphere (Rutz 


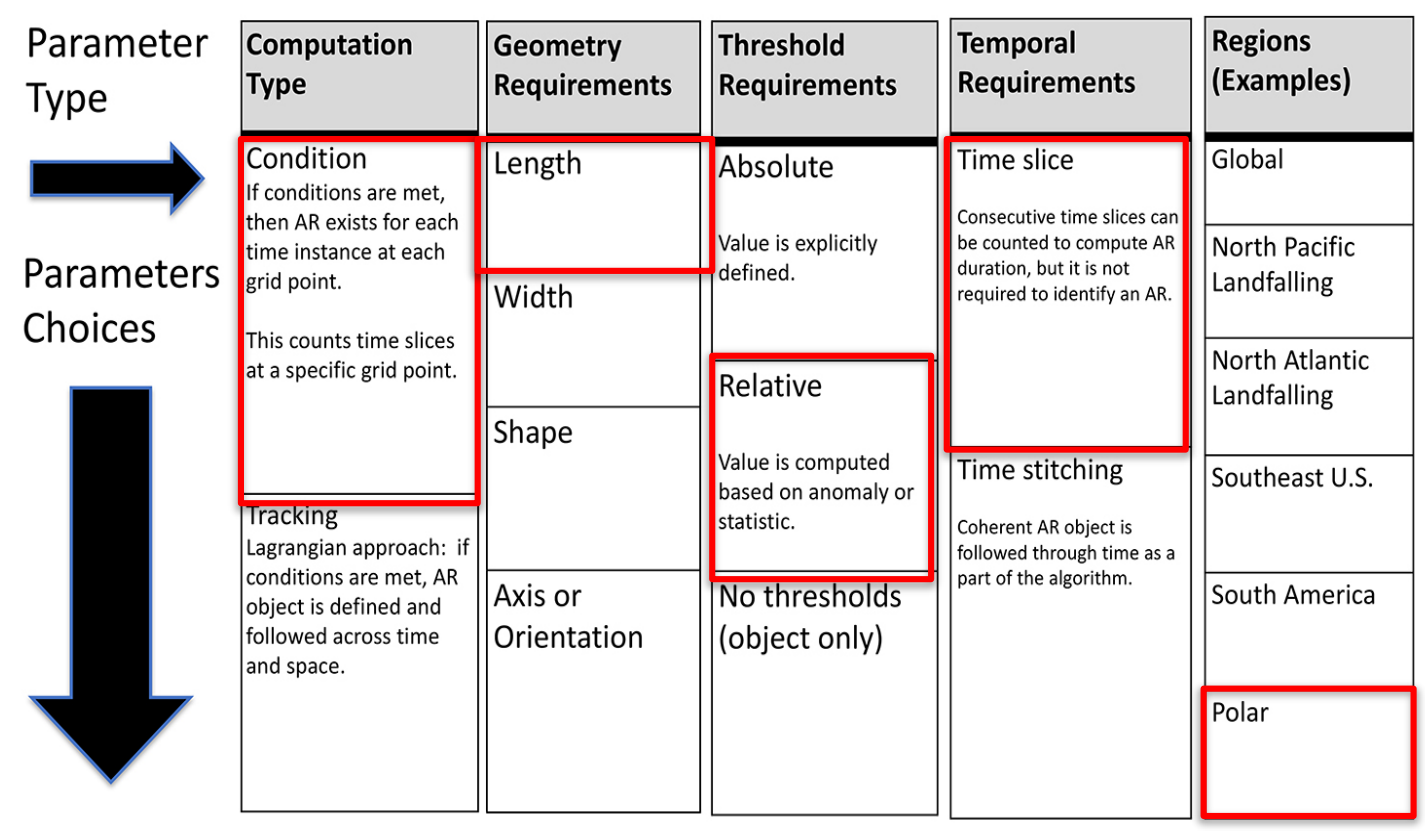

Figure 2.1: A schematic diagram summarizing the various AR identification and tracking methods found in current literature. The red boxes represent the parameters utilized in the Antarctic AR detection algorithm developed during this thesis. Source: Rutz et al. [2019].

et al. [2019]). This only further highlights the need for a regional Antarctic focused AR detection algorithm.

\subsubsection{The development of the polar atmospheric river detection algorithm}

The first goal of developing an AR detection algorithm for Antarctica was to develop a tool that would only detect clearly defined ARs and ignore ordinary extratropical cyclones. These developments were performed in collaboration with Ambroise Dufour and Jai Chowdhry Beeman. The algorithm developed in this thesis is an adaption of the original Antarctic AR detection algorithm developed in Gorodetskaya et al. [2014], who demonstrated that the global AR detection algorithm from Guan and Waliser [2015] was flagging ordinary extra-tropical cyclones as ARs while these cyclones were ignored by the original Antarctic AR detection. This raised confidence that an algorithm adapted from Gorodetskaya et al. [2014] would be sufficiently strict in its AR detection. Here an IWV threshold was chosen to account for the decreased 
saturation vapor pressure of the colder, higher latitudes as seen in equation 2.1,

$$
I W V \leq I W V_{\text {sat,mean }}+A R_{\text {coef } f}\left(I W V_{\text {sat,max }}-I W V_{\text {sat,mean }}\right)
$$

where $I W V_{\text {sat,mean }}$ is a zonal mean saturated $I W V$ on a given latitude, $I W V_{\text {sat,max }}$ is the maximum value of $I W V_{\text {sat }}$ along the same latitude, and $A R_{\text {coeff }}$ is a subjective coefficient determining the AR strength (Gorodetskaya et al. [2014]). This algorithm defined ARs that exceeded the IWV threshold for at least $20^{\circ}$ latitude continuously from a coastal latitude on Dronning Maud Land, but with a limited width of at most $30^{\circ}$ longitude. It also uses the same $20^{\circ}$ latitude length requirement but has no restriction on width. The algorithm developed for this thesis incorporates a similar relative moisture threshold although switches to a simpler percentile-based threshold of IWV and vIVT (The v component of IVT) that does not require temperature data. We initially developed the algorithm around IWV like in Gorodetskaya et al. [2014], but later incorporated vIVT to account for moisture fluxes with a strong poleward orientation and then compare against IWV.

\section{Wille_v1 algorithm}

The Antarctic AR detection algorithm developed for this thesis has two distinct versions. The first version (henceforth Wille_v1) provided the results described in Chapter 3 while the second version (henceforth Wille_v2) was utilized for Chapters 4 and 5. Both versions were developed in the Python programming language, have an vIVT scheme and IWV scheme, and follow the parameters highlighted in Fig. 2.1. In Wille_v1, the algorithm searches for grid cells within the circumpolar domain $45^{\circ} \mathrm{S}$ and $80^{\circ} \mathrm{S}$ for which the IWV or vIVT belongs in the 98th percentile of all the monthly climatological values for a particular model grid cell. If contiguous grid cells verify the same criteria, they become a 'meridional segment'. If the meridional segments of anomalously high IWV or vIVT have no discontinuities greater than $1^{\circ}$ and extend at least $20^{\circ}$ in the meridional direction, the algorithm outputs the corresponding date into an index of $A R$ dates. If a detected $A R$ reaches the latitude of the coastline or further south, it is classified as an AR landfall. The IWV and vIVT data used in Wille_v1 came from 6-hourly reanalysis data initially developed using ERA-Interim 
(Dee et al. [2011]), but later incorporated JRA-55 (Kobayashi et al. [2015]), CFSR (Saha et al. [2010]), MERRA-2 (Gelaro et al. [2017]), NCEP/NCAR V1 (Kalnay et al. [1996]) and NCEP/DOE V2 (Kanamitsu et al. [2002]). The AR climatology results from these various reanalysis products are described in Chapter 3.

For the results in Chapter 1 (e.g. Wille et al., 2019), IWV $\left(\mathrm{kg} \mathrm{m}^{-2}\right)$ is the integrated water

$$
I W V=-\frac{1}{g} \int_{900 h P a}^{300 h P a} q d p
$$

vapor, $q\left(\mathrm{~kg} \mathrm{~kg}^{-1}\right)$ is the specific humidity, $g\left(\mathrm{~m} \mathrm{~s}^{-2}\right)$ is the gravitational acceleration, and $p$ is the atmospheric pressure $(\mathrm{hPa})$. The meridional component of integrated vapor transport (vIVT, $\mathrm{kg} \mathrm{m}^{-1} \mathrm{~s}^{-1}$ ) was calculated as

$$
v I V T=-\frac{1}{g} \int_{900 h P a}^{300 h P a} q V d p
$$

where $\mathrm{V}$ is the wind vector $\left(\mathrm{m} \mathrm{s}^{-1}\right)$. Following the AR detection algorithm in Gorodetskaya et al. [2014], the lowest level of the atmosphere was removed from consideration to avoid possible detection complications from the drying katabatic wind draining off the Antarctic plateau. The purpose of the Wille_v1 algorithm is to determine if an AR makes landfall anywhere on the Antarctic continent. Since multiple ARs landfalls can occur at the same time, the continent was divided into four evenly spaced quadrants between $0^{\circ}, 90^{\circ} \mathrm{E}, 180^{\circ}$ and $90^{\circ} \mathrm{W}$ : the Dronning Maud Land and Princess Elisabeth Land, Wilkes Land and Victoria Land, WAIS, AP and the Weddell Sea region respectively. Antarctica was also divided into halves to account for ARs that might travel between the quadrants (Fig. 2.2). The code for Wille_v1 is in Appendix D.

The Wille_v1 algorithm went through extensive testing and modifications to best capture shapes adhering to the AR definition. Various experiments were performed with the parameters of the algorithm such as, lowering and raising relative IWV and IVT thresholds, allowing discontinuities in the AR shapes, and shifting the $45^{\circ} \mathrm{S}$ and $80^{\circ} \mathrm{S}$ domain north and south (see Table 2.1).

While Wille_v1 was sufficient to produce the results with a regional focus seen in Chapter 3 (Wille et al. [2019]), it was improved to remove errors at the detection domain boundaries as ARs that traversed the boundaries would not be counted 


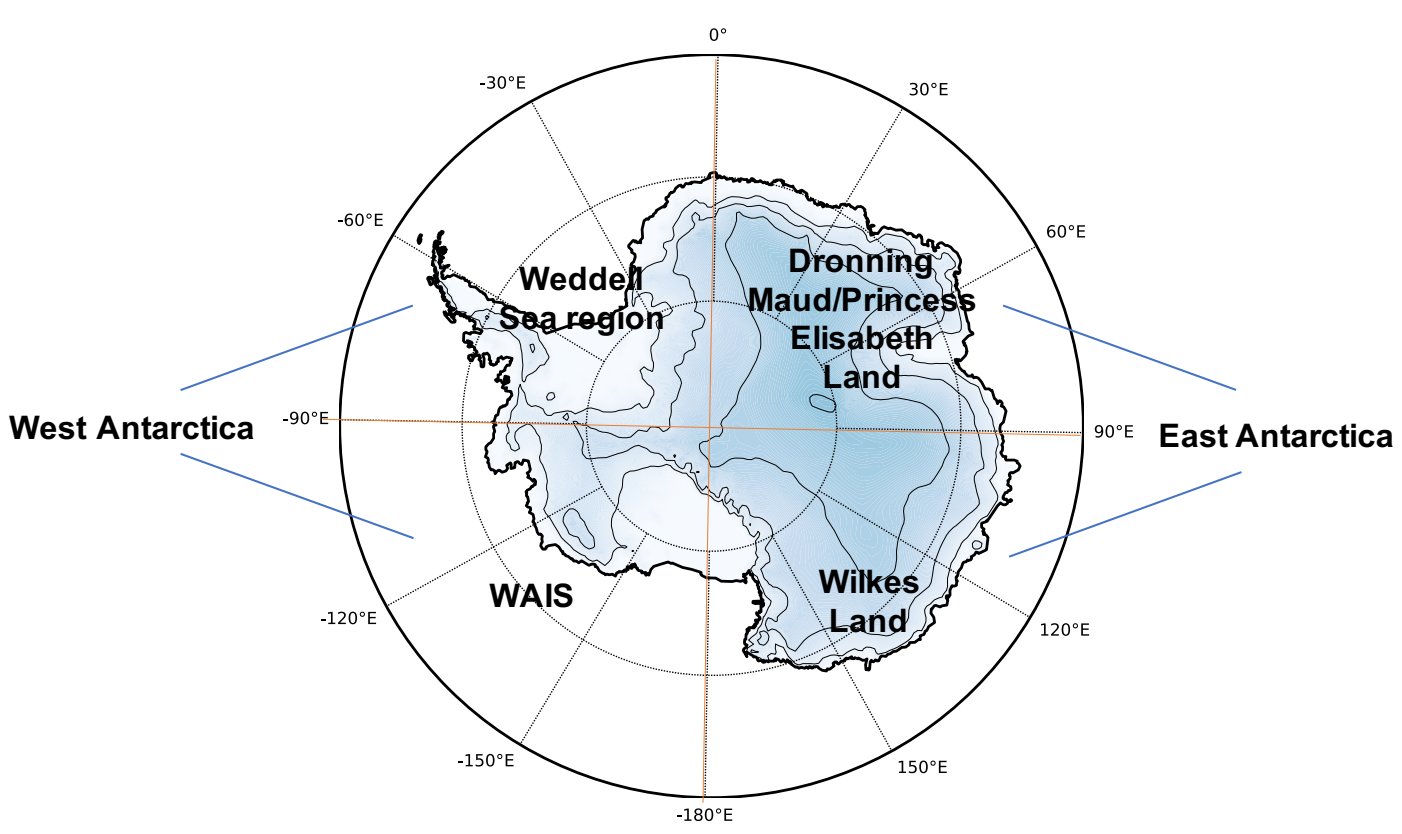

Figure 2.2: The quadrants and halves where Wille_v1 was run and accordingly labelled.

with the use of quadrants and halves. Also using quadrants makes it difficult to track any associated precipitation for individual AR events and make a detailed analysis of AR impacts on precipitation patterns across Antarctica (see Chapter 5). Upon publishing Wille et al. [2019], there was interest from the ARTMIP group of having our Antarctic detection algorithm in their database. To accomplish this meant upgrading the algorithm to provide the AR shapes and coordinates for every timestep in addition to AR landfall dates.

\section{Wille_v2 algorithm}

Transitioning the algorithm to detecting shapes meant expanding much of the code in Wille_v1. Like the previous version, Wille_v2 still initially locates grid cells that are within the 98th percentile of IWV or vIVT and then loops through each timestep testing their shape. However in Wille_v2, a series of test are made to identify discrete AR shapes and cut out grid cells that are not part of the AR. The algorithm searches for continuous grid cells in the meridional direction within the 98th percentile of IWV or vIVT that extend at least $20^{\circ}$ in length (see Appendix E. The main 


\begin{tabular}{|l|l|l|}
\hline & Wille_v1 & Wille_v2 \\
\hline Publications presented & Wille et al., 2019, Nat Geo, published & $\begin{array}{l}\text { Wille et al., 2020, Nat Geo, in review } \\
\text { Wille et al., 2020, JGR - Atmos, in review }\end{array}$ \\
\hline AR detection domain & Antarctic quadrant and half based & Antarctic and Arctic-wide \\
\hline Algorithm output & Date of AR landfall & AR shapes and coordinates \\
\hline ARTMIP member? & No & Yes \\
\hline Pressure levels & $900 \mathrm{hPa}-300 \mathrm{hPa}$ & All pressure levels \\
\hline Temporal resolution & $6-\mathrm{hourly}$ & 3 and 1-hourly \\
\hline Antarctic meridional range & $45^{\circ}-80^{\circ} \mathrm{S}$ & $37.5^{\circ}-80^{\circ} \mathrm{S}$ \\
\hline
\end{tabular}

Table 2.1: Summary of the differences between the two versions of the Antarctic AR detection algorithm.

difference is this algorithm can save the position of multiple simultaneous individual AR shapes around Antarctica. An example of the algorithm output is seen in Fig. 2.3. Overall, the AR detection algorithm outputs shapes that meet a common statistical metric. The results presented throughout this manuscript gives a unique physical meaning to these statistical shapes.

To be compatible with ARTMIP format, Wille_v2 reads in MERRA-2 reanalysis vIVT and IWV data at a 3-hourly frequency. The definitions of vIVT and IWV are basically the same as Wille_v1, except Wille_v2 uses data at all model levels. There were no obvious changes in allowing the use of all model levels as opposed to Wille_v1 that incorporated data from $900 \mathrm{hPa}-300 \mathrm{hPa}$. The range of latitudes considered for AR detection around Antarctica is slightly expanded to $37.5^{\circ} \mathrm{S}-80^{\circ} \mathrm{S}$ (Will_v1: $45^{\circ} \mathrm{S}$ $80^{\circ} \mathrm{S}$ ) to better capture ARs over the Antarctic Peninsula. Wille_v2 also has a domain for AR detection over the Arctic within the latitude range of $42.5^{\circ} \mathrm{N}-85^{\circ} \mathrm{N}$. Only the vIVT appears reliable over the Arctic as the IWV scheme confuses summertime mesoscale thunderstorm complexes over landmasses as ARs. The AR detection outputs over the Arctic have not been utilized in any studies related with this thesis but have been shared with other research groups interested in studying Arctic ARs (Further discussed in the Perspectives, Chapter 6). The domain of Wille_v2 is visualized in Fig. 2.5. To add confidence to the Antarctic AR detection using MERRA-2, Wille_v2 was also tested with ERA-5 reanalysis data interpolated to a $1^{\circ} \times 1^{\circ}$ horizontal grid. The results from these algorithm runs are presented in Chapters 4 and 5.

Finally, Wille_v2 is part of an ARTMIP Tier 2 Reanalysis Project which looks to test the sensitivity of multiple AR detection algorithms to different reanalysis datasets. 


\section{8-Nov-2019 09UTC}

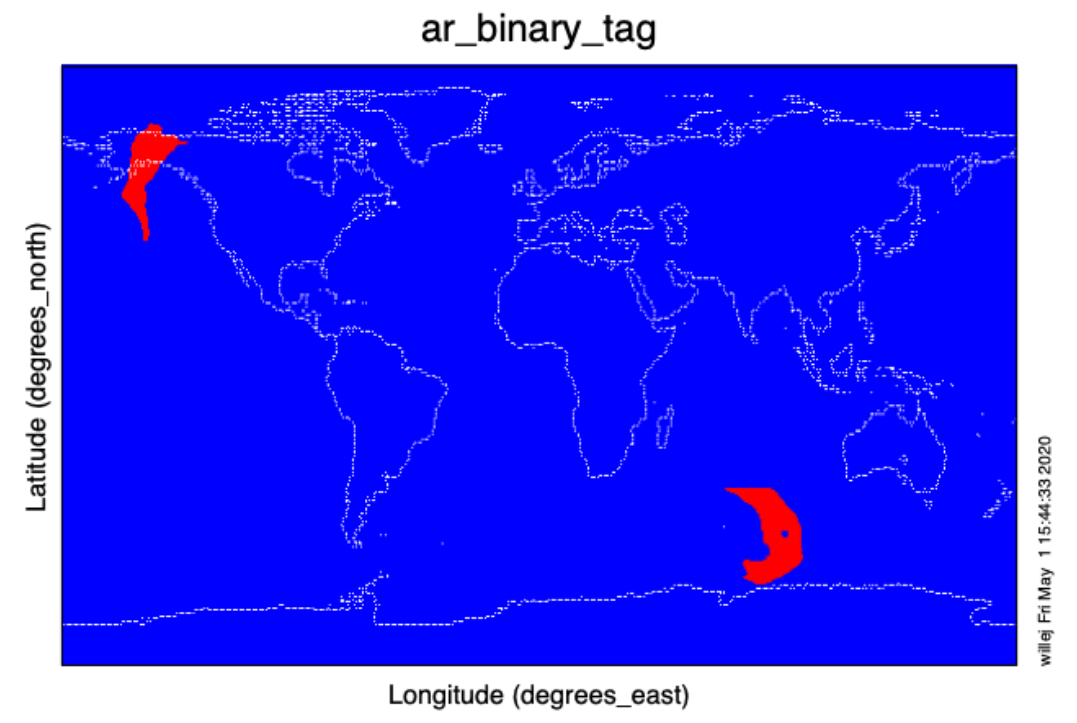

Range of ar_binary_tag: 0 to 1 (null)

Range of Longitude: -180 to 179.375 degrees_east

Range of Latitude: - 90 to 90 degrees_north

Current time: 1.05109e+06 hours since 1900-01-01 00:00:00.0

Frame 2652 in File MERRA2.ar_tag.Wille_v2.3_vIVT.3hourly.20190101-20191231.nc4

Figure 2.3: An example of the output from Wille_v2 displayed in Ncview.

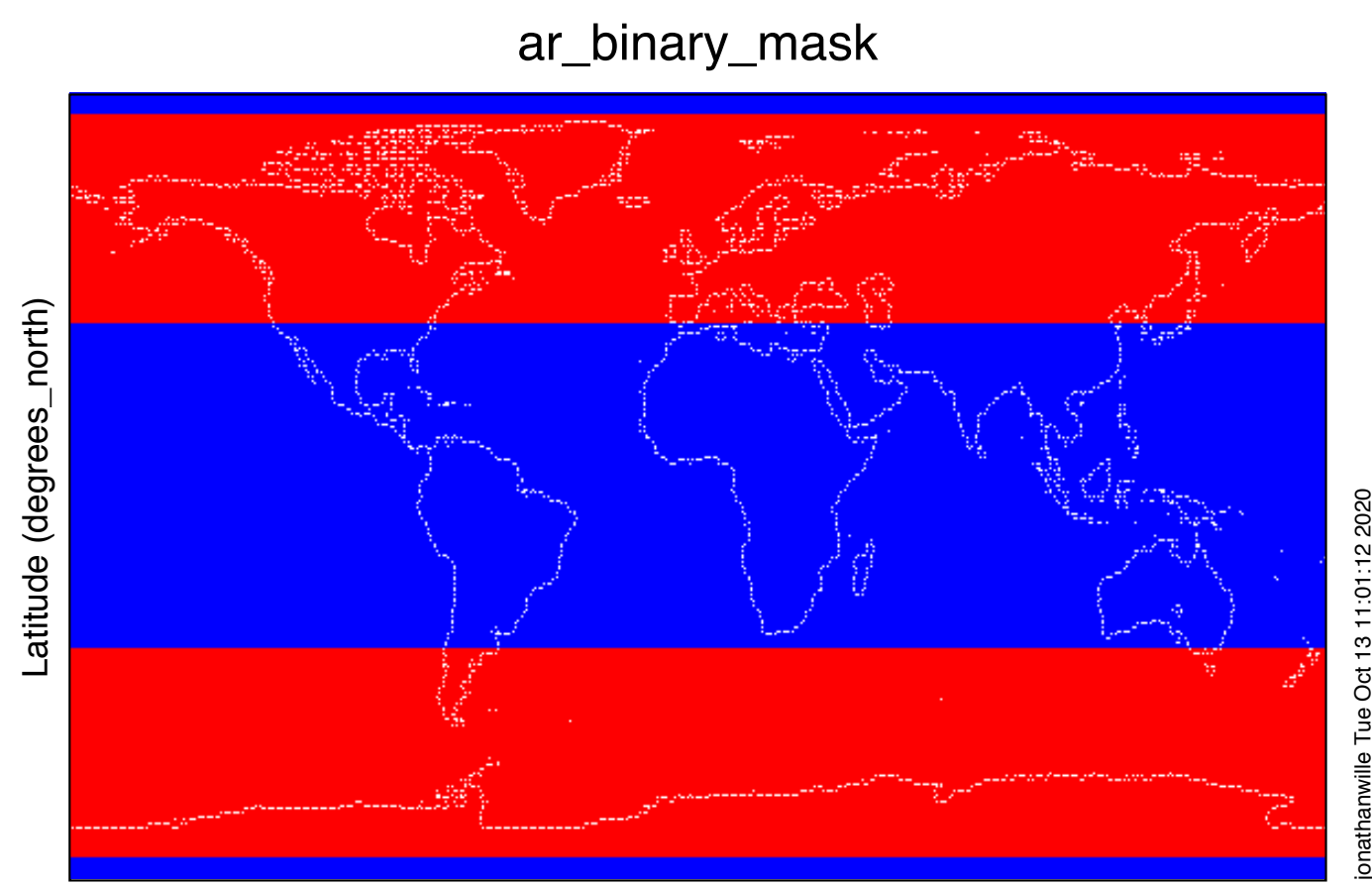

Longitude (degrees_east)

Figure 2.4: The domain of Wille_v2. Red areas are where the algorithm scans for ARs. 
Joining this project meant running Wille_v2 (vIVT scheme) on 1-hourly MERRA2 and ERA-5 reanalysis data on their native grids. Running Wille_v2 on 1-hourly MERRA-2 data was relatively straightforward, but the large size of the native ERA-5 data $\left(0.25^{\circ} \times 0.25^{\circ}\right.$ resolution $)$ required dividing the Wille_v2 script into multiple partitions. Currently the analysis of the ARTMIP Tier 2 Reanalysis Project is in its early stages being led by researchers from NASA and the University of Colorado, Boulder.

\subsection{The MAR}

The Modèle Atmosphérique Régional (MAR) is used extensively throughout this thesis and while we did not develop any unique MAR products for this project, a quick description of the model is warranted. MAR is a polar-oriented regional atmospheric model that is capable of providing accurate SMB estimations on the Antarctic ice sheet (Agosta et al. [2019]). As described in Agosta et al. [2019], the atmospheric dynamics in MAR are based on the hydrostatic approximation of the primitive equations (Gallée and Schayes [1994]). MAR represents five water species (specific humidity, cloud droplets, ice crystals, raindrops, and snow particles) whose interactions with the air (e.g., evaporation, sublimation, condensation, etc.) contribute directly to the heat and moisture budget of the atmosphere. Taking into account the direct contribution of the sublimation of airborne snow particles has been shown to improve the simulation of surface snowfall accumulation (Agosta et al. [2019]), which is not a process handled by the ERA-Interim and Polar WRF (e.g. Wille et al. [2016]). The radiative transfer through the atmosphere takes into account the effects snow particles on the atmospheric optical depth (Gallée and Gorodetskaya [2008]). MAR uses the SISVAT (soil ice snow vegetation atmosphere transfer) surface scheme to account for the energy and mass exchanges between the surface, snow, and atmosphere (De Ridder and Gallée [1998]). The snow-ice component of SISVAT utilizes the multilayer snow model Crocus, which calculates meltwater at the surface when it reaches the melting point in combination with a surplus of energy (Brun et al. [1992]). Percolation through the snowpack is determined through a tipping bucket method based on snow density (Datta et al. [2018]). The teams at University of Liège (Christoph Kittel, Xavier Fettweis, and Charles Amory) and the LSCE (Cécile Agosta) provided the 
MAR products used in this thesis along with the assistance necessary for its implementation.

The version of MAR utilized for the results in Chapter 3 (Wille et al. [2019]) was run at a $35 \times 35 \mathrm{~km}^{2}$ horizontal resolution over the Antarctic continent forced by ERA-Interim boundary conditions and provided output ever 6 h. This simulation is fully presented in Agosta et al. [2019]. In chapter 5, the MAR was upgraded to use ERA-5 for the boundary conditions and provided output every three hours while the domain size and resolution remained the same. The MAR version used for Chapter 4 is the most recent using a $7.5 \times 7.5 \mathrm{~km}^{2}$ horizontal resolution over the Antarctic
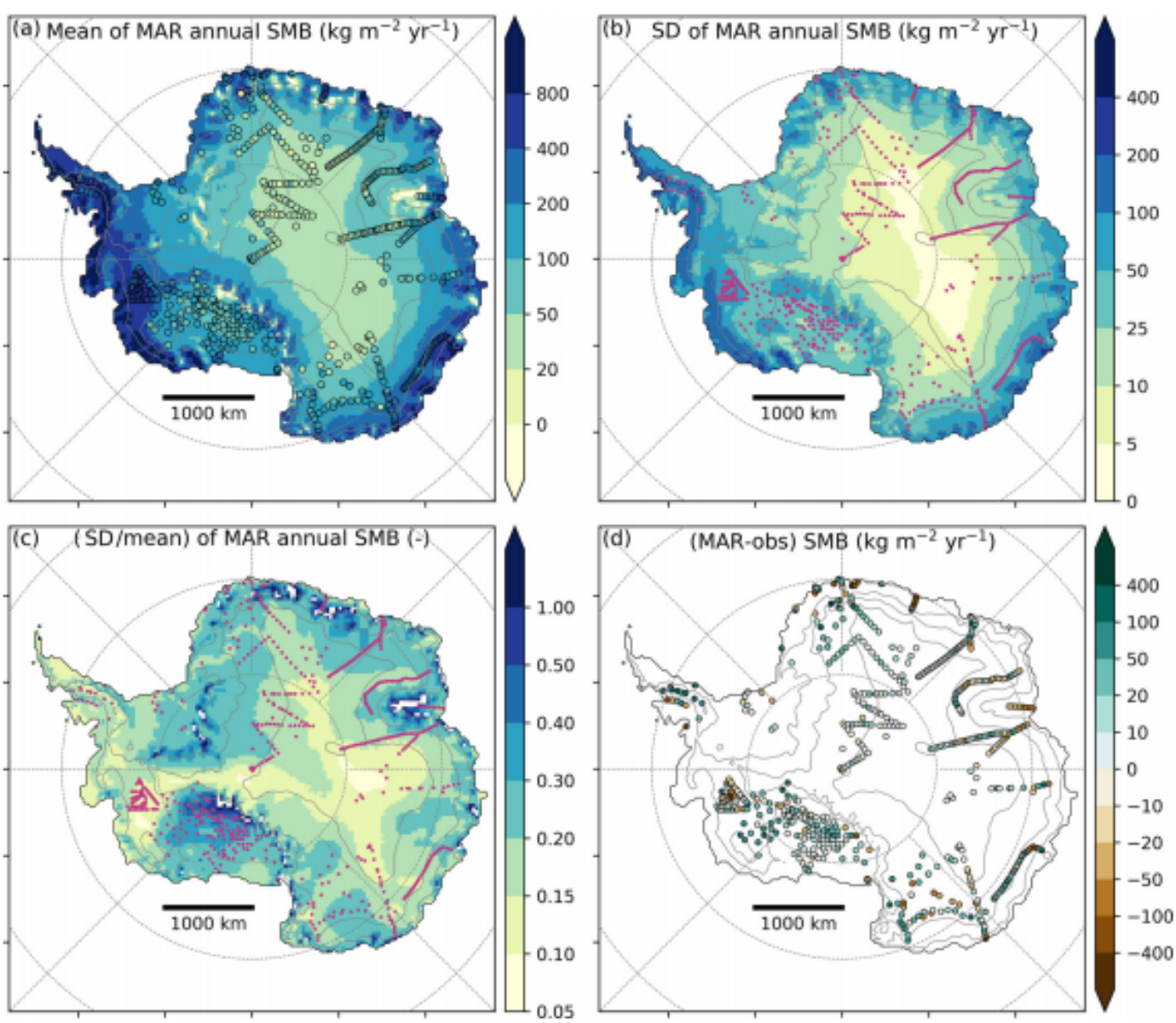

Figure 2.5: The MAR SMB from 1979-2015. (a) The mean annual SMB with the colored dots representing SMB observations. (b) The standard deviation of the annual SMB. (c) Standard deviation divided by the mean annual SMB. (d) The difference between the MAR simulated and observed SMB where observations were available. The SMB observations are from the GLACIOCLIM-SAMBA dataset (Favier et al. [2013]; Wang et al. [2016]). Source: Agosta et al. [2019]. 
Peninsula. This simulation has not been published elsewhere yet, but an evaluation of the MAR melting and runoff outputs are also presented in the Methods of Chapter 4.2 .

\subsection{Other datasets}

The AR detection algorithm and the MAR are the most utilized tools throughout this thesis. The following results chapters contain methods that are unique to their projects and are discussed within the chapter. This includes daily surface observations from passive microwave radiometer data provided by SMMR and SSM/I in Chapter 3; MODIS-Terra Aqua images for identifying ice shelf disintegration events and sea ice fraction and ocean wave data from ERA-5 in Chapter 4; and the Marshall SAM index in Chapter 5. 


\section{Chapter 3}

\section{Surface melting in West Antarctica}

\section{and atmospheric rivers}

\subsection{Foreword}

In this chapter, we discuss the relationship between atmospheric rivers (ARs) and surface melting in West Antarctica. This was the first study conducted with new developed AR detection algorithm (Wille_v1; see Chapter 2). The hypothesis behinds this study was that the January 2016 melt event in West Antarctica described in Nicolas et al. [2017] was related to an AR. Using Wille_v1, we detected a large, longduration AR that coincided with the period of melting in Marie Byrd Land and the Ross Ice Shelf plus other large melt events since 1979 had coincided with AR landfalls. An intense winter surface melting event on the Larsen C Ice Shelf in May 2016 raised another science question of what synoptic-scale system could cause melt on the Antarctic Peninsula in the middle of the dark Antarctic winter (Kuipers Munneke et al. [2018]). Our study discovered that the winter melting event in May 2016 along with other winter melting events on the Antarctic Peninsula were linked with AR activity. Within the framework of Wille_v1 (see Chapter 2), this study was the first to attempt the creation of an AR climatology over the Antarctic continent.

The major implications of this study were: (1) There is a high degree of interannual variability in AR occurrences, but their frequency has significantly increased over West Antarctica during the last couple decades. (2) Despite their rarity of occurrence (1.6-3.0\%), ARs explain 50-90\% of summer melt occurrences on the Ross 
Ice shelf and winter melt on the Antarctic Peninsula ice shelves, where large surface melting could create meltwater ponds and trigger hydrofracturing (DeConto and Pollard [2016]. (3) While ARs are present for most melt events on the Ross Ice Shelf and Marie Byrd Land, melt events in general are currently rare. However, a $1-2^{\circ} \mathrm{C}$ increase in the baseline temperature across West Antarctica would significantly increase the occurrence of AR triggered melt events. This temperature increase is well within the range of future warming projections according to the CMIP5 simulations (Palerme et al. [2017]). (4) Because significantly higher melting may be associated with ARs under future climate forcing, this study demonstrates that ARs should be analyzed more cautiously in future sea level rise projections. Finally, this study demonstrated the potential of using an AR catalogue to study how ARs could impact the Antarctic climatology in short time scales. The paper that resulted from this study was published in Nature Geoscience in October 2019. The following section displays the original article which includes the accompanying references. The supplementary materials and figures are in Appendix A. Many of the processes that lead to surface melt in West Antarctica are also discussed in (Donat-Magnin et al. [2020]), where I am a coauthor.

\subsection{Article: West Antarctic surface melt triggered by atmospheric rivers}




\title{
West Antarctic surface melt triggered by atmospheric rivers
}

\author{
Jonathan D. Wille ${ }^{1 \star}$, Vincent Favier ${ }^{\circledR 1}$, Ambroise Dufour', Irina V. Gorodetskaya $\mathbb{1}^{2}$, John Turner ${ }^{3}$, \\ Cécile Agosta ${ }^{4}$ and Francis Codron ${ }^{5}$
}

Recent major melting events in West Antarctica have raised concerns about a potential hydrofracturing and ice shelf instability. These events often share common forcings of surface melt-like anomalous radiative fluxes, turbulent heat fluxes and föhn winds. Using an atmospheric river detection algorithm developed for Antarctica together with surface melt datasets, we produced a climatology of atmospheric river-related surface melting around Antarctica and show that atmospheric rivers are associated with a large percentage of these surface melt events. Despite their rarity (around 12 events per year in West Antarctica), atmospheric rivers are associated with around $\mathbf{4 0 \%}$ of the total summer meltwater generated across the Ross Ice Shelf to nearly $100 \%$ in the higher elevation Marie Byrd Land and $\mathbf{4 0 - 8 0 \%}$ of the total winter meltwater generated on the Wilkins, Bach, George IV and Larsen B and C ice shelves. These events were all related to high-pressure blocking ridges that directed anomalous poleward moisture transport towards the continent. Major melt events in the West Antarctic Ice Sheet only occur about a couple times per decade, but a $1-2{ }^{\circ} \mathrm{C}$ warming and continued increase in atmospheric river activity could increase the melt frequency with consequences for ice shelf stability.

$\mathrm{R}$ ecent estimates of the Antarctic mass balance revealed a significant acceleration of ice wastage in the West Antarctic Ice Sheet (WAIS) ${ }^{1,2}$, where the grounding line retreat over a retrograde slope of the glacier bedrock ${ }^{3}$ and changes in the warm water fluxes at the base of the glaciers ${ }^{4}$ have driven the recent glacier mass loss. There is concern that large ice shelf collapses on the Antarctic Peninsula (AP) and WAIS could lead to accelerated glacier velocities due to the removal of the buttressing effects on the surrounding glaciers $^{5-7}$. The risk increases in the presence of surface meltwater ponding, which acted as a primary driver of the ice shelf collapse for Larsen $\mathrm{B}^{5,6}$ and Larsen $\mathrm{C}^{8,9}$. Recently, an atmospheric river (AR) was observed to play a critical role in a winter melting event in the $\mathrm{AP}^{10}$ and led to melt pond formation on the land-fast sea ice in the Larsen $\mathrm{A}$ and Larsen $\mathrm{B}$ embayments ${ }^{10}$. Here we focus on the Antarctic AR climatology in relationship to the total surface melt budget on the ice shelves.

$\mathrm{ARs}^{11,12}$ represent narrow bands that contain enhanced water vapour fluxes typically associated with the low-level jet ahead of an extratropical cyclone's cold front ${ }^{13}$ and within the cyclone's warm conveyer belt ${ }^{14,15}$. Despite covering around $10 \%$ of the globe's surface, ARs account for more than $90 \%$ of the meridional moisture transport in the mid-to-high latitudes ${ }^{16,17}$. In the polar regions, an AR's ability to transport heat in addition to moisture becomes consequential for the cryosphere. ARs are important contributors to snowfall accumulation in East Antarctica ${ }^{18}$, sea ice decline in the Arctic ${ }^{19,20}$ and the decreasing ice mass on the Greenland ice sheet due to the enhanced downward longwave radiation and warm air advection ${ }^{21-23}$. Thus, a single AR can cause both strong snowfall and melt and contribute either positively or negatively to the surface mass balance.

We used an AR detection algorithm developed for Antarctica and tested it on a multireanalysis dataset that covered 1979-2017. Using the results from the detection algorithm applied to the European
Centre for Medium-Range Weather Forecasts interim reanalysis (ERA-Interim), we examined daily surface melt observations from the Scanning Multichannel Microwave Radiometer (SMMR) and the Special Sensor Microwave/Imager ${ }^{24}$ (SSM/I), and simulated melting magnitudes from a regional climate model (RCM) driven by ERA-Interim and especially adapted for polar regions, Modèle Atmosphérique Régional (MAR) ${ }^{25}$, to produce the first climatology of AR-related surface melting around Antarctica. To analyse the distribution of the ARs and their associated impacts, we divided Antarctica into four evenly spaced quadrants between $0^{\circ}, 90^{\circ} \mathrm{E}, 180^{\circ}$ and $90^{\circ} \mathrm{W}$-the Dronning Maud Land and Princess Elisabeth Land, Wilkes Land and Victoria Land, WAIS, AP and the Weddell Sea region. We also divided Antarctica into halves to account for ARs that might travel between the quadrants (Fig. 1c and Supplementary Figs. 1 and 2).

\section{Summer surface melting}

ARs can lead to extensive surface melt in regions that rarely experience melting conditions. Within interior portions of the Ross Ice Shelf along the base of the Transantarctic Mountains, melting conditions were observed for about $3 \%$ of the melt season (December and January) days from 1979 to $2017^{26}$, whereas AR conditions in West Antarctica were detected in 1.0-2.5\% of all the days, or around 12 distinct AR events per year (Fig. 1a,b). Of the melt days in this region, $30-50 \%$ occurred on the day of an AR landfall or within one day after landfall (Supplementary Fig. 3a). Further inland and higher up from the Siple Coast into Marie Byrd Land, the total number of observed melt days decreased (between 10 and 100 melt days from 1979 to 2017), but the percentage related to ARs increased to $60-90 \%$. The simulated meltwater percentages from MAR during the melt season are in good agreement with the melting day percentages from satellite observations in the WAIS region; however, the melt

1'Institut des Géosciences de l'Environnement, CNRS/UGA, Saint Martin d'Hères, France. ${ }^{2}$ CESAM-Centre for Environmental and Marine Studies, Department of Physics, University of Aveiro, Aveiro, Portugal. ${ }^{3}$ British Antarctic Survey, Cambridge, UK. ${ }^{4}$ Laboratoire des Sciences du Climat et de I'Environnement, LSCE-IPSL, CEA-CNRS-UVSQ, Université Paris-Saclay, Gif-sur-Yvette, France. ${ }^{5}$ LOCEAN, Sorbonne Université, Paris, France. *e-mail: Jonathan.Wille@univ-grenoble-alpes.fr 


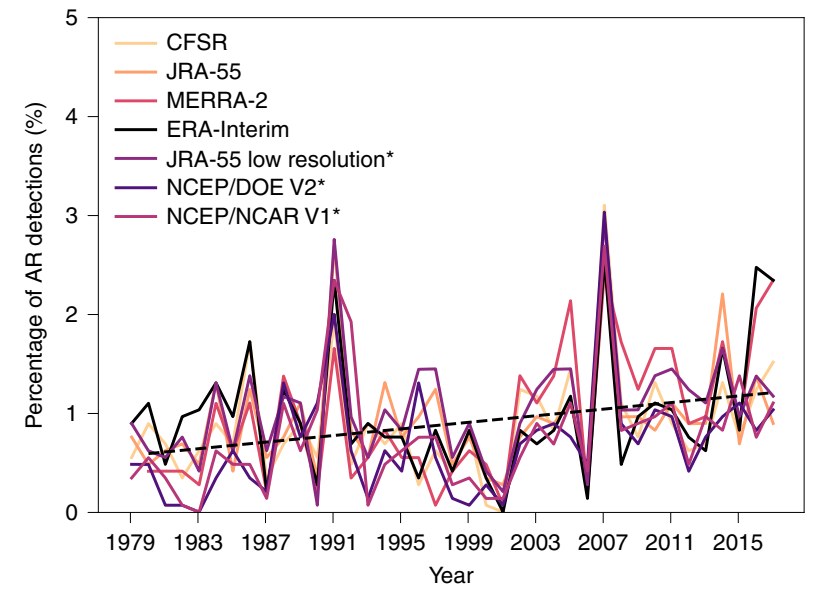

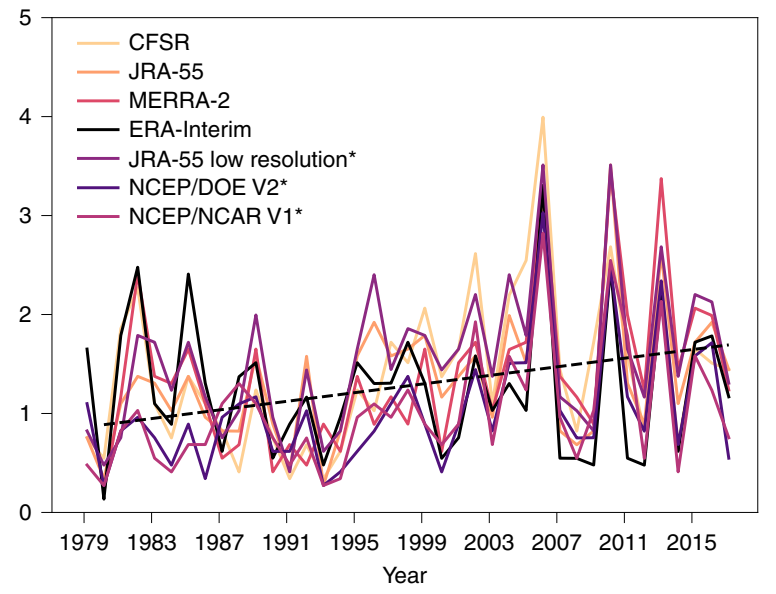

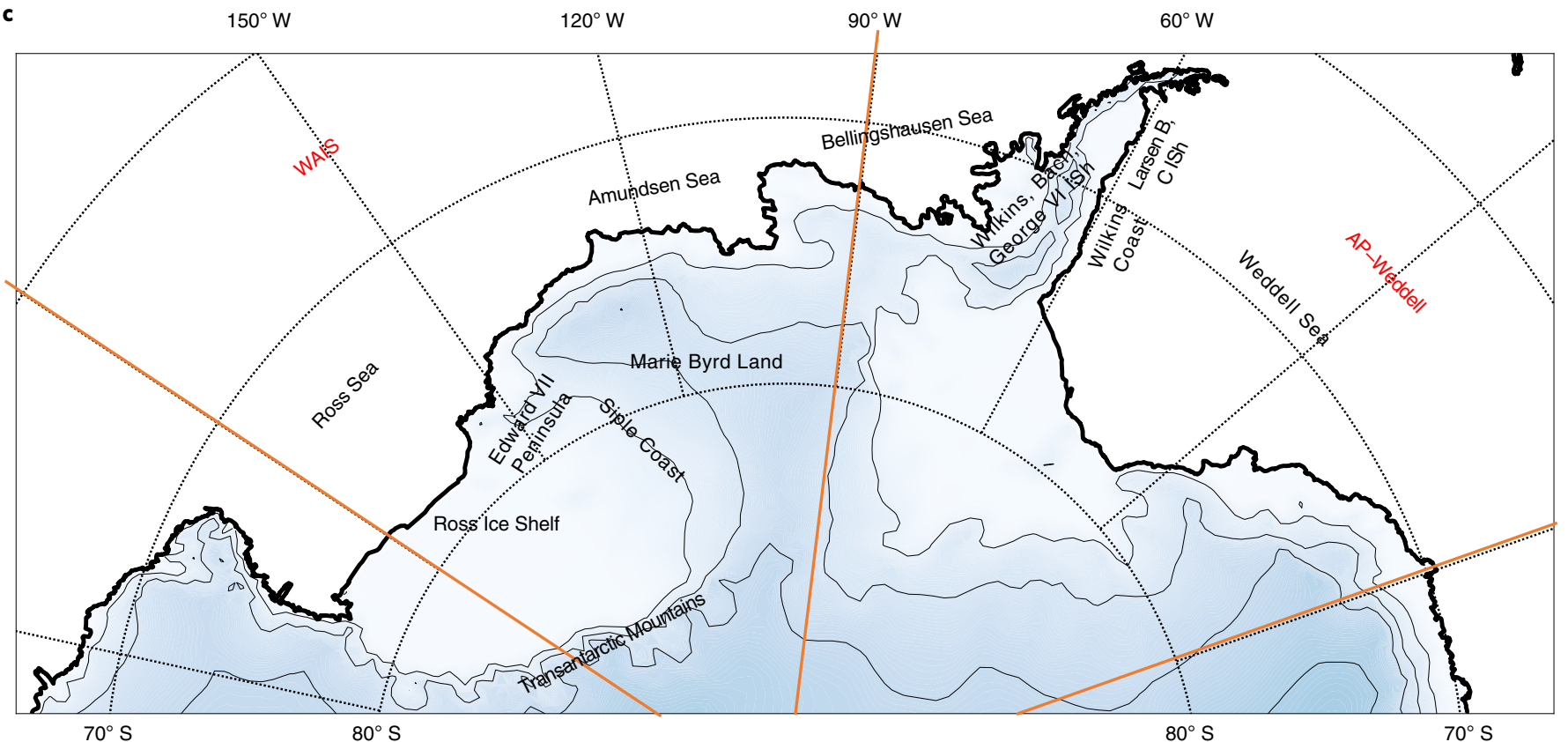

Fig. 1 The yearly percentage of six-hourly AR occurrences to make landfall detected in the multireanalysis dataset and points of interest.

$\mathbf{a}, \mathbf{b}$, An AR detection algorithm was run in the WAIS (a) and AP-Weddell (b) quadrants. These quadrants represent the partition of West Antarctica (c). The dashed lines represent the linear regression of the mean AR landfall occurrence between all the reanalysis datasets. The asterisks represent the reanalysis datasets with a horizontal resolution too coarse for the AR detection algorithm, so the AR detection algorithm was run with an integrated water vapour continuity requirement of $3^{\circ}$ latitude instead of $1^{\circ}$ for these datasets. The reanalysis datasets displayed in $\mathbf{a}$ and $\mathbf{b}$ are ERA-I, ERA-Interim reanalysis; JRA-55, Japanese 55-year Reanalysis; CFSR, Climate Forecast System Reanalysis; MERRA-2, Modern-Era Retrospective Analysis for Research and Applications, Version 2; NCEP/NCAR V1, National Centers for Environmental Prediction/National Center for Atmospheric Research Reanalysis Version 1; NCEP/DOE V2, National Centers for Environmental Prediction/Department of Energy Reanalysis Version 2.

extent in MAR extends $300 \mathrm{~m}$ higher in Marie Byrd Land compared to the SMMR and SSM/I observations. Overall, from the simulated meltwater magnitudes from MAR, which range from 100 to $500 \mathrm{~mm}$ water equivalent over the region during the study period, $20-40 \%$ of the total melt on the Ross Ice Shelf and $40-100 \%$ of the total melt from $300 \mathrm{~m}$ to $1,500 \mathrm{~m}$ elevation in Marie Byrd Land occurred during an AR landfall or within 24 hours after the landfall (Fig. 2a).

When ARs make landfall over WAIS, they trigger melting through various physical mechanisms. Intrusions of high integrated water vapour (IWV) (also known as precipitable water) filaments that come from the South Pacific Ocean lead to the development of mixedphase clouds with high liquid and ice water paths. In the composite spatial and temporal evolution of an AR landfall life cycle, it is clear that melting is most closely related with the anomalously high cloud liquid and ice water content and therefore downward longwave radiation, which is slightly compensated by the net shortwave radiation with the anomalous sensible heat fluxes (SHFs) generally low (Fig. 2c,d and Supplementary Fig. 4a,b). Mixed-phase clouds act to reduce radiative cooling during the night-time by increasing the downward longwave radiation when the incoming shortwave radiation is small, which has been shown to decrease meltwater refreezing $^{27}$. Towards the Amundsen Sea coast, a strong surface melting is also intensified by rainfall brought by ARs (Supplementary Fig. 5a,b), which thus decreases the surface albedo and leads to a greater chance of additional melt in the region (Fig. 2c). Further inland, on the Ross Ice Shelf, there is often a slight delay between the intial AR landfall 
a

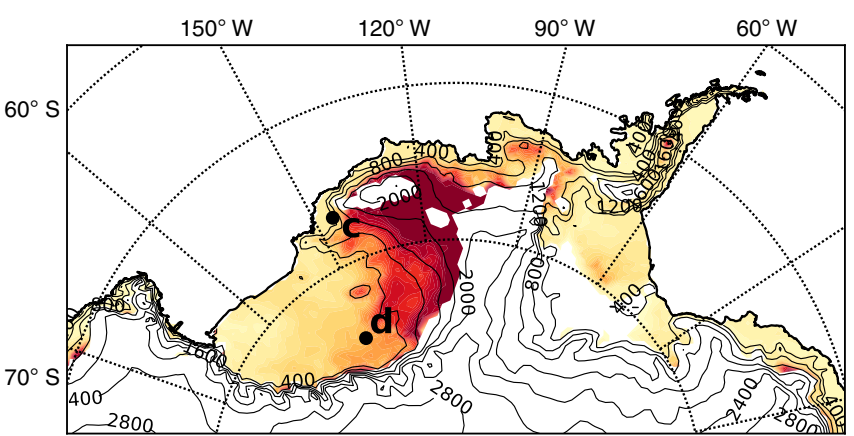

c

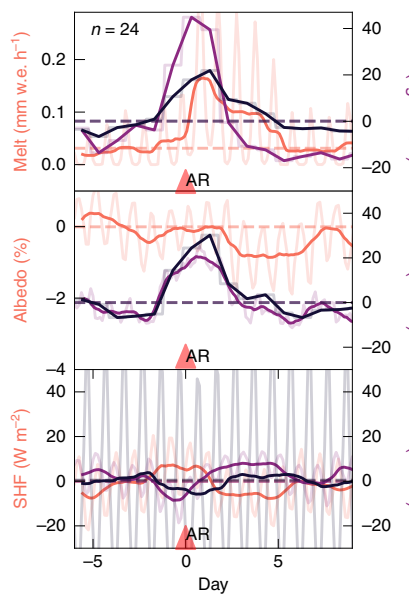

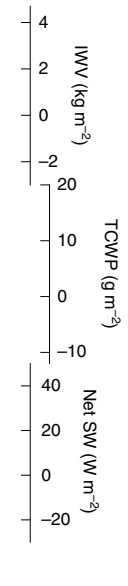

d

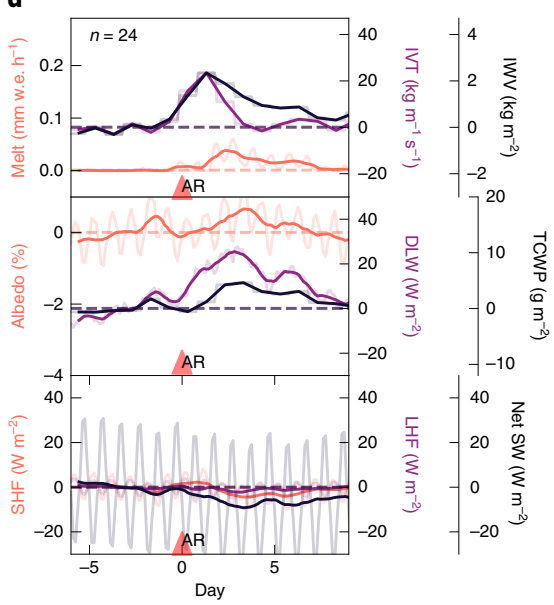

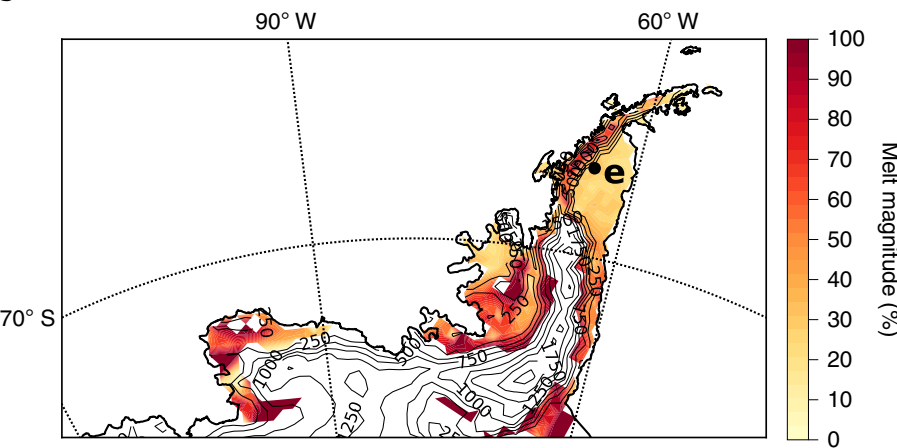

Fig. 2 I Surface melt associated with ARs and average AR life cycle on landfall. a,b, The percentage of total surface meltwater from $1979-2017$ according to MAR that occurred when an AR made landfall and within $24 \mathrm{~h}$ after landfall during summer (December and January) (a) and winter (March-October) (b). c-e, The AR landfall dates were calculated by running the detection algorithm over West Antarctica (WAIS quadrant + AP-Weddell quadrant) using ERA-Interim data. The panel plots are a composite of anomalous IVT, IWV, surface melt magnitude (upper panels), surface albedo, total cloud water path (TCWP) and downward longwave radiation (DLW) (middle panels), and the net shortwave (SW) radiation and turbulent heat fluxes (lower panels) during AR events near to the Edward VII Peninsula (summer) (c), further inland along the Siple Coast (summer) (d) and on the Larsen C Ice Shelf (winter) (e) using MAR data (Methods). The averaged $3 \mathrm{~h}$ anomaly of all the events (light lines) and the 1-day running mean of anomalies (dark lines) are displayed over the 16 days of the initial landfall detection (red triangles). Also shown are the mean values for the 6 days that precede the ARs (dashed lines). The locations for $\mathbf{c}$ and $\mathbf{d}$ are plotted on $\mathbf{a}$, and the location of $\mathbf{e}$ is plotted on $\mathbf{b}$ (black circles). w.e., water equivalent.

and the melting response along with an increase in surface albedo, likely in response to fresh snowfall (Fig. 2d). If the strong integrated vapour transport (IVT) associated with an AR is perpendicular to the coastal mountain ranges near the Amundsen Sea coast, then a resulting föhn wind can enhance the surface SHFs through isentropic drawdown in the leeward regions of Marie Byrd Land and the Edward VII Peninsula ${ }^{28}$. After the AR makes landfall and dissipates, the residual high precipitable water and resulting mixed-phase clouds continue to cause surface melt for around five days until the airmass is transported away (Fig. 2c,d). Such phenomena were observed during a recent and intense melt event that occurred in January 2016 over the Ross Ice Shelf and Marie Byrd Land ${ }^{29,30}$, in which a multiday AR event was detected (Supplementary Fig. 6). There appears to be little relation between the AR intensity (measured through the maximum IVT at landfall) and the magnitude of the $2 \mathrm{~m}$ temperature anomalies, so the effects of increasing IVT and IWV (not shown) on the temperature anomalies are negligible after the initial $2 \mathrm{~m}$ temperature increase on crossing the threshold for AR detection (Supplementary Fig. 7a).

\section{Winter surface melting}

Although summer melting from solar radiation dominates the annual melt budget over the $\mathrm{AP}^{31}$, recent winter melting events on the AP account for nearly one-quarter of the annual surface melt due to local mesoscale climatic features ${ }^{32}$. From March to October in the years 1979-2017, the total meltwater magnitudes on the AP ice shelves were around $1,000 \mathrm{~mm}$ (and exceeded $100 \mathrm{~mm}$ during some AR events, as in March 2015 (Supplementary Fig. 8a)) along the base AP mountain range, according to MAR. During these winter months (March-October), ARs and their residual moisture accounted for $40-60 \%$ of the melt days on the Larsen B and Larsen $\mathrm{C}$ ice shelves along the central portion of the eastern AP and represent $20-40 \%$ of the melt magnitude, according to MAR (Supplementary Figs. 2b and 3c). Further south along the outlet glaciers on the Wilkins Coast, $90-100 \%$ of winter melt days and melt magnitude are linked with AR activity. An AR signature is also present on the western AP, where $40-80 \%$ of winter melt days and similarly melt magnitudes on the Wilkins, Bach and George VI ice shelves occurred during AR conditions. The largest AR-associated winter melt magnitudes appeared in the eastern side of the AP along the base of the mountains and edge of the Larsen C Ice Shelf (Supplementary Fig. 8a,b), probably in response to the föhn wind. Winter melting does appear outside the AP, such as in the Pine Island Glacier region, but at much smaller and insignificant magnitudes compared to those within the AP.

As during the AR-related summer melting conditions in Marie Byrd Land, the presence of a high IWV, cloud liquid water paths 
a

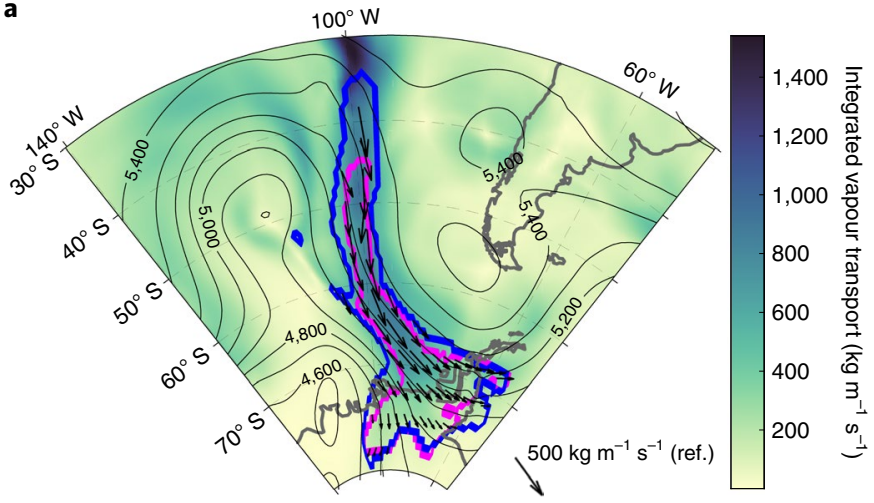

c

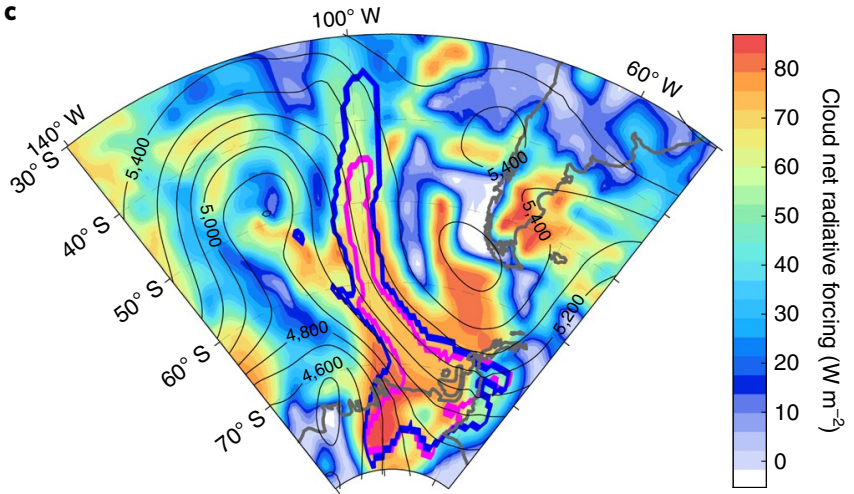

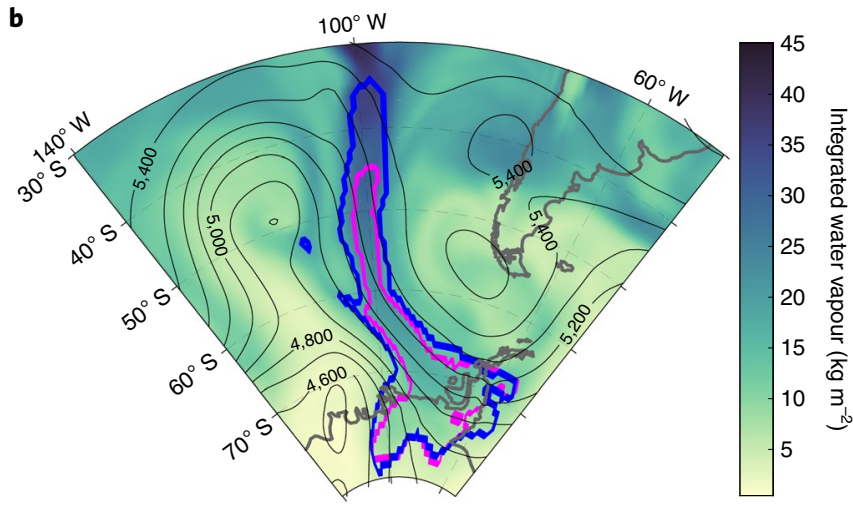

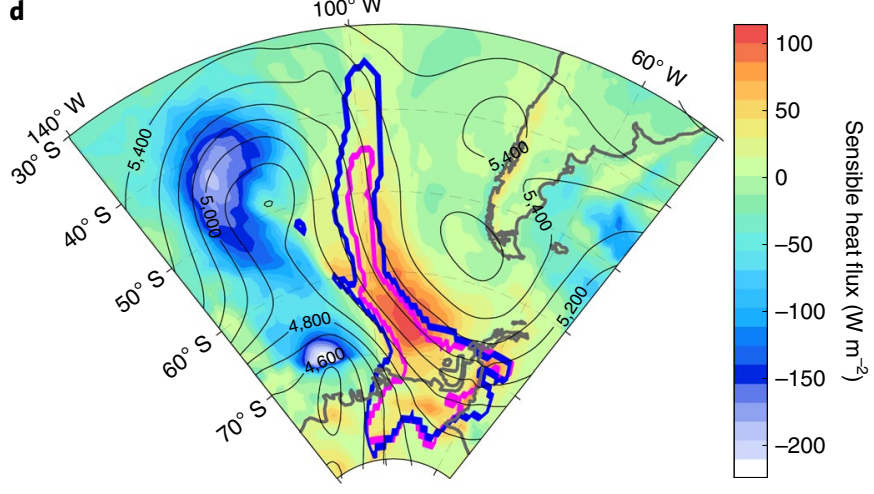

Fig. 3 | Atmospheric variables associated with an AR that contributed to the 25-30 May 2016 melt event. a-d, The purple contours show the AR shape at the peak of the event at 12.00 (coordinated universal time) on 25 May 2016 with the spatial distribution of IVT (a), IWV (b), cloud net radiative forcing at the surface (c) and SHF (d), all from ERA-Interim. The contours represent the $500 \mathrm{hPa}$ geopotential height contours ( $\mathrm{m}$ ) and the dark blue contour and black arrows represent the AR shape and AR IVT (reference magnitude arrow included (ref.)), respectively, according to the original Antarctic AR tracking algorithm ${ }^{18}$.

and resulting downward longwave radiation provides considerable melt energy during winter melt events on the AP (Fig. 2e). However, given the local topography and persistent westerly flow, föhn winds that descend the leeward side of the AP mountain ranges play a more crucial role in triggering winter melt events ${ }^{33}$. When ARs make landfall perpendicular to the mountain ranges, IVT is orographically lifted over the windward side of the mountains and generates precipitation and latent heat release, which act to enhance the föhn wind on the leeward side. The drying of the leeside downslope wind causes sublimation, which leads to a slightly negative latent heat flux (LHF), but a much larger surface $\mathrm{SHF}^{10,32}$ (Fig. 2e and Supplementary Fig. 4d) that combines with high downward longwave radiative fluxes (Supplementary Fig. 4c). The increased wind shear mixes the boundary layer and prevents the development of a surface inversion over the ice, which thus increases the efficacy of the downward turbulent fluxes ${ }^{34}$. Strong SHFs along with significant longwave radiative forcing were observed during two major AR-related melt events over the AP in winter (Fig. 3c,d and Supplementary Figs. 9c,d and $10 \mathrm{c}, \mathrm{d})$. The peak surface melting occurred in conjunction with the maximum anomalies in IVT, downward longwave radiation and SHF and dissipated more quickly compared to the summer melting on WAIS (Fig. 2e). In addition, $30-50 \%$ of the winter rainfall over the AP ice shelves during the study period was associated with AR activity, which thus enabled further melting through warming the snowpack (Supplementary Fig. 5c). Unlike during the summer AR events in Marie Byrd Land, there is a positive relationship between the AR intensity (measured through the maximum IVT at landfall) and the maximum positive $2 \mathrm{~m}$ temperature anomalies (Supplementary Figs. 7b,c).

\section{Large-scale atmospheric background}

Previous research has already highlighted the importance of atmospheric blocking for WAIS surface melting events ${ }^{29,35}$ and we found that a nearly identical pattern holds true for the meridional moisture transport within ARs that cause melt in Antarctica. The dominant large-scale atmospheric signal during an AR landfall along the entirety of the Antarctic coastline is a blocking ridge upstream of the AR's position (Supplementary Fig. 11). Such a blocking pattern preceded the WAIS January 2016 ${ }^{29}$ and AP 25-30 May 2016 and 22-28 March 2015 melt events.

The observed atmospheric blocking during AR activity in the WAIS quadrant (Fig. 4a) resembles the geopotential height anomalies observed during the Pacific-South American pattern $(\mathrm{PSA} 1)^{36}$. The PSA1 pattern has been shown to correlate with melting events in WAIS ${ }^{35}$ and is related to the El Niño-Southern Oscillation variability as it is coupled with tropical convection anomalies within the western Pacific ${ }^{37,38}$. We observe a significant positive trend in the AR frequency in the WAIS quadrant from the beginning of the twenty-first century that is similar to an observed increase in blocking activity in the Amundsen Sea during the same period, which was attributed to the PSA1 pat$\operatorname{tern}^{35}$ (Fig. 1a and Supplementary Tables 1 and 2). There is also a clear shift of the Amundsen Sea Low to the west towards the Ross Sea during times when ARs made landfall in the WAIS quadrant (not shown), which further indicates a connection with the PSA1 pattern ${ }^{39}$. The observed geopotential height anomalies are also similar to the anomalies associated with the Interdecadal Pacific Oscillation, which was also known to drive warming on the Ross Ice Shelf ${ }^{40}$. 


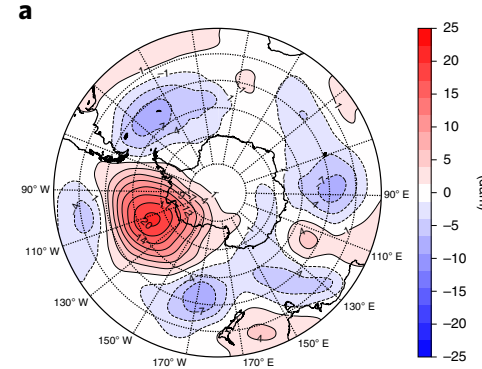

$n=65$

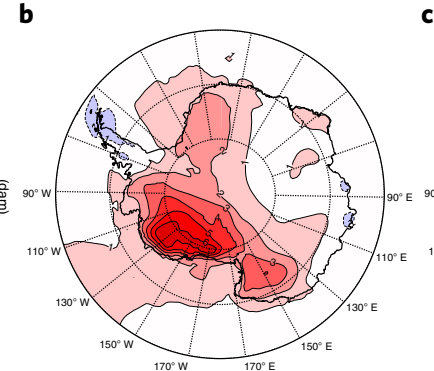

$n=160$

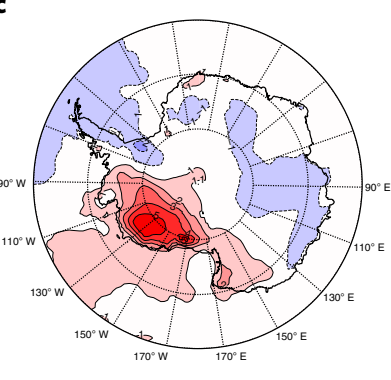

$n=65$ d

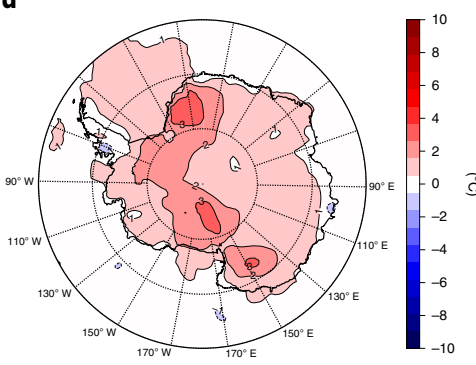

Fig. 4 | Corresponding conditions during the detected ARs in WAIS. a, Composite $500 \mathrm{hPa}$ geopotential height anomalies. b, The $2 \mathrm{~m}$ temperature anomalies associated with Ross Ice Shelf melting events (December 1982, December 1988, December 1991, January 2005 and January 2016) during the study period. c, Composite $2 \mathrm{~m}$ temperature anomalies during the ARs that made landfall in the WAIS quadrant for December and January from 1979 to 2017. d, The difference in $2 \mathrm{~m}$ temperature anomalies associated with the Ross Ice Shelf melting events (December 1982, December 1988, December 1991, January 2005 and January 2016) in $\mathbf{b}$ and the AR temperature anomalies in c (essentially b minus c). The geopotential height and $2 \mathrm{~m}$ temperatures are from ERA-Interim.

\section{AR and melt-event temperature anomalies}

A composite analysis of the ARs that made landfall in the WAIS quadrant during December and January shows an average $2 \mathrm{~m}$ temperature anomaly of $4-5^{\circ} \mathrm{C}$ in parts of the Ross Ice Shelf and Marie Byrd Land when compared to the 1979-2017 average (Fig. 4c). However, melt events are rare in these interior and higher elevation regions. For example, there were about five major melting events on the Ross Ice Shelf and Marie Byrd Land during the study period and the algorithm detected ARs during three of those (December 1982, January 2005 and January 2016). However, when the temperature anomalies associated with these melting events on the Ross Ice Shelf and Marie Byrd Land (Fig. 4b) are compared against the anomalies associated with all the ARs to reach the WAIS coastline, the difference between them is around $1-2{ }^{\circ} \mathrm{C}$ (Fig. 4d). Predicted future warming ${ }^{41}$ could close this difference in temperature anomalies between the ARs and melt events and make AR-related melting more frequent. Owing to the effect of the föhn wind and orientation of the coastline, the temperature anomaly is $7-10^{\circ} \mathrm{C}$ warmer during the winter melting events on the AP (May 2016 and March 2015) than it is when ARs make landfall on average (Supplementary Fig. 12).

\section{Implications of AR behaviour changes}

ARs are a critical factor in surface melting on the major ice shelves of West Antarctica. ARs trigger surface melting due to the associated increases in IWV and cloud liquid and ice water content, which warm the surface via an increased downward longwave radiation, decreased surface albedo due to rainfall (with a potential impact during the summer (Supplementary Section 3)) and increased SHFs. The last is both due to the heat transport over a cold surface and a combination of the AR forcing adiabatic warming from leeside föhn winds. Currently, the impact of ARs on the melt is limited, given that melt events occur only about a couple times per decade on the Ross Ice Shelf and Marie Byrd Land. However, we suggest that continued warming ${ }^{42}$ and an increase in AR activity ${ }^{43}$ could lead to an increased melt frequency. The vulnerable ice shelves on the $\mathrm{AP}^{44}$ at which AR-related surface melts occur are already observed to have highly saturated firn layers and thus an increased surface melt could lead to an enhanced surface runoff, ponding ${ }^{45}$ and hydrofracturing ${ }^{44,46}$. Already, two of these ice shelves, Larsen $B^{5,6}$ and Wilkins ${ }^{47}$, affected by the AR-related melt have collapsed and progressively disintegrated, respectively. Equally as important, this study highlights the necessity to examine changes in extreme events in addition to changes in the mean climate when studying future changes in the Antarctic surface mass balance.

\section{Online content}

Any methods, additional references, Nature Research reporting summaries, source data, statements of code and data availability and associated accession codes are available at https://doi.org/10.1038/ s41561-019-0460-1.

Received: 5 February 2019; Accepted: 30 August 2019; Published online: 28 October 2019

\section{References}

1. Shepherd, A. et al. A reconciled estimate of ice-sheet mass balance. Science 338, 1183-1189 (2012)

2. The IMBIE team Mass balance of the Antarctic Ice Sheet from 1992 to 2017. Nature 558, 219-222 (2018).

3. Favier, L. et al. Retreat of Pine Island Glacier controlled by marine ice-sheet instability. Nat. Clim. Change 4, 117-121 (2014).

4. Bintanja, R., van Oldenborgh, G. J., Drijfhout, S. S., Wouters, B. \& Katsman, C. A. Important role for ocean warming and increased ice-shelf melt in Antarctic sea-ice expansion. Nat. Geosci. 6, 376-379 (2013).

5. Glasser, N. F. \& Scambos, T. A. A structural glaciological analysis of the 2002 Larsen B ice-shelf collapse. J. Glaciol. 54, 3-16 (2008).

6. De Rydt, J., Gudmundsson, G. H., Rott, H. \& Bamber, J. L. Modeling the instantaneous response of glaciers after the collapse of the Larsen B Ice Shelf. Geophys. Res. Lett. 42, 5355-5363 (2015).

7. Bell, R. E., Banwell, A. F., Trusel, L. D. \& Kingslake, J. Antarctic surface hydrology and impacts on ice-sheet mass balance. Nat. Clim. Change $\mathbf{8}$, 1044-1052 (2018).

8. Luckman, A. et al. Surface melt and ponding on Larsen C Ice Shelf and the impact of föhn winds. Antarct. Sci. 26, 625-635 (2014).

9. Borstad, C. P., Rignot, E., Mouginot, J. \& Schodlok, M. P. Creep deformation and buttressing capacity of damaged ice shelves: theory and application to Larsen C ice shelf. Cryosphere 7, 1931-1947 (2013).

10. Bozkurt, D., Rondanelli, R., Marín, J. C. \& Garreaud, R. Foehn event triggered by an atmospheric river underlies record-setting temperature along continental Antarctica. J. Geophys. Res. Atmos. 123, 3871-3892 (2018).

11. Zhu, Y. \& Newell, R. E. Atmospheric rivers and bombs. Geophys. Res. Lett. 21, 1999-2002 (1994).

12. Ralph, F. M. et al. Atmospheric rivers emerge as a global science and applications focus. Bull. Am. Meteorol. Soc. 98, 1969-1973 (2017).

13. Ralph, F. M., Neiman, P. J. \& Wick, G. A. Satellite and CALJET aircraft observations of atmospheric rivers over the eastern north Pacific Ocean during the winter of 1997/98. Monthly Weather Rev. 132, 1721-1745 (2004).

14. Harrold, T. W. Mechanisms influencing the distribution of precipitation within baroclinic disturbances. Q. J. Roy. Meteorol. Soc. 99, 232-251 (1973).

15. Dacre, H. F., Clark, P. A., Martinez-Alvarado, O., Stringer, M. A. \& Lavers, D. A. How do atmospheric rivers form? Bull. Am. Meteorol. Soc. 96, 1243-1255 (2015).

16. Zhu, Y. \& Newell, R. E. A proposed algorithm for moisture fluxes from atmospheric rivers. Monthly Weather Rev. 126, 725-735 (1998).

17. Nash, D., Waliser, D., Guan, B., Ye, H. \& Ralph, F. M. The role of atmospheric rivers in extratropical and polar hydroclimate. J. Geophys. Res. Atmos. 123, 6804-6821 (2018). 
18. Gorodetskaya, I. V, et al. The role of atmospheric rivers in anomalous snow accumulation in East Antarctica. Geophys. Res. Lett. 41, 6199-6206 (2014).

19. Hegyi, B. M. \& Taylor, P. C. The unprecedented 2016-2017 Arctic sea ice growth season: the crucial role of atmospheric rivers and longwave fluxes. Geophys. Res. Lett. 45, 5204-5212 (2018).

20. Komatsu, K. K., Alexeev, V. A., Repina, I. A. \& Tachibana, Y. Poleward upgliding Siberian atmospheric rivers over sea ice heat up Arctic upper air Sci. Rep. 8, 2872 (2018)

21. Mattingly, K. S., Mote, T. L. \& Fettweis, X. Atmospheric river impacts on Greenland ice sheet surface mass balance. J. Geophys. Res. Atmos. 123, 8538-8560 (2018).

22. Neff, W., Compo, G. P., Martin Ralph, F. \& Shupe, M. D. Continental heat anomalies and the extreme melting of the Greenland ice surface in 2012 and 1889: melting of Greenland in 1889 and 2012. J. Geophys. Res. Atmos. 119, 6520-6536 (2014).

23. Neff, W. Atmospheric rivers melt Greenland. Nat. Clim. Change 8, 857-858 (2018).

24. Picard, G. \& Fily, M. Surface melting observations in Antarctica by microwave radiometers: correcting 26-year time series from changes in acquisition hours. Remote Sens. Environ. 104, 325-336 (2006).

25. Agosta, C. et al. Estimation of the Antarctic surface mass balance using the regional climate model MAR (1979-2015) and identification of dominant processes. Cryosphere 13, 281-296 (2019).

26. Liu, H., Wang, L. \& Jezek, K. C. Spatiotemporal variations of snowmelt in Antarctica derived from satellite Scanning Multichannel Microwave Radiometer and Special Sensor Microwave Imager data (1978-2004). J. Geophys. Res. 111, F01003 (2006).

27. Van Tricht, K. et al. Clouds enhance Greenland ice sheet meltwater runoff. Nat. Commun. 7, 10266 (2016).

28. Zou, X., Bromwich, D. H., Nicolas, J. P., Montenegro, A. \& Wang, S. West Antarctic surface melt event of January 2016 facilitated by föhn warming. Q. J. Roy. Meteorol. Soc. 145, 687-704 (2019).

29. Nicolas, J. P. et al. January 2016 extensive summer melt in West Antarctica favoured by strong El Niño. Nat. Commun. 8, 15799 (2017)

30. Hu, X., Sejas, S. A., Cai, M., Li, Z. \& Yang, S. Atmospheric dynamics footprint on the January 2016 ice sheet melting in West Antarctica. Geophys. Res. Lett. 46, 2829-2835 (2019).

31. Kuipers Munneke, P., van den Broeke, M. R., King, J. C., Gray, T. \& Reijmer, C. H. Near-surface climate and surface energy budget of Larsen C ice shelf, Antarctic Peninsula. Cryosphere 6, 353-363 (2012).

32. Kuipers Munneke, P. et al. Intense winter surface melt on an Antarctic ice shelf Geophys. Res. Lett. 45, 7615-7623 (2018).

33. Cape, M. R. et al. Foehn winds link climate-driven warming to ice shelf evolution in Antarctica. J. Geophys. Res. Atmos. 120, 11,037-11,057 (2015).

34. Elvidge, A. D., Renfrew, I. A., King, J. C., Orr, A. \& Lachlan-Cope, T. A. Foehn warming distributions in nonlinear and linear flow regimes: a focus on the Antarctic Peninsula: foehn warming distributions in nonlinear and linear flow regimes. Q. J. Roy. Meteorol. Soc. 142, 618-631 (2016).

35. Scott, R. C., Nicolas, J. P., Bromwich, D. H., Norris, J. R. \& Lubin, D. Meteorological drivers and large-scale climate forcing of West Antarctic surface melt. J. Clim. 32, 665-684 (2019)

36. Marshall, G. J., Thompson, D. W. J. \& van den Broeke, M. R. The signature of southern hemisphere atmospheric circulation patterns in Antarctic precipitation. Geophys. Res. Lett. 44, 11,580-11,589 (2017).

37. Schneider, D. P., Okumura, Y. \& Deser, C. Observed Antarctic interannual climate variability and tropical linkages. J. Clim. 25, 4048-4066 (2012)

38. Mo, K. C. \& Higgins, R. W. The Pacific-South American modes and tropical convection during the Southern Hemisphere winter. Monthly Weather Rev. 126 1581-1596 (1998).
39. Turner, J., Phillips, T., Hosking, J. S., Marshall, G. J. \& Orr, A. The Amundsen Sea low. Int. J. Climatol. 33, 1818-1829 (2013)

40. Clem, K. R., Orr, A. \& Pope, J. O. The springtime influence of natural tropical Pacific variability on the surface climate of the Ross Ice Shelf, West Antarctica: implications for ice shelf thinning. Sci. Rep. 8, 11983 (2018)

41. Palerme, C. et al. Evaluation of current and projected Antarctic precipitation in CMIP5 models. Clim. Dyn. 48, 225-239 (2017).

42. Bromwich, D. H. et al. Central West Antarctica among the most rapidly warming regions on Earth. Nat. Geosci. 6, 139-145 (2012).

43. Espinoza, V., Waliser, D. E., Guan, B., Lavers, D. A. \& Ralph, F. M. Global analysis of climate change projection effects on atmospheric rivers. Geophys. Res. Lett. 45, 4299-4308 (2018)

44. Alley, K. E., Scambos, T. A., Miller, J. Z., Long, D. G. \& MacFerrin, M. Quantifying vulnerability of Antarctic ice shelves to hydrofracture using microwave scattering properties. Remote Sens. Environ. 210, 297-306 (2018).

45. Kingslake, J., Ely, J. C., Das, I. \& Bell, R. E. Widespread movement of meltwater onto and across Antarctic ice shelves. Nature 544, 349-352 (2017).

46. DeConto, R. M. \& Pollard, D. Contribution of Antarctica to past and future sea-level rise. Nature 531, 591-597 (2016).

47. Scambos, T. et al. Ice shelf disintegration by plate bending and hydro-fracture: satellite observations and model results of the 2008 Wilkins ice shelf break-ups. Earth Planet. Sci. Lett. 280, 51-60 (2009).

\section{Acknowledgements}

This study is part of the $\mathrm{PhD}$ project of J.D.W. conducted at the Universite Grenoble Alpes. We acknowledge support from the Agence Nationale de la Recherche, project ANR-14-CE01-0001 (ASUMA), ANR-16-CE01-0011 (EAIIST) and ANR-15-CE01-0015 (AC-AHC2). I.V.G. thanks FCT/MCTES for the financial support to CESAM (UID/ $\mathrm{AMB} / 50017 / 2019)$ through national funds. C.A. acknowledges support from the Fondation Albert 2 de Monaco under project Antarctic-Snow (2018-2020). C.A. performed the MAR simulations during her Belgian Fund for Scientific Research (F.R.S.-FNRS) research fellowship. Computational resources were provided by the Consortium des Équipements de Calcul Intensif (CÉCI), funded by the F.R.S.-FNRS under grant no. 2.5020.11

\section{Author contributions}

J.D.W. devised the study and led the writing of the manuscript using input from the co-authors. A.D. supplied the reanalysis datasets and aided in the development of the AR detection algorithm. I.V.G. advised on the physics of ARs, applied the second AR detection algorithm, analysed the data, plotted and provided descriptive text for Fig. 3 and Supplemetary Figs. 6, 9 and 10. C.A. performed the MAR simulations and advised on its implementation. V.F., J.T., and F.C. contributed to the development of the study and the preparation of the manuscript.

\section{Competing interests}

The authors declare no competing interests.

\section{Additional information}

Supplementary information is available for this paper at https://doi.org/10.1038/ s41561-019-0460-1.

Correspondence and requests for materials should be addressed to J.D.W Peer review information Primary Handling Editor(s): Heike Langenberg. Reprints and permissions information is available at www.nature.com/reprints. Publisher's note Springer Nature remains neutral with regard to jurisdictional claims in published maps and institutional affiliations.

(c) The Author(s), under exclusive licence to Springer Nature Limited 2019 


\section{Methods}

The AR detection algorithm. To analyse the ARs, we created a detection algorithm based on six-hourly specific humidity fields integrated between 300 and $900 \mathrm{hPa}$ atmospheric pressure levels to create an IVT term:

$$
\mathrm{IWV}=-\frac{1}{g} \int_{900 \mathrm{hPa}}^{300 \mathrm{hPa}} q \mathrm{~d} p
$$

where $q\left(\mathrm{~kg} \mathrm{~kg}^{-1}\right)$ is the specific humidity, $g\left(\mathrm{~m} \mathrm{~s}^{-2}\right)$ is the gravitational acceleration and $p$ is the atmospheric pressure $(\mathrm{hPa})$. As the strong and persistent katabatic wind from the ice sheet plateau reduces the boundary layer specific humidity and is not uniform across the Antarctic coastal regions, removing the lowest section of the atmosphere in the algorithm reduces the risk of AR detection biases in Antarctica ${ }^{18,48}$. The algorithm searches for grid cells between $45^{\circ}$ and $80^{\circ} \mathrm{S}$ for which the IWV belongs in the 98th percentile of all the monthly climatological IWV values for a particular model grid cell from 1979 to 2017 Using a percentile requirement relative to location accounts for the decreased saturation capacity closer to the Antarctic continent, as demonstrated in a previous Antarctic AR study ${ }^{18}$. If contiguous grid cells verify the same criteria, they become a 'meridional segment'. If the meridional segments of anomalously high IWV have no discontinuities greater than $1^{\circ}$ and extend at least $20^{\circ}$ in the meridional direction, the algorithm outputs the corresponding date into an index of AR dates. If a detected AR reaches the latitude of the coastline or further south, it is classified as an AR landfall.

The AR detection algorithm we designed for Antarctica follows the outline of other AR detection algorithm schemes found in the literature in terms of computation type (conditional for each time step), geometry requirements (length), threshold requirements (relative base of IWV anomalies) and temporal requirements ${ }^{49}$ (time slice). The second AR detection algorithm depicted in Fig. and Supplementary Figs. 6, 9 and 10 is the algorithm described in a previous Antarctic AR study ${ }^{18}$ and is also included in the Atmospheric River Tracking Method Intercomparison Project ${ }^{49}$ and verified in a global AR study ${ }^{50}$. Although there are some important differences in how the two algorithms detect ARs, they both agree well in determining the shape and position of the AR approaching the ice sheet. The original AR algorithm developed for Antarctica ${ }^{18}$ compares instantaneous IWV against zonal mean IWV with a threshold determined by the maximum atmospheric moisture holding capacity calculated using temperature profiles and applies geometric criteria on the length and width of the detected ARs. The maximum atmospheric moisture holding capacity is expressed as the saturated precipitable water:

$$
W_{\mathrm{s}}=-\frac{1}{g} \int_{900 \mathrm{hPa}}^{300 \mathrm{hPa}} q_{\mathrm{s}}(T) \mathrm{d} p
$$

where $q_{\mathrm{s}}(T)$ is the saturation specific humidity $\left(\mathrm{kg} \mathrm{kg}^{-1}\right)$ for the corresponding temperature $T(\mathrm{~K})$ at each $p$ level of the ERA-Interim reanalysis according to the Clausius-Clapeyron relation. IVT $\left(\mathrm{kg} \mathrm{m}^{-1} \mathrm{~s}^{-1}\right)$, shown in Fig. 3 and Supplementary Figs. 6, 9 and 10, was calculated as:

$$
\text { IVT }=-\frac{1}{g} \int_{900 \mathrm{hPa}}^{300 \mathrm{hPa}} q \mathbf{V d} p
$$

where $\mathbf{V}$ is the wind vector $\left(\mathrm{m} \mathrm{s}^{-1}\right)$. The algorithm utilized in this study detected $90 \%$ of the ARs detected by the original AR algorithm in East Antarctica from 2009 to $2012^{18}$. We also developed an IVT-based AR detection algorithm that generated similar results in the AR detection and surface melt attribution compared to the IWV-based algorithm described in this study (Supplementary Figs. 14 and 15). Currently, the Atmospheric River Tracking Method Intercomparison Project is attempting to enhance the state of AR science through compiling various AR detection algorithms (www.cgd.ucar.edu/projects/artmip/).

Surface melt data. The daily surface melt observations were obtained from the dataset ${ }^{24}$ now extended until 2018 derived from passive microwave radiometer data provided by SMMR and SSM/I at a resolution of $25 \times 25 \mathrm{~km}^{2}$. The passive microwave signal is sensitive to surface melting, that is, the presence of liquid water in the first metre of the firn, which causes large changes in brightness temperature. The surface melting datase ${ }^{24}$ is based on the brightness temperature threshold between dry snow and melting snow, calculated taking into account the variability in dry snow emissivity, and provides the status of melted or not melted for every pixel.

To obtain more detailed information on the melt magnitudes and rainfall, we utilized $\mathrm{MAR}^{51}$, a RCM run at a $35 \times 35 \mathrm{~km}^{2}$ horizontal resolution over the whole Antarctic continent with $120 \mathrm{~s}$ time steps and outputs every $6 \mathrm{~h}\left(\right.$ ref. $\left.{ }^{25}\right)$. The MAR RCM includes the multilayer snow model Crocus ${ }^{52}$, which calculates meltwater at the surface when it reaches the melting point in combination with a surplus of energy (a deficit results in refreezing). The presence of meltwater alters the snow characteristics, for example, the type and size of the snow grains and the albedo. Percolation through the snowpack is determined through a tipping bucket method based on snow density. We used 30 snow or ice layers of variable thicknesses from the surface to a $20 \mathrm{~m}$ depth ${ }^{53}$. This version of MAR has been extensively tested over the Antarctic ice sheet ${ }^{25}$ and recently utilized by the Ice Sheet Mass Balance Inter-comparison Exercise team ${ }^{2}$.

When comparing the times when an AR was detected according to the detection algorithm against the times of surface melting in the SMMR and SSM/I satellite observations and MAR, we looked $24 \mathrm{~h}$ into the future to account for residual moisture after an AR landfall. For the daily surface melt satellite observations, this meant including the day an AR made landfall plus the next day in the time record. For the MAR melt simulations, this meant including the time an AR made landfall plus the next four six-hourly time steps when making the time record. We accounted for instances in which ARs were detected in consecutive time steps to ensure that the same time step was not counted twice. We performed the same procedure for MAR rainfall.

Reanalysis and RCM datasets. The datasets used to test the algorithm were ERA-Interim ${ }^{54}$, JRA- $55^{55}$, CFSR ${ }^{56}$, MERRA-2 ${ }^{57}$, NCEP/NCAR V1 ${ }^{58}$ and NCEP/ DOE V2 ${ }^{59}$. We also utilized an interpolated version of the JRA-55 over a lower spatial resolution, but all other specifications remained the same. Further information on the reanalyses is given in Supplementary Tables 1 and 2. Given the previously demonstrated abilities of ERA-Interim with regards to moisture biases $^{59}$, the results in this article were created by applying the AR detection algorithm to IWV calculated by ERA-Interim. We also developed an IVT-based AR detection algorithm (Supplementary Fig. 14) in addition to the IWV-based algorithm used in this study that generated similar results in the AR detection and surface melt attribution (Supplementary Figs. 14 and 15).

As some of the reanalysis datasets (JRA-55 interpolated to lower spatial resolution, NCEP/NCAR V1 and NCEP/DOE V2) have horizontal resolutions that are too coarse for a $1^{\circ}$ continuity requirement, a second version of the algorithm with a continuity requirement of $3^{\circ}$ was applied to all the reanalysis datasets. The less-strict continuity requirement slightly increased the amount of detected ARs and slightly increased the positive trend in yearly AR occurrences (Supplementary Table 2 and Supplementary Fig. 2).

We performed a composite analysis using the time indices provided by the AR detection algorithm and applied them to the ERA-Interim $2 \mathrm{~m}$ temperature, $500 \mathrm{hPa}$ geopotential height and mean sea level pressure. ERA-Interim was also used to analyse various atmospheric variables that can potentially contribute to the melt occurrence, which included cloud vertically integrated liquid and ice water paths, net longwave and shortwave radiative fluxes (used to calculate the cloud net radiative forcing at the surface), skin temperature and SHFs and LHFs.

For the temporal composite plots (Fig. 2c-e), the spatial composite plots (Supplementary Fig. 4) and rainfall plots (Supplementary Fig. 5), we utilized $M{ }^{25}$ IWV, IVT, downward longwave radiation, surface albedo, net shortwave radiation, TCWP (cloud water plus cloud ice paths), SHF, LHF, rainfall and surface melt. For Fig. 2c-e, an AR event begins when an AR makes landfall (set to day 0 ) and is examined over the preceding six days and the following ten days after landfall. If a new AR detection occurs within the following ten days after the landfall, then it is considered as the same event. For each event, the anomaly is computed with regard to the mean value observed during the preceding six days of AR detection. In Fig. 2c,d, the composite of the AR events comes from using AR landfalls in the WAIS quadrant. In Fig. 2e, we only included ARs that made landfall on the AP and did not use a predefined quadrant.

\section{Data availability}

The MAR data are publicly available from https://doi.org/10.5281/zenodo.3362277. The daily surface melt satellite observations are publicly available at http://pp.igegrenoble.fr/pageperso/picardgh/melting/

\section{Code availability}

The scripts for the AR detection algorithms discussed in this paper are available at https://github.com/jwille45/Antarctic-lab. Additional versions of the algorithm will be made available as they are completed.

\section{References}

48. Dufour, A., Charrondière, C. \& Zolina, O. Analysed and observed moisture transport as a proxy for snow accumulation in East Antarctica. Cryosphere Discuss. https://doi.org/10.5194/tc-2018-156 (2018).

49. Shields, C. A. et al. Atmospheric River Tracking Method Intercomparison Project (ARTMIP): project goals and experimental design. Geoscientific Model Dev. 11, 2455-2474 (2018).

50. Guan, B. \& Waliser, D. E. Atmospheric rivers in 20 year weather and climate simulations: a multimodel, global evaluation. J. Geophys. Res. Atmos. 122, 5556-5581 (2017)

51. Agosta, C., Fettweis, X. \& Wille, J. D. Antarctic continent MAR 6-hourly data [Data set]. Zenodo Digital Repository https://doi.org/10.5281/zenodo.3362277 (2019).

52. Brun, E., David, P., Sudul, M. \& Brunot, G. A numerical model to simulate snow-cover stratigraphy for operational avalanche forecasting. J. Glaciol. $\mathbf{3 8}$ 13-22 (1992). 
53. Datta, R. T. et al. Melting over the northeast Antarctic Peninsula (1999-2009): evaluation of a high-resolution regional climate model. Cryosphere 12, 2901-2922 (2018)

54. Dee, D. P. et al. The ERA-Interim reanalysis: configuration and performance of the data assimilation system. Q. J. Roy. Meteorol. Soc. 137, 553-597 (2011).

55. Kobayashi, S. et al. The JRA-55 reanalysis: general specifications and basic characteristics. J. Meteorol. Soc. Jpn 93, 5-48 (2015).
56. Saha, S. et al. The NCEP Climate Forecast System Reanalysis. Bull. Am. Meteorol. Soc. 91, 1015-1058 (2010).

57. Gelaro, R. et al. The Modern-Era Retrospective Analysis for Research and Applications, Version 2 (MERRA-2). J. Clim. 30, 5419-5454 (2017).

58. Kalnay, E. et al. The NCEP/NCAR 40-Year Reanalysis Project. Bull. Am Meteorol. Soc. 77, 437-472 (1996).

59. Kanamitsu, M. et al. NCEP-DOE AMIP-II Reanalysis (R-2). Bull. Am. Meteorol. Soc. 83, 1631-1644 (2002). 


\section{Chapter 4}

\section{The role of atmospheric rivers in ice shelf collapse on the Antarctic}

\section{Peninsula}

\subsection{Foreword}

In this chapter, we investigate the role that atmospheric rivers (ARs) play in the preconditioning and final collapses on the ice shelves of the Antarctic Peninsula (AP). On February 6th, 2020, the Antarctic climate made the mainstream news when a new continental high temperature record of $18.3^{\circ} \mathrm{C}$ was set at Esperanza Base. After an initial examination, it was clear that an AR landfall on the AP coincided with this record temperature occurrence. This is in line with a prior case study that concluded the previous Antarctic high temperature record set at Esperanza Base on March 2015 was caused by foehn winds triggered by an AR landfall (Bozkurt et al. [2018]. The results in Wille et al. [2019] (Chapter 3) showed that ARs were related with only 10-20\% of the total summer melt on the AP, and thus did not appear to play a major role in iceshelf stability. However, upon further investigation on the relationship between ARs and extreme melt rates at a climatological scale, it became apparent that ARs were responsible for extreme melt events and might be affecting ice-shelf stability. Using the latest version of the AR detection algorithm (Wille_v2), we discovered AR landfalls on the AP coincided with the collapses of the Larsen A and B. Upon this discovery, we carried out a more in-depth study that examined how AR-related processes impact 
ice-shelf stability.

The major implications of this study were: (1) The previous two continental Antarctic high temperature records occurred during AR landfalls from the associated foehn winds and radiative fluxes. (2) Despite their rarity of occurrence (1-5 landfalls per summer), over $50 \%$ of the most intense melt and runoff occurrences over the Larsen ice shelves occurred during AR events since 1980. This excess meltwater leads to melt pond formation and subsequent hydrofracturing bringing the ice shelves closer to collapse (DeConto and Pollard [2016]). (3) The spectacular and surprising collapse of the Larsen A ice shelf in January 1995 was immediately preceded by one of the most intense ARs observed during the study period. Then the collapse of the Larsen B in 2002 occurred in a summer with high AR activity where melt ponds became more evident after each passing system until the final collapse. Also, we observed that AR activity reduced the regional sea ice cover throughout the study period allowing swells to apply further strain to the ice shelf front (Massom et al. [2018]). (4) The Larsen $\mathrm{C}$ is the next vulnerable ice shelf that is sensitive to AR-related melt and large icebergs already have calved off the ice shelf's northern margins in 2005 following AR landfalls. After a lull in AR landfalls throughout the 2010s, AR activity is increasing again, and warming temperatures may expand the AR threat to other Antarctic ice shelves. At the time of this writing, the paper is under review in Nature Geoscience. The following section displays the submitted article slightly formatted to fit this thesis format and the supplementary materials can be found in Appendix B

\subsection{Article: The atmospheric river threat to Antarc- tic Peninsula ice-shelf collapse}

\section{The atmospheric river threat to Antarctic Peninsula ice-shelf collapse}

Jonathan D. Wille ${ }^{1}$, Vincent Favier ${ }^{1}$, Nicolas C. Jourdain ${ }^{1}$, Christoph Kittel ${ }^{2}$, Xavier Fettweis $^{2}$, Charles Amory ${ }^{2}$, Irina V. Gorodetskaya ${ }^{3}$, Cécile Agosta ${ }^{4}$, Francis Codron ${ }^{5}$ 1. Institut des Géosciences de l'Environnement, CNRS/UGA, Saint Martin d'Hères, France 
2. Laboratory of Climatology, Department of Geography, University of Liège, Liège, Belgium

3. CESAM - Centre for Environmental and Marine Studies, Department of Physics, University of Aveiro, Portugal

4. Laboratoire des Sciences du Climat et de l'Environnement, LSCE-IPSL, CEA-CNRSUVSQ, Université Paris-Saclay, Gif-sur-Yvette, France.

5. LOCEAN, Sorbonne Université, Paris, France.

\section{Abstract}

The disintegration of the ice shelves along the Antarctic Peninsula have spurred much discussion on the time scales of the various atmospheric and oceanic processes leading to their eventual dramatic collapse. Atmospheric rivers (ARs) have been recently shown to force surface melting in winter along the Antarctic Peninsula. Here, using an AR climatology along with a regional climate model, we show that ARs and the associated extreme integrated vapor transport are responsible for both preconditioning ice shelves for collapse and for the majority of observed ice shelf calving/collapse events including major collapses of the Larsen A and B. Preconditioning results from the generation of high temperature extremes (including the February 2020 continental record of $18.3^{\circ} \mathrm{C}$ ), intense summer melt, and runoff leading to melt pond formation. Beyond preconditioning, the AR triggers the removal of the sea ice buffer allowing a wave-induced flexure on the ice-shelf margins, additional extreme surface melt (i.e. over $7 \mathrm{Gt}$ simulated during the Larsen A collapse), and subsequent hydrofracturing. This understanding on how ARs unify various ice-shelf collapse theories is essential for identifying other at-risk ice shelves susceptible to hydrofracturing in Antarctica.

\section{Main manuscript}

For about the past 30 years, the large and dramatic collapses of the Larsen A, Larsen B, along with other major ice shelves along the Antarctic Peninsula (AP) have served as a cautionary tale of future ice shelf collapse further south. The associated loss of the buttressing effect and consequent acceleration of continental ice loss could become a critical contribution to sea-level rise (Smith et al. [2020]). In question is the 
timescale of the preconditioning processes to lead to an ice shelf final collapse and what triggers that collapse.

There are many processes that precondition an ice shelf for collapse that begin with gradual weakening from non-atmospheric related processes like thinning from increased basal melt (Holland et al. [2015]; Pritchard et al. [2012]; Mueller et al. [2012]; Dinniman et al. [2012]), ice dynamics involving the propagation of preexisting weaknesses such as fractures, crevasses, rifts, and rheological weakening (Vieli et al. [2007]; Scambos et al. [2009]; Khazendar et al. [2007]; Glasser and Scambos [2008]), and ice shelf flexure induced by meltwater surface drainage via tides (Banwell et al. [2019]). Over shorter time scales from a few years to a single season, hydrofracturing is considered the most important process leading to ice-shelf collapse (Robel and Banwell [2019]). This process occurs through increased surface melting driving firn air depletion which allows crevasses to later be filled with water generating a hydrostatic pressure and ultimately destabilizing the ice shelf (Alley et al. [2018]). During a season with particularly high melt pond formation and hydrofracturing (van den Broeke [2005]; Scambos et al. [2000], the ice shelf's final collapse can be triggered by storm related swells and waves causing calving on the ice-shelf front in the absence of a regional sea-ice cover (Massom et al. [2018]. This occurred in January 1995 when a storm triggered the final disintegration of the Larsen A and caused widespread calving on the Larsen B (Scambos et al. [2000]. Here, we propose a mechanism that unifies many of the shorter time scale ice-shelf collapse processes from preconditioning to final collapse as a response to rapid intrusions of warm, moist air from the low to mid-latitudes in the form of atmospheric rivers (ARs).

ARs are narrow long bands of enhanced water vapor fluxes ahead of an extratropical cyclone's cold front capable of transporting low latitude warm, moist air masses to higher latitudes (Rutz et al. [2019]. While rare in Antarctica (2-3\% frequency in Antarctic Peninsula region; Wille et al. [2019]), they correspond with the presence of an extremely high temperature and moisture state in the lower Antarctic troposphere (Gorodetskaya et al. [2020]). ARs have already been shown to generate extreme precipitation in East Antarctica (Gorodetskaya et al. [2014], 40\% of summer surface melt in parts of West Antarctica, and $40-80 \%$ of total winter melting along many of the AP ice shelves (Wille et al. [2016]). ARs induce surface warming through the presence 
of mixed phase clouds with high supercooled liquid water and ice water content that increase downward longwave radiation towards the surface (Wille et al. [2019]). On the AP, ARs also enhance the melting potential of the dry, warm, downsloping foehn winds descending over the eastern AP ice shelves (Wille et al. [2019]; Bozkurt et al. [2018]; Luckman et al. [2014], but their impact on ice shelf's long-term melt has never been analyzed.

Using an updated AR detection algorithm previously utilized for studying melt events in West Antarctica (Wille et al. [2019]), we conjointly analyzed melt, runoff, extreme temperature, and ice-shelf disintegration occurrences along the AP. The AR detection algorithm searches for continuous areas where the meridional (v) component of the integrated vapor transport (vIVT) or integrated water vapor (IWV) exceeds the 98th monthly climatological percentile in MERRA-2 and ERA-5 reanalysis products. Melting, runoff, and 2 m temperature data from 1980-February 2020 are provided by the Modèle Atmosphérique Régional (MAR; Agosta et al. [2019]), a regional climate model with a $7.5 \mathrm{~km}$ resolution forced by ERA-5. Runoff as defined by MAR and described in this study refers to liquid water beyond the saturation point of the snowpack that does not necessarily drain into the ocean and could remain on the ice shelf.

\section{Continental record warmth events}

The radiative forcing and Foehn winds related to ARs are responsible for the warmest temperatures observed on the Antarctic continent (Bozkurt et al. [2018]). On the AP, ARs are associated with a majority of temperature occurrences in the 99th (40-70\% out of 2803 -hourly occurrences) monthly percentile of simulated $2 \mathrm{~m}$ temperatures (Extended Data Figs. 4.1a and 4.1b) and nearly all occurrences within the 99.9th percentiles (50-100\% out of $~ 40$ occurrences) from 1980-2019, especially in the mountainous regions (Fig. 4.2a; Fig. 4.3d).

An example of an AR triggered high temperature record recently occurred in February 6, 2020, when a temperature of $18.3^{\circ} \mathrm{C}$ was recorded Esperanza Base thus beating the previous record also caused by an AR in March 2015 and causing visible widespread melting on surrounding glaciers with monthly $2 \mathrm{~m}$ temperature anomalies exceeding $+20{ }^{\circ} \mathrm{C}$ (Fig. 4.1 and 4.3c; Table 4.1; Extended Data Fig. 4.2). Both 


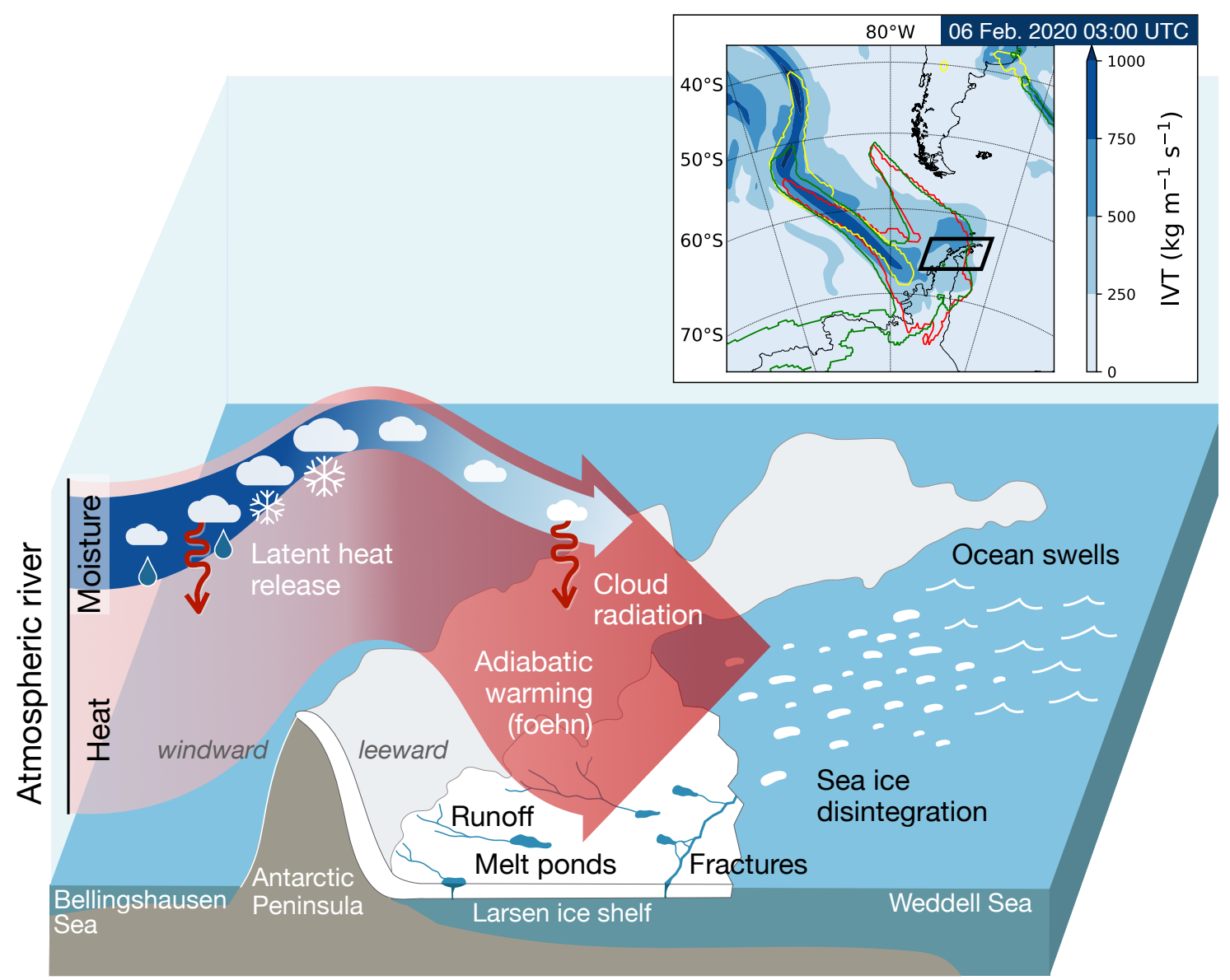

Figure 4.1: Antarctic Peninsula atmospheric river example. An illustration of a typical intense atmospheric river over the northern Antarctic Peninsula and the associated observed meteorological features and impacts consequential to ice-shelf stability. Also, an example of a detected AR landfall on Feb. 6th, 2020 with the corresponding IVT values. The yellow, red, and green outlines are the shape of the AR as determined by the vIVT AR detection scheme, IWV AR detection scheme, and the original Antarctic AR detection algorithm respectively (Gorodetskaya et al. [2020, 2014]). 
the 2020 and 2015 warm events and most AR landfalls have very similar conditions: strong atmospheric blocking directing an extremely moist air mass with clouds laden with liquid water towards a landfall on the western AP that is perpendicular to the mountain ranges, with orographically enhanced precipitation formation, contributing to the stronger foehn winds and sensible heat flux on the leeward ice shelves (Fig. 4.1; Extended Data Fig. 4.3; Bozkurt et al. [2018]). The foehn-driven sensible heat flux combines with increased downward longwave radiation from high level clouds to generate surface melt on the Larsen ice shelves and surrounding land-fast and sea ice (Fig. 4.2c and 4.2d). Even though the dry foehn winds typically scour low-level moisture and clouds, downward longwave radiation typically remains elevated likely due to enhanced moisture aloft while shortwave radiation still reaches the surface (Extended Data Fig. 4.3b; Elvidge et al. [2020]).

\section{Ice-shelf preconditioning relationships}

The AR climatology for the AP generated by the AR detection algorithm reveals that summer AR activity was highly variable during the last 40 years. It was particularly high during the late 1990s/early 2000s which was a period marked with notable ice-shelf retreats. Then, AR activity decreased in the decade following a maximum in 2005 before increasing again in more recent years (Fig. 3f; Extended Data Figs. 4.4a and 4.4b).

Despite the rarity of AR landfalls ( 1-5 landfalls per summer), they are strongly linked with intense melt and runoff periods. While melting occurring around AR events contribute $\sim 20 \%$ of the annual cumulative melt on the AP (Wille et al. [2019]), ARs were highly related to occurrences of extreme melt and runoff rates during the study period (Fig. 4.3e and 4.3f). Along the ice shelves, $\sim 50 \%$ of melt within the 99th monthly percentile and nearly all extreme melt on the glaciers in the mountainous regions occurred within the 24-hour period surrounding AR landfalls (Fig. 4.2b; Extended Data Figs. 4.1c, 4.1d). High runoff values, produced by melting (and rainfall) when the firn is already saturated with liquid water, are detrimental for ice-shelf stability (Costi et al. [2018]; Vaughan [2006]). Runoff rates show similar relationships to AR activity as melt rates, the only difference being that runoff is predominately constrained to the lower-elevation ice shelves (Fig. 4.2b; Extended Data Figs. 4.1e, 4.1f). 

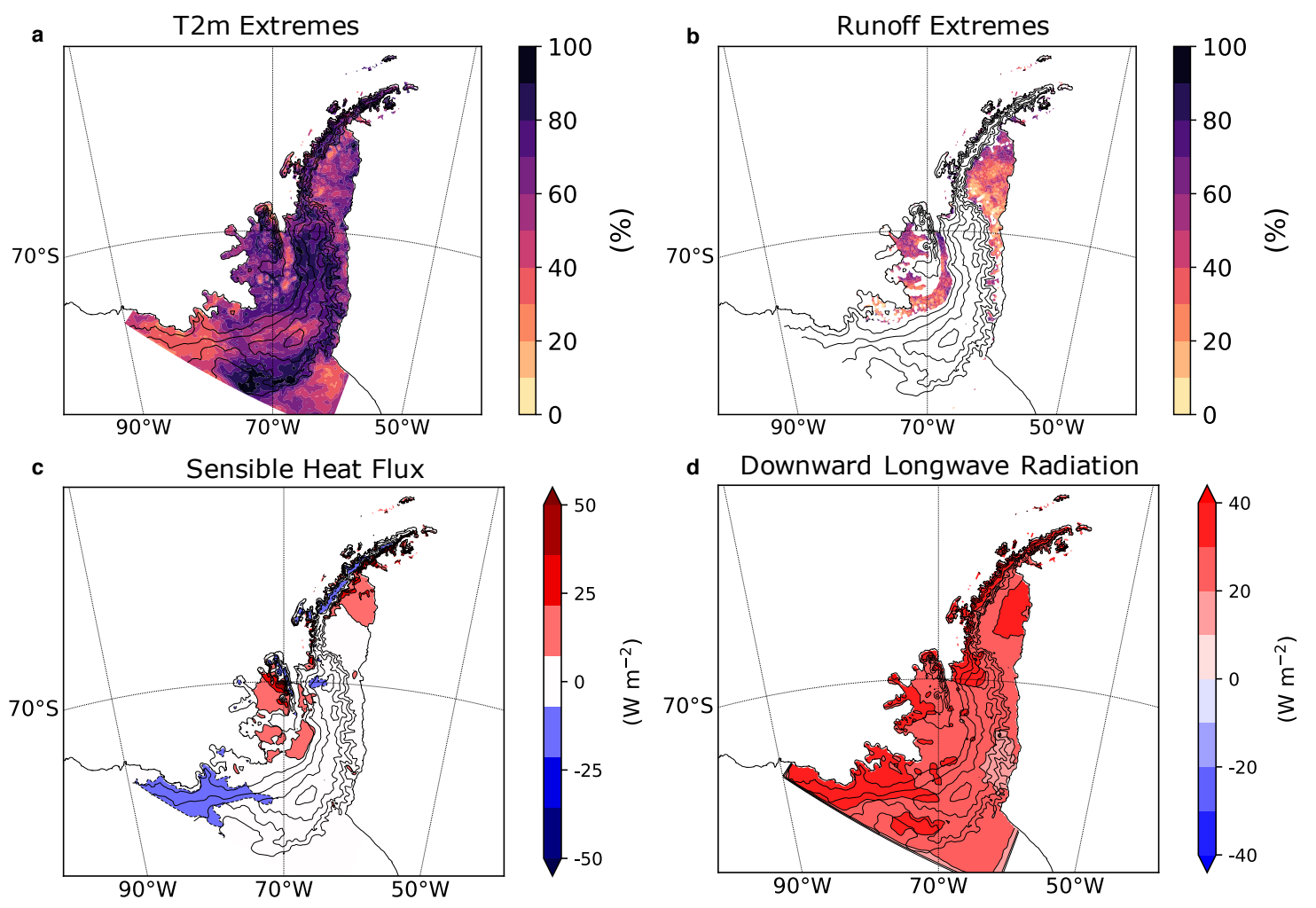

Figure 4.2: Atmospheric river meteorological components responsible for sur-

face melting. The percentage of MAR summer $\mathbf{a} 2 \mathrm{~m}$ temperature occurrences and $\mathbf{b}$ runoff at or above the 99.9th percentile of the 1980-2019 monthly mean climatology that occurred within 24 hours before and after an AR landfall on the AP. Composite MAR $\mathbf{c}$ sensible heat flux and $\mathbf{d}$ downward longwave radiation anomalies for summer AR landfalls from 1980-2019. Summer is defined as DJFM for $\mathbf{a}$ and $\mathbf{b}$ and DJ for $\mathbf{c}$ and $\mathbf{d}$ to highlight the peak seasonal solar forcing.

In regard to precipitation, ARs are mostly associated with the heaviest rainfall events (80-100\%) on the Wilkins and mountain bases of the Larsen A and B while contributing more to heavy snowfall events (60-70\%) on the southern Larsen C (Extended Data Fig. 4.5).

AR strength and impacts can be characterized by considering the maximum IVT upon landfall and the landfall duration which is based on the scale used to classify ARs in the western North America (Ralph et al. [2019]). When applied to AR landfalls on the AP, a clear relationship between intensity and melting effects appear. There is an exponential relationship between maximum IVT upon landfall and both total melt and runoff along the Larsen ice shelves with the average 3-hourly melt and runoff increasing from $<0.05 \mathrm{Gt} 3 \mathrm{~h}^{-1}$ for the weakest ARs to $\sim 0.4 \mathrm{Gt}^{3 h^{-1}}$ for the strongest 
(Extended Data Fig. 4.6). These most extreme ARs (IVT $>800 \mathrm{~kg} \mathrm{~m}^{-1} \mathrm{~s}^{-1}$ ) only occur around once every five years but have the capability to dramatically and quickly alter the cryosphere (Bozkurt et al. [2018]). Moreover, when measuring the annual AR footprint using the cumulative maximum IVT for each AR landfall timestep, a significant correlation $(\mathrm{p}<0.025)$ appears between summer AR activity and annual cumulative melt values across the mountainous regions and the northern Larsen ice shelf (Extended Data Fig. 4.7a and 4.7b). Similar significant correlations for runoff are found on the northern Larsen ice shelf which also coincides with the area that has the highest runoff magnitude on the AP (Extended Data Fig. 4.7c and 4.7d). When examining the points with high $\mathrm{AR} /$ melt correlations in the northern Larsen, large AR activity in 1989, 1999, 2002 and 2005 were associated with high summer melt values (Fig. 4.3f).

We also examined other AP ice-shelf preconditioning theories for relationships to AR activity, however we did not find conclusive evidence for a relationship between ice-shelf basal melting, one of the known long-term precursors of ice shelf collapse (Holland et al. [2015]), and AR activity. Indeed, looking at ocean hindcasts (extended to 1979-2018; Merino et al. [2018]), we did not find any important correlation between either yearly AR frequency or yearly cumulative maximum IVT and either the ocean temperature at the depth of the ice-shelf drafts or Ekman pumping (a driver of basal ice-shelf melt variations according to Etourneau et al. [2019] near Larsen or Wilkins ice shelves.

\section{Final Collapse Processes}

After successive years of ice shelf collapse preconditioning brought on by high melt magnitudes, melt pond formation, drainage, hydrofracturing, along with other preconditioning processes seemingly unrelated to AR activity (Pritchard et al. [2012]; Mueller et al. [2012]; Dinniman et al. [2012]; Vieli et al. [2007]; Khazendar et al. [2007]; Glasser and Scambos [2008]), a final collapse can be triggered from single season of intense melt causing simultaneous small hydrofracture cascades (Robel and Banwell [2019] as well as wave-induced flexure in the absence of regional sea ice cover (Massom et al. [2018]).

Following the aforementioned mechanisms, we documented multiple cases of major final calving and collapse events preceded by AR landfalls (Fig. 4.3a, Ta- 
ble 2.1). After examining calving and collapse events using MODIS-Terra and Aqua images from 2000-2020, we found 20 main calving and collapses, 12 of which were preceded by an AR landfall within 5 days prior. Also, summers with high melt and large cumulative IVT values from AR activity serve as a better precursor of ice shelf disintegration events than just associating with years of high melt (i.e. 2002, 2005, 2006, 2008; Fig. 4.3f). Before 2000, one prominent example was the collapse of the Larsen A after January 24th, 1995 which was preceded by an historically intense AR landfall (Max IVT $\sim 840 \mathrm{~kg} \mathrm{~m}^{-1} \mathrm{~s}^{-1}$, in the 99.7th intensity percentile) followed by the recorded calving of large icebergs $\left(\sim 1700 \mathrm{~km}^{2}\right)$ from the Larsen B (Supplementary Fig. B.1; Scambos et al. [2000]; Rott et al. [1996]). The storm generated 6.5 Gt (7.6 $\mathrm{Gt}$ ) of runoff (meltwater) over 5 days and a roughly three-tenths reduction of sea ice concentration in the Larsen embayment (Supplementary Fig. B.1). This particular AR also triggered an intense sensible heat flux over the Larsen A corresponding with extreme temperatures and intense surface runoff (Supplementary Fig. B.3).

The 2001/2002 summer season also witnessed multiple AR landfalls starting with an intense AR (Max IVT $\sim 660 \mathrm{~kg} \mathrm{~m}^{-1} \mathrm{~s}^{-1}$, in the 98.2th intensity percentile) that made landfall on December 13th, generated 1.0 Gt (3.2 Gt) of runoff (meltwater), and initiated melt pond formation on the Larsen B (Supplementary Fig. B.4; Hubbard et al. [2016]). Another intense long duration AR (IVT $740 \mathrm{~kg} \mathrm{~m}^{-1} \mathrm{~s}^{-1}$, in the 99.2th intensity percentile) occurred from December 31 - January 2 that generated another 2.1 Gt (4.4 Gt) runoff (meltwater) and pushed the Larsen B towards its collapse in early February (Supplementary Fig. B.5). Then a series of moderately intense ARs in February likely hastened the ongoing collapse (Supplementary Fig. B.7). These ARs were associated with amplified swells of high wave periods reaching the ice shelf in the absence of sea ice likely adding strain to the ice-shelf margins (Supplementary Fig. B.7e and B.7e). Throughout February, the numerous AR landfalls elevated the sensible heat flux and runoff rates over the ice shelf during a summer defined by a persistent northwesterly flow and strong foehn events31,32 (Supplementary Fig. B.6b; Cape et al. [2015]; Massom et al. [2006]). Similar processes were found behind other AR-related collapses and calving events (see the Appendix B).

During these ice-shelf disintegration events, the influence of ocean wave energy on the ice-shelf margins in the absence of a sea-ice cover was a prerequisite for 


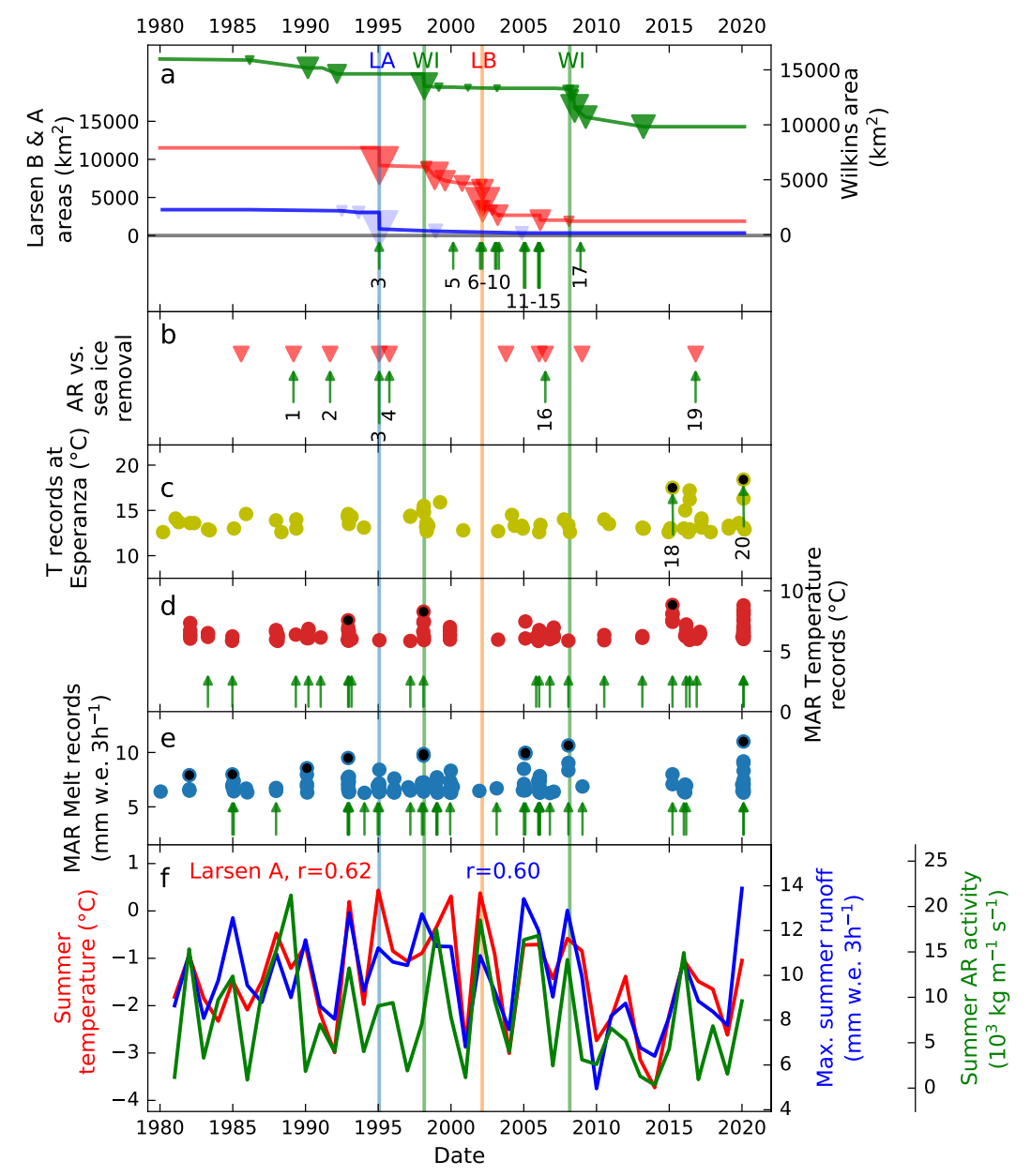

Figure 4.3: Link between AR occurrences, collapses and extreme events. a, Changes in area of Larsen A (LA), Larsen B (LB) and Wilkins (WI) ice shelves. The size of triangles relates to the area lost at each calving or collapse event. b, The 10 highest two-day sea ice fraction decreases east of the Larsen ice shelves. c, The 99.9th percentile of observed highest daily temperature at Esperanza using a 1956-2020 climatology (yellow circles), and maximum temperature records during the study period (black circles). d, The 99.9th percentile of 3-hourly temperature (red dots) and maximum temperature records simulated MAR (black circles). e, The same as $\mathbf{d}$, but for 3-hourly surface melt values. f, Time series and correlations between cumulative summer (December, January, and February) maximum IVT values during AR landfalls (green), mean summer temperature (red) and mean maximum runoff (blue). AR activity is according to the vIVT detection scheme and colored r-values relate to the color of the corresponding variable. For $\mathbf{a}, \mathbf{b}, \mathbf{c}, \mathbf{d}$, and e, the arrows are AR landfalls within 5 days prior to the event date while the arrow numbers in $\mathbf{a}, \mathbf{b}$, and $\mathbf{c}$ relate to further event descriptions in Table 1. For $\mathbf{d}, \mathbf{e}$, and $\mathbf{f}$, the points chosen for analysis on the remnant Larsen A and B ice shelves are shown in Extended Data Fig. 4.11. 
the final collapse (Massom et al. [2018]). In the Larsen embayment, large sea-ice decay over short periods are often associated with AR landfalls on the AP likely from the added wind stress and longwave fluxes (Fig. 4.3b; Bozkurt et al. [2018]; Hegyi and Taylor [2018]; Komatsu et al. [2018]). The most sensitive location along the AP to AR activity appears on the northern edge of the Larsen A/B embayment with intense ARs on average causing a one-tenth decline in sea-ice fraction over a two-day period (Extended Data Fig. 4.8a and 4.8b). Nearly all rapid sea-ice disintegrations in this region were concurrent with intense AR events (Extended Data Fig. 4.8c and 4.8d). West of the AP, the average sea-ice decline in response to ARs is smaller, yet still notable around the Wilkins ice shelf and especially along the sea-ice front in the Bellingshausen sea like during 2002 and 2005 when AR activity was elevated32,35 (Fig. 4.3f; Extended Data Fig. 4.8a, 4.8b; Massom et al. [2006, 2008]). Conversely after 2010, a period of relatively low AR activity coincided with summers of more stable sea-ice conditions and less calving events around the Larsen ice shelves.

In the reduction of a regional sea-ice cover, the ice-shelf fronts become exposed to long wave period swells propagating across the open ocean often during the peak melt season thus possibly leading to calving of large icebergs and the retreat of the compressive arch (Massom et al. [2018]; Doake et al. [1998]) like what occurred on the Larsen B in 2002. The winds found near the surface of an AR within the low-level jet are often quite extreme as noticed during the AR landfalls in summer 2001/200218,37(Supplementary Fig. B.6; Gorodetskaya et al. [2020]; Waliser and Guan [2017]) and can lead to significant swell heights. This is especially true over the Bellingshausen sea where the west-east storm motions enable a longer fetch length leading to swells $\sim 1 \mathrm{~m}$ higher than normal (Extended Data Fig. 4.9e). East of the AP, the AR-driven disintegration of sea ice in the Larsen embayment enables swells generated in the South Atlantic to apply a strain on the ice-shelf front as documented in 2002 (Massom et al. [2018]). There is a noticeable increase in wave heights during AR events, however these waves are the product of wind waves and not swells (Extended Data Fig. 4.9b and 4.9d). While it has been shown that long period ocean swells exert more strain on ice shelves than wind waves favored by ARs east of the AP (Massom et al. [2018]), the role of wind waves on the erosion of ice shelf fronts (melting+calving of small pieces) remains elusive, but it could also play a significant role 
in ice-shelf collapses as this has been suggested to be the dominant mass loss term for icebergs (Martin and Adcroft [2010]).

\section{Future ice-shelf stability}

Understanding AR behavior is a crucial component of predicting the health of the remaining ice shelves along the AP. Attention is now on the Larsen $\mathrm{C}$ ice shelf after a giant iceberg calving event on July 10-12, 2017. This event has been attributed to basal melting from subsurface ocean warming (Holland et al. [2015]; Hutchinson et al. [2020]; Hogg and Gudmundsson [2017]). A relatively strong winter AR on July 5-6, 2017 may have applied a wind stress prior to the calving, but the impacts of winter ARs on ice-shelf stability are unclear. Other calving events on the Larsen C like in January and February 2005 are more directly related to ARs (Fig. 4.3a, Table A.1; Supplementary Fig. B.10; Supplementary Fig. B.11). Summer AR occurrences on the AP are also significantly correlated to melt pond observations from MODIS across the Cabinet Inlet on the Larsen C30(Extended Data Fig. 4.10). There, foehn wind events have been correlated with surface melting (Elvidge et al. [2020]; Turton et al. [2020, 2018]), some of which we later connected with AR landfalls (Datta et al. [2019]. If the Larsen $\mathrm{C}$ recedes beyond its compressive arch or the passive shelf ice decays (Doake et al. [1998]; Fürst et al. [2016], the shelf would possibly become vulnerable to collapse from further surface melting and hydrofracturing (Lai et al. [2020]). Given the exponential nature of AR landfall intensity and melt on the Larsen ice shelves (Extended Data Fig. 4.6), intense AR landfalls (IVT $>800 \mathrm{~kg} \mathrm{~m}^{-1} \mathrm{~s}^{-1}$ ) deserve careful scrutiny for possible subsequent ice shelf disintegration or instability like observed during the Larsen A collapse. In addition, measuring summer cumulative IVT in regard to AR activity is a useful complementary tool in assessing ice shelf disintegration risk along with surface melt. With the predictions of an extended melt season (Chyhareva et al. [2019]), a southward migration of surface and subsurface melting conditions (Etourneau et al. [2019]; Siegert et al. [2019]), and an increase in AR frequency and intensity across the Southern Ocean in future global warming scenarios (Espinoza et al. [2018]), the Larsen $\mathrm{C}$ may become increasingly vulnerable to future changes in AR behavior. Predicting these future changes requires an understanding of the teleconnections that control the prevalence of blocking conditions that dictate AR activity over the AP and 


\begin{tabular}{|c|c|c|c|c|}
\hline \multirow{3}{*}{$\frac{\text { AR number }}{1}$} & \multirow{3}{*}{$\begin{array}{l}\text { Typical event } \\
\text { Sea ice removal }\end{array}$} & \multicolumn{2}{|c|}{ Event date IVT $\left(\mathrm{kg} \mathrm{m}^{-1} \mathrm{~s}^{-1}\right)$} & \multirow[t]{3}{*}{ ) date $A R$ (first detection) } \\
\hline & & & & \\
\hline & & $3 / 5 / 89$ & 8762 & \\
\hline 2 & Sea ice removal & 9/10/91 & 3979 & 9/10/91 \\
\hline 3 & Sea ice removal/Calving/collapse & $1 / 24 / 95$ & 3987 & $1 / 24 / 95$ \\
\hline 4 & Sea ice removal & $10 / 8 / 95$ & 9033 & $10 / 6 / 95$ \\
\hline 5 & Calving/collapse & $2 / 27 / 00$ & 555 & $2 / 25 / 00$ \\
\hline 6 & Calving/collapse & $1 / 6 / 02$ & 7421 & $12 / 31 / 01$ \\
\hline 7 & Calving/collapse & $3 / 2 / 02$ & 5602 & $2 / 25 / 02$ \\
\hline 8 & Calving/collapse & $1 / 18 / 03$ & 391 & $1 / 13 / 03$ \\
\hline 9 & Calving/collapse & $2 / 23 / 03$ & 919 & $2 / 19 / 03$ \\
\hline 10 & Calving/collapse & $4 / 18 / 03$ & 3532 & $4 / 18 / 03$ \\
\hline 11 & Calving/collapse & $1 / 3 / 05$ & 7299 & $1 / 3 / 05$ \\
\hline 12 & Calving/collapse & 2/11/05 & 6387 & $2 / 9 / 05$ \\
\hline 13 & Calving/collapse & $1 / 1 / 06$ & 3752 & $12 / 29 / 05$ \\
\hline 14 & Calving/collapse & $1 / 20 / 06$ & 9147 & $1 / 18 / 06$ \\
\hline 15 & Calving/collapse & 2/11/06 & 2838 & $2 / 6 / 06$ \\
\hline 16 & Sea ice removal & $6 / 29 / 06$ & 13429 & $6 / 26 / 06$ \\
\hline 17 & Calving/collapse & $11 / 30 / 08$ & 4370 & $11 / 26 / 08$ \\
\hline 18 & Maximum temperature & $3 / 24 / 15$ & 8484 & $3 / 22 / 15$ \\
\hline 19 & Sea ice removal & $10 / 24 / 16$ & 1344 & $10 / 23 / 16$ \\
\hline 20 & Maximum temperature & $2 / 7 / 20$ & 6081 & $2 / 2 / 20$ \\
\hline
\end{tabular}

Table 4.1: Supplement to Figure 4.3. Dates of notable occurrences on the Antarctic Peninsula and corresponding AR detection date and cumulative maximum IVT values. The IVT values are calculated by taking the maximum IVT value found both within the shape of the AR and on the AP throughout each continuous timestep where an AR landfall is detected and then summed together (see Extended Data Fig. 4.4e). 
the rest of Antarctica (Wille et al. [2019]). Fully comprehending the threat ARs pose to ice shelves across other polar regions (Francis et al. [2020]), means assessing a particular ice shelf's vulnerability to hydrofracturing and wave-induced stress (Lai et al. [2020]; Massom et al. [2018]). Our suggested link between ice-shelf collapse and ARs is observational and should be complemented with ice dynamic models to identify at-risk ice shelves.

\section{Methods}

\section{The atmospheric river detection algorithm}

The atmospheric river (AR) detection algorithm utilized for this study is an updated version of the AR detection algorithm presented in a previous study of ARs in West Antarctica (Wille et al. [2019]). The latest version of the algorithm has two detection schemes based on integrated water vapor (IWV) and the v-component of the integrated vapor transport (vIVT). In both schemes, the algorithm scans 3-hourly IWV and vIVT fields from $37.5^{\circ} \mathrm{S}-80^{\circ} \mathrm{S}$ for values within the 98th percentile of all monthly climatological values defined from 1980-2019. If contiguous grid cells in the meridional direction satisfy this condition and extend at least 20 degrees in the meridional direction, then the shape is flagged as an AR. If any grid cell in the AR shape intersects with the mask of the Antarctic Peninsula shown in Extended Data Fig. 4.4e, then the date and the maximum IVT within the AR mask are recorded.

$$
\begin{gathered}
I W V=-\frac{1}{g} \int_{\text {surface }}^{t o p} q d p \\
v I V T=-\frac{1}{g} \int_{\text {surface }}^{t o p} q v d p
\end{gathered}
$$

Here IWV $\left(\mathrm{kg} \mathrm{m}^{-2}\right)$ and vIVT $\left(\mathrm{kg} \mathrm{m}^{-1} \mathrm{~s}^{-1}\right)$ are calculated based on the specific humidity, $q\left(\mathrm{~kg} \mathrm{~kg}^{1}\right), \mathrm{g}\left(\mathrm{m} \mathrm{s}^{-2}\right)$ gravitational acceleration, $v$ meridional wind velocity $\left(\mathrm{m} \mathrm{s}^{-1}\right)$, and $p$ atmospheric pressure (hPa). Using both an IWV and vIVT scheme in this study captures some of the variability between different approaches of AR detection. The IWV scheme is slightly advantageous for studying the effects of ARs on surface melting since excessive IWV leads to the development of mixed phase clouds containing anomalously high liquid and ice water paths with higher radiative fluxes 
(Wille et al. [2019]). However, the meridional wind component in the vIVT scheme captures some of the dynamical processes that lead to Foehn wind generation and subsequent sensible heat fluxes on the AP ice shelves. While the vIVT generally detects more ARs than the IWV scheme, controlling for maximum IVT upon landfall greatly reduces this disparity and shows that differences in AR detection is mainly influenced by the depiction of weaker ARs (Extended Data Fig. 4.4b and 4.4d).

The AR detection algorithm in this study was configured to be included in the Atmospheric River Tracking Method Intercomparison Project (ARTMIP; Rutz et al. [2019]; Payne et al. [2020]). This entails running the detection algorithm on fields from the Modern-Era Retrospective analysis for Research and Applications, Version 2 (MERRA-2; Gelaro et al. [2017]) on all pressure levels and outputting the AR shapes in binary form. For the sake of comparison, the AR detection algorithm was also run on ERA-5 IWV and vIVT fields on a $1 \times 1$ degree grid. The previous study of ARs over Antarctica confirmed that the AR detection frequency is similar amongst various modern reanalysis products (Wille et al. [2019]) and it is confirmed again in this study between MERRA-2 and ERA-5 (Extended Data Fig. 4.4).

\section{Regional climate model and reanalysis datasets}

MAR is a regional climate model specifically designed for simulating polar climate (Agosta et al. [2019]; Fettweis et al. [2017]). MAR atmospheric dynamics are based on the hydrostatic approximation of the primitive equations (Gallée and Schayes [1994]). The exchanges between the atmospheric part of MAR and the surface is handled by the complex energy-balance snow model SISVAT (Ridder and Schayes [1997]), based on CROCUS that explicitly simulates 30 layers resolving the 20 first meters of snow (Brun et al. [1989]). The surface module notably represents percolation of meltwater and its retention into the snowpack. Runoff occurs when the snowpack can no longer absorb additional liquid water (i.e., snowpack water content exceeding 5\% or surface liquid water over bare ice or an ice-lense layer). MARv3.11 was run at a resolution of $7.5 \mathrm{~km}$ and was forced by 6-hourly outputs of the latest ERA5 reanalysis between 1979 and March 2020. The first two years were discarded as spin-up. 


\section{Sea ice and wave simulations}

ERA-5 includes a two-dimensional wave model coupled to the atmosphere. It solves the wave energy balance equation, using wave spectra with 24 directions and 30 frequencies, and includes assimilation of altimeter wave height (Hersbach et al. [2020]). Although advanced methods to represent wave-sea ice interactions have been tested at ECMWF (Doble and Bidlot [2013]), their representation in ERA-5 is very simple: the wave energy is set to zero where the sea ice concentration exceeds $30 \%$, and there is no wave attenuation for lower concentrations (Bidlot, J. R., personal communication).

\section{Satellite observations}

MODIS-Terra Aqua images were acquired at the (https://worldview.earthdata.nasa.gov) over the entire period of availability, between February 25, 2000 and April 28, 2020. The worldview interface allows comparing images between two different dates, making it possible to accurately retrieve the exact occurrence of the main calving events and collapses of the ice shelves. Since the foehn effect induces a reduction of the cloud cover at the east of the Antarctic Peninsula, it was possible to retrieve the approximate occurrence of most events of the Larsen A, B and $\mathrm{C}$ ice shelves. Accurate examination of images before winter (end of April) and after winter (beginning of August) allowed us to verify that most large ice-shelf calving/collapse on the Larsen ice shelves occurred during the summer in the 20 years of observation (see images in supplementary material). Over the 20 calving events retrieved, 12 were preceded by an AR detected less than 5 days before the collapse (Table 2.1, Figure 4.3a). Considering 1000 random selections of 20 dates between February 25, 2000 and April 28, 2020, we observed that the coincidence of AR is largely lower (mean is 2 events; maximum is 5), demonstrating that AR and collapse occurrences are linked. It is important to note that the dates we link with calving/collapse events are subject uncertainty based on when sky conditions allow us to observe these events.

Since daily MODIS images were not available before February 25, 2000, collapses and large calving events occurring before this date were not considered in our analysis. Nevertheless, we analyzed the well documented collapse of the Larsen A ice shelf (Scambos et al. [2000] using AVHRR satellite images available on the NSCID 
website (Scambos [2001]) surrounding the data of the Larsen A collapse. Similar examination was more limited over the Wilkins ice shelf because cloud cover is generally denser, so collapses and calving events are generally observed a few days after their occurrence. Moreover, contrary to the eastern side, several large events that occurred in the darker autumn and winter periods were not visible in MODIS datasets. This made the attribution of ARs to calving occurrences more difficult on the western side of the AP.

\section{MAR evaluation}

MAR has been thoroughly compared to observation from weather stations, satellite melt extent, AWS-forced melt estimates and SMB measurements over the Antarctic ice sheet (Agosta et al. [2019]; Kittel et al. [2018]; Donat-Magnin et al. [2020]; Mottram et al. [2020]) and more specifically over the Peninsula (Datta et al. [2019, 2018]). The model is also abundantly evaluated over the Greenland ice sheet (e.g. Fettweis et al. [2020]). The ability of MAR to represent melting over the peninsula has already been discussed in Datta et al. [2018, 2019]; Donat-Magnin et al. [2020], so that we present here a short comparison with AWS observations and melt estimates. MAR correctly represents the variation in near-surface temperature (Extended Data Fig. 4.11a) with a centered RMSE (i.e., RMSE where we removed systematic biases attributed to elevation difference) of $2.6{ }^{\circ} \mathrm{C}$ over the ice shelves and $3.2{ }^{\circ} \mathrm{C}$ over the grounded ice. The comparison also reveals a mean negative bias. MAR tends to slightly underestimate the high (positive) temperatures while overestimating the low temperatures that can be found over higher elevations or in winter. Despite the high resolution of these simulations $(7.5 \mathrm{~km})$, the altitude of pixels relating to AWS near the margins is overestimated in MAR by slightly less than 100 meters, likely explaining a significant part of the negative bias over low-elevation areas and ice shelves. There is no direct observation of melt, so we compared MAR to melt estimates using an AWS-forced snow model (Jakobs et al. [2020]). Only AWS locations whose elevation difference with MAR does not exceed $250 \mathrm{~m}$ were selected. This comparison (Extended Data Fig. 4.11b) reveals that the model correctly reproduces the annual surface melt at the AWS situations (located on the Larsen C and Scar Inlet of Larsen B), except in 2017 at Larsen C West where MAR overestimated melt. 


\section{Data availability}

The Modèle Atmosphérique Régionale (MAR) data is available from C. Kittel. AVHRR imagery was acquired from the NSCID58. MODIS-Terra Aqua images were acquired at the (https://worldview.earthdata.nasa.gov).

\section{Code availability}

The code for the AR detection algorithm discussed in this paper is available at https://doi.org/10.5281/zenodo.4009663.

\section{Acknowledgements}

This study is part of the PhD project of J.D.W. conducted at the Universite Grenoble Alpes. We acknowledge support from the Agence Nationale de la Recherche, projects ANR-14-CE01-0001 (ASUMA), ANR-16-CE01-0011 (EAIIST) and ANR-15CE01-0015 (AC-AHC2). I.V.G. thanks FCT/MCTES for the financial support to CESAM (UIDP/50017/2020 and UIDB/50017/2020) through national funds and support to project ATLACE (CIRCNA/CAC/0273/2019) funded by FEDER, through COMPETE2020 - Programa Operacional Competitividade e Internacionalização (POCI), and by national funds (OE), through FCT/MCTES. C.A. acknowledges support from the Fondation Albert 2 de Monaco under project Antarctic-Snow (2018-2020). Computational resources were provided by the Consortium des Équipements de Calcul Intensif (CÉCI), funded by the F.R.S.-FNRS under grant no. 2.5020.11. Particular thanks to Simon Gascoin for providing help in the MODIS images retrieval and to Alison Delhasse for for her monitoring of the MAR simulations.

\section{Author contributions}

J.D.W. and V.F. devised the study and led the writing of the manuscript using input from the co-authors. C. Agosta developed the schematic in Fig. 1. I.V.G. contributed to the physics of ARs and an AR detection algorithm, Fig. 1 and ERA5 analysis in Extended Data Fig. 2. C. K. performed the MAR simulations and evaluated MAR results. X. F., C. Amory, C. Agosta, C. K. advised on its implementation and interpretation of MAR outputs. N. C. J. analyzed ocean behavior for AR relationships. F. C. analyzed 
ENSO and SAM teleconnections for AR connections. All authors contributed to the development of the study and the preparation of the manuscript.

\section{Additional Information}

Supplementary information and figures on ice-shelf collapse case studies are available for this paper. Tables containing information on all ice-shelf disintegration events during the study period are also available. 


\section{Extended Data Figures}
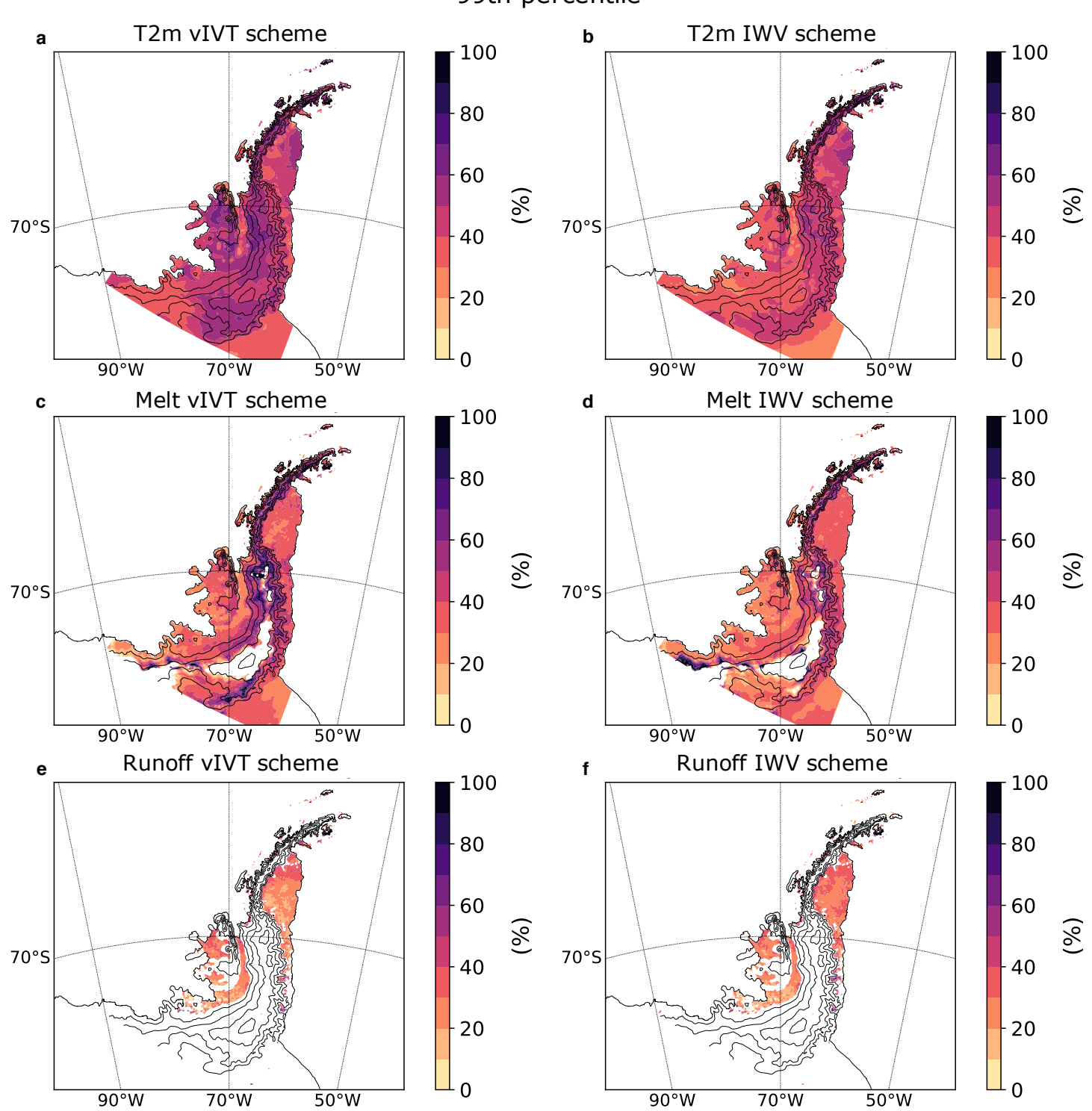

Extended Data Fig. 4.1: The relationship between ARs and extreme temperature, melt, and runoff events. The percentage of MAR a, b $2 \mathrm{~m}$ temperature occurrences, c, d surface melt, and e, f runoff at or above the 99th percentile of the 1980-2019 climatology that occurred within 24 hours before and after an AR landfall on the AP. $\mathbf{a}, \mathbf{b}, \mathbf{c}$ are from the AR climatology generated by the vIVT scheme and $\mathbf{d}, \mathbf{e}, \mathbf{f}$ are from the IWV scheme when both are applied to the MERRA-2 reanalysis. 

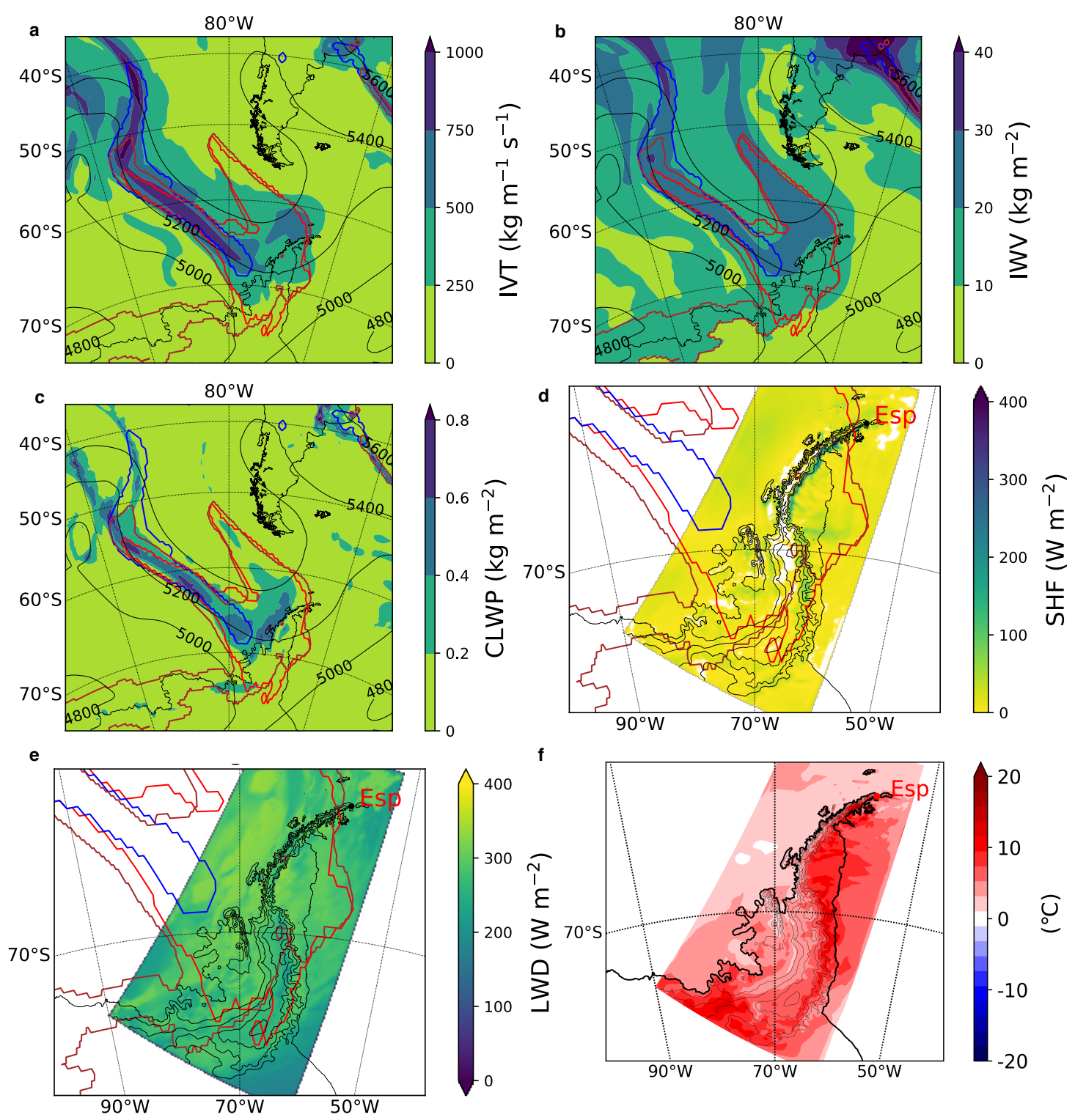

Extended Data Fig. 4.2: Atmospheric variables associated with an AR contributing to the February 2020 high temperature record. The AR shape according to several detection algorithms on 03 UTC 6 February 2020 with spatial distribution of a integrated vapor transport (IVT), b integrated water vapor (IWV), c cloud liquid water path (CLWP), d sensible heat flux (SHF), and e downward longwave radiation (LWD) all from ERA-5. Contours represent the $500 \mathrm{hPa}$ geopotential height contours in meters. The blue, red, and brown outlines are the shape of the AR as determined by the vIVT AR detection scheme, IWV AR detection scheme, and the original Antarctic AR detection algorithm respectively (Gorodetskaya et al. [2014, 2020]). f $2 \mathrm{~m}$ temperature anomalies from MAR on 6 February 18 UTC with respect to the 1980-2019 climatology. 
a 500hPA GPH Anomalies

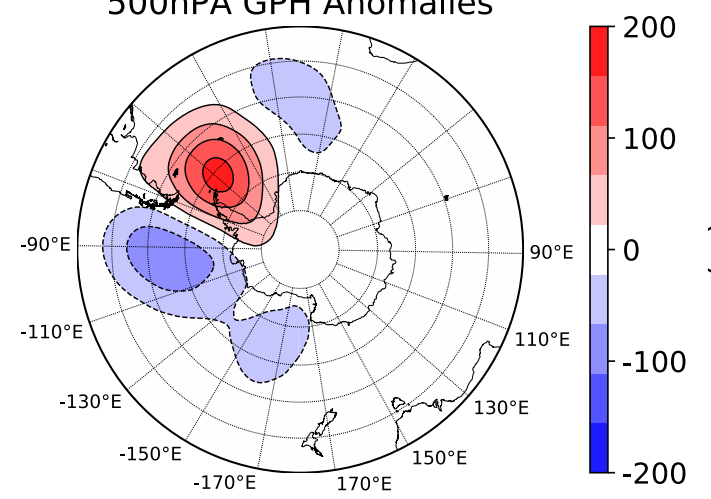

b

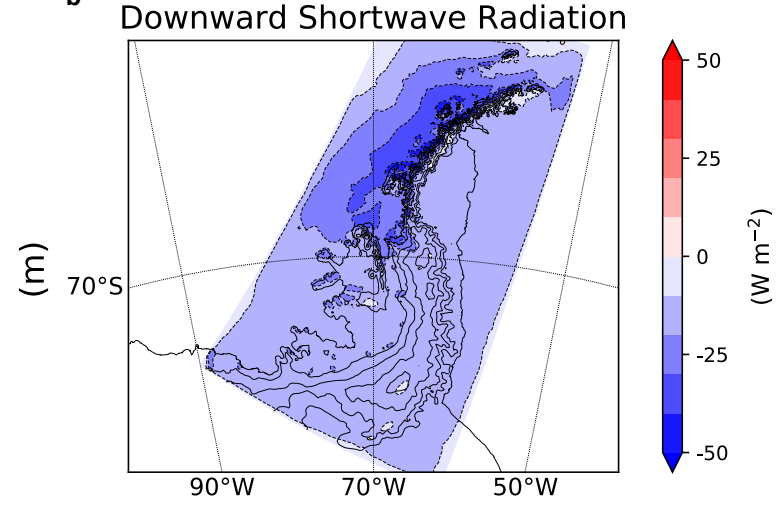

Extended Data Fig. 4.3: Composite a MERRA-2 500 hPa geopotential height anomalies and b MAR daily mean downward shortwave radiation anomalies. Monthly anomalies are with respect to the corresponding climatological monthly mean and then averaged together. The climatology is DJFM 1980-2018 in a and DJ 1980-2019 in b. 

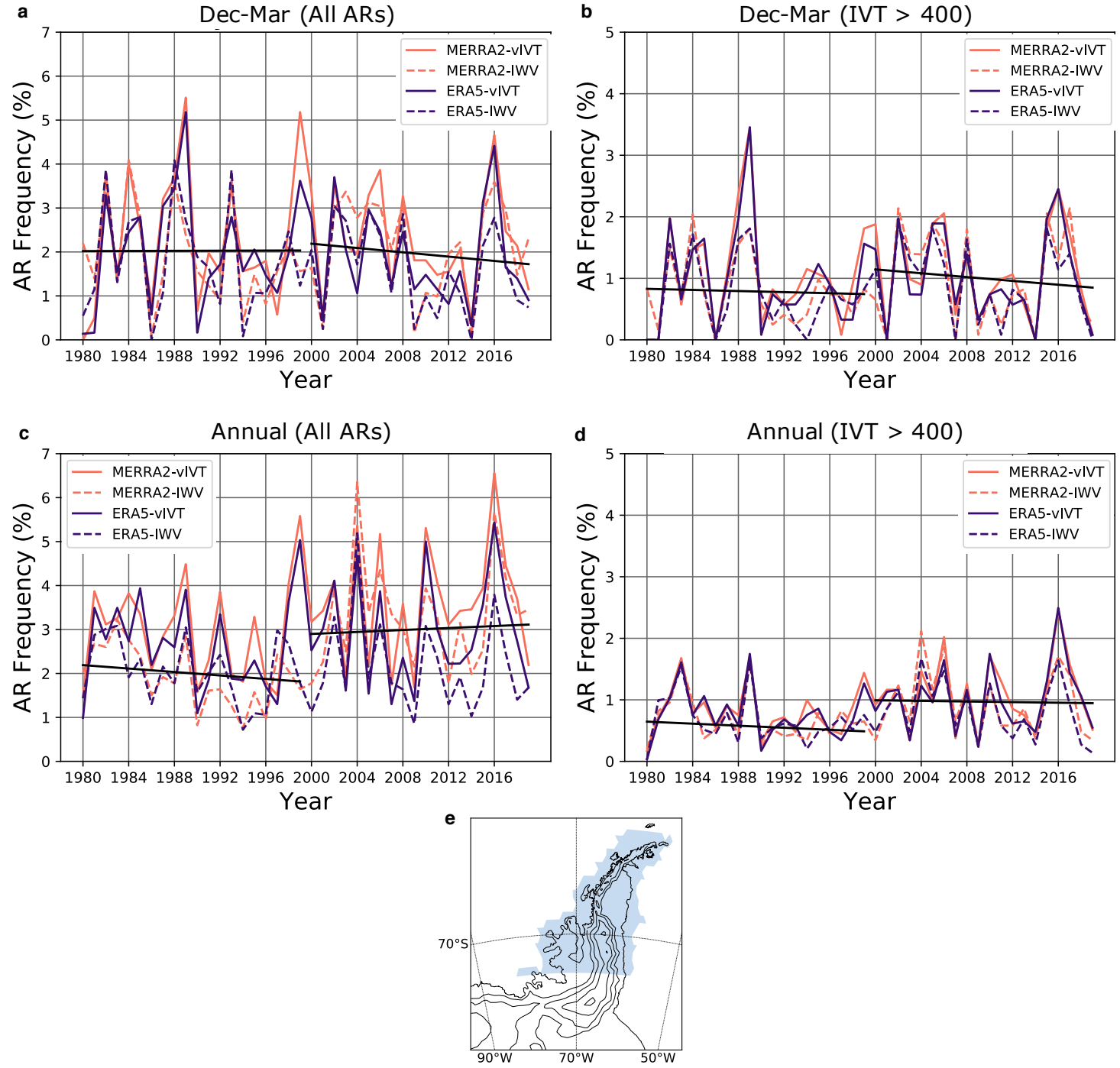

Extended Data Fig. 4.4: Frequency of AR landfalls on the Antarctica Peninsula for a, b December - March and $\mathbf{c}, \mathbf{d}$ yearly according to the VIVT and IWV AR detections schemes when applied to MERRA-2 and ERA-5 reanalysis. $\mathbf{b}, \mathbf{d}$ represent the AR frequency when all AR landfalls with a maximum IVT below $400 \mathrm{~kg} \mathrm{~m}^{-1} \mathrm{~s}^{-1}$ are removed from the record. The year in $\mathbf{a}$ and $\mathbf{b}$ refers to the year of January, February, March (i.e. the austral summer of 1988-1989 is referenced as 1989 in the plots). An AR landfall is counted if an AR shape touches the region highlighted in $\mathbf{e}$. 

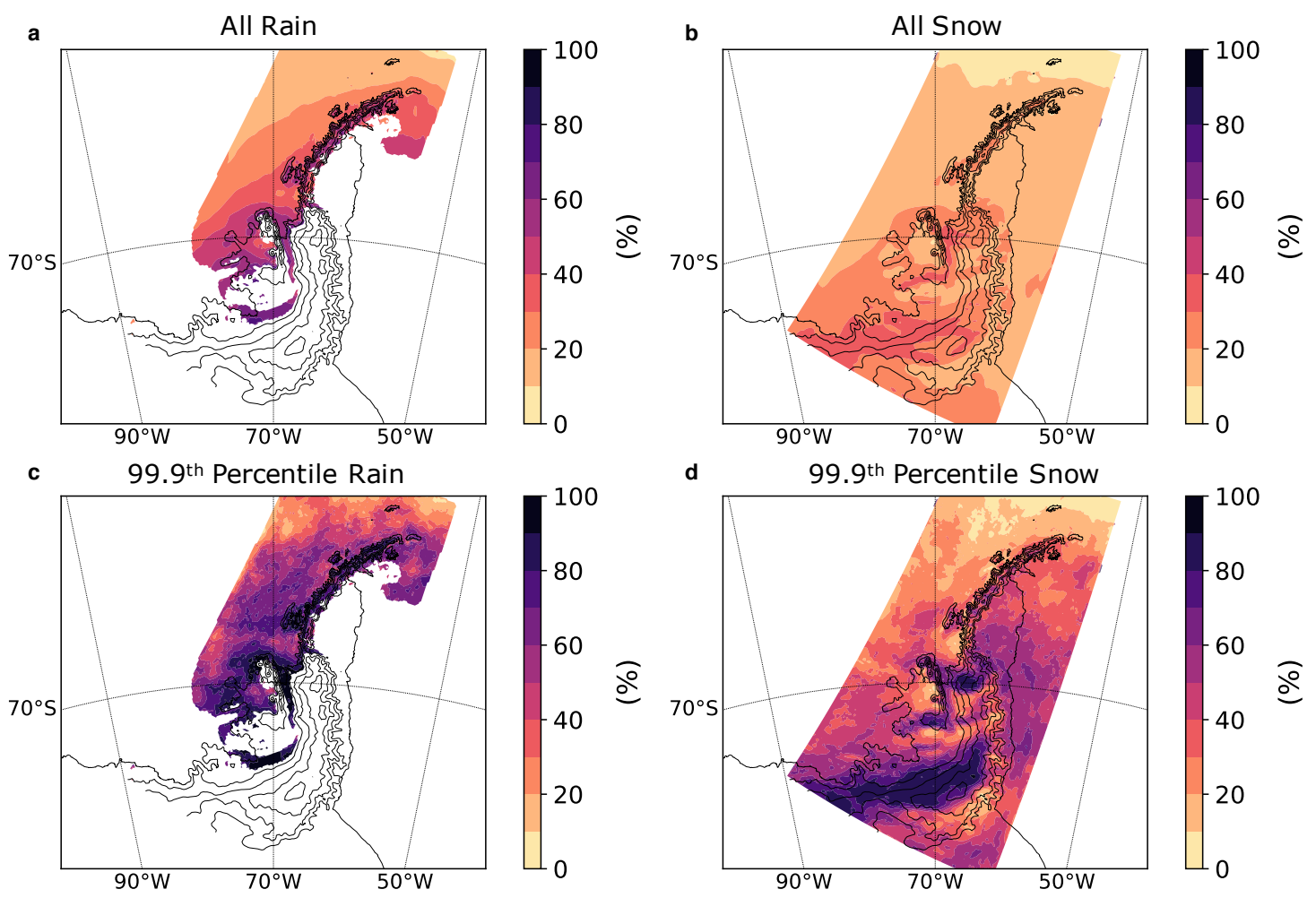

Extended Data Fig. 4.5: The relationship between ARs and precipitation. The percentage of all a rainfall and $\mathbf{b}$ snowfall and $\mathbf{c}$ rainfall and $\mathbf{d}$ snowfall rates at or above the 99.9th percentiles of the 1980-2019 climatology that occurred within 24 hours before and after an AR landfall on the AP. Precipitation data comes from MAR and all areas with yearly rainfall less than $1 \mathrm{~cm}$ per year are masked out for $\mathbf{a}$ and $\mathbf{c}$. 

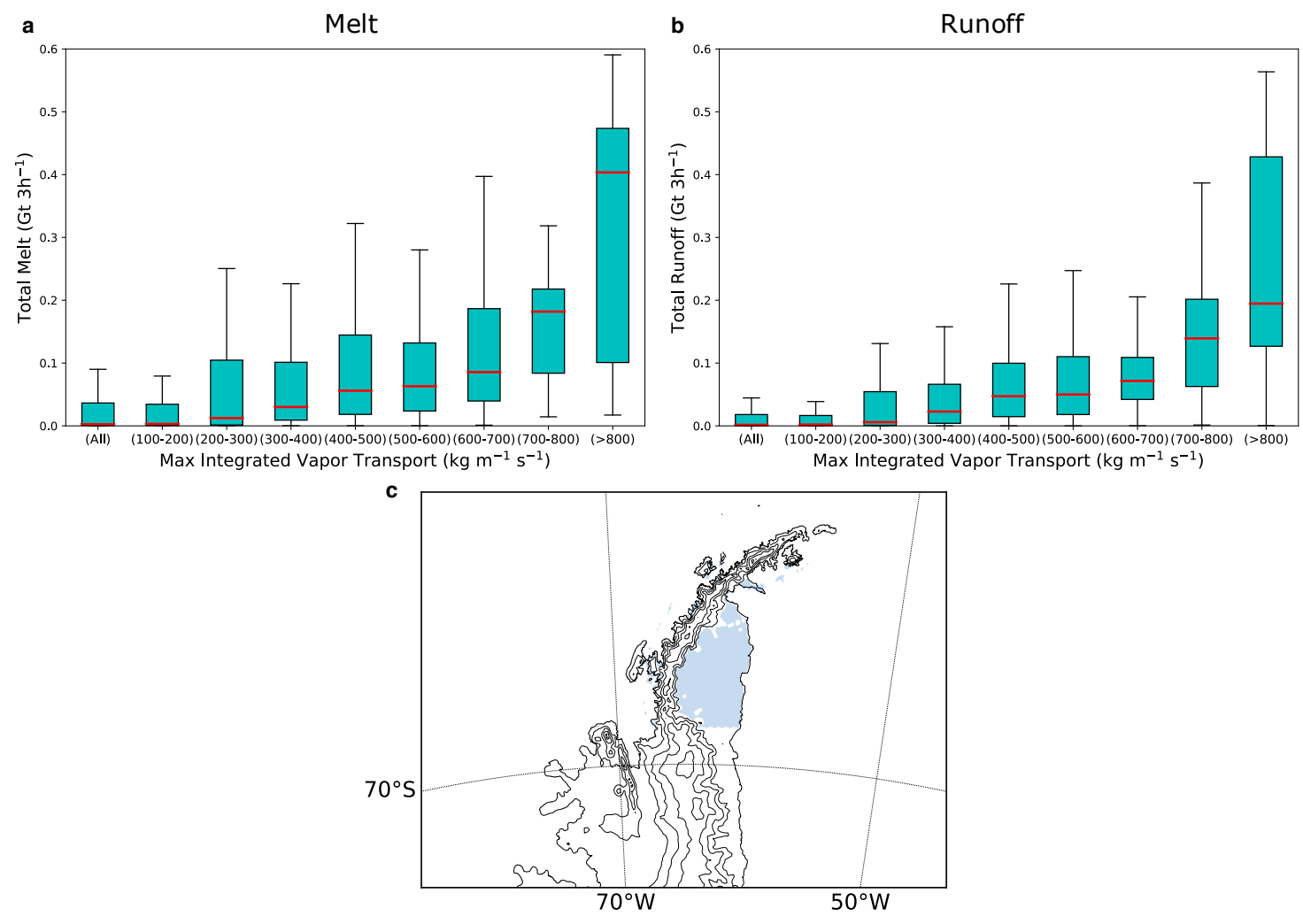

Extended Data Fig. 4.6: The maximum integrated vapor transport (IVT) upon landfall for each detected AR timestep and the corresponding 3-hourly cumulative a surface melt and $\mathbf{b}$ runoff over $\mathbf{c}$ the area shaded in blue using MERRA-2 for IVT and MAR for surface melt and runoff. The most common IVT intensity was $300-400 \mathrm{~kg}$ $\mathrm{m}^{-1} \mathrm{~s}^{-1}(\mathrm{n}=273)$, while the least common IVT intensity was $>800 \mathrm{~kg} \mathrm{~m}^{-1} \mathrm{~s}^{-1}(\mathrm{n}=14)$ over the December-March period. The area of the blue shaded region is $\sim 91,400 \mathrm{~km}^{2}$ 

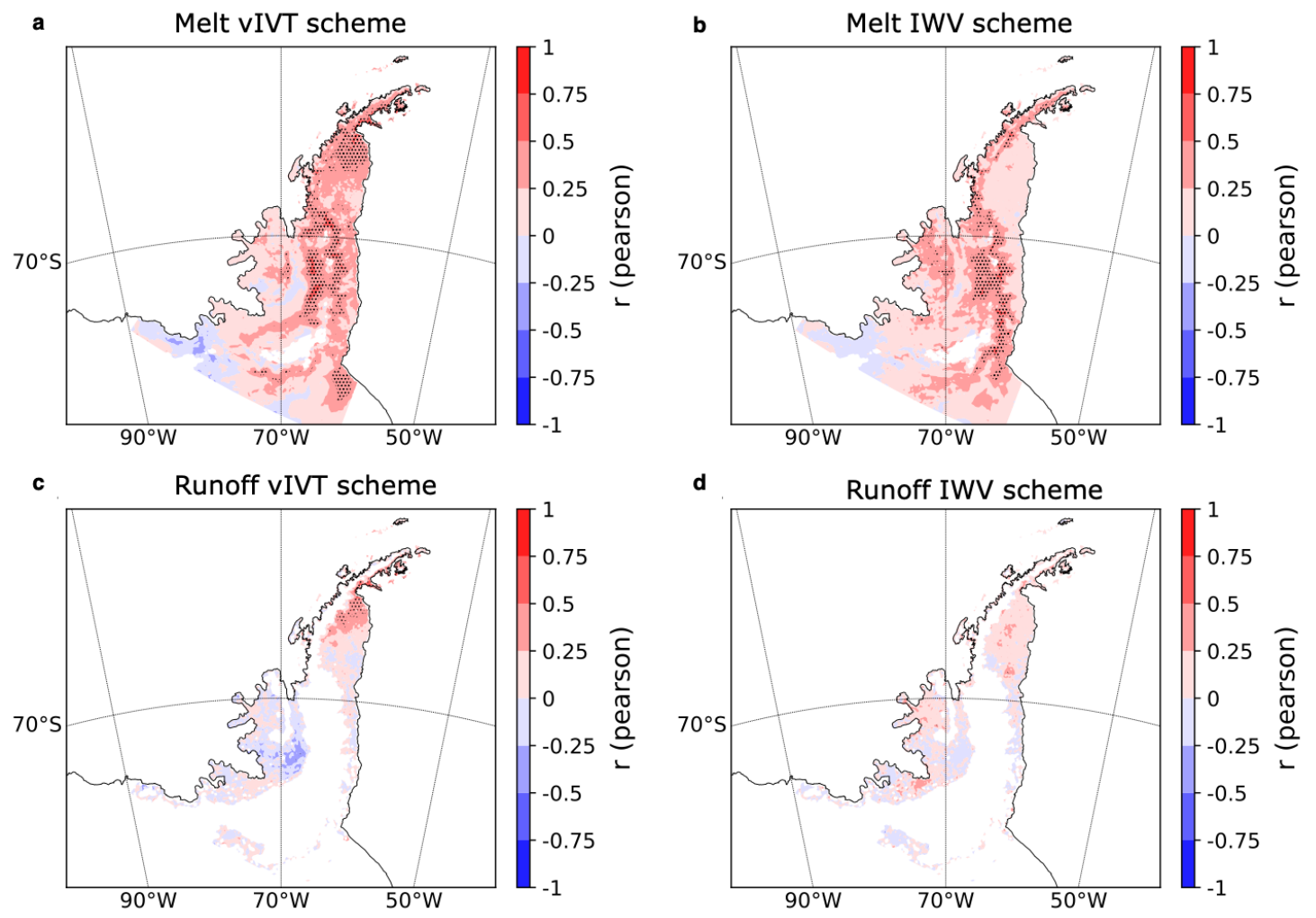

Extended Data Fig. 4.7: The inter-annual correlations between annual cumulative AR landfall intensity and cumulative $\mathbf{a}, \mathbf{b}$ melt and $\mathbf{c}, \mathbf{d}$ runoff from December-March using the a, b vIVT and $\mathbf{c}, \mathbf{d}$ IWV scheme applied to the MERRA-2 reanalysis. Black circles represent areas of significant correlations ( $p$-value $<0.025)$. 

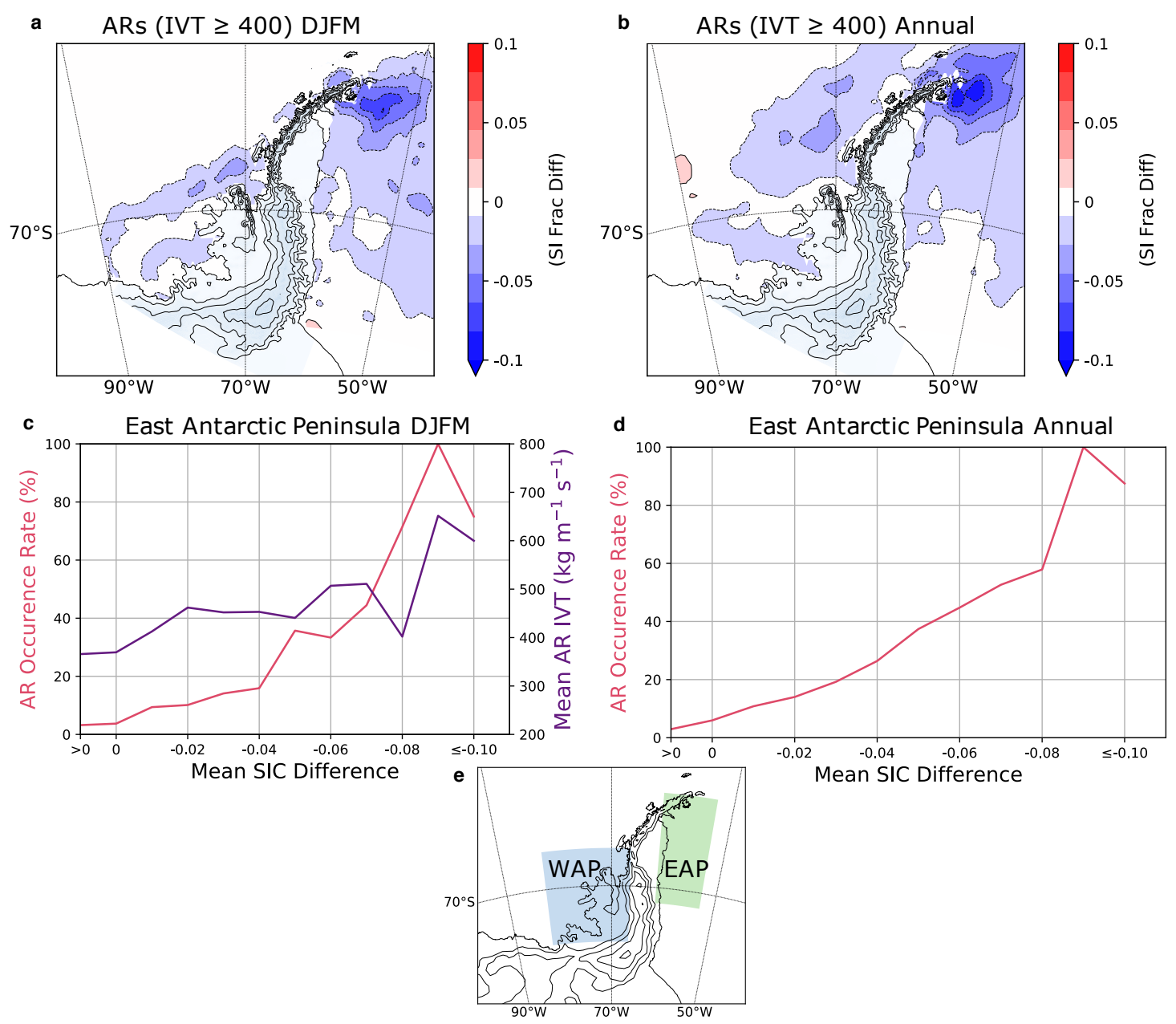

Extended Data Fig. 4.8: The composite two-day sea ice fraction difference for $\mathbf{c}$ summer AR landfalls with a maximum IVT at or above $400 \mathrm{~kg} \mathrm{~m}^{-1} \mathrm{~s}^{-1}(\mathrm{n}=145)$, and $\mathbf{d}$ annual AR landfalls with a maximum IVT at or above $400 \mathrm{~kg} \mathrm{~m}^{-1} \mathrm{~s}^{-1}(\mathrm{n}=357)$. The percentage of two-day mean sea ice fraction differences associated with an AR landfall on the Antarctic Peninsula in regions east of the Antarctic Peninsula for e December-March and $\mathbf{f}$ all months. The areas considered the West Antarctic Peninsula (WAP) and East Antarctic Peninsula are shown in e. The line for mean AR IVT is not included in $\mathbf{f}$ as AR intensity decreases in the non-summer months. 

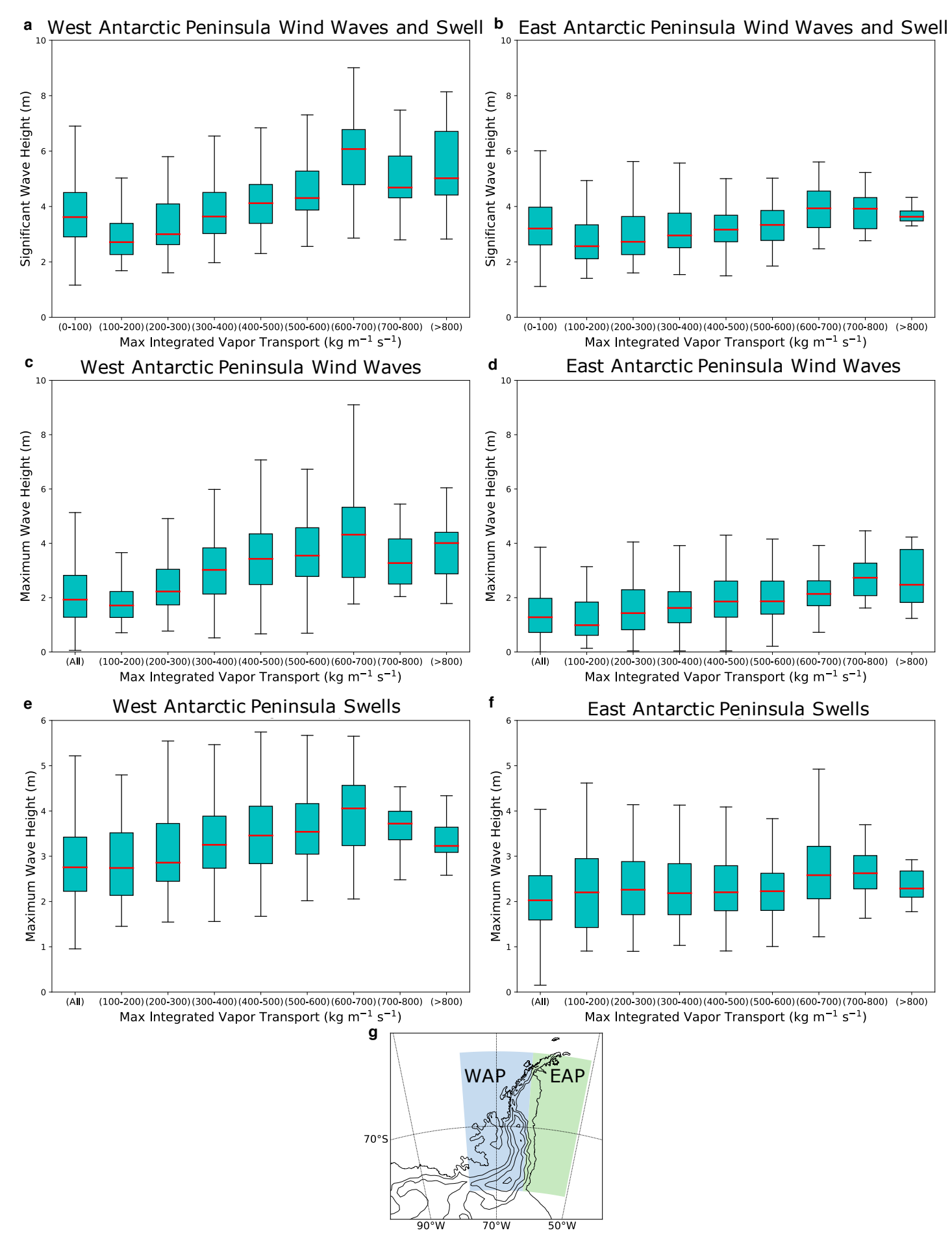

Extended Data Fig. 4.9: The maximum integrated vapor transport (IVT) upon landfall for each detected AR and the associated maximum swell heights $\mathbf{a}$ west and $\mathbf{b}$ east of the Antarctic Peninsula during the melt season (December-March) using MERRA-2 for IVT and ERA-5 for wave heights. The areas considered the West Antarctic Peninsula (WAP) and East Antarctic Peninsula are shown in g. 


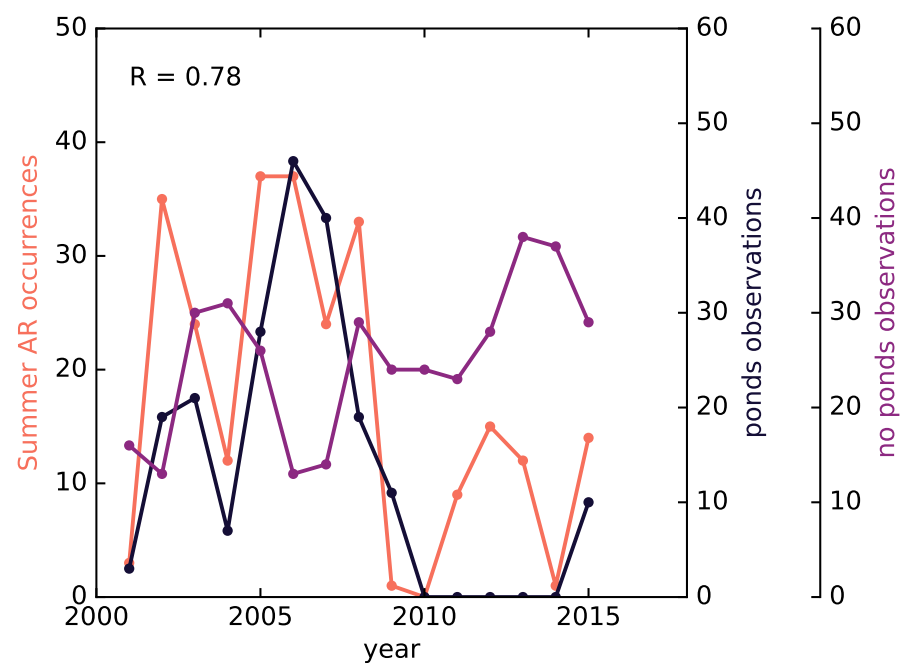

Extended Data Fig. 4.10: Comparison between the number of summer (DJF) AR 3hourly occurrences and melt pond and no melt pond observations. $r=0.78$ between summer AR occurrences and melt pond observations. Melt pond observations are from Hubbard et al. [2016]. 

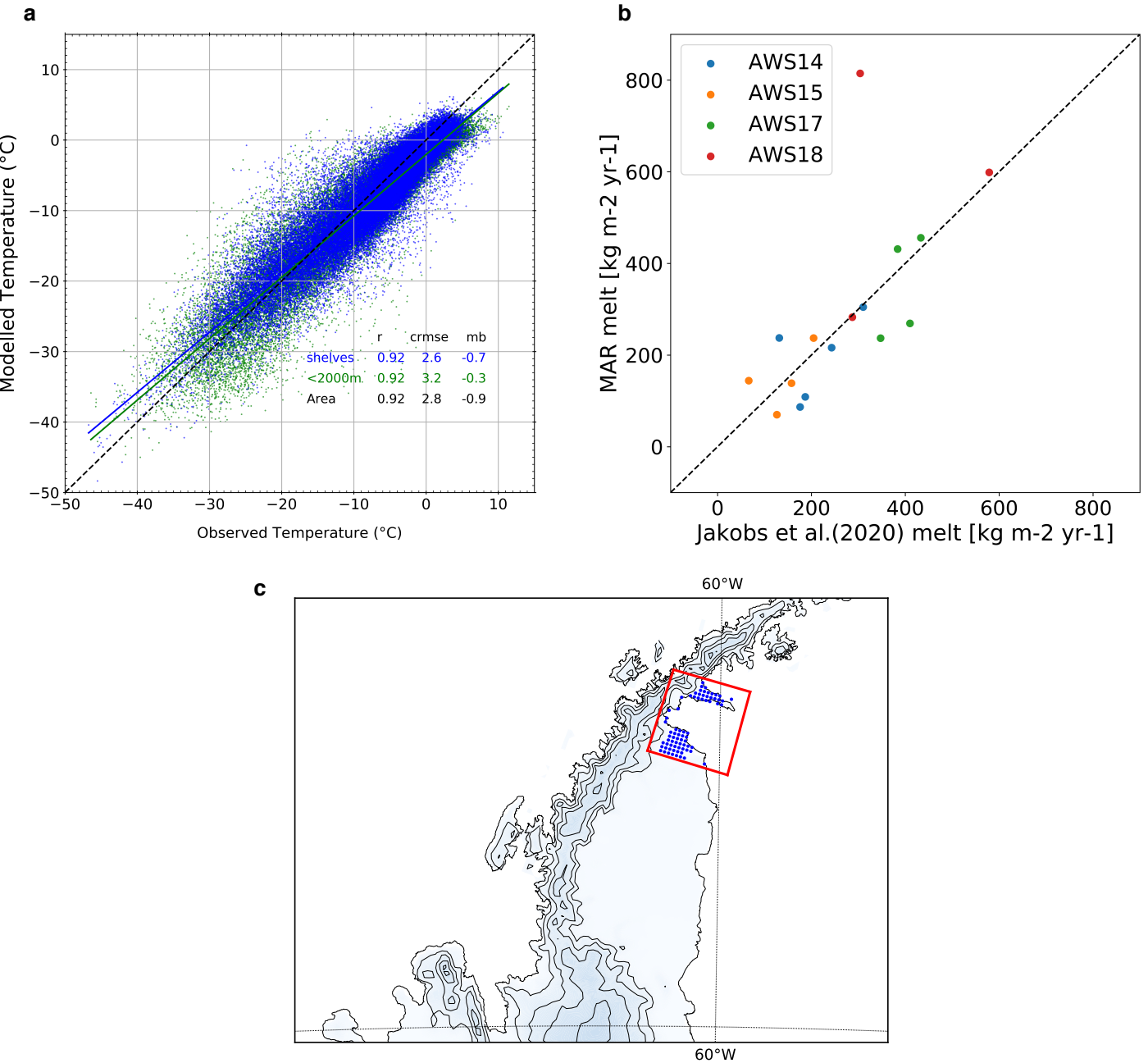

Extended Data Fig. 4.11: a Comparison of MAR near-surface temperature modelled to near-surface observed temperature from weather stations over the peninsula between 1981-2018. The comparison is made independently for ice shelves (blue), the grounded ice (all the stations are located below $2000 \mathrm{~m}$ ) (green), and over the whole area (both ice shelves and grounded ice included). Correlation (r), centered RMSE (crmse) and mean biases are indicated. b Comparison of the annual surface melting modelled by MAR to Jakobs et al. [2020] to estimates for four AWS located on the Antarctic peninsula. c Location of where MAR data was used for calculations given in Figure 4.3. Blue dots are cells where correlation between annual mean runoff and cumulative summer IVT values exceeds 0.6 used for Fig. 4.2d and 4.2e (mainly located along the shore of the remnant Larsen A and B ice shelves). The blue circles correspond with the points used for the analysis presented in Fig. 4.3d, 4.3e, and 4.3f. The red square corresponds to the $20 \times 20$ cells with the area used for the analysis presented in the supplementary materials. 


\section{Chapter 5}

\section{An Antarctic atmospheric river climatology}

\subsection{Foreword}

In this chapter, we present the first climatology of atmospheric rivers (ARs) in Antarctica and their impacts on the Antarctic precipitation budget. Gorodetskaya et al. [2014] highlighted how two years of high AR activity basically drove the surface mass balance (SMB) of Dronning Maud Laud and opened the door to further understanding how ARs affect the Antarctic-wide SMB. In addition, the publication of Turner et al. [2019], where I am a coauthor, provided great insight into the importance of extreme precipitation events and how they can dictate the SMB over the desert landscape of the Antarctic ice sheet. Following our work in Turner et al. [2019], a large science question remained; what was driving these extreme precipitation events across the continent? With the second version of the AR detection algorithm (Wille_v2), the development of a precipitation-attribution scheme, and reliable snowfall simulation from MAR, we could carry out a study that tracked all AR activity across Antarctica since 1980 in a detailed matter and make an AR-attribution study of precipitation across Antarctica that addressed the questions raised in Gorodetskaya et al. [2014] and Turner et al. [2019].

The overarching implication from this study is that ARs, despite their rarity, play a pivotal role in controlling Antarctic precipitation trends and variability. Their effects on snowfall appear to most pronounced in East Antarctica where they account 
for $20-30 \%$ of the total snowfall budget, but most importantly account for $60-70 \%$ of the all extreme precipitation events at coastal and near-coastal areas. Also AR variability is driving modern snowfall trends in many locations while controlling interannual precipitation across most of the continent. We believe this study will serve as a cornerstone for future research efforts on Antarctic precipitation studies, efforts to interpret isotope composition from ice-cores for past-climate reconstruction, and how future changes in AR behavior will influence Antarctic SMB. At the time of this writing, the paper is under review in the Journal of Geophysical Research - Atmospheres. The following section displays the submitted article slightly formatted to fit this thesis format and the supplementary figures can be found in Appendix C.

\subsection{Article: Antarctic atmospheric river climatology and precipitation impacts}

\section{Antarctic atmospheric river climatology and precipitation impacts}

Jonathan D. Wille ${ }^{1}$, Vincent Favier ${ }^{1}$, Irina V. Gorodetskaya ${ }^{2}$, Cécile Agosta $^{3}$, Christoph Kittel $^{4}$, Jai Chowdhry Beeman ${ }^{1}$, Nicolas C. Jourdain ${ }^{1}$, Jan T. M. Lenaerts ${ }^{5}$, Francis Codron $^{6}$

1 Institut des Géosciences de l'Environnement, CNRS/UGA/IRD/G-INP, Saint Martin d'Hères, France

2 CESAM - Centre for Environmental and Marine Studies, Department of Physics, University of Aveiro, Portugal

3 LSCE - Laboratoire des Sciences du Climat et l'Environnement, Gif-sur-Yvette, France 4 Laboratory of Climatology, Department of Geography, University of Liège, Liège, Belgium

5 Department of Atmospheric and Oceanic Sciences, University of Colorado, Boulder CO, USA

6 Université Pierre and Marie Curie, LOCEAN, Paris, France

Key Points: 
- Atmospheric rivers in Antarctica are rare events, but are a crucial component of the mass balance

- Their impact on precipitation is most pronounced in East Antarctica where they are responsible for $20-30 \%$ of the total snowfall budget

- Atmospheric rivers are driving the modern snowfall trends and controlling precipitation variability across the Antarctic continent

\section{Abstract}

The Antarctic ice sheet is sensitive to short-term extreme meteorological events that can leave long-term impacts on the continent's surface mass balance. We investigate the impacts of atmospheric rivers (ARs) on the precipitation budget using an AR detection algorithm and a regional climate model (MAR) from 1980-2018. While ARs and their associated extreme vapor transport are relatively rare events over Antarctica ( $\sim 3$ days per year), they have a significant impact on precipitation processes. ARs are more frequent in winter and present a high interannual variability. The maximum snowfall is linearly related with AR intensity when intensity is measured by maximum vertically integrated meridional water vapor transport upon landfall. ARs are responsible for $20-30 \%$ of snowfall across East Antarctica and a majority of the heaviest precipitation events. Annual snowfall trends across East Antarctic since 1980 were primarily driven by trends in AR frequency and ARs controlled the inter-annual variability of precipitation across most of the Antarctic ice sheet.

AR landfalls are most likely when the circumpolar jet is highly amplified during blocking conditions. There is a fingerprint of the Southern Annual Mode (SAM) on AR variability in West Antarctica likely as SAM is positively (negatively) correlated with AR activity in the Antarctic Peninsula (Amundsen-Ross Sea coastline). Given the relatively large influence ARs have on precipitation across the continent, it is advantageous for future studies of moisture transport to Antarctica to consider an AR framework especially when considering future surface mass balance changes. 


\section{Plain Language Summary}

The Antarctic continent like many deserts in the world receives a large percentage of its precipitation from just a few intense precipitation events. Atmospheric rivers (ARs), narrow corridors of intense moisture transporting moisture from low to high latitudes, are commonly associated with heavy rain and snowfall in the midlatitudes like in the Pacific northwest. In the Antarctic, ARs are rarer, but still have a major influence on the continent's mass balance, especially in East Antarctica. While most regions in Antarctica experience AR conditions a few days per year, they are responsible for 20-30\% of the total snowfall in parts of East Antarctica. This contribution to the snowfall budget is the component that has been driving the snowfall trends in Dronning Maud, Wilkes Land, and the Antarctic Peninsula. Across most the Antarctic ice sheet, ARs control the year to year variability of precipitation. This means that variations in AR activity will impart corresponding variations in precipitation. Therefore, increased AR activity in the future would result in higher snowfall accumulation on the Antarctic continent and possibly offset some sea-level rise from dynamic ice loss, but this must be considered in balance with increased melting frequency already documented with ARs.

\section{Introduction}

\subsection{Precipitation in Antarctica}

The Antarctic ice sheet is a desert and similar to other deserts around the world, where the annual precipitation is dependent on a few episodic precipitation events. Recent research has highlighted that certain regions of the Antarctic ice sheet receive $40-60 \%$ of their total annual precipitation from the largest $10 \%$ of daily precipitation events (Turner et al. [2019]). There is a high coast-inland snowfall gradient, as most snowfall that falls in the Antarctic is the result of cyclonic activity advecting marine air masses towards the coastline while a persistent inland polar anticyclone and the steep slope of the high Antarctic plateau prevents those air masses from traveling far inland due to cyclone decay from topographically induced vorticity compression (Agosta et al. [2019]; Bromwich [1988]; Hobbs [1915]; Kittel et al. [2018]). The most common precipitation type for the interior of Antarctica is clear-sky precipi- 
tation in the form of very light snow or diamond dust induced by strong radiative cooling (Bromwich [1988]; King and Turner [2007]; Picard et al. [2019]; Stenni et al. [2016]). Marine air intrusions, although rare, can penetrate far into the Antarctic continent, delivering quick yet relatively intense snowfall. These features are often responsible for the extreme precipitation events across and near the Antarctic coastline (Turner et al. [2019]). Intrusions of maritime air into the Antarctic interior are frequently the result of large blocking ridges in the Southern Ocean directing air masses from sub-tropical and mid-latitude origin towards the Antarctic continent (Hirasawa et al. [2013]; Kurita et al. [2016]; Massom et al. [2004]; Naithani et al. [2002]; Schlosser et al. [2010]). Some studies have connected these blocking related moist air intrusions to atmospheric rivers (ARs) that caused large localized snowfall and melting events (Bozkurt et al. [2018]; Gorodetskaya et al. [2014]; Kurita et al. [2016]; Wille et al. [2019]). However, the link between ARs and Antarctic-wide precipitation climatology and surface mass balance (SMB) has not been described yet.

\subsection{Atmospheric rivers}

An atmospheric river as defined in the American Meteorological Society (AMS) Glossary of Meteorology is "a long, narrow, and transient corridor of strong horizontal water vapor transport that is typically associated with a low-level jet stream ahead of the cold front of an extratropical cyclone." ARs often exhibit a moist-stable vertical stratification and produce heavy precipitation when the air parcels are orographically lifted upon landfall or isentropically lifted within the cyclone's warm conveyor belt (Neiman et al. [2008a, 2013]; Ralph et al. [2017, 2005]). A single AR event can persist through sequential cyclones in favorable atmospheric blocking conditions where a corridor linking the moisture source and sink regions is maintained (Benedict et al. [2019]; Sodemann and Stohl [2013]). This results in an AR landfall event sometimes consisting of multiple rounds of heavy precipitation, as mesoscale frontal waves can transport successive vorticity maxima along the edge of a blocking ridge (Dacre et al. [2015]; Martin et al. [2019]; Neiman et al. [2016]). ARs are a crucial component of the global hydrological cycle, accounting for $\sim 90 \%$ of the meridional water vapor transport while covering just $\sim 10 \%$ of the earth's zonal circumference in the mid-latitudes (Zhu and Newell [1998]). 
When ARs approach polar regions, they become very important to snowfall and melt processes in the cryosphere. The enhanced radiative fluxes associated with the anomalously high liquid water content in the clouds contribute to sea ice disintegration in the Arctic (Hegyi and Taylor [2018]; Komatsu et al. [2018]), ice mass loss over the Greenland ice sheet (Mattingly et al. [2018]; Neff [2018]; Neff et al. [2014]), and large scale surface melt in West Antarctica (Wille et al. [2019]). While ARs can deliver enhanced atmospheric water vapor that increases the chances for surface melt, the anomalously high moisture content can also lead to heavy snowfall events. At Princess Elizabeth Station in East Antarctica, ARs were shown to be responsible for 74-80\% of accumulated snowfall in 2009 and 2011, which were two years of unprecedented AR activity in the past 40 years in that region (Gorodetskaya et al. [2014]; Wille et al. [2019]). Establishing the AR contribution to Antarctic snowfall would improve our understanding of how extreme precipitation events impact the Antarctic SMB and how those changes in SMB might impact sea level rise by offsetting dynamic mass loss (Ligtenberg et al. [2013]). Using an atmospheric river detection algorithm, we continue the development of an Antarctic AR climatology from Wille et al. [2019] and discuss AR frequency (Section 3.1), the AR precipitation budget (Section 3.2), AR and snowfall trends (Section 3.3), precipitation and AR inter-annual variability correlations (Section 3.4), AR blocking behavior (Section 3.5), and AR frequency correlations with SAM (Section 3.6).

\section{Data and Methods}

\subsection{The atmospheric river detection algorithm}

The atmospheric river detection algorithm utilized in this study is an updated version of the vertically integrated meridional vapor transport (vIVT) detection algorithm originally described in Wille et al. [2019]. The algorithm identifies grid cells between $45^{\circ} \mathrm{S}-80^{\circ} \mathrm{S}$, where vIVT is at or above the 98th percentile of all monthly climatological vIVT from 1980-2018. The 98th percentile was found to be ideal for AR detection as lower percentiles like the 95th led to the identification of shapes not consistent with the definition of ARs like more typical extra-tropical cyclones without a lower-latitude moisture connection. If the algorithm detects a continuous filament of extreme vIVT that extends at least 20 degrees in the meridional direction, it is classi- 
fied as an AR. Here vIVT is calculated as

$$
v I \overrightarrow{V T}=-\frac{1}{g} \int_{\text {surface }}^{t o p} q \vec{V} d p
$$

where $q\left(\mathrm{~kg} \mathrm{~kg}^{-1}\right)$ is the specific humidity, where $v$ is the meridional wind velocity $\left(\mathrm{m} \mathrm{s}^{-1}\right), g\left(\mathrm{~m} \mathrm{~s}^{-2}\right)$ is the gravitational acceleration, and $p$ is the atmospheric pressure (hPa).

Wille et al. [2019] developed two detection algorithms schemes based on vertically integrated water vapor (IWV) and meridional vertically integrated vapor transport (vIVT). In the aforementioned study, it was demonstrated that IWV was a slightly more appropriate choice for studying the effects of ARs on surface melting. Excessive IWV over the ice sheet is related with the development of mixed phase clouds containing anomalously high liquid and ice water paths thus creating high downward longwave radiations fluxes to the surface. Conversely, vIVT was found to be better for studying snowfall patterns, since adding the meridional wind speed component reflects the dynamical processes that lead to precipitation generation. The authors also found little difference in AR detection frequency between the IWV and vIVT detection schemes. The maximum snowfall intensity within ARs increases more linearly with the AR intensity when AR detections and intensities are based on vIVT compared to IWV (Supplementary Fig. C.1).

The latest version of the AR detection algorithm was updated to be compatible with the Atmospheric River Tracking Method Intercomparison Project (ARTMIP; Rutz et al. [2019]). This means running the detection algorithm on 3-hourly fields from the Modern-Era Retrospective analysis for Research and Applications, Version 2 (MERRA-2) on all pressure levels (Gelaro et al. [2017]) to create an AR catalog. Unlike the previous version, in which the algorithm was applied individually to quadrants over Antarctica, the latest version is now run over the entire Antarctic domain with the ability to detect multiple ARs in a single time step and return their associated shapes. This allows for a more detailed analysis of AR climatology and their local impacts. Wille et al. [2019] found that using MERRA-2 for detecting AR frequency gave similar results than when using other reanalysis products such as JRA-55, ERAInterim, and CFSR (Dee et al. [2011]; Kobayashi et al. [2015]; Saha et al. [2010]). For a more direct comparison to the regional atmospheric model MAR (described in the fol- 
lowing section; Section 2.2), we also created an AR detection catalog initialized with ERA-5 (Forecasts [2017]) reanalysis interpolated onto a $1^{\circ} \times 1^{\circ}$ horizontal grid, calculate the vIVT using equation (1), and compare results between the two AR catalogs throughout the study.

\subsection{Regional climate model}

The precipitation (rainfall and snowfall) information was obtained from the Modèle Atmosphérique Régional (MARv3.10.2), a regional climate model (RCM) forced by 6-hourly ERA-5 and run at 35 x $35 \mathrm{~km}^{2}$ horizontal resolution over the Antarctic domain with a 120 second time step and outputs every three hours (Agosta et al. [2019]). MAR represents five water species (specific humidity, cloud droplets, ice crystals, raindrops, and snow particles) whose interactions with the air (e.g., evaporation, sublimation, condensation, etc.) contribute directly to the heat and moisture budget of the atmosphere. For instance, sublimation of airborne snow particles during their advection into the atmosphere was shown to be a significant process controlling surface accumulation (Agosta et al. [2019]). Due to its polar-oriented physics and higher resolution, MAR improves the representation of the middle and lower troposphere compared to the driving reanalysis, as well as interactions with snow-covered surface, whereas large-scale circulation patterns are constrained by the forcing fields leading to similar snow accumulation at the surfaces regardless of the reanalysis used in forcing (Agosta et al. [2019]).

\subsection{Atmospheric river precipitation attribution}

The AR shapes provided by the algorithm were compared against the MAR precipitation (snowfall and rainfall) to calculate the percentage of total precipitation attributed to ARs. Any precipitation that occurred within the footprint of an AR landfall during and within 24 hours after the landfall is counted toward that grid point's total AR precipitation. Counting precipitation on the temporal periphery of AR landfalls is helpful as often precipitation succeeds the AR event (Gorodetskaya et al. [2020]) since residual moisture after the AR departs may contribute to lingering precipitation (Wille et al. [2019]). When analyzing individual AR examples and the associated snowfall, we found many instances of heavy snowfall occurring just outside of the 


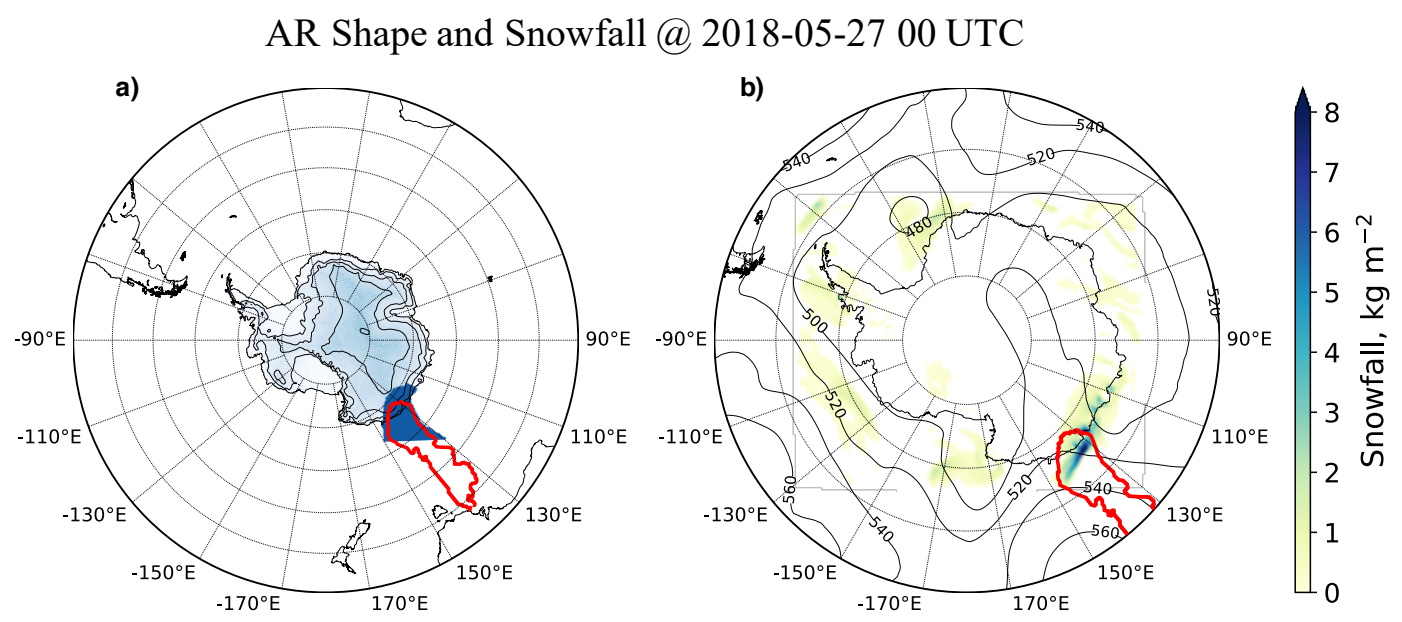

Figure 5.1: An example AR detection on 00 UTC 27 May 2018 with the a) area sampled by the snowfall attribution scheme described in the methods and the b) simulated snowfall from MAR. The red outline is the AR shape from the detection algorithm and the blue shading is the region sampled by the snowfall attribution scheme.

AR shape like in one example from May 27th, 2018 in Wilkes Land (Fig. 5.1b). The AR shapes outputted by the detection algorithm represent an extratropical cyclone's warm conveyor belt that covers the region of precipitation found in the ascent region along and ahead of the cold front. The other major region of ascent and heavy precipitation occurs ahead of the warm and occluded front where IVT values are often lower and thus sometimes not considered by the AR detection algorithm (Dacre et al. [2015]; Houze [2014]). Even though the precipitation falling in a cyclone's occluded band is outside of the AR shape, the diabatic heating from the evaporation of moisture provided by the AR enhances positive omega forcing and negative geopotential tendency according to the quasi-geostrophic equations thus contributing to the intensity of the whole cyclone (Tsuji and Takayabu [2019]). Thus, the precipitation that falls near the detected AR shape can be attributed to the AR. To capture this precipitation outside the AR footprint, the precipitation that occurs in the grid cells around the AR shape that are within the 90th percentile of climatological vIVT (as opposed to the 98th percentile for AR detection) are added to the AR's precipitation total (Fig. 5.1a). This precipitation attribution method is utilized for figures 5.3, 5.4, and 5.7 and supplementary figures C.6, C.7, and C.11. The combined counting of additional grid cells from the precipitation attribution method and timesteps after AR landfalls results in a counting frequency around Antarctica of 1-3\% (Supplementary Fig. C.2). 


\subsection{Atmospheric blocking analysis}

To analyze the connection between ARs and atmospheric blocking ridges, we created a blocking index inspired by the results of Wille et al. [2019] and Scott et al. [2019]. For each AR shape, a $180^{\circ}$ azimuth centered on the mean longitude of the AR is created. In a zonal band from $60^{\circ} \mathrm{S}-75^{\circ} \mathrm{S}$ within the azimuth, we calculate the maximum and minimum $500 \mathrm{hPa}$ geopotential heights compiled over a 24-hour period centered around the AR landfall and compare that to the respective monthly average to get anomaly values. The difference between the maximum and minimum height anomalies becomes the blocking index. To compare the AR blocking indices against non-AR blocking indices around Antarctica, four $180^{\circ}$ azimuths are created around Antarctica $\left(0^{\circ}\right.$ to $180^{\circ}, 90^{\circ}$ to $270^{\circ}, 180^{\circ}$ to $360^{\circ}, 270^{\circ}$ to $\left.90^{\circ}\right)$. For each timestep without an AR detection, the difference between the maximum and minimum 24-hour averaged height anomalies for each azimuth within the zonal band from $60^{\circ} \mathrm{S}-75^{\circ}$ $\mathrm{S}$ are calculated. The azimuth with the greatest difference becomes the blocking index for that timestep. We take the blocking index from the azimuth with the highest value to show that AR landfalls are associated with a much higher amplitude jet pattern compared to non-AR days. A schematic showing the area where the blocking index is calculated can be found in Supplementary Fig. C.3. Geopotential height is provided by MERRA-2 reanalysis data.

\section{Results}

\subsection{Atmospheric river frequency}

Overall, ARs occur relatively rarely around Antarctica. Following the framework established in Rutz et al. [2019], AR frequency defined here refers to the percentage of time a particular location is under the spatial footprint of ARs. The annual AR frequency is highest over the Southern Ocean at around 1.2\% (or 3.5 days per year) and then decreases progressively from the Antarctic coast ( $\sim 1.0 \%$ or 3 days per year) to the interior (Fig. 5.2; Supplementary Fig. C.4). The lowest frequency occurs over interior portions of the eastern Antarctic continent near the Transantarctic Mountains $(\sim 0.2 \%$ or less than 1 day per year; location names found on Supplementary Fig. C.5). On the Antarctic continent, the Antarctic Peninsula, Dronning Maud Land, and Enderby 
Land have the highest AR frequency of around 1.0-1.2\%. A noticeable minimum in AR frequency is found over the Ross Sea, where a topographically induced cyclonic eddy generally steers extratropical cyclones towards the Amundsen Sea coast (Baines and Fraedrich [1989]). A similar climatology is found using the AR detection algorithm with ERA-5 data with a slightly lower AR frequency across the study domain (Supplementary Fig. C.6). Since cyclones undergo cyclolysis upon landfall from vorticity compression induced from topography, detecting ARs over the continent becomes more complex and frequency results have to be taken more cautiously far inland.

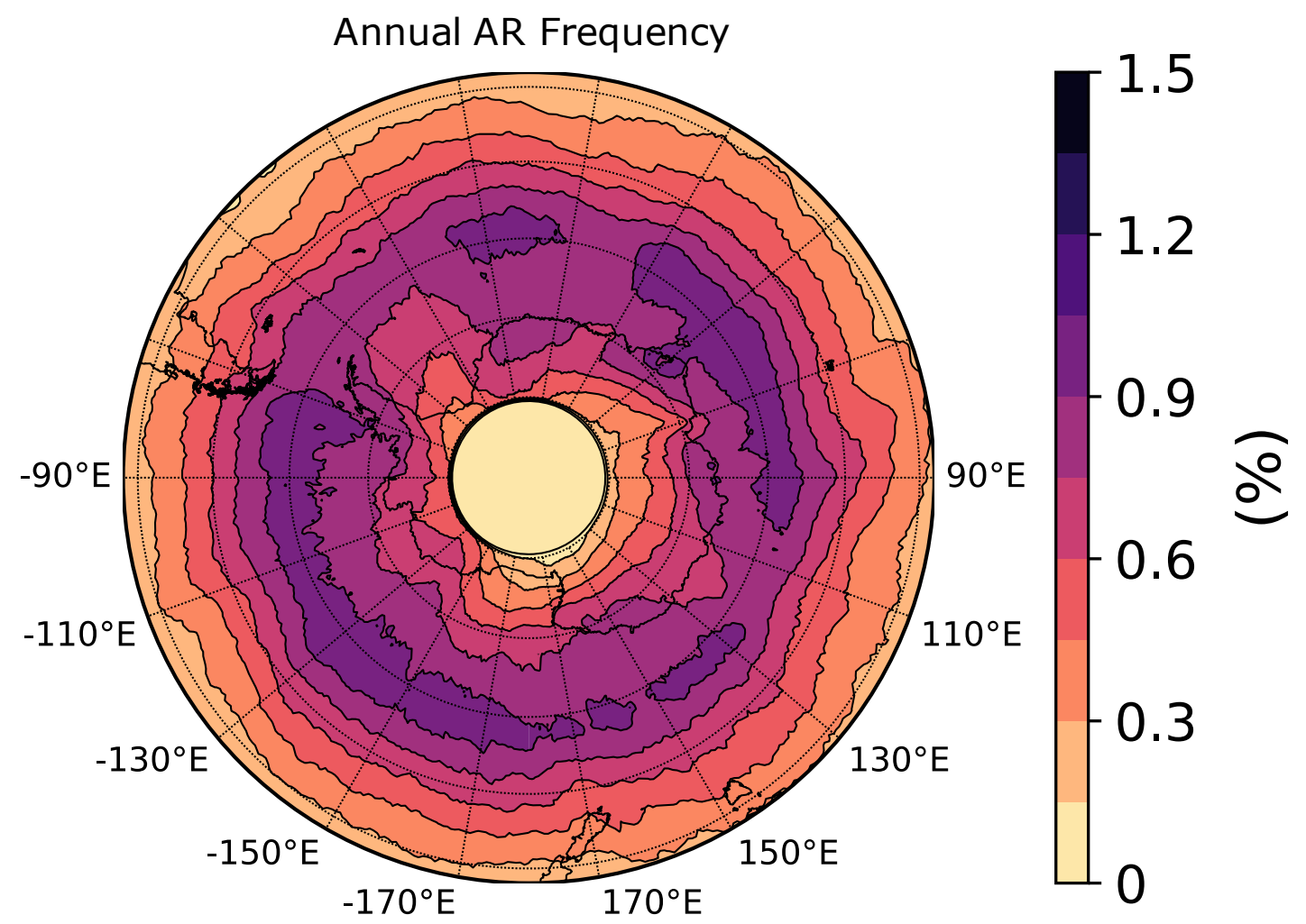

Figure 5.2: AR frequency from the vIVT scheme of the AR detection algorithm for 1980-2018.

Breaking down the annual AR climatology into seasons reveals a greater variability in AR density compared to an annual perspective. Like the general pattern of cyclones, there is a greater frequency of ARs in the winter (JJA) compared to the summer (DJF) (Supplementary Fig. C.8). During DJF, the areas of maximum AR density are further offshore, with three local maxima at the northern Antarctic Peninsula, Dronning Maud Land, and Enderby Land, specifically near Neumayer and Syowa stations (Supplementary Fig. C.7a). In MAM, AR activity increases relative to 
summer in the Amundsen-Bellingshausen Sea and Wilkes Land especially near Dumont d'Urville station and Davis station (Supplementary Fig. C.7b). The highest AR frequency occurs in JJA, with relatively high AR frequency along most of the Antarctic coastline. The areas with the highest AR frequency include most of the Antarctic Peninsula and Enderby Land (Supplementary Fig. C.7c). AR frequency remains high in the spring (SON) with regional areas of AR frequency maxima near Neumayer and Davis stations in a pattern that is similar to the fall (MAM, Supplementary Fig. C.7d).

Given the dependence between ARs and extra-tropical cyclones, the AR frequency patterns around Antarctica look similar to the cyclone density from a cyclone tracking algorithm (Simmonds et al. [2003]; Uotila et al. [2013]). However, while the highest cyclone density is generally found nearby the Antarctic coast, the highest AR frequency occurs further north in the Southern Ocean. This is expected, as ARs generally occur in a highly amplified jet pattern and are defined by the meridional transport of water vapor that originates further north compared to standard cyclogenesis, which typically occurs in a more zonal jet pattern (Chen et al. [2015]; Wille et al. [2019]).

\subsection{Atmospheric river precipitation contribution}

\subsubsection{Mean snowfall}

Despite the rare occurrence of ARs across Antarctica, they have a disproportionately large impact on the snowfall budget in East Antarctica. ARs are responsible for $20-30 \%$ of annual snowfall across a broad swath of East Antarctica, as calculated using the snowfall attribution technique detailed in the methodology (Fig. 5.3a). The highest percentages ( $30 \%)$ are found in small pockets across Dronning Maud Land and a region near the southern extent of the Amery Ice Shelf, although the southernmost part of the Amery Ice Shelf receives less snowfall compared to other regions across Antarctica with high AR activity (Fig. 5.3b). Across West Antarctica in Marie Byrd Land, AR activity is less influential with lower percentages ( $10 \%)$ compared to East Antarctica. When using the AR climatology from the ERA-5, very few differences in snowfall percentages appear compared against the MERRA-2 which has slightly lower AR-related snowfall amounts east of the Amery Ice Shelf and on the southwestern Antarctic Peninsula ( $3 \mathrm{cmWE} \mathrm{yr}^{-1}$; Supplementary Fig. C.8). There is little variation in AR snowfall attribution across the seasons (Supplementary Fig. 
C.9). Although, there are a few small exceptions, such as Adélie Land, where ARs have a slightly smaller impact on the total snowfall budget in the summer (DJF; max percentage $\sim 20 \%$ ) compared to the winter (JJA; max percentage $\sim 30 \%$. Meanwhile in Dronning Maud Land, ARs are most impactful in the summer (DJF; 30-40\%) and have the smallest AR snowfall percentage in fall (MAM, 20-30\%).
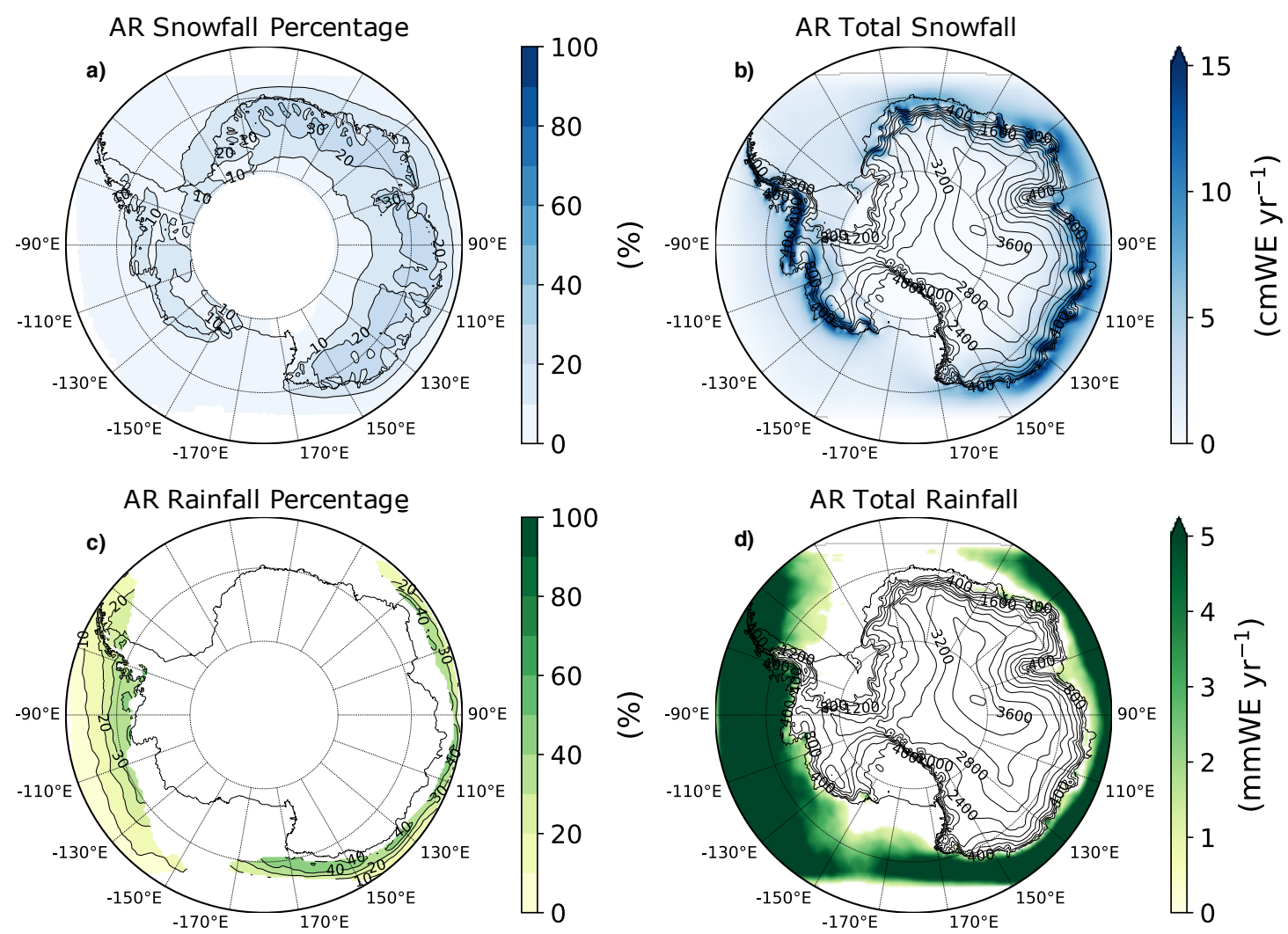

Figure 5.3: The percentage of the total a) snowfall and c) rainfall that can be attributed to AR landfalls and the AR-related accumulated b) snowfall and $\mathbf{d}$ ) rainfall simulated by MAR from 1980-2018 using the precipitation attribution method described in the methodology. For c), areas with annual rainfall less than $5 \mathrm{~mm} \mathrm{yr}^{-1}$ are not considered.

\subsubsection{Mean rainfall}

While ARs influence the total snowfall budget more in East Antarctica than in West Antarctica, the reverse is true in regard to the total rainfall budget. Along the coastline of the Amundsen and Bellingshausen Seas where rainfall amounts exceed $5 \mathrm{~mm}$ per year, ARs are responsible for $30-50 \%$ of the total rainfall over several ice shelves along the western Antarctic Peninsula (Fig. 5.3c and 5.3d). These results are 
in agreement with the previous rainfall analysis from Wille et al. [2019]. As ARs are the primary transport mechanism for heat transport from the tropics and high liquid water content clouds onto the Antarctic continent, it is of little surprise they have a larger fingerprint in rainfall events compared to snowfall events. Yearly rainfall amounts are negligible across most of the remaining Antarctic continent, however just offshore of the East Antarctic coastline ARs are responsible for 20-40\% of total rainfall (Fig. 5.3c).
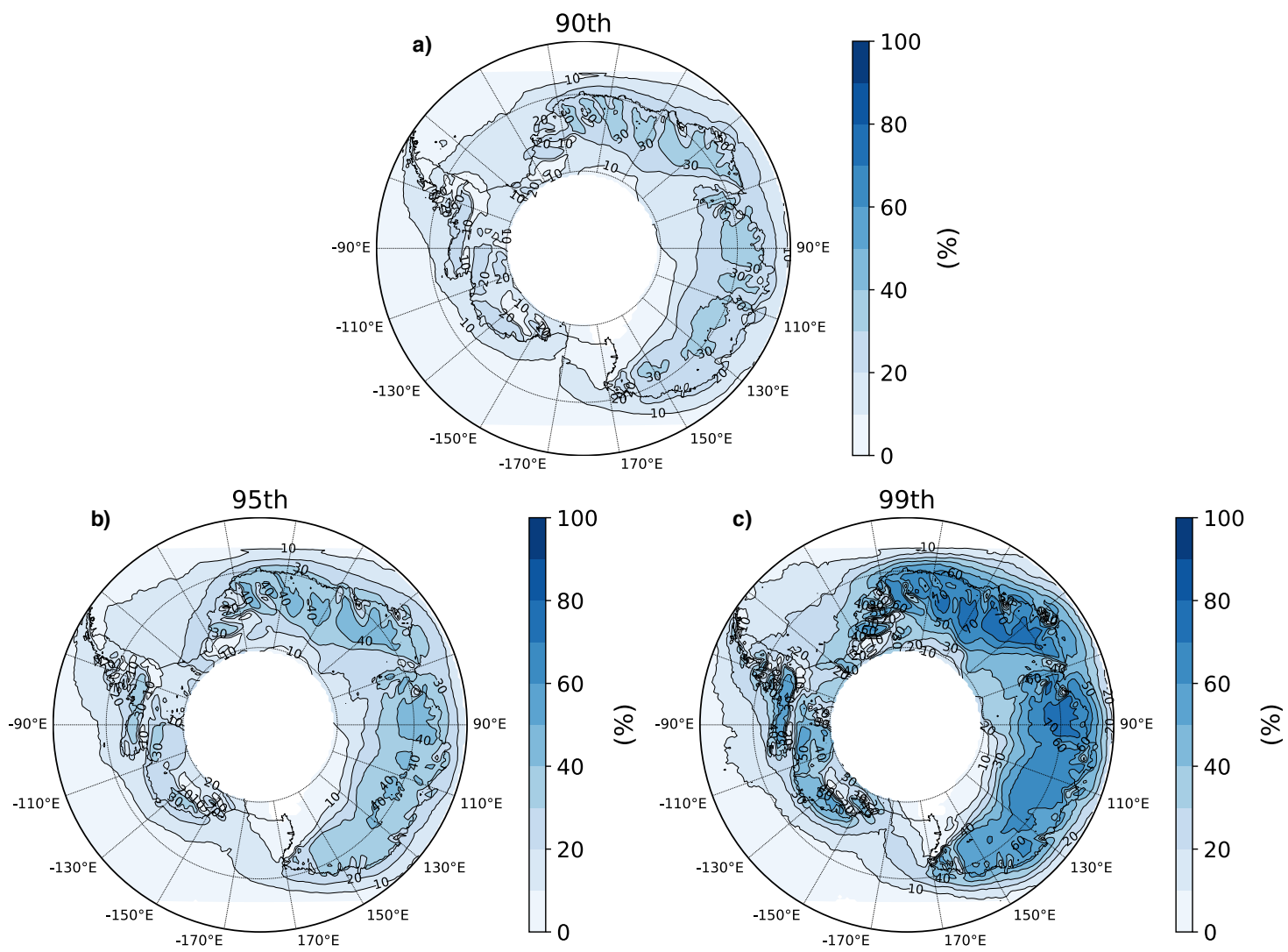

Figure 5.4: AR high precipitation event (HPE) attribution. The percentage of precipitation that can be attributed to AR landfalls when all 3-hourly precipitation outside the a) 90th percentile b) 95th percentile, and c) 99th percentile is removed from the precipitation total from 1980-2018.

\subsubsection{High precipitation events}

Turner et al. [2019] examined the role of extreme precipitation events (EPEs) in snowfall variability across Antarctica and suggested that ARs may represent some of these EPEs. To test how often ARs were responsible for EPEs, we compounded precipitation values that were within the 90th, 95th, and 99th percentile of all 3-hourly 
precipitation from 1980-2018. Overlaying these precipitation events with AR occurrence gives insight in the ratio of EPEs explained by ARs. Within all the EPE percentiles, the precipitation percentage patterns are similar to the snowfall percentages with ARs being responsible for more EPEs in East Antarctica than West Antarctica (Fig. 5.4 and Fig. 5.3a). Generally, the maximum EPE percentage in West Antarctica is 10 percentage points less than the maximum in East Antarctica. Across East Antarctica, the percentage of EPEs attributed to ARs is around 25-35\%, 35-45\%, and 60-70\% when using an EPE threshold of 90, 95, and 99 respectively (Fig. 5.4). Therefore, ARs often represent the most intense snowfall events across large portions of Antarctica.

\subsection{Atmospheric river and snowfall trends}

\subsubsection{Annual trends}

Across most of Antarctica, AR frequency has increased since 1979 as demonstrated in Wille et al. [2019]. Here we show a greater nuance and spatial variability in this result. Indeed, from 1980-2018, AR activity has increased over most of the Southern Ocean and Antarctic continent, with the greatest increasing trends occurring over the Amundsen-Bellingshausen sea and into West Antarctica, and over the Southern Indian Ocean extending down into Dronning Maud Land and Enderby Land (Fig. 5.5c). The only region with a significant decrease is Wilkes Land around Law Dome and further inland. The trends in the ERA-5 AR catalog show a smaller increasing trend over West Antarctica and the Amundsen-Bellingshausen sea, but continues to have a statistically significant increasing trend in Dronning Maud Land and Enderby Land (Supplementary Fig. C.10). To further examine the temporal evolution of these trends and put them in the context of previous teleconnection research, we broke down the trends into two periods, 1980-1999 and 2000-2018. In the first half of the reanalysis period from 1980-1999, there was a widespread decreasing trend in AR frequency in the Ross Sea and the entirety of East Antarctica (Fig. 5.5a). Only by Neumayer station was there a large increase in AR frequency. Since 2000, the overall trend reversed with more regions like the Ross Sea and Dronning Maud Land showing increases in AR frequency (Fig. 5.5b). Like in the trend for the entire 1980-2018 period, the greatest decrease in AR frequency is found in the region surrounding Law Dome 

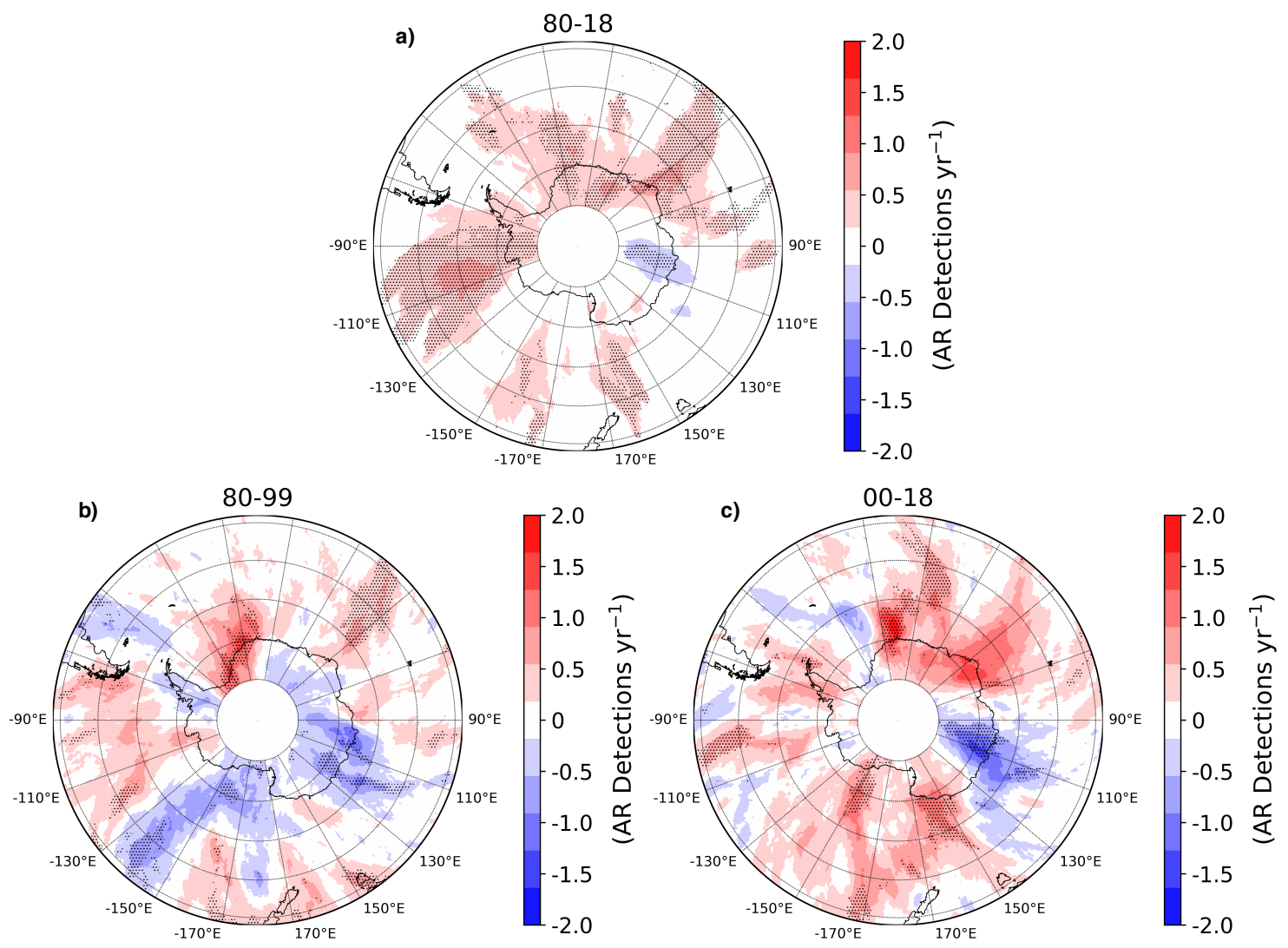

Figure 5.5: The trends in annual AR frequency measured by detections per year for a) 1980-1999, b) 2000-2018, and c) 1980-2018. Black circles represent areas of significant trends ( $\mathrm{p}$-value $<0.025)$.

in Wilkes Land. Overall, the negative trend in Wilkes Land appears less prominent in the entire study period 1980-2018, compared to the separate trends from 1980-1999 and 2000-2018. From looking at individual trends in this region and the results from Wille et al. [2019], this likely resulted from a couple years of exceptional frequent AR activity in 2001 and 2002 followed by less active years.

\subsubsection{Seasonal trends}

The AR frequency trends for 1980-2018 become more varied when broken down by seasonality (Supplementary Fig. C.11). In Enderby Land, significant positive trends appeared in JJA and SON while to the east in Dronning Maud Land the highest positive trends occurred in MAM. Across the Antarctic Peninsula and parts of West Antarctica, significant positive trends were prominent in the shoulder seasons of MAM and SON. Meanwhile the highest negative trend in Wilkes Land occurred during MAM. 


\subsubsection{Simulated MAR snowfall trends}

Upon seeing the trends in AR occurrence, we examine if these trends imprint onto other trends in precipitation across Antarctica. Using MAR snowfall data, we show there are noticeable trends in snowfall accumulation across Antarctica, some significant, during the three periods used in Fig. 5.5 (1980-1999, 2000-2018, and 19802018). From 1980-2018, there have been significant increases in snowfall across portions of the Dronning Maud Land and Enderby Land and the western Antarctic Peninsula ( $\sim 5 \mathrm{mmWE} \mathrm{yr}^{-1}$; Fig. 5.6a). Meanwhile, annual snowfall decreased significantly along the Amundsen Sea coast and coastal parts of Wilkes Land. When breaking down the study period into two time periods, the same aforementioned significant trends appear for both time periods. However, the snowfall trends in Wilkes Land, Enderby Land, Dronning Maud Land, and the western Antarctic Peninsula are more amplified for 2000-2018 (Fig. 5.6b and 5.6c). These trends in the 2000-2018 period in East Antarctica are very similar to the SMB anomalies observed in RACMO2 from 2003-2012, especially the negative SMB anomalies in Wilkes Land and the positive SMB anomalies in Dronning Maud Land (Lenaerts et al. [2013]). Plus, heavy snowfall accumulation over a large spatial extent like observed during ARs is more likely to result in local SMB increases than light snowfall (Souverijns et al. [2018]). The negative snowfall trend in Wilkes Land for 1980-1999 also appears reminiscent of the snowfall trends resolved from ice cores for 1957-2000 (Medley and Thomas [2019]). It is important to note the snowfall trends with regional climate simulations forced by various reanalysis products become more similar after 2000 (Agosta et al. [2019]). Breaking down the 1980-2018 trends into seasonality reveals a few interesting details. The decreasing snowfall trend in Wilkes Land is highest during JJA (Supplementary Fig. C.12c) while the decreasing trend along the Amundsen Sea Coast is strongest during MAM and JJA (Supplementary Fig. C.12b and C.12c).

\subsubsection{Comparing snowfall and AR trends}

When comparing trends in AR-related snowfall against total snowfall trends (Fig. 5.7), it appears quite clear that the positive trends in AR occurrence in Dronning Maud Land and Enderby Land are mostly driven by the corresponding increasing frequency of AR activity (Fig. 5.5 and Fig. 5.6), especially when taking into account 
trends in AR-related annual snowfall (Fig. 5.7). The maximum trend in AR-related

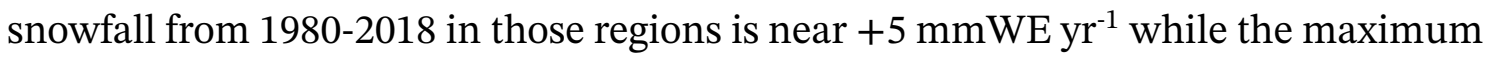
trend in total snowfall reaches +7 to $+8 \mathrm{mmWE}^{-1}$ (Fig. 5.7a). Meanwhile, the negative AR trends in Wilkes Land appear related to the corresponding decreasing trends in AR occurrence. Similar snowfall trends for total snowfall and AR-related snowfall appear for the 1980-1999 and 2000-2018 periods ( -7 to $-8 \mathrm{mmWE} \mathrm{yr}^{-1}$, Fig. 5.7b and 5.7c), however a much smaller trend for both is seen for 1980-2018 (Fig. 5.7a). Like the AR frequency trends, a couple years of exceptional AR-related snowfall in Wilkes Land during the early 2000s skews the 1980-2018 trend more positive while creating a more negative trend for 2000-2018. The snowfall trends along the western Antarctic Peninsula are more complicated. A significant trend is evident in AR related snow-

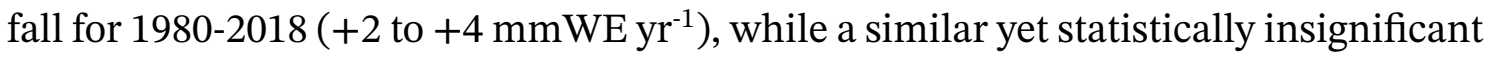
trend appears for all snowfall. Elsewhere, the significant decreasing total snowfall trend along the Amundsen Sea coast is seemingly unrelated to changes in AR activ-
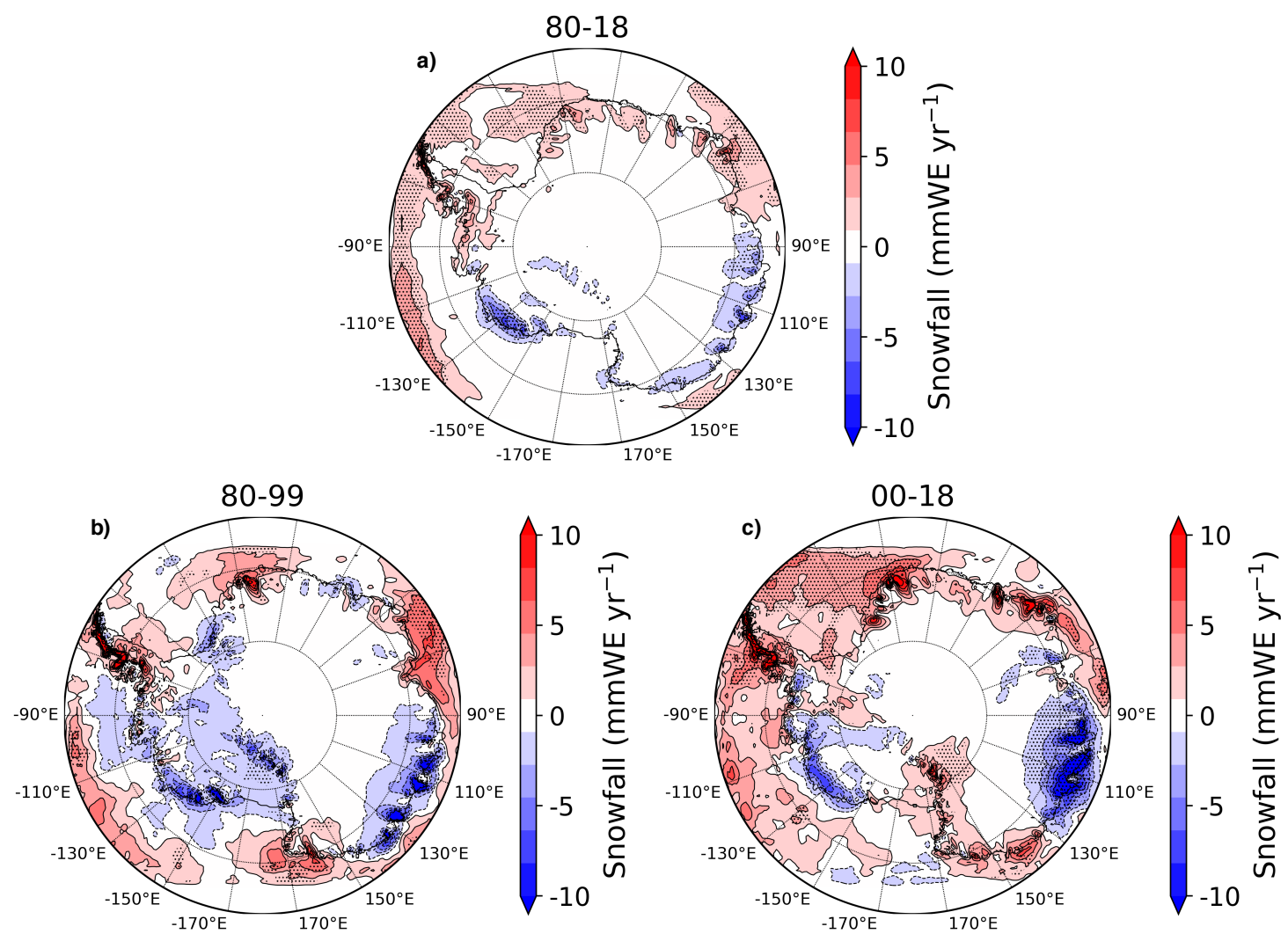

Figure 5.6: Trends in annual accumulated snowfall simulated by MAR for a) 19801999, b) 2000-2018, and c) 1980-2018. Black circles represent areas of significant trends ( $\mathrm{p}$-value $<0.025$ ). 


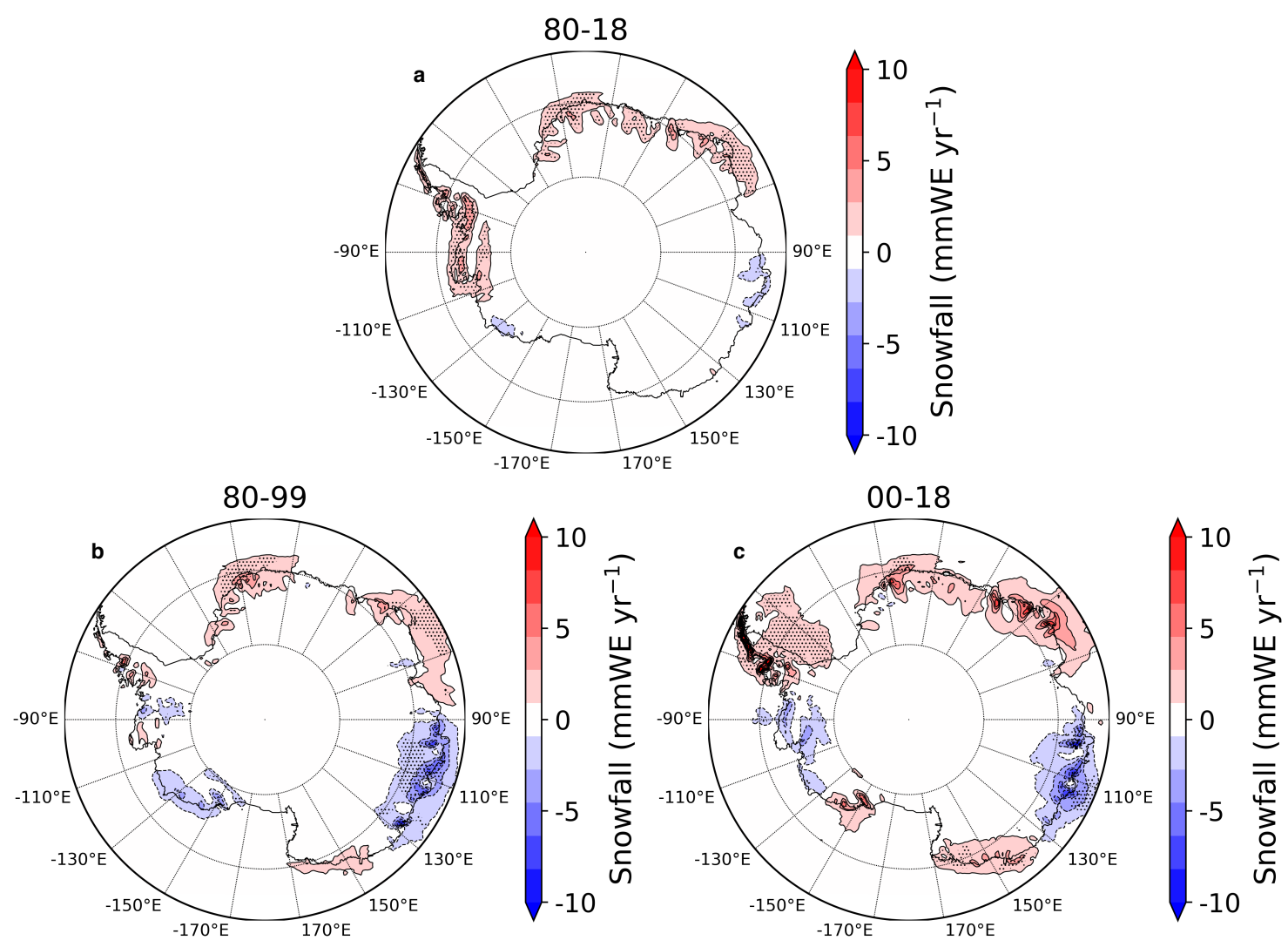

Figure 5.7: Trends in annual accumulated snowfall simulated attributed to AR landfalls (see Fig. 5.3) for a) 1980-1999, b) 2000-2018, and c) 1980-2018. Black circles represent areas of significant trends ( $\mathrm{p}$-value $<0.025$ ).

ity as there is a small and not statistically significant decreasing trend in AR-related snowfall although there is a significant decreasing trend in AR frequency according to ERA-5 (-0.5 AR detections per year; Supplementary Fig. C.10a). On a seasonal scale, the positive trends in AR occurrence and AR-related snowfall (not shown) are similar to the positive trends in snowfall in the Dronning Maud Land and Antarctic Peninsula region for MAM and SON 1980-2018 (Supplementary Fig. C.11 and C.12). The large decreasing trend in snowfall seen in JJA over the Wilkes Land area does not appear to be significantly reciprocated in the JJA AR and AR-related snowfall trends.

\subsection{Atmospheric river interannual variability and precipitation}

\subsubsection{Atmospheric river variability}

While a few regions in Antarctica exhibit notable trends in AR frequency, Wille et al. [2019] demonstrated that there is a large amount of interannual variability 
for ARs across most of Antarctica. This is quantified in this analysis where the standard deviation of annual AR frequency from 1980-2018 is around 20 AR detections or about 2.5 days over Enderby and Dronning Maud Land (Fig. 5.8c). The high variability over Enderby Land is the product of unprecedented AR activity in this region during 2009 and 2011 (Gorodetskaya et al. [2014]). Around the rest of coastal Antarctica, the standard deviation is around 15 AR detections per year. While there are appreciable trends in AR frequency across the continent, the inter-annual variability in AR frequency is a far more prominent signal.

\subsubsection{Impact of ARs on snowfall interannual variability}

While ARs appear to control long-term snowfall trends in certain portions of Antarctica, they control the inter-annual variability of snowfall basically across most of the ice sheet. After removing the trends from both datasets, the annual AR occurrence and annual snowfall accumulation across East and parts of West Antarctica are significantly positively correlated from 1980-2018 (Fig. 5.8a). On a seasonal scale, the strongest relationship between ARs and snowfall occurs during JJA where nearly most of the Antarctic continent has a significant correlation (Supplementary Fig. C.13c), but widespread high correlations exist in the other seasons as well. During winter, a positive relation appears on the western side of the Antarctic Peninsula while a negative correlation appears on the eastern side. This is likely reflective of the fact that most ARs make landfall on the western side of the Peninsula and create a precipitation shadow on the other side of the mountain range. There is little difference in the correlation of AR frequency and annual snowfall when comparing the ERA-5 AR catalog against the MERRA-2 AR catalog (not shown).

\subsubsection{Impact of ARs on rainfall interannual variability}

There are small areas of significant anticorrelations between AR activity and snowfall over the South Pacific Ocean (Fig. 5.8a and Supplementary Fig. C.13). This implies that the prevalence of ARs and the associated warm air advection over the ocean reduces the likelihood of snowfall. When looking to see if this connection extends to rainfall, we see that the inter-annual variability of rainfall (where climatological yearly rainfall values exceeds $5 \mathrm{mmWE}$ yr-1) is significantly positively correlated to 


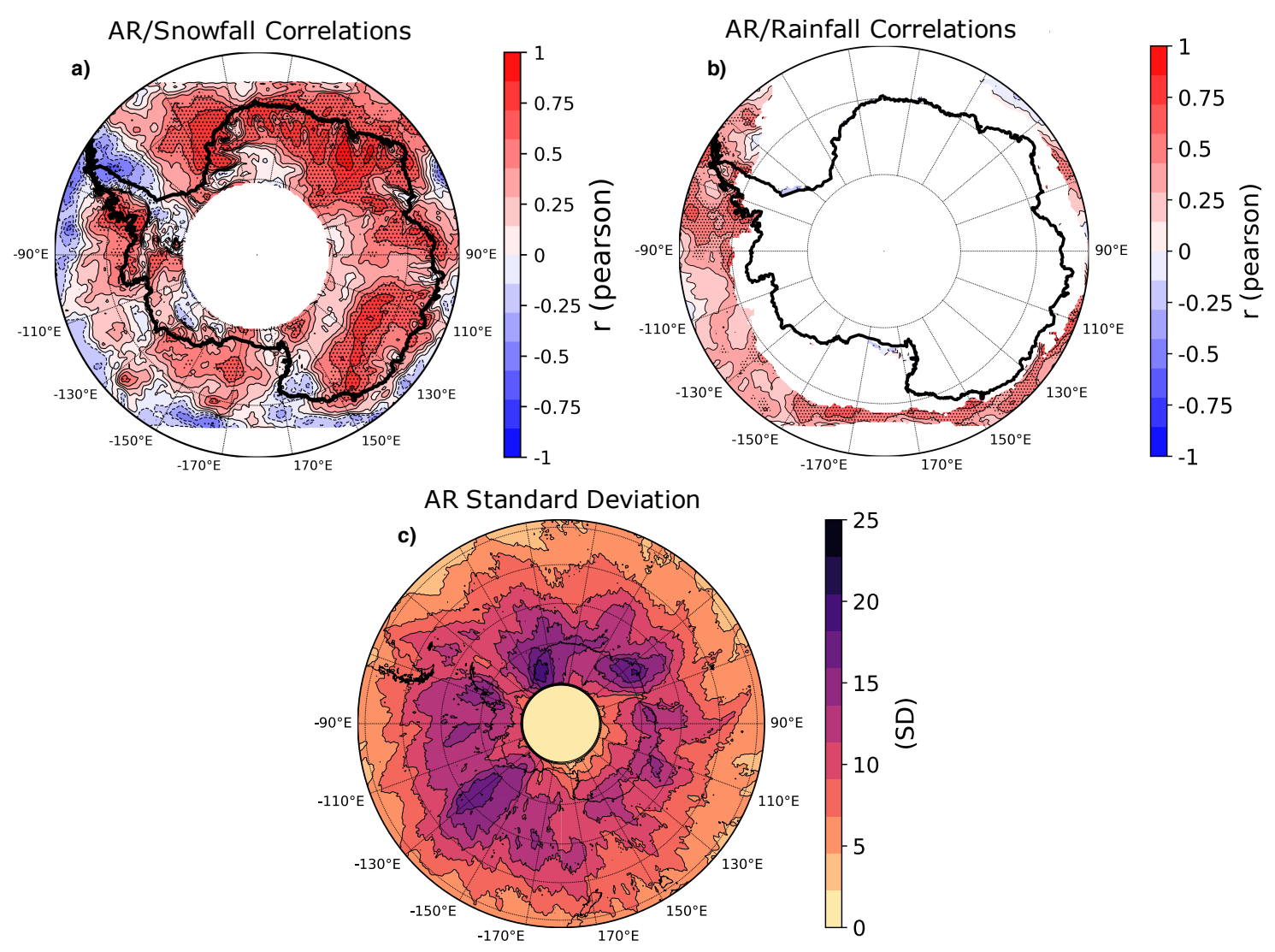

Figure 5.8: The Pearson's correlation coefficient (r-values) between annual AR frequency and a) total annual snowfall accumulation and b) total annual rainfall from MAR for 1980-2018. Areas with less than $5 \mathrm{~mm}$ of annual rainfall are not considered for b). Black circles represent areas of significant correlations ( $\mathrm{p}$-value $<0.025$ ). c) The standard deviation in annual 3-hourly AR occurrences from 1980-2018. All datasets are detrended.

AR occurrences across most of the offshore regions from Wilkes Land extending eastward across the Southern Ocean to the northern Antarctic Peninsula for 1980-2018 (Fig. 5.8b).

\subsection{ARs and blocking behavior}

\subsubsection{AR geopotential height anomalies}

We established that ARs have a major impact on the inter-annual variability and trends of precipitation across Antarctica, so now we look at what controls AR variability across Antarctica. Wille et al. [2019] showed that AR landfalls across Antarctica are accompanied by a blocking ridge upstream of the landfall location. A 
composite of the $500 \mathrm{hPa}$ geopotential heights of all AR landfalls in Antarctica from 1980-2018 shows a broad area of positive height anomalies over the continent with maximums over the Antarctic Peninsula and East Antarctica (Fig. 5.9). Meanwhile, negative height anomalies are seen in a circular band from $40^{\circ} \mathrm{S}-50^{\circ} \mathrm{S}$. Seasonally, the highest positive anomalies associated with AR landfalls occur during MAM while the lowest are in DJF (Supplementary Fig. C.14a and C.14b). During JJA, three distinct positive anomaly maxima occur around the Antarctica Peninsula, Wilkes Land, and Dronning Maud Laud (Supplementary Fig. C.14c). The upper level height patterns suggest that an enhancement of the wavenumber-3 pattern promotes increased AR landfalls in every season although this appears less obvious during summer (Supplementary Fig. C.14a; Cai et al. [1999]). Similar 500 hPa geopotential height anomalies are seen when using AR landfall dates from the ERA-5 AR catalog (not shown).

\subsubsection{Blocking index}

To better understand atmospheric blocking around Antarctica, we use a blocking index as described in the methodology to quantify the magnitude of blocking associated with AR landfalls. In general, AR landfalls are associated with an atmospheric blocking strength that is generally 30-60 $\mathrm{m}$ higher than the background blocking index for all months (Fig. 5.10a). The degree of blocking observed during an AR landfall is highest during the winter and lowest during the summer while the background blocking index follows the same pattern. The difference between the blocking index for AR landfalls and the climatological background could potentially be useful as a predictive index on synoptic timescales. Compiling the observed blocking index for all AR landfalls against the monthly climatological blocking index shows that the probability of an AR landfall increases as the blocking index increases (Fig. 5.10b). When the blocking index is greater than $200 \mathrm{~m}$, there is a $\sim 40 \%$ probability of an AR landfall in Antarctica. As a potential AR forecast tool over synoptic time-periods, this blocking index analysis would need to be examined over different regions of Antarctica as the probability of an AR landfall is dependent on the latitude of the coastline (Wille et al. [2019]). 


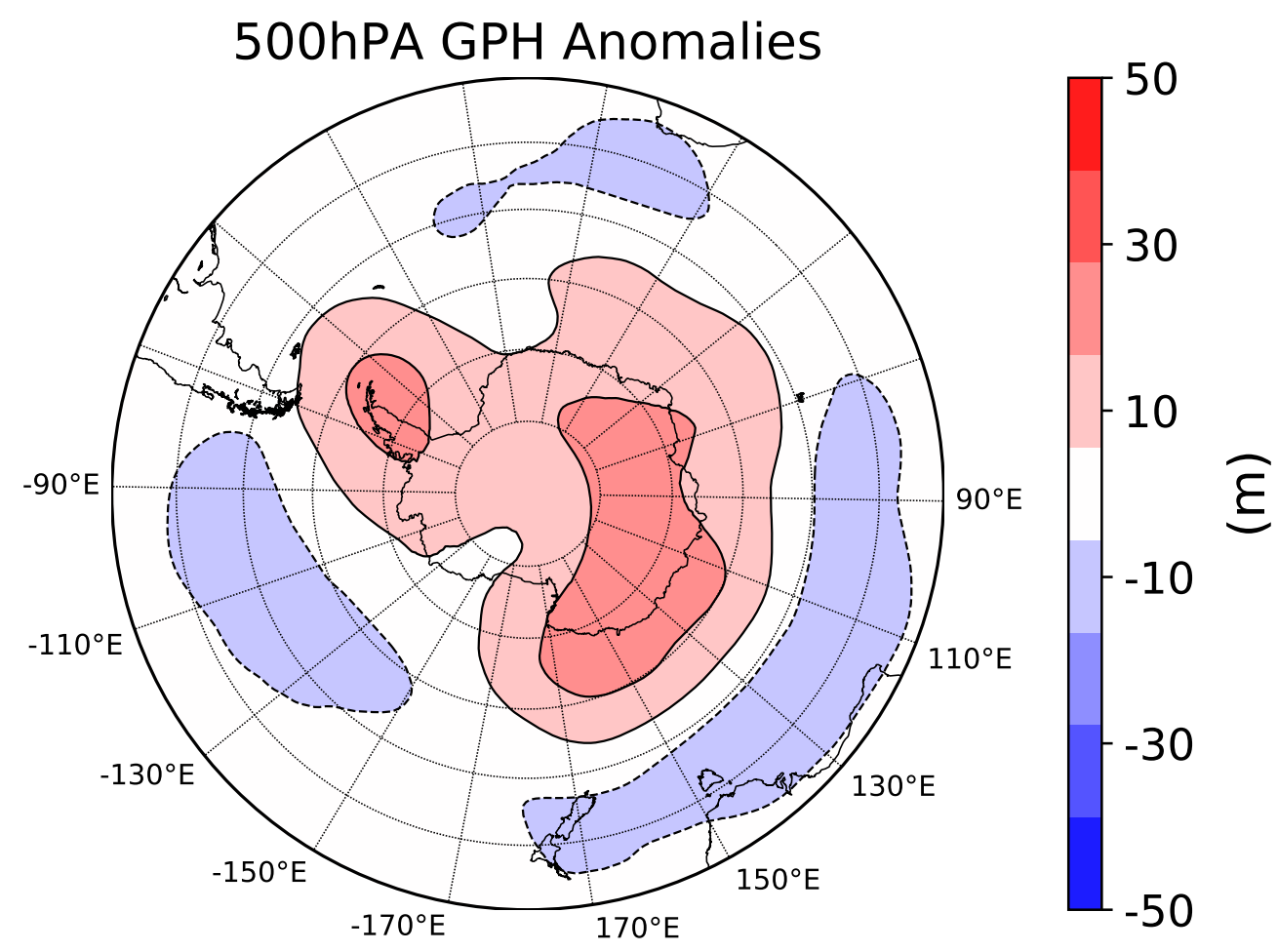

Figure 5.9: Composite MERRA-2 $500 \mathrm{hPa}$ geopotential height anomalies for all $\mathrm{AR}$ landfalls from 1980-2018. Monthly anomalies are with respect to the corresponding 1980-2018 monthly mean and then averaged together for this annual anomaly.

\subsection{ARs and SAM}

\subsubsection{Correlations to SAM}

The zonal distribution of the $500 \mathrm{hPa}$ geopotential height anomalies associated with AR landfalls in Fig. 5.9 resembles the negative phase of the Southern Annual Mode (SAM), which is the leading empirical orthogonal function (EOF) of geopotential height in the southern hemisphere mid-to-high latitudes (Spensberger et al. [2020]; Thompson and Wallace [2000]). Using a detrended Marshall SAM index (Marshall [2003]), we see that AR interannual and SAM interannual variability are significantly correlated in certain areas (Fig. 5.11). From 1980-2018, annual AR variability was significantly correlated to SAM on the western Antarctic Peninsula and anti-correlated around the Amundsen-Ross Sea (Fig 5.11a). These correlations between AR variability and SAM appear highest for 1980-1999 (Fig. 5.11b and 5.11c). 
The ERA-5 AR catalog has a slightly stronger correlation over the Antarctic Peninsula and a slightly weaker yet still significant anti-correlation around the Amundsen-Ross Sea for 1980-2018 (Supplementary Fig. C.15a). Seasonally, the strongest anticorrelation with AR variability and SAM in the Amundsen-Ross Sea region occurred during winter (JJA) for both AR catalogs (Supplementary Fig. C.16c and Supplementary Fig. C.17c), while summer (DJF) actually has a significant positive correlation focused over the Amundsen Sea (Supplementary Fig. C.16a and Supplementary Fig. C.17a). The weakest correlations over the Antarctic Peninsula occurred during summer (DJF). Outside of West Antarctica, a slight significant correlation between AR interannual variability and SAM for 1980-2018 is evident east of the Amery Ice Shelf that is stronger when using the ERA-5 catalog (Fig. 5.11a; Supplementary Fig. C.15a). On seasonal scales, a significant anticorrelation appears in both catalogs during MAM in Dronning Maud Laud and during SON in the western Ross Sea although the latter area also has the lowest AR frequency (Supplementary Fig. C.16b, C.16c; Supplementary Fig. C.17b, C.17c; Fig. 5.2).

\subsubsection{Teleconnection impacts on ARs}

The overall anticorrelation implies that SAM- (westerly winds expanded towards the equator) is more conducive for ARs to reach Marie Byrd Land while SAM+ (westerly winds contracted towards Antarctica) increases the likelihood of ARs reaching the peninsula. Generally, SAM- is related with a weaker Amundsen Sea Low (ASL) and shifts the ASL southward, increasing the amplitude of the polar jet and allows for more atmospheric blocking and moisture intrusions onto the continent (Scott et al. [2019]; Turner et al. [2013]). Although if the ASL strength is defined using relative central pressure instead of absolute central pressure (Hosking et al. [2013]), then the link to SAM is diminished (Donat-Magnin et al. [2020]). SAM+ is associated with enhanced moisture fluxes towards the Antarctic Peninsula accompanied by a more eastbound storm track related to the strengthening of the circumpolar westerlies (Lubin et al. [2008]; Marshall et al. [2017]). Beyond the SAM, the reversal of a negative to positive trend from 1980-1999 to 2000-2018 in the Ross Sea matches the trend in increasing blocking activity after 2000 observed in Scott et al. [2019] (Fig. 5.5a and 5.5b). Still the correlations between SAM and AR frequency is not very robust outside of West 


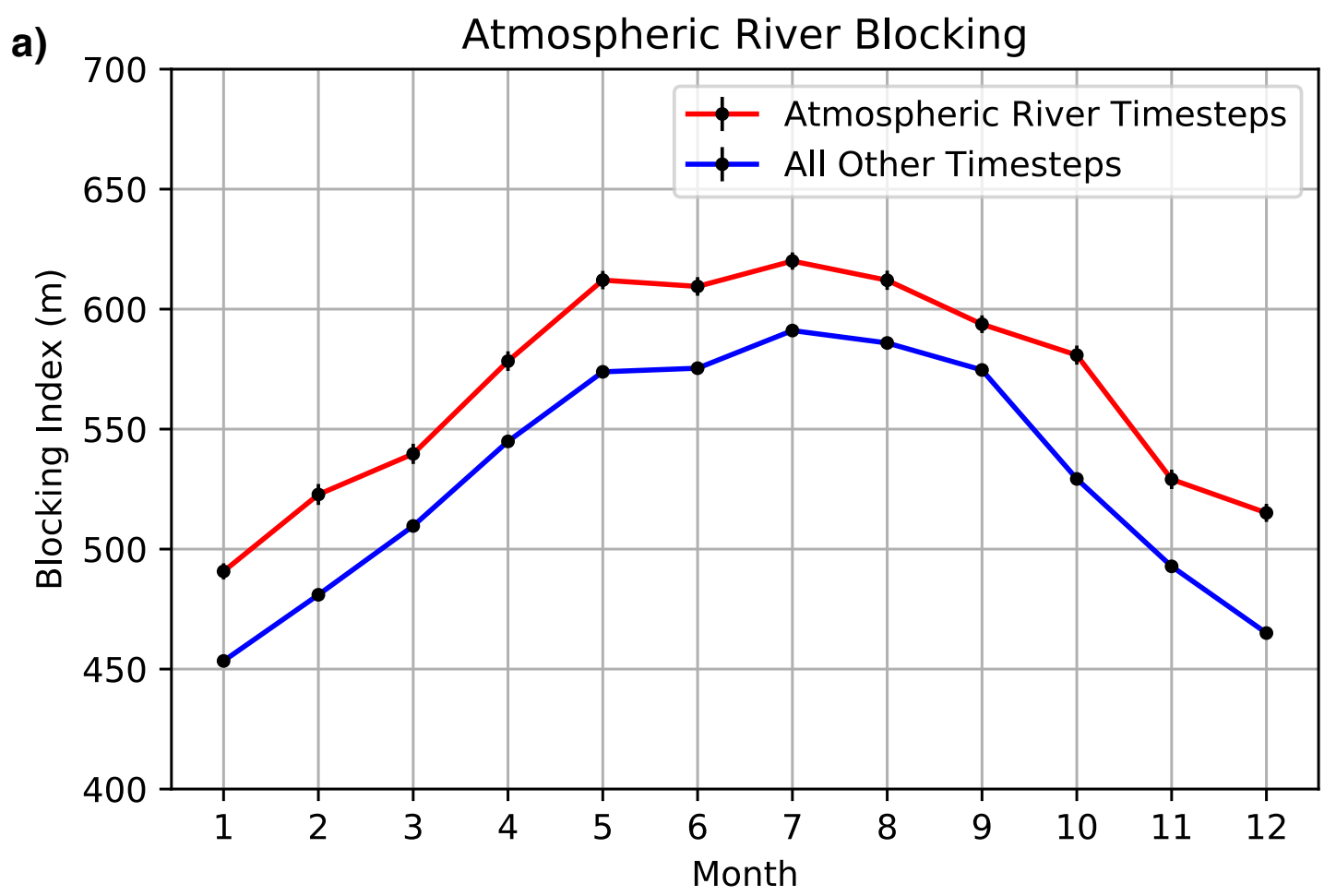

b)

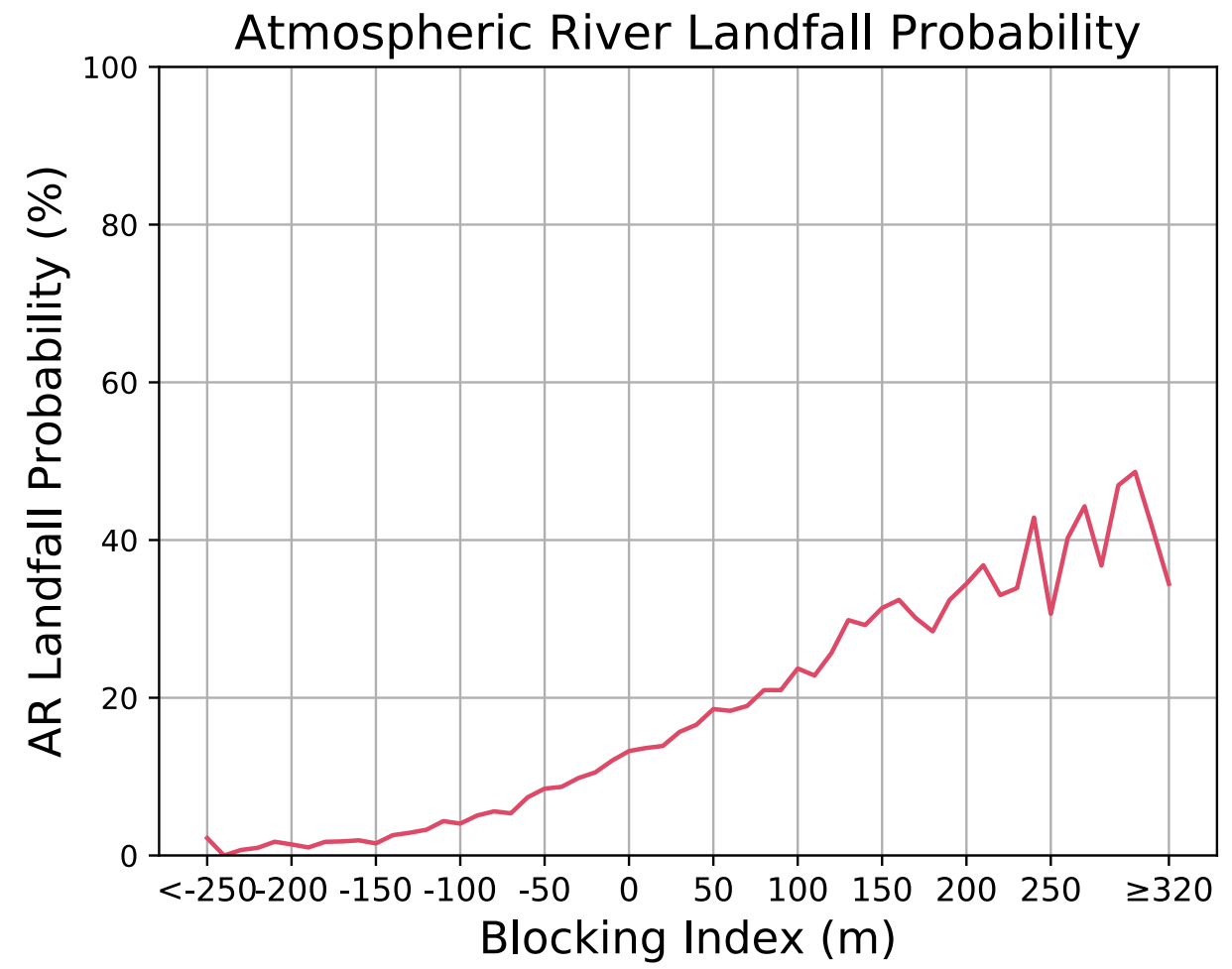

Figure 5.10: a) The average monthly blocking index during AR landfalls (red line) and all other timesteps (blue line). b) The probability of an AR landfall in Antarctica based on the value of the blocking index (red line - blue line). The description of the blocking index is found in the Methods (Section 2.5). 
Antarctica and further research is needed to properly understand the SAM/AR relationship, plus other teleconnections like the El Niño-Southern Oscillation (ENSO) which may influence blocking around West Antarctica (Scott et al. [2019]). Idealized model simulations would be an appropriate method for future studies to better understand these processes.

\section{Discussion and conclusions}

Using ARs to study moisture transport unites much of the existing literature on "moisture intrusions" in Antarctica into a common framework. ARs are defined by relatively consistent meteorological parameters involving moisture transport embedded within synoptic scale extra-tropical cyclones, so using the AR terminology can make descriptions of moisture intrusions more consistent. The detection algorithm utilized in this study detected ARs that led to high precipitation events in Dronning Maud from 2003-2006 (Schlosser et al. [2010]), record warmth at Dome Fuji in June 1997 (Hirasawa et al. [2013]), the advection of high moisture isotopes into East Antarctica (Kurita et al. [2016]; already described as an AR), and record melting and precipitation in Marie Byrd Land (Nicolas et al. [2017]; Wille et al. [2019]).

Previous to this study, the only climatology of ARs nearby Antarctica came from a global AR detection algorithm (Guan and Waliser [2015]). This algorithm showed a higher frequency of ARs in the Southern Ocean compared to the climatology presented here, although this global algorithm uses methods that induce a strong positive latitudinal dependence compared to other regional detection methods ( $R u t z$ et al. [2019]). Regional AR detection algorithms designed for polar regions are advantageous for the higher latitudes as they can account for the reduced moisture capacity of the polar atmosphere (Gorodetskaya et al. [2014]; Guan and Waliser [2015]; Mattingly et al. [2018]; Wille et al. [2019]).

ARs represent short-term extreme weather events that have significant impacts on large term melting trends (Wille et al. [2019]), and as we show here, the precipitation budget. Due to the short life span of an AR event, their impacts on the SMB are often missed when focusing on changes in the mean climate. By creating a climatology of ARs around Antarctica, we establish their impacts on the trends and variability of precipitation while highlighting the external forcings and teleconnections 
that control AR behavior. We show that while ARs contribute a modest percentage ( $20 \%)$ of the annual snowfall across the Antarctic ice sheet, this sum drives positive and negative snowfall trends in East Antarctica and controls the inter-annual variability of snowfall across most of the continent since 1980. In addition, $70 \%$ of the highest $1 \%$ of precipitation events can be attributed to ARs across East Antarctica, connecting ARs to high precipitation events (HPEs) shown to control the inter-annual variability of snow accumulation (Turner et al. [2019]).

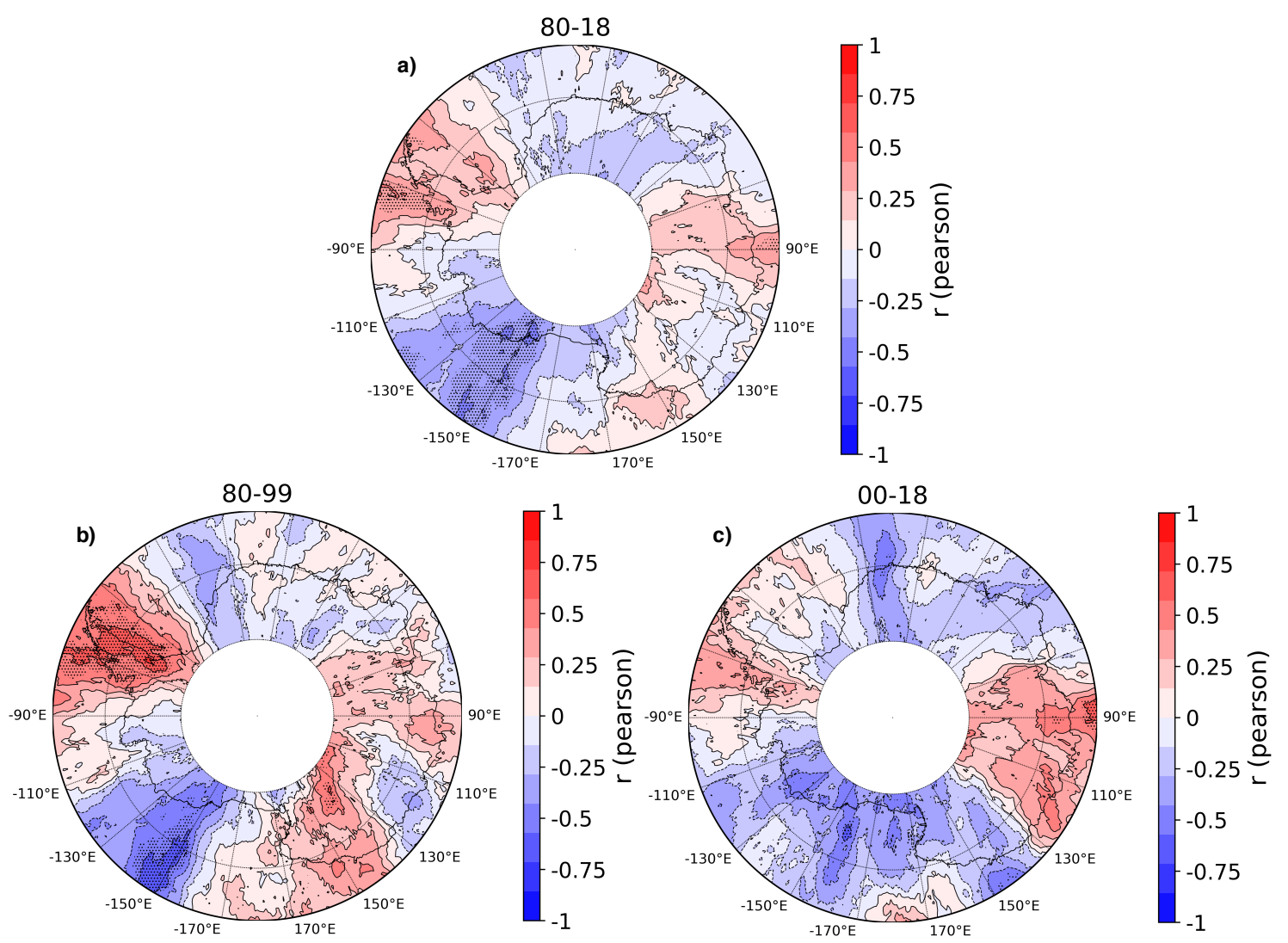

Figure 5.11: The Pearson's correlation coefficient (r-values) between annual AR frequency and annually averaged Marshall SAM index for a) 1980-1999, b) 2000-2018, and c) 1980-2018. Black circles represent areas of significant correlations (p-value < $0.025)$ and both datasets are detrended.

The polarity of the SAM appears related to AR occurrences through the relationship between SAM and the ASL. A positive (negative) SAM phase deepens (weakens) the ASL and shifts its position to direct the storm track towards (away) the Antarctic Peninsula (Amundsen-Ross Sea coast) (Turner et al. [2013]). Atmospheric blocking serves as the main control mechanism for AR landfalls, and the $500 \mathrm{hPa}$ geopotential height patterns favorable for AR landfalls resemble the SAM- which has been 
shown to favor blocking patterns over West Antarctica (Scott et al. [2019]). However, the higher velocity zonal winds often observed during SAM+ do not preclude an increased jet amplitude and blocking as observed during a series of intense AR landfalls in Marie Byrd Land in January 2016 (Nicolas et al. [2017]). Further research is necessary to properly understand how SAM, tropical forcings, and sea surface temperature variations interact to create blocking patterns conducive for AR landfalls, especially in East Antarctica where the AR relationship with SAM appears less clear.

A warming climate implies a greater saturation vapor pressure via the ClausiusClapeyron relationship and thus a greater snowfall potential over the Antarctic ice sheet that could offset some sea level rise from dynamic ice loss (Ligtenberg et al. [2013]; Petit et al. [1999]). Understanding atmospheric circulation changes in a moister atmosphere are essential for future climate projections, but these are not well captured in model simulations (Fudge et al. [2016]). Our study suggests that AR variability drives many of the Antarctic mass balance changes which are likely not being resolved in climate models. As AR frequency and intensity are predicted to increase in the Southern Ocean in future climate projections, it is paramount for climate simulations to capture changes in extreme weather patterns like ARs to accurately predict the future of the Antarctic ice sheet.

\section{Acknowledgments and Data}

We thank Ambriose Dufour for his assistance in developing the first version of the AR detection algorithm. This study is part of the PhD project of J. D. W. conducted at the Université Grenoble Alpes. The Authors acknowledge the support from Agence Nationale de la Recherche, projects ANR-14-CE01-0001 (ASUMA), ANR-16CE01-0011 (EAIIST), ANR-15-CE01-0005-01 (TROIS AS) and ANR-15-CE01-0015 (ACAHC2). I. V. G. thanks FCT/MCTES for the financial support to CESAM (UID/AMB/50017/2019), through national funds. CA acknowledges the support from Fondation Albert 2 de Monaco under the project Antarctic-Snow (2018-2020). Computational resources have been provided by the Consortium des Équipements de Calcul Intensif (CÉCI), funded by the F.R.S.-FNRS under grant no. 2.5020.11. MERRA-2 vIVT and IWV was compiled and distributed by members of ARTMIP (Atmospheric River Tracking Method Intercomparison Project). The code for the AR detection algo- 
rithm discussed in this paper is available at https://doi.org/10.5281/zenodo.4009663. The MARv3.10.2 code is available on http://mar.cnrs.fr and the 3-hourly $35 \mathrm{~km}$ outputs are available upon request. ERA-5 data produced by ECMWF are available through the Copernicus Climate Data Store. The Marshall Southern Annual Mode (SAM) index is available at (https://legacy.bas.ac.uk/met/gjma/sam.html). The manuscript was primarily written in the small village of Stiappa, Tuscany while being graciously hosted by Ugo Nanni. 


\section{Chapter 6}

\section{Conclusions and perspectives}

\subsection{Conclusions}

In order to better understand moisture transport towards the Antarctic continent and the associated impacts on the surface mass balance (SMB), I developed a polar-oriented AR detection algorithm and utilized the MAR regional climate model to create a detailed climatology of AR behavior and AR-related impacts on the Antarctic for the past 40 years. We established atmospheric rivers (ARs) as a crucial mechanism of poleward mass transport with major implications for Antarctic melt, ice-shelf stability, and snowfall processes. The results proposed in this thesis further our understanding Antarctic SMB influences, working towards the overarching goal of constraining future sea level rise projections.

First ARs were linked with the occurrence of widespread melt events across West Antarctica. Using the AR detection algorithm and MAR, we found that ARs were responsible for 30-40\% of observed and simulated surface melt on the Ross Ice Shelf and nearly all melting in the higher elevations of Marie Byrd Land. In addition, ARs were causing $40-80 \%$ of the total winter melting along the Wilkins, Bach, George IV, and Larsen ice shelves on the Antarctic Peninsula (AP). The ARs in West Antarctica typically trigger melting conditions through enhanced downward longwave radiative fluxes to the surface in response to clouds of unusually high cloud liquid water content over the ice sheet. Enhanced sensible heat fluxes associated with AR landfalls also drive melt over the Marie Byrd Land, but this effect most pronounced on the Antarctic Peninsula (AP) where there are more regular Foehn winds. Annual AR 
frequency showed a high degree in interannual variability across Antarctica with AR activity controlled by the presence of blocking ridges upstream of the AR landfall location. Still, most summer AR landfalls in West Antarctica don't cause surface melt and major melt events are generally rare occurring once every five years or so. However, a $1-2{ }^{\circ} \mathrm{C}$ warming in the background temperature would make surface melt a regular occurrence during summer AR landfalls along the Ross Ice Shelf with consequences for future ice shelf stability.

While the summer AR-related melting along the Ross Ice Shelf and winter melt along the AP ice shelves are not a major concern for current ice-shelf stability, periods of extreme surface melting on the AP during austral summer AR landfalls are an immediate risk for ice-shelf stability and likely triggered the final collapse of the Larsen A and B ice shelves. We demonstrated that ARs were preconditioning the Larsen ice shelves for collapse through the formation of melt pond formation, a prerequisite for hydrofracturing. Through intense Foehn winds and downward longwave radiative transport, landfalling ARs on the AP were responsible for up to 90\% of temperature occurrences, $\sim 80 \%$ of melt on the ice shelves and nearly all melt on the higher elevation mountainous regions, and $\sim 70 \%$ of runoff on the ice shelves all in the 99.9th percentile of climatological values from 1980-2019. In fact, the past two continental Antarctic high temperature records (March 2015, February 2020), occurred during AR landfalls on the AP. Not all AR landfalls are equal in terms of impacts with the strongest ARs (IVT $>800 \mathrm{~kg} \mathrm{~m}^{-1} \mathrm{~s}^{-1}$ ) generating exponentially more melt and runoff than the weakest when intensity is measured by the maximum integrated vapor transport (IVT) upon landfall. The collapse of the Larsen A ice shelf in 1995 can be traced back to a single historically strong AR landfall while the collapse of the Larsen B in 2002 occurred during a summer of successive AR landfalls of moderatehigh intensity. Overall, 12 out of 20 observed ice shelf calving/collapse events since 2000 were preceded by an AR landfall within five days prior. Beyond intense periods of hydrofracturing, ARs triggered the ice-shelf final collapse via the removal of the sea-ice buffer along the ice shelf margins allowing long-period swells to apply a strain to the ice-shelf front. All the preconditioning and final collapse process related to ARs identified in this study now threaten the stability of the Larsen $\mathrm{C}$ ice shelf and possibly other ice shelves around Antarctica. 
Looking on the other side of AR impacts in Antarctica, the snowfall patterns across the continent behave in concert with changes in AR variability. After developing a method of attributing snowfall to individual AR landfalls and detailing the Antarctic AR climatology, we found that while AR landfalls are rare (typically affecting coastal regions $\sim 3$ days a year), they have an oversized impact on the precipitation budget, trends, and variability. Expanding upon the results in Gorodetskaya et al. [2014] and Turner et al. [2019], ARs are responsible for 20-30\% of snowfall in East Antarctica and a majority of high precipitation events (snowfall rates above the 99th climatological percentile).AR intensity when measured via maximum IVT upon landfall has a positive correlation with AR impacts which in this case is maximum snowfall rates. From 1980-2018, AR frequency has increased in a statistically significant manner across Dronning Maud Land and Enderby Land while decreasing in Wilkes Land near Law Dome. The simulated trends by MAR for annual snowfall accumulation nearly match the trends in AR-related snowfall amounts in Wilkes Land, Dronning Maud Land, Enderby Land, and the southern AP. Also, the interannual variability of snowfall across most of Antarctica is significantly correlated with the interannual variability of AR frequency. A similar correlation exists for rainfall along the western and northern AP. Expanding from the analysis of blocking (Wille et al. [2019]), blocking ridges are an integral component within the atmospheric circulation to direct ARs towards the Antarctic continent. AR landfalls become increasingly more likely as the degree of blocking around Antarctic increases. Finally, a preliminary analysis of the correlation between the Southern Annual Mode (SAM) and AR behavior showed a statistically significant positive correlation between the SAM phase and annual AR frequency along the AP and an anticorrelation around the Marie Byrd Land/Ross Ice Shelf. These correlations appear to occur in response to the SAM's modulation of the Amundsen Sea Low.

The research efforts during this thesis individually studied the impacts of ARs on melting and snowfall patterns, but not the overall contributions to the SMB. The reason for this is primarily because of our current knowledge limitations on AR behavior beyond the Antarctic coastline. The science on AR dynamics is established well enough to confidently track AR objects across the Southern Ocean until the point of landfall. However the challenge will be assessing how GCMs resolve ARs approach- 
ing Antarctica as they interact with the katabatic winds, the persistent polar anticyclone, and topographically induced vorticity compression as the associated cyclone progresses inland (Beaumet et al. [2019]; Krinner et al. [2020]; Krinner and Flanner [2018]; Bromwich [1988]; Hobbs [1915]). Without this understanding and further research, extending the AR detection algorithm closer to the South Pole runs the risk of identifying features that may not meet the AR definition. Thus, without a proper climatology of AR behavior in the Antarctic high latitudes, a complete understanding of AR-related snowfall patterns is currently unavailable, and a continent-wide SMB analysis would be premature. There are currently studies being carried out to further develop AR dynamics over Antarctica which brings us closer to tracing ARs and their associated snowfall across all of Antarctica.

The main take-home message from this thesis is that short-lived and infrequent extreme weather events can leave lasting marks on the Antarctic ice sheet that outweigh any long-term trends in the mean climate. The anomalously high AR-driven snowfall accumulation years of 2009 and 2011 in Dronning Maud Land and the ARassociated collapses of the Larsen A and B ice shelves are good examples of events that are specks on the timeline of Antarctica but have very real lasting effects on the SMB and sea-level rise potential of the ice-sheet. The newest generation of general circulation models (GCMs) in CMIP6 show advances in representing temperature and storm track around Antarctica, but still struggle with depicting precipitation (Priestley et al. [2020]; Roussel et al. [2020]). A major science question going forward is to examine whether GCMs can accurately simulate the statistical distribution of extreme events and then resolve the surface mass balance impacts from those events. Therefore, to obtain a clear idea on future SMB changes on the Antarctic ice-sheet, we must be able to resolve changes in future AR behavior which means determining if ARs are correctly simulated in GCMs.

\subsection{Perspectives}

This PhD project leaves open many exciting scientific questions about ARs in Antarctica, while motivating and informing the recently funded ANR Atmospheric River Climatology in Antarctica (ARCA) project. This ARCA project will allow this 
research to continue moving forward. Inspired from the results in this $\mathrm{PhD}$, the ARCA project looks to further establish an understanding of AR activity in Antarctica for the present, past, and future. As mentioned in the previous section, a complete estimation of the AR impacts on Antarctic-wide SMB is not possible without knowing how ARs behave further into the ice-sheet. Extra radiosondes measurements launched in during the Year of Polar Prediction Special Observing Period (YOPP-SOP) in austral summer 2018-2019 already have highlighted the strength of the moisture transport within the low-level jet (Gorodetskaya et al. [2020]). Further initiatives within YOPP-SH are currently being discussed for more observations during AR landfalls. In addition, recent advances such as an observed vertical decoupling of the moisture transport and low-level jets during Antarctic AR landfalls (Irina Gorodetskaya, personal communication), and future plans to compare various AR detection algorithms over Antarctica will move us closer to fully comprehending present AR behavior over Antarctica and realize AR impacts on SMB.

In addition to improving our capabilities to measure the AR signature and our understanding of AR dynamics over Antarctica, there is still much to understand on how AR behavior is influences by teleconnections. In Chapter 5, we addressed some early results connecting AR frequency with the SAM phase over West Antarctica. These results are purely observational and should be complimented with model simulations to see how moisture transport is influenced by the phases of SAM. Also while a SAM correlation was observed in West Antarctica, the results were more muddled in East Antarctica where other modes of variability are likely involved. In regards with ENSO, preliminary results performed during the analysis of ARs on the AP (see Chapter 4. A linear regression of AR frequency with sea surface temperatures suggested a significant correlation with increased AR landfalls on the AP and El Niño. However, this signal was highly sensitive to the selection of months and AR detection scheme and it became clear that a dedicated study was necessary to full explore this relationship.

Concerning the projection of future AR activity, recent improvements of the horizontal resolution of GCMs now make it possible to apply AR detection algorithms directly to the model outputs and track changes in AR frequency and intensity. Individual efforts have already occurred for the North Pacific, North Atlantic (Shields and 
Kiehl [2016]), and the Southern Ocean (Espinoza et al. [2018]). Early results from an ARTMIP experiment aimed at examining various AR detection models applied to CMIP5/CMIP6 indicate that differences in AR detection criteria are the driving uncertainty-factor for AR projections in the Pacific and Atlantic Oceans (O'Brien et al. [2020]). This highlights the need for using a regional AR detection algorithm for future AR projection in the Antarctic domain instead of relying on results from global algorithms like the one described in Guan and Waliser [2015]. When applying the AR detection algorithm to a GCM under various RCP scenarios, consideration has to be made towards how the algorithms accounts for increasing background precipitable water as the general climate warms. There should also be consideration of potential biases within the various GCMs and whether a bias-corrected GCM would more accurately resolve the Antarctic atmospheric moisture content (Beaumet et al. [2019]; Krinner et al. [2019]). An accurate projection of future AR frequency and intensity around Antarctica will significantly improve our predictions of SMB changes and future ice-shelf stability.

However, to constrain our future AR projections, we must study AR behavior in the past. As ARs over Antarctica represent the transport of moisture from warmer areas to the ice sheet, there possibly is a measurable AR fingerprint within ice core records. Past temperature reconstructions utilize water stable isotopes $\left(\delta^{18} \mathrm{O}, \mathrm{D}\right)$ that are sensitive to the sea surface temperature and humidity of the moisture source region, temperature along the water vapor pathway, and temperature at condensation (Bonne et al. [2019]; Stenni et al. [2016]). The impact of ARs on ice cores may cause biases in the estimated annual mean temperature when using water isotope records due to the short yet intense influx of snowfall that likely contains enriched $\delta^{18} \mathrm{O}$ isotopes, outside of the seasonal average for $\delta^{18} \mathrm{O}$ (Dittmann et al. [2016]; Schlosser et al. [2016]; Servettaz et al. [2020]). ARs are also drive the high degree of interannual variability in precipitation across many ice core drilling sites on the continent which may complicate the dating of the ice cores (Turner et al. [2019]).

To understand how an AR signal could be retrieved in paleoclimate records, first we must be able to consistently identify AR occurrences in $\delta^{18} \mathrm{O}$ measurements from short term records either from snow pits or instrument measurements. There are plans to collect these measurements from Picarro isotopic water analyzers located 
at Dumont D'Urville and soon to be installed at Davis Station in collaborations with the LSCE and Australian Antarctic Program respectively. Ice and firn cores are sensitive to the atmospheric circulation patterns specific to their drilling site. To depict an AR signal in these core records requires knowledge on the regional moisture transport and blocking patterns that govern precipitation and temperature variability (Scarchilli et al. [2011]). In collaboration with the Institute for Marine and Antarctic Studies (IMAS), we plan to study regional moisture transports and retrieve the $\delta^{18} \mathrm{O}$ bias related to ARs for the ice core drilling sites at Law Dome and Mount Brown South and then search for an AR signal within the ice core records. Preliminary results suggest that ARs are controlling the interannual snowfall variability at Mount Brown South, but further efforts are needed to improve the retrieval of ARs from ice cores using a multi proxy approach (Fig. 6.1). If an accurate retrieval of ARs is possible in ice cores, than a past AR climatology could be created. We also are working on other studies around the goal of studying the Law Dome and Mount Brown South ice cores that include examining atmospheric circulation patterns and teleconnections in the region. Already progress is being made with the submission of Crockart et al., where using sea salt concentrations retrieved in ice cores from Law Dome and Mount Brown South, we examined moisture transport in relation with the ENSO signal. To achieve our goal of retrieving an AR signal from ice cores and creating an AR paleoclimatology will require the development of new methods to parse the AR influence on $\delta^{18} \mathrm{O}$ measurements, aerosol contents, and use advanced isotope tracing schemes in regional climate models like MAR.

The aforementioned perspectives comprise the defined scope of the ARCA project, but as the project is in its infancy and as Antarctic atmospheric river science moves from being a niche topic to a topic of critical importance for Antarctic cryosphere science, research adjustments and new collaborations are likely. Outside of framework of the ARCA project, other collaborations related with polar ARs are ongoing. Working with researchers from Rutgers University and Friedrich-AlexanderUniversity, we are using the two different AR detection algorithms (one is Wille_v2) and a foehn wind index to study melting behavior in NE Greenland. Wille_v2 is also being used to study extreme snowfall events around the Pine Island Glacier area with researchers from the University of Colorado, Boulder. Further collaboration with 
ARTMIP is planned like the ongoing ARTMIP Tier 2 Reanalysis Project (see Chapter 2) in hopes of establishing AR detection uncertainty in the polar regions. The ability to discern intrusions of warm, moist air under a common AR framework opens up possibilities to study AR impacts on fields outside of the geosciences. For instance, there might be a link between ARs and penguin colony collapse as penguin colonies are highly sensitive to heavy, warm precipitation events (Gao et al. [2018]). Rainfall can kill Adélie penguin chicks via hypothermia if they get wet since they lack waterproof plumage whereas heavy snowfall can bury eggs leading to penguin nest failure (Boersma and Rebstock [2014]; Ainley et al. [2010]; Cimino et al. [2014]. Stormrelated sudden reductions in sea ice have also been linked to penguin colony collapse (Boersma [2008]. However the relationship between sea ice extent and penguin colony
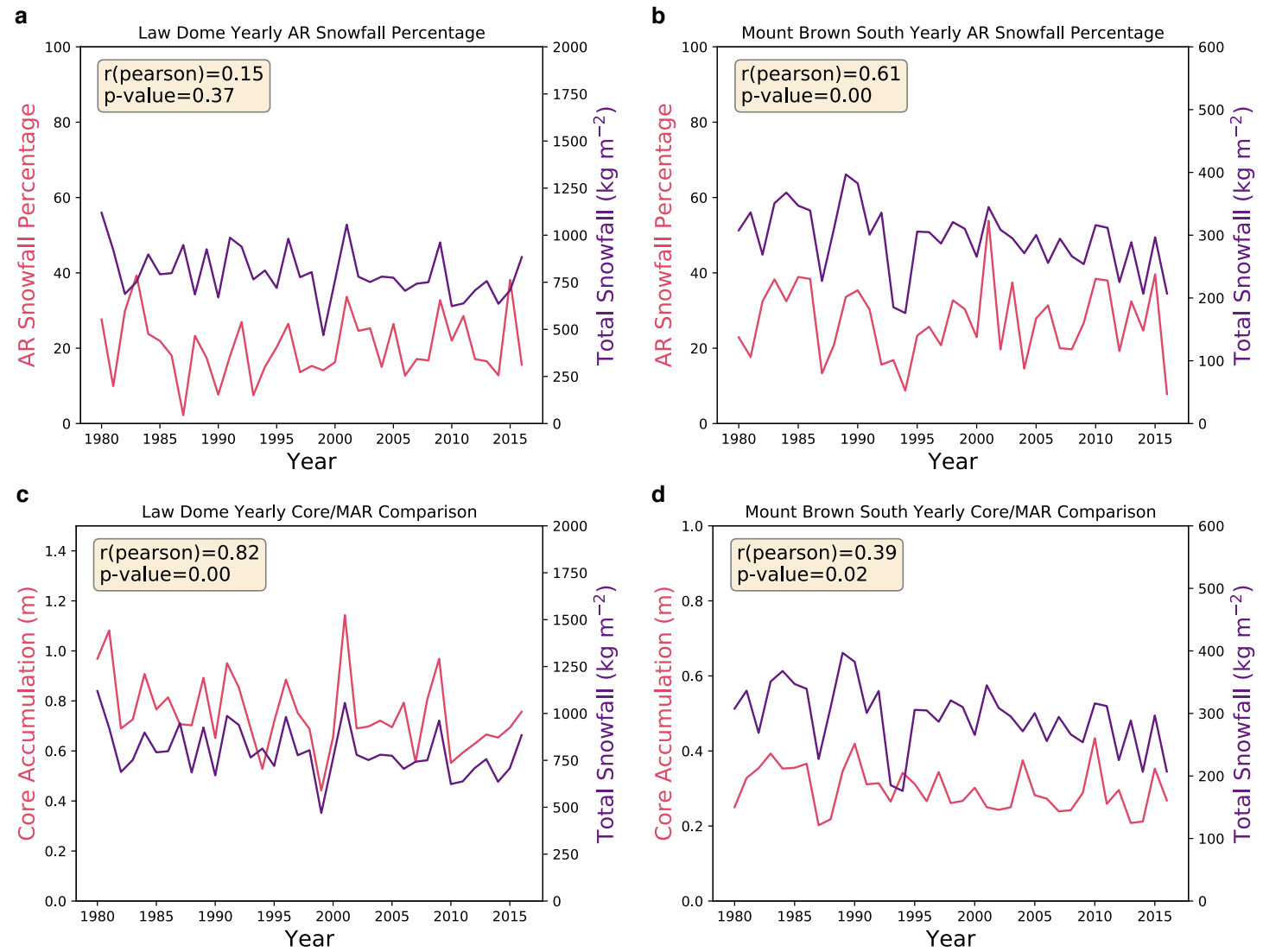

Figure 6.1: The percentage of annual snowfall attributable to ARs (red line) and the annual snowfall accumulation (purple line) simulated by MAR a Law Dome and $\mathbf{b}$ Mount Brown South. The annual snowfall accumulated measured from the ice core (red line) and simulated by the MAR (purple line) for $\mathbf{c}$ Law Dome and $\mathbf{d}$ Mount Brown South 
morbidity is complex as high sea ice concentrations restrict access to foraging while low sea ice decreases krill availability, the penguin's food source (Cimino et al. [2014]; Atkinson et al. [2004]. Many of these penguin mortality events are related to AR processes that could be examined in future inter-disciplinary efforts. Overall, the aforementioned efforts look to continue pushing the young field of polar AR science forward into mainstream discussions of polar atmospheric science, in which I would be keen to contribute. 


\section{Bibliography}

Abram, N. J., R. Mulvaney, F. Vimeux, S. J. Phipps, J. Turner, and M. H. England, Evolution of the Southern Annular Mode during the past millennium, Nature Climate Change, 4(7), 564-569, doi: 10.1038/nclimate2235, 2014.

Agosta, C., V. Favier, G. Krinner, H. Gallée, X. Fettweis, and C. Genthon, Highresolution modelling of the Antarctic surface mass balance, application for the twentieth, twenty first and twenty second centuries, Climate Dynamics, 41(11-12), 3247-3260, doi: 10.1007/s00382-013-1903-9, 2013.

Agosta, C., X. Fettweis, and R. Datta, Evaluation of the CMIP5 models in the aim of regional modelling of the Antarctic surface mass balance, The Cryosphere, 9(6), 2311-2321, doi: 10.5194/tc-9-2311-2015, 2015.

Agosta, C., et al., Estimation of the Antarctic surface mass balance using the regional climate model MAR (1979-2015) and identification of dominant processes, The Cryosphere, 13(1), 281-296, doi: 10.5194/tc-13-281-2019, 2019.

Ainley, D., J. Russell, S. Jenouvrier, E. Woehler, P. O. Lyver, W. R. Fraser, and G. L. Kooyman, Antarctic penguin response to habitat change as Earth's troposphere reaches $2{ }^{\circ} \mathrm{C}$ above preindustrial levels, Ecological Monographs, 80(1), 49-66, doi: 10.1890/08-2289.1, publisher: John Wiley \& Sons, Ltd, 2010.

Alley, K., T. Scambos, J. Miller, D. Long, and M. MacFerrin, Quantifying vulnerability of Antarctic ice shelves to hydrofracture using microwave scattering properties, Remote Sensing of Environment, 210, 297-306, doi: 10.1016/j.rse.2018.03.025, 2018.

Atkinson, A., V. Siegel, E. Pakhomov, and P. Rothery, Long-term decline in krill stock and increase in salps within the Southern Ocean, Nature, 432(7013), 100-103, doi: 10.1038/nature02996, 2004. 
Baines, P. G., and K. Fraedrich, Topographic Effects on the Mean Tropospheric Flow Patterns around Antarctica, Journal of the Atmospheric Sciences, 46(22), 3401-3415, doi: 10.1175/1520-0469(1989)046<3401:TEOTMT>2.0.CO;2, 1989.

Banwell, A. F., I. C. Willis, G. J. Macdonald, B. Goodsell, and D. R. MacAyeal, Direct measurements of ice-shelf flexure caused by surface meltwater ponding and drainage, Nature Communications, 10(1), 730, doi: 10.1038/s41467-019-08522-5, 2019.

Bao, J.-W., S. A. Michelson, P. J. Neiman, F. M. Ralph, and J. M. Wilczak, Interpretation of Enhanced Integrated Water Vapor Bands Associated with Extratropical Cyclones: Their Formation and Connection to Tropical Moisture, Monthly Weather Review, 134(4), 1063-1080, doi: 10.1175/MWR3123.1, 2006.

Beaumet, J., M. Déqué, G. Krinner, C. Agosta, and A. Alias, Effect of prescribed sea surface conditions on the modern and future Antarctic surface climate simulated by the ARPEGE atmosphere general circulation model, The Cryosphere, 13(11), 30233043, doi: 10.5194/tc-13-3023-2019, 2019.

Bell, R. E., A. F. Banwell, L. D. Trusel, and J. Kingslake, Antarctic surface hydrology and impacts on ice-sheet mass balance, Nature Climate Change, 8(12), 1044-1052, doi: 10.1038/s41558-018-0326-3, 2018.

Benedict, J. J., A. C. Clement, and B. Medeiros, Atmospheric Blocking and Other Large-Scale Precursor Patterns of Landfalling Atmospheric Rivers in the North Pacific: A CESM2 Study, Journal of Geophysical Research: Atmospheres, 124(21), 11,330-11,353, doi: 10.1029/2019JD030790, 2019.

Bertler, N. A. N., Barrett, Pert J., Mayewski, Paul A., Fogt, Ryan L., Kreutz, Karl J., and Shulmeister, James, El Niño suppresses Antarctic warming, Geophysical Research Letters, 31(15), doi: 10.1029/2004GL020749, 2004.

Bintanja, R., G. J. van Oldenborgh, S. S. Drijfhout, B. Wouters, and C. A. Katsman, Important role for ocean warming and increased ice-shelf melt in Antarctic sea-ice expansion, Nature Geoscience, 6, 376, 2013. 
Bjerknes, J., On The Structure of Moving Cyclones, Monthly Weather Review, 47(2), 95-99, doi: 10.1175/1520-0493(1919)47<95:OTSOMC>2.0.CO;2, 1919.

Bjerknes, J., Atmospheric Teleconnections from the Equatorial Pacific, Monthly Weather Review, 97(3), 163-172, doi: 10.1175/1520-0493(1969)097<0163: ATFTEP $>$ 2.3.CO;2, 1969 .

Bluestein, H. B., Synoptic-dynamic meteorology in midlatitudes: Volume 1, principles of kinematics and dynamics, Oxford University Press, 1992.

Boening, C., M. Lebsock, F. Landerer, and G. Stephens, Snowfall-driven mass change on the East Antarctic ice sheet, Geophysical Research Letters, 39(21), doi: 10.1029/ 2012GL053316, publisher: John Wiley \& Sons, Ltd, 2012.

Boersma, P. D., Penguins as Marine Sentinels, BioScience, 58(7), 597-607, doi: 10. 1641/B580707, 2008.

Boersma, P. D., and G. A. Rebstock, Climate Change Increases Reproductive Failure in Magellanic Penguins, PLoS ONE, 9(1), e85,602, doi: 10.1371/journal.pone.0085602, 2014.

Bonne, J.-L., M. Behrens, H. Meyer, S. Kipfstuhl, B. Rabe, L. Schönicke, H. C. Steen-Larsen, and M. Werner, Resolving the controls of water vapour isotopes in the Atlantic sector, Nature Communications, 10(1), 1632, doi: 10.1038/ s41467-019-09242-6, 2019.

Bonne, J.-L., et al., The summer 2012 Greenland heat wave: In situ and remote sensing observations of water vapor isotopic composition during an atmospheric river event, Journal of Geophysical Research: Atmospheres, 120(7), 2970-2989, doi: 10.1002/2014JD022602, publisher: John Wiley \& Sons, Ltd, 2015.

Boutle, I. A., S. E. Belcher, and R. S. Plant, Moisture transport in midlatitude cyclones, Quarterly Journal of the Royal Meteorological Society, 137(655), 360-373, doi: 10. 1002/qj.783, 2011.

Bozkurt, D., R. Rondanelli, J. C. Marín, and R. Garreaud, Foehn Event Triggered by an Atmospheric River Underlies Record-Setting Temperature Along Continental 
Antarctica, Journal of Geophysical Research: Atmospheres, 123(8), 3871-3892, doi: 10.1002/2017JD027796, 2018.

Braun, M., A. Humbert, and A. Moll, Changes of Wilkins Ice Shelf over the past 15 years and inferences on its stability, The Cryosphere, 3(1), 41-56, doi: 10.5194/ tc-3-41-2009, 2009.

Bromwich, D. H., Snowfall in high southern latitudes, Reviews of Geophysics, 26(1), 149, doi: 10.1029/RG026i001p00149, 1988.

Bromwich, D. H., J. P. Nicolas, and A. J. Monaghan, An Assessment of Precipitation Changes over Antarctica and the Southern Ocean since 1989 in Contemporary Global Reanalyses, Journal of Climate, 24(16), 4189-4209, doi: 10.1175/ 2011JCLI4074.1, 2011a.

Bromwich, D. H., D. F. Steinhoff, I. Simmonds, K. Keay, and R. L. Fogt, Climatological aspects of cyclogenesis near Adélie Land Antarctica, Tellus A: Dynamic Meteorology and Oceanography, 63(5), 921-938, doi: 10.1111/j.1600-0870.2011.00537.x, 2011b.

Bromwich, D. H., J. P. Nicolas, A. J. Monaghan, M. A. Lazzara, L. M. Keller, G. A. Weidner, and A. B. Wilson, Central West Antarctica among the most rapidly warming regions on Earth, Nature Geoscience, 6(2), 139-145, doi: 10.1038/ngeo1671, 2012.

Brun, E., Martin, V. Simon, C. Gendre, and C. Coleou, An Energy and Mass Model of Snow Cover Suitable for Operational Avalanche Forecasting, Journal of Glaciology, 35(121), 333-342, doi: 10.3189/S0022143000009254, 1989.

Brun, E., P. David, M. Sudul, and G. Brunot, A numerical model to simulate snowcover stratigraphy for operational avalanche forecasting, Journal of Glaciology, 38(128), 13-22, doi: 10.3189/S0022143000009552, 1992.

Cai, W., P. G. Baines, and H. B. Gordon, Southern Mid- to High-Latitude Variability, a Zonal Wavenumber-3 Pattern, and the Antarctic Circumpolar Wave in the CSIRO Coupled Model, Journal of Climate, 12, 3087-3104,, doi: 10.1175/1520-0442(1999) 012<3087:SMTHLV>2.0.CO;2, 1999. 
Cape, M. R., M. Vernet, P. Skvarca, S. Marinsek, T. Scambos, and E. Domack, Foehn winds link climate-driven warming to ice shelf evolution in Antarctica, Journal of Geophysical Research: Atmospheres, 120(21), 11,037-11,057, doi: 10.1002/ 2015JD023465, 2015.

Carlson, T. N., Airflow Through Midlatitude Cyclones and the Comma Cloud Pattern, Monthly Weather Review, 108(10), 1498-1509, doi: 10.1175/1520-0493(1980) 108<1498:ATMCAT>2.0.CO;2, 1980.

Carrasco, J. F., and D. H. Bromwich, Mesoscale cyclogenesis dynamics over the southwestern Ross Sea, Antarctica, Journal of Geophysical Research: Atmospheres, 98(D7), 12,973-12,995, doi: 10.1029/92JD02821, publisher: John Wiley \& Sons, Ltd, 1993.

Chen, B., S. R. Smith, and D. H. Bromwich, Evolution of the Tropospheric Split Jet over the South Pacific Ocean during the 1986-89 ENSO Cycle, Monthly Weather Review, 124(8), 1711-1731, doi: 10.1175/1520-0493(1996)124<1711:EOTTSJ>2.0. CO;2, 1996.

Chen, G., J. Lu, D. A. Burrows, and L. R. Leung, Local finite-amplitude wave activity as an objective diagnostic of midlatitude extreme weather, Geophysical Research Letters, 42(24), 10,952-10,960, doi: 10.1002/2015GL066959, 2015.

Chen, J. L., C. R. Wilson, and B. D. Tapley, Contribution of ice sheet and mountain glacier melt to recent sea level rise, Nature Geoscience, 6(7), 549-552, doi: 10.1038/ ngeo1829, 2013.

Chyhareva, A., S. Krakovska, and D. Pishniak, Climate projections over the Antarctic Peninsula region to the end of the 21st century. Part 1: cold temperature indices, Ukrainian Antarctic Journal, (1(18)), 62-74, doi: 10.33275/1727-7485.1(18).2019. 131, 2019.

Cimino, M., W. Fraser, D. Patterson-Fraser, V. Saba, and M. Oliver, Large-scale climate and local weather drive interannual variability in Adélie penguin chick fledging mass, Marine Ecology Progress Series, 513, 253-268, doi: 10.3354/meps10928, 2014. 
Clem, K. R., and J. A. Renwick, Austral Spring Southern Hemisphere Circulation and Temperature Changes and Links to the SPCZ, Journal of Climate, 28(18), 73717384, doi: 10.1175/JCLI-D-15-0125.1, 2015.

Clem, K. R., J. A. Renwick, J. McGregor, and R. L. Fogt, The relative influence of ENSO and SAM on Antarctic Peninsula climate, Journal of Geophysical Research: Atmospheres, 121(16), 9324-9341, doi: 10.1002/2016JD025305, publisher: John Wiley \& Sons, Ltd, 2016.

Clem, K. R., R. L. Fogt, J. Turner, B. R. Lintner, G. J. Marshall, J. R. Miller, and J. A. Renwick, Record warming at the South Pole during the past three decades, Nature Climate Change, 10(8), 762-770, doi: 10.1038/s41558-020-0815-z, 2020.

Codron, F., Relations between Annular Modes and the Mean State: Southern Hemisphere Winter, Journal of the Atmospheric Sciences, 64(9), 3328-3339, doi: 10.1175/ JAS4012.1, 2007.

Costi, J., J. Arigony-Neto, M. Braun, B. Mavlyudov, N. E. Barrand, A. B. da Silva, W. C. Marques, and J. C. Simões, Estimating surface melt and runoff on the Antarctic Peninsula using ERA-Interim reanalysis data, Antarctic Science, 30(6), 379-393, doi: 10.1017/S0954102018000391, 2018.

Cullather, R. I., D. H. Bromwich, and M. L. Van Woert, Interannual variations in Antarctic precipitation related to El Niño-Southern Oscillation, Journal of Geophysical Research: Atmospheres, 101(D14), 19,109-19,118, doi: 10.1029/96JD01769, 1996.

Dacre, H. F., P. A. Clark, O. Martinez-Alvarado, M. A. Stringer, and D. A. Lavers, How Do Atmospheric Rivers Form?, Bulletin of the American Meteorological Society, 96(8), 1243-1255, doi: 10.1175/BAMS-D-14-00031.1, 2015.

Dacre, H. F., O. Martínez-Alvarado, and C. O. Mbengue, Linking Atmospheric Rivers and Warm Conveyor Belt Airflows, Journal of Hydrometeorology, 20(6), 1183-1196, doi: 10.1175/JHM-D-18-0175.1, 2019.

Datta, R. T., M. Tedesco, C. Agosta, X. Fettweis, P. Kuipers Munneke, and M. R. van den Broeke, Melting over the northeast Antarctic Peninsula (1999-2009): eval- 
uation of a high-resolution regional climate model, The Cryosphere, 12(9), 29012922, doi: 10.5194/tc-12-2901-2018, 2018.

Datta, R. T., M. Tedesco, X. Fettweis, C. Agosta, S. Lhermitte, J. T. M. Lenaerts, and N. Wever, The Effect of Foehn-Induced Surface Melt on Firn Evolution Over the Northeast Antarctic Peninsula, Geophysical Research Letters, 46(7), 3822-3831, doi: 10.1029/2018GL080845, publisher: John Wiley \& Sons, Ltd, 2019.

De Ridder, K., and H. Gallée, Land Surface-Induced Regional Climate Change in Southern Israel, Journal of Applied Meteorology, 37(11), 1470-1485, doi: 10.1175/ 1520-0450(1998)037<1470:LSIRCC>2.0.CO;2, 1998.

DeConto, R. M., and D. Pollard, Contribution of Antarctica to past and future sea-level rise, Nature, 531, 591, 2016.

Dee, D. P., et al., The ERA-Interim reanalysis: configuration and performance of the data assimilation system, Quarterly Journal of the Royal Meteorological Society, 137(656), 553-597, doi: 10.1002/qj.828, 2011.

Dettinger, M., Fifty-two years of Pineapple-Express storms across the west coast of North America California Energy Commission PIER Energy-Related Environmental Research Report CEC-500-2005-004, California Energy Commission, p. 15, 2004.

Dettinger, M., Climate Change, Atmospheric Rivers, and Floods in California - A Multimodel Analysis of Storm Frequency and Magnitude Changes1, JAWRA Journal of the American Water Resources Association, 47(3), 514-523, doi: 10.1111/j. 1752-1688.2011.00546.x, publisher: John Wiley \& Sons, Ltd, 2011.

Ding, Q., E. J. Steig, D. S. Battisti, and J. M. Wallace, Influence of the Tropics on the Southern Annular Mode, Journal of Climate, 25(18), 6330-6348, doi: 10.1175/ JCLI-D-11-00523.1, 2012.

Dinniman, M. S., J. M. Klinck, and E. E. Hofmann, Sensitivity of Circumpolar Deep Water Transport and Ice Shelf Basal Melt along the West Antarctic Peninsula to Changes in the Winds, Journal of Climate, 25(14), 4799-4816, doi: 10.1175/ JCLI-D-11-00307.1, 2012. 
Dittmann, A., E. Schlosser, V. Masson-Delmotte, J. G. Powers, K. W. Manning, M. Werner, and K. Fujita, Precipitation regime and stable isotopes at Dome Fuji, East Antarctica, Atmospheric Chemistry and Physics, 16(11), 6883-6900, doi: 10. 5194/acp-16-6883-2016, 2016.

Doake, C. S. M., H. F. J. Corr, H. Rott, P. Skvarca, and N. W. Young, Breakup and conditions for stability of the northern Larsen Ice Shelf, Antarctica, Nature, 391(6669), 778-780, doi: 10.1038/35832, 1998.

Doble, M. J., and J.-R. Bidlot, Wave buoy measurements at the Antarctic sea ice edge compared with an enhanced ECMWF WAM: Progress towards global waves-in-ice modelling, Ocean Surface Waves, 70, 166-173, doi: 10.1016/j.ocemod.2013.05.012, 2013.

Donat-Magnin, M., et al., Interannual variability of summer surface mass balance and surface melting in the Amundsen sector, West Antarctica, The Cryosphere, 14(1), 229-249, doi: 10.5194/tc-14-229-2020, 2020.

Dufour, A., C. Charrondière, and O. Zolina, Analysed and observed moisture transport as a proxy for snow accumulation in East Antarctica, The Cryosphere Discussions, pp. 1-23, doi: 10.5194/tc-2018-156, 2018.

Edwards, T. L., et al., Revisiting Antarctic ice loss due to marine ice-cliff instability, Nature, 566(7742), 58-64, doi: 10.1038/s41586-019-0901-4, 2019.

Elvidge, A. D., P. Kuipers Munneke, J. C. King, I. A. Renfrew, and E. Gilbert, Atmospheric Drivers of Melt on Larsen C Ice Shelf: Surface Energy Budget Regimes and the Impact of Foehn, Journal of Geophysical Research: Atmospheres, 125(17), e2020JD032,463, doi: 10.1029/2020JD032463, 2020.

Espinoza, V., D. E. Waliser, B. Guan, D. A. Lavers, and F. M. Ralph, Global Analysis of Climate Change Projection Effects on Atmospheric Rivers, Geophysical Research Letters, 45(9), 4299-4308, doi: 10.1029/2017GL076968, publisher: John Wiley \& Sons, Ltd, 2018.

Etourneau, J., et al., Ocean temperature impact on ice shelf extent in the east- 
ern Antarctic Peninsula, Nature Communications, 10(1), 304, doi: 10.1038/ s41467-018-08195-6, 2019.

Fahnestock, M. A., W. Abdalati, and C. A. Shuman, Long melt seasons on ice shelves of the Antarctic Peninsula: an analysis using satellite-based microwave emission measurements, Annals of Glaciology, 34, 127-133, doi: 10.3189/ $172756402781817798,2002$.

Favier, L., G. Durand, S. L. Cornford, G. H. Gudmundsson, O. Gagliardini, F. GilletChaulet, T. Zwinger, A. J. Payne, and A. M. Le Brocq, Retreat of Pine Island Glacier controlled by marine ice-sheet instability, Nature Climate Change, 4(2), 117-121, doi: 10.1038/nclimate2094, 2014.

Favier, V., C. Agosta, S. Parouty, G. Durand, G. Delaygue, H. Gallée, A.-S. Drouet, A. Trouvilliez, and G. Krinner, An updated and quality controlled surface mass balance dataset for Antarctica, The Cryosphere, 7(2), 583-597, doi: 10.5194/ tc-7-583-2013, 2013.

Favier, V., G. Krinner, C. Amory, H. Gallée, J. Beaumet, and C. Agosta, AntarcticaRegional Climate and Surface Mass Budget, Current Climate Change Reports, doi: 10.1007/s40641-017-0072-z, 2017.

Favier, V., et al., Atmospheric drying as the main driver of dramatic glacier wastage in the southern Indian Ocean, Scientific Reports, 6(1), 32,396, doi: 10.1038/srep32396, 2016.

Fettweis, X., J. E. Box, C. Agosta, C. Amory, C. Kittel, C. Lang, D. van As, H. Machguth, and H. Gallée, Reconstructions of the 1900-2015 Greenland ice sheet surface mass balance using the regional climate MAR model, The Cryosphere, 11(2), 1015-1033, doi: 10.5194/tc-11-1015-2017, 2017.

Fettweis, X., et al., GrSMBMIP: Intercomparison of the modelled 1980-2012 surface mass balance over the Greenland Ice sheet, The Cryosphere Discussions, 2020, 1-35, doi: 10.5194/tc-2019-321, 2020.

Fogt, R. L., and D. H. Bromwich, Decadal Variability of the ENSO Teleconnection to 
the High-Latitude South Pacific Governed by Coupling with the Southern Annular Mode*, Journal of Climate, 19(6), 979-997, doi: 10.1175/JCLI3671.1, 2006.

Fogt, R. L., J. Perlwitz, A. J. Monaghan, D. H. Bromwich, J. M. Jones, and G. J. Marshall, Historical SAM Variability. Part II: Twentieth-Century Variability and Trends from Reconstructions, Observations, and the IPCC AR4 Models*, Journal of Climate, 22(20), 5346-5365, doi: 10.1175/2009JCLI2786.1, 2009.

Fogt, R. L., D. H. Bromwich, and K. M. Hines, Understanding the SAM influence on the South Pacific ENSO teleconnection, Climate Dynamics, 36(7-8), 1555-1576, doi: 10.1007/s00382-010-0905-0, 2011.

Fogt, R. L., J. M. Jones, and J. Renwick, Seasonal Zonal Asymmetries in the Southern Annular Mode and Their Impact on Regional Temperature Anomalies, Journal of Climate, 25(18), 6253-6270, doi: 10.1175/JCLI-D-11-00474.1, 2012a.

Fogt, R. L., A. J. Wovrosh, R. A. Langen, and I. Simmonds, The characteristic variability and connection to the underlying synoptic activity of the AmundsenBellingshausen Seas Low, Journal of Geophysical Research: Atmospheres, 117(D7), doi: 10.1029/2011JD017337, publisher: John Wiley \& Sons, Ltd, 2012b.

Forecasts, E. C. F. M.-R. W., ERA5 Reanalysis, doi: 10.5065/D6X34W69, artwork Size: 320.061 Tbytes Medium: WMO GRIB1,netCDF4 Pages: 320.061 Tbytes type: dataset, 2017.

Francis, D., K. S. Mattingly, S. Lhermitte, M. Temimi, and P. Heil, Atmospheric extremes triggered the biggest calving event in more than 50 years at the Amery Ice shelf in September 2019, The Cryosphere Discussions, 2020, 1-30, doi: 10.5194/ tc-2020-219, 2020.

Fretwell, P., et al., Bedmap2: improved ice bed, surface and thickness datasets for Antarctica, The Cryosphere, 7(1), 375-393, doi: 10.5194/tc-7-375-2013, 2013.

Frieler, K., P. U. Clark, F. He, C. Buizert, R. Reese, S. R. M. Ligtenberg, M. R. van den Broeke, R. Winkelmann, and A. Levermann, Consistent evidence of increasing Antarctic accumulation with warming, Nature Climate Change, 5(4), 348-352, doi: 10.1038/nclimate2574, 2015. 
Fudge, T. J., B. R. Markle, K. M. Cuffey, C. Buizert, K. C. Taylor, E. J. Steig, E. D. Waddington, H. Conway, and M. Koutnik, Variable relationship between accumulation and temperature in West Antarctica for the past 31,000 years, Geophysical Research Letters, 43(8), 3795-3803, doi: 10.1002/2016GL068356, 2016.

Fürst, J. J., G. Durand, F. Gillet-Chaulet, L. Tavard, M. Rankl, M. Braun, and O. Gagliardini, The safety band of Antarctic ice shelves, Nature Climate Change, 6(5), 479-482, doi: 10.1038/nclimate2912, 2016.

Gallée, H., and I. V. Gorodetskaya, Validation of a limited area model over Dome C, Antarctic Plateau, during winter, Climate Dynamics, 34(1), 61, doi: 10.1007/ s00382-008-0499-y, 2008.

Gallée, H., and G. Schayes, Development of a Three-Dimensional Meso- $\gamma$ Primitive Equation Model: Katabatic Winds Simulation in the Area of Terra Nova Bay, Antarctica, Monthly Weather Review, 122(4), 671-685, doi: 10.1175/ 1520-0493(1994)122<0671:DOATDM>2.0.CO;2, 1994.

Gao, Y., L. Yang, Z. Xie, L. Emmerson, C. Southwell, Y. Wang, and L. Sun, Last Millennium Adélie Penguin Mortality and Colony Abandonment Events on Long Peninsula, East Antarctica, Journal of Geophysical Research: Biogeosciences, 123(9), 28782889, doi: 10.1029/2018JG004550, publisher: John Wiley \& Sons, Ltd, 2018.

Gelaro, R., et al., The Modern-Era Retrospective Analysis for Research and Applications, Version 2 (MERRA-2), Journal of Climate, 30(14), 5419-5454, doi: 10.1175/ JCLI-D-16-0758.1, 2017.

Glasser, N., and T. Scambos, A structural glaciological analysis of the 2002 Larsen B ice-shelf collapse, Journal of Glaciology, 54(184), 3-16, doi: 10.3189/ $002214308784409017,2008$.

Glasser, N., B. Kulessa, A. Luckman, D. Jansen, E. King, P. Sammonds, T. Scambos, and K. Jezek, Surface structure and stability of the Larsen C ice shelf, Antarctic Peninsula, Journal of Glaciology, 55(191), 400-410, doi: 10.3189/ $002214309788816597,2009$. 
Gong, D., and S. Wang, Definition of Antarctic Oscillation index, Geophysical Research Letters, 26(4), 459-462, doi: 10.1029/1999GL900003, 1999.

Gong, T., S. B. Feldstein, and D. Luo, The Impact of ENSO on Wave Breaking and Southern Annular Mode Events, Journal of the Atmospheric Sciences, 67(9), 28542870, doi: 10.1175/2010JAS3311.1, 2010.

Goodwin, B. P., E. Mosley-Thompson, A. B. Wilson, S. E. Porter, and M. R. SierraHernandez, Accumulation Variability in the Antarctic Peninsula: The Role of Large-Scale Atmospheric Oscillations and Their Interactions*, Journal of Climate, 29(7), 2579-2596, doi: 10.1175/JCLI-D-15-0354.1, 2016.

Gorodetskaya, I. V., N. P. M. Van Lipzig, M. R. Van den Broeke, A. Mangold, W. Boot, and C. H. Reijmer, Meteorological regimes and accumulation patterns at Utsteinen, Dronning Maud Land, East Antarctica: Analysis of two contrasting years, Journal of Geophysical Research: Atmospheres, 118(4), 1700-1715, doi: 10.1002/jgrd.50177, 2013.

Gorodetskaya, I. V., M. Tsukernik, K. Claes, M. F. Ralph, W. D. Neff, and N. P. M. Van Lipzig, The role of atmospheric rivers in anomalous snow accumulation in East Antarctica, Geophysical Research Letters, 41(17), 6199-6206, doi: 10.1002/ 2014GL060881, 2014.

Gorodetskaya, I. V., T. Silva, H. Schmithüsen, and N. Hirasawa, Atmospheric River Signatures in Radiosonde Profiles and Reanalyses at the Dronning Maud Land Coast, East Antarctica, Advances in Atmospheric Sciences, 37(5), 455-476, doi: 10.1007/s00376-020-9221-8, 2020.

Gregory, S., and D. Noone, Variability in the teleconnection between the El Niño-Southern Oscillation and West Antarctic climate deduced from West Antarctic ice core isotope records, Journal of Geophysical Research: Atmospheres, 113(D17), doi: 10.1029/2007JD009107, publisher: John Wiley \& Sons, Ltd, 2008.

Groves, D. G., Moisture budget of the Arctic atmosphere from TOVS satellite data, Journal of Geophysical Research, 107(D19), doi: 10.1029/2001JD001191, 2002. 
Guan, B., and D. E. Waliser, Detection of atmospheric rivers: Evaluation and application of an algorithm for global studies: Detection of Atmospheric Rivers, Journal of Geophysical Research: Atmospheres, 120(24), 12,514-12,535, doi: 10.1002/ 2015JD024257, 2015.

Guan, B., and D. E. Waliser, Atmospheric rivers in 20 year weather and climate simulations: A multimodel, global evaluation, Journal of Geophysical Research: Atmospheres, 122(11), 5556-5581, doi: 10.1002/2016JD026174, 2017.

Hegyi, B. M., and P. C. Taylor, The Unprecedented 2016-2017 Arctic Sea Ice Growth Season: The Crucial Role of Atmospheric Rivers and Longwave Fluxes, Geophysical Research Letters, 45(10), 5204-5212, doi: 10.1029/2017GL076717, 2018.

Hendon, H. H., D. W. J. Thompson, and M. C. Wheeler, Australian Rainfall and Surface Temperature Variations Associated with the Southern Hemisphere Annular Mode, Journal of Climate, 20(11), 2452-2467, doi: 10.1175/JCLI4134.1, 2007.

Hersbach, H., et al., The ERA5 global reanalysis, Quarterly Journal of the Royal Meteorological Society, 146(730), 1999-2049, doi: 10.1002/qj.3803, 2020.

Hirasawa, N., H. Nakamura, H. Motoyama, M. Hayashi, and T. Yamanouchi, The role of synoptic-scale features and advection in prolonged warming and generation of different forms of precipitation at Dome Fuji station, Antarctica, following a prominent blocking event, Journal of Geophysical Research: Atmospheres, 118(13), 69166928, doi: 10.1002/jgrd.50532, 2013.

Hobbs, W. H., The Role of the Glacial Anticyclone in the Air Circulation of the Globe, Proceedings of the American Philosophical Society, 54(218), 185-225, publisher: American Philosophical Society, 1915.

Hogg, A. E., and G. H. Gudmundsson, Impacts of the Larsen-C Ice Shelf calving event, Nature Climate Change, 7(8), 540-542, doi: 10.1038/nclimate3359, 2017.

Holland, P. R., A. Brisbourne, H. F. J. Corr, D. McGrath, K. Purdon, J. Paden, H. A. Fricker, F. S. Paolo, and A. H. Fleming, Oceanic and atmospheric forcing of Larsen C Ice-Shelf thinning, The Cryosphere, 9(3), 1005-1024, doi: 10.5194/tc-9-1005-2015, 2015. 
Hosking, J. S., A. Orr, G. J. Marshall, J. Turner, and T. Phillips, The Influence of the Amundsen-Bellingshausen Seas Low on the Climate of West Antarctica and Its Representation in Coupled Climate Model Simulations, Journal of Climate, 26(17), 6633-6648, doi: 10.1175/JCLI-D-12-00813.1, 2013.

Hosking, J. S., R. Fogt, E. R. Thomas, V. Moosavi, T. Phillips, J. Coggins, and D. Reusch, Accumulation in coastal West Antarctic ice core records and the role of cyclone activity: The Role of Cyclones on Accumulation, Geophysical Research Letters, 44(17), 9084-9092, doi: 10.1002/2017GL074722, 2017.

Hoskins, B. J., and K. I. Hodges, A New Perspective on Southern Hemisphere Storm Tracks, Journal of Climate, 18(20), 4108-4129, doi: 10.1175/JCLI3570.1, 2005.

Hoskins, B. J., and D. J. Karoly, The Steady Linear Response of a Spherical Atmosphere to Thermal and Orographic Forcing, Journal of the Atmospheric Sciences, 38(6), 1179-1196, doi: 10.1175/1520-0469(1981)038<1179:TSLROA>2.0.CO;2, 1981.

Hoskins, B. J., M. E. McIntyre, and A. W. Robertson, On the use and significance of isentropic potential vorticity maps, Quarterly Journal of the Royal Meteorological Society, 111(470), 877-946, doi: 10.1002/qj.49711147002, publisher: John Wiley \& Sons, Ltd, 1985.

Houze, R. A., Clouds and Precipitation in Extratropical Cyclones, in International Geophysics, vol. 104, pp. 329-367, Elsevier, doi: 10.1016/B978-0-12-374266-7. 00011-1, 2014.

Hu, X., S. A. Sejas, M. Cai, Z. Li, and S. Yang, Atmospheric Dynamics Footprint on the January 2016 Ice Sheet Melting in West Antarctica, Geophysical Research Letters, doi: 10.1029/2018GL081374, 2019.

Hubbard, B., et al., Massive subsurface ice formed by refreezing of ice-shelf melt ponds, Nature Communications, 7, 11,897, 2016.

Huning, L. S., S. A. Margulis, B. Guan, D. E. Waliser, and P. J. Neiman, Implications of Detection Methods on Characterizing Atmospheric River Contribution to Seasonal Snowfall Across Sierra Nevada, USA, Geophysical Research Letters, 44(20), 10,44510,453, doi: 10.1002/2017GL075201, 2017. 
Hutchinson, K., J. Deshayes, J. Sallee, J. A. Dowdeswell, C. Lavergne, I. Ansorge, H. Luyt, T. Henry, and S. E. Fawcett, Water Mass Characteristics and Distribution Adjacent to Larsen C Ice Shelf, Antarctica, Journal of Geophysical Research: Oceans, 125(4), doi: 10.1029/2019JC015855, 2020.

IMBIE, Mass balance of the Antarctic Ice Sheet from 1992 to 2017, Nature, 558(7709), 219-222, doi: 10.1038/s41586-018-0179-y, 2018.

Jakobs, C. L., C. H. Reijmer, C. J. P. P. Smeets, L. D. Trusel, W. J. van de Berg, M. R. van den Broeke, and J. M. van Wessem, A benchmark dataset of in situ Antarctic surface melt rates and energy balance, Journal of Glaciology, 66(256), 291-302, doi: 10.1017/jog.2020.6, 2020.

Jomelli, V., et al., Sub-Antarctic glacier extensions in the Kerguelen region $\left(49^{\circ} \mathrm{S}, \mathrm{In}-\right.$ dian Ocean) over the past 24,000 years constrained by $36 \mathrm{Cl}$ moraine dating, Quaternary Science Reviews, 162, 128-144, doi: 10.1016/j.quascirev.2017.03.010, 2017.

Jones, J. M., et al., Assessing recent trends in high-latitude Southern Hemisphere surface climate, Nature Climate Change, 6(10), 917-926, doi: 10.1038/nclimate3103, 2016.

Kalnay, E., et al., The NCEP/NCAR 40-Year Reanalysis Project, Bulletin of the American Meteorological Society, 77(3), 437-472, doi: 10.1175/1520-0477(1996)077<0437: TNYRP>2.0.CO;2, 1996.

Kanamitsu, M., W. Ebisuzaki, J. Woollen, S.-K. Yang, J. J. Hnilo, M. Fiorino, and G. L. Potter, NCEP-DOE AMIP-II Reanalysis (R-2), Bulletin of the American Meteorological Society, 83(11), 1631-1644, doi: 10.1175/BAMS-83-11-1631, 2002.

Karoly, D. J., Southern Hemisphere Circulation Features Associated with El NiñoSouthern Oscillation Events, Journal of Climate, 2(11), 1239-1252, doi: 10.1175/ 1520-0442(1989)002<1239:SHCFAW>2.0.CO;2, 1989.

Karoly, D. J., The role of transient eddies in low-frequency zonal variations of the Southern Hemisphere circulation, Tellus A, 42(1), 41-50, doi: 10.1034/j.1600-0870. 1990.00005.x, 1990. 
Khazendar, A., E. Rignot, and E. Larour, Larsen B Ice Shelf rheology preceding its disintegration inferred by a control method, Geophysical Research Letters, 34(19), L19,503, doi: 10.1029/2007GL030980, 2007.

Khazendar, A., C. P. Borstad, B. Scheuchl, E. Rignot, and H. Seroussi, The evolving instability of the remnant Larsen B Ice Shelf and its tributary glaciers, Earth and Planetary Science Letters, 419, 199-210, doi: 10.1016/j.epsl.2015.03.014, 2015.

Kidson, J. W., Eigenvector Analysis of Monthly Mean Surface Data, Monthly Weather Review, 103(3), 177-186, doi: 10.1175/1520-0493(1975)103<0177:EAOMMS>2.0. $\mathrm{CO} ; 2,1975$.

Kidson, J. W., Indices of the Southern Hemisphere Zonal Wind, Journal of Climate, 1(2), 183-194, doi: 10.1175/1520-0442(1988)001<0183:IOTSHZ>2.0.CO;2, 1988a.

Kidson, J. W., Interannual Variations in the Southern Hemisphere Circulation, Journal of Climate, 1(12), 1177-1198, doi: 10.1175/1520-0442(1988)001<1177:IVITSH> 2.0.CO;2, 1988b.

Kiladis, G. N., and K. C. Mo, Interannual and Intraseasonal Variability in the Southern Hemisphere, in Meteorology of the Southern Hemisphere, edited by D. J. Karoly and D. G. Vincent, pp. 307-336, American Meteorological Society, Boston, MA, doi: 10. 1007/978-1-935704-10-2_11, 1998.

King, J. C., and J. Turner, Antarctic Meteorology and Climatology, Cambridge University Press, google-Books-ID: KpSqH8gxz1IC, 2007.

King, M. A., and C. S. Watson, Antarctic Surface Mass Balance: Natural Variability, Noise, and Detecting New Trends, Geophysical Research Letters, 47(12), e2020GL087,493, doi: 10.1029/2020GL087493, publisher: John Wiley \& Sons, Ltd, 2020.

King, M. A., R. J. Bingham, P. Moore, P. L. Whitehouse, M. J. Bentley, and G. A. Milne, Lower satellite-gravimetry estimates of Antarctic sea-level contribution, $\mathrm{Na}$ ture, 491, 586, 2012. 
Kittel, C., C. Amory, C. Agosta, A. Delhasse, S. Doutreloup, P.-V. Huot, C. Wyard, T. Fichefet, and X. Fettweis, Sensitivity of the current Antarctic surface mass balance to sea surface conditions using MAR, The Cryosphere, 12(12), 3827-3839, doi: 10.5194/tc-12-3827-2018, 2018.

Knippertz, P., and H. Wernli, A Lagrangian Climatology of Tropical Moisture Exports to the Northern Hemispheric Extratropics, Journal of Climate, 23(4), 987-1003, doi: 10.1175/2009JCLI3333.1, 2010.

Kobayashi, S., et al., The JRA-55 Reanalysis: General Specifications and Basic Characteristics, Journal of the Meteorological Society of Japan. Ser. II, 93(1), 5-48, doi: 10.2151/jmsj.2015-001, 2015.

Komatsu, K. K., V. A. Alexeev, I. A. Repina, and Y. Tachibana, Poleward upgliding Siberian atmospheric rivers over sea ice heat up Arctic upper air, Scientific Reports, 8(1), doi: 10.1038/s41598-018-21159-6, 2018.

Krinner, G., and M. G. Flanner, Striking stationarity of large-scale climate model bias patterns under strong climate change, Proceedings of the National Academy of Sciences, 115(38), 9462, doi: 10.1073/pnas.1807912115, 2018.

Krinner, G., C. Largeron, M. Ménégoz, C. Agosta, and C. Brutel-Vuilmet, Oceanic Forcing of Antarctic Climate Change: A Study Using a Stretched-Grid Atmospheric General Circulation Model, Journal of Climate, 27(15), 5786-5800, doi: 10.1175/ JCLI-D-13-00367.1, 2014.

Krinner, G., J. Beaumet, V. Favier, M. Déqué, and C. Brutel-Vuilmet, Empirical RunTime Bias Correction for Antarctic Regional Climate Projections With a StretchedGrid AGCM, Journal of Advances in Modeling Earth Systems, 11(1), 64-82, doi: 10. 1029/2018MS001438, publisher: John Wiley \& Sons, Ltd, 2019.

Krinner, G., V. Kharin, R. Roehrig, J. Scinocca, and F. Codron, Historically-based run-time bias corrections substantially improve model projections of 100 years of future climate change, Communications Earth \& Environment, 1(1), 29, doi: 10.1038/s43247-020-00035-0, 2020. 
Kuipers Munneke, P., et al., Intense Winter Surface Melt on an Antarctic Ice Shelf, Geophysical Research Letters, 45(15), 7615-7623, doi: 10.1029/2018GL077899, 2018.

Kumar, A., and M. P. Hoerling, The Nature and Causes for the Delayed Atmospheric Response to El Niño, Journal of Climate, 16(9), 1391-1403, doi: 10.1175/ 1520-0442-16.9.1391, 2003.

Kurita, N., N. Hirasawa, S. Koga, J. Matsushita, H. C. Steen-Larsen, V. MassonDelmotte, and Y. Fujiyoshi, Influence of large-scale atmospheric circulation on marine air intrusion toward the East Antarctic coast, Geophysical Research Letters, 43(17), 9298-9305, doi: 10.1002/2016GL070246, 2016.

Lachlan-Cope, T., and W. Connolley, Teleconnections between the tropical Pacific and the Amundsen-Bellinghausens Sea: Role of the El Niño/Southern Oscillation, Journal of Geophysical Research: Atmospheres, 111(D23), doi: 10.1029/2005JD006386, publisher: John Wiley \& Sons, Ltd, 2006.

Lai, C.-Y., J. Kingslake, M. G. Wearing, P.-H. C. Chen, P. Gentine, H. Li, J. J. Spergel, and J. M. van Wessem, Vulnerability of Antarctica's ice shelves to meltwater-driven fracture, Nature, 584(7822), 574-578, doi: 10.1038/s41586-020-2627-8, 2020.

Lavers, D. A., G. Villarini, R. P. Allan, E. F. Wood, and A. J. Wade, The detection of atmospheric rivers in atmospheric reanalyses and their links to British winter floods and the large-scale climatic circulation, Journal of Geophysical Research: Atmospheres, 117(D20), doi: 10.1029/2012JD018027, publisher: John Wiley \& Sons, Ltd, 2012.

Leeson, A. A., J. M. Van Wessem, S. R. M. Ligtenberg, A. Shepherd, M. R. Van Den Broeke, R. Killick, P. Skvarca, S. Marinsek, and S. Colwell, Regional climate of the Larsen B embayment 1980-2014, Journal of Glaciology, 63(240), 683-690, doi: 10.1017/jog.2017.39, 2017.

Lenaerts, J. T. M., E. van Meijgaard, M. R. van den Broeke, S. R. M. Ligtenberg, M. Horwath, and E. Isaksson, Recent snowfall anomalies in Dronning Maud Land, East Antarctica, in a historical and future climate perspective, Geophysical Research Letters, 40(11), 2684-2688, doi: 10.1002/grl.50559, 2013. 
Ligtenberg, S. R. M., W. J. van de Berg, M. R. van den Broeke, J. G. L. Rae, and E. van Meijgaard, Future surface mass balance of the Antarctic ice sheet and its influence on sea level change, simulated by a regional atmospheric climate model, Climate Dynamics, 41(3-4), 867-884, doi: 10.1007/s00382-013-1749-1, 2013.

Limpasuvan, V., and D. L. Hartmann, Eddies and the annular modes of climate variability, Geophysical Research Letters, 26(20), 3133-3136, doi: 10.1029/ 1999GL010478, 1999.

Limpasuvan, V., and D. L. Hartmann, Wave-Maintained Annular Modes of Climate Variability, Journal of Climate, 13(24), 4414-4429, doi: 10.1175/1520-0442(2000) 013<4414:WMAMOC>2.0.CO;2, 2000.

Lorenz, D. J., and D. L. Hartmann, Eddy-Zonal Flow Feedback in the Southern Hemisphere, Journal of the Atmospheric Sciences, 58(21), 3312-3327, doi: 10.1175/ 1520-0469(2001)058<3312:EZFFIT>2.0.CO;2, 2001.

Lubin, D., R. A. Wittenmyer, D. H. Bromwich, and G. J. Marshall, Antarctic Peninsula mesoscale cyclone variability and climatic impacts influenced by the SAM, Geophysical Research Letters, 35(2), L02,808, doi: 10.1029/2007GL032170, 2008.

Lucchitta, B. K., and C. E. Rosanova, Retreat of northern margins of George VI and Wilkins Ice Shelves, Antarctic Peninsula, Annals of Glaciology, 27, 41-46, doi: 10. 3189/1998AoG27-1-41-46, 1998.

Luckman, A., A. Elvidge, D. Jansen, B. Kulessa, P. Kuipers Munneke, J. King, and N. E. Barrand, Surface melt and ponding on Larsen C Ice Shelf and the impact of föhn winds, Antarctic Science, 26(06), 625-635, doi: 10.1017/S0954102014000339, 2014.

Mantua, N. J., S. R. Hare, Y. Zhang, J. M. Wallace, and R. C. Francis, A Pacific Interdecadal Climate Oscillation with Impacts on Salmon Production, Bulletin of the American Meteorological Society, 78(6), 1069-1079, doi: 10.1175/1520-0477(1997) 078<1069:APICOW>2.0.CO;2, 1997.

Marshall, G. J., Trends in the Southern Annular Mode from Observations and Re- 
analyses, Journal of Climate, 16(24), 4134-4143, doi: 10.1175/1520-0442(2003) 016<4134:TITSAM>2.0.CO;2, 2003.

Marshall, G. J., and D. W. J. Thompson, The signatures of large-scale patterns of atmospheric variability in Antarctic surface temperatures: Antarctic Temperatures, Journal of Geophysical Research: Atmospheres, 121(7), 3276-3289, doi: 10.1002/ 2015JD024665, 2016.

Marshall, G. J., D. W. J. Thompson, and M. R. van den Broeke, The Signature of Southern Hemisphere Atmospheric Circulation Patterns in Antarctic Precipitation, Geophysical Research Letters, 44(22), 11,580-11,589, doi: 10.1002/2017GL075998, 2017.

Martin, A. C., F. M. Ralph, A. Wilson, L. DeHaan, and B. Kawzenuk, Rapid Cyclogenesis from a Mesoscale Frontal Wave on an Atmospheric River: Impacts on Forecast Skill and Predictability during Atmospheric River Landfall, Journal of Hydrometeorology, 20(9), 1779-1794, doi: 10.1175/JHM-D-18-0239.1, 2019.

Martin, T., and A. Adcroft, Parameterizing the fresh-water flux from land ice to ocean with interactive icebergs in a coupled climate model, Ocean Modelling, 34(3-4), 111124, doi: 10.1016/j.ocemod.2010.05.001, 2010.

Massom, R. A., M. J. Pook, J. C. Comiso, N. Adams, J. Turner, T. Lachlan-Cope, and T. T. Gibson, Precipitation over the Interior East Antarctic Ice Sheet Related to Midlatitude Blocking-High Activity, Journal of Climate, 17(10), 1914-1928, doi: 10.1175/1520-0442(2004)017<1914:POTIEA>2.0.CO;2, 2004.

Massom, R. A., S. E. Stammerjohn, W. Lefebvre, S. A. Harangozo, N. Adams, T. A. Scambos, M. J. Pook, and C. Fowler, West Antarctic Peninsula sea ice in 2005: Extreme ice compaction and ice edge retreat due to strong anomaly with respect to climate, Journal of Geophysical Research, 113(C2), C02S20, doi: 10.1029/ 2007JC004239, 2008.

Massom, R. A., T. A. Scambos, L. G. Bennetts, P. Reid, V. A. Squire, and S. E. Stammerjohn, Antarctic ice shelf disintegration triggered by sea ice loss and ocean swell, Nature, 558(7710), 383-389, doi: 10.1038/s41586-018-0212-1, 2018. 
Massom, R. A., et al., Extreme Anomalous Atmospheric Circulation in the West Antarctic Peninsula Region in Austral Spring and Summer 2001/02, and Its Profound Impact on Sea Ice and Biota*, Journal of Climate, 19(15), 3544-3571, doi: 10.1175/JCLI3805.1, 2006.

Mattingly, K. S., J. T. McLeod, J. A. Knox, J. M. Shepherd, and T. L. Mote, A climatological assessment of Greenland blocking conditions associated with the track of Hurricane Sandy and historical North Atlantic hurricanes, International Journal of Climatology, 35(5), 746-760, doi: 10.1002/joc.4018, publisher: John Wiley \& Sons, Ltd, 2015.

Mattingly, K. S., T. L. Mote, and X. Fettweis, Atmospheric River Impacts on Greenland Ice Sheet Surface Mass Balance, Journal of Geophysical Research: Atmospheres, 123(16), 8538-8560, doi: 10.1029/2018JD028714, 2018.

Medley, B., and E. R. Thomas, Increased snowfall over the Antarctic Ice Sheet mitigated twentieth-century sea-level rise, Nature Climate Change, 9(1), 34-39, doi: 10.1038/s41558-018-0356-x, 2019.

Merino, N., N. C. Jourdain, J. Le Sommer, H. Goosse, P. Mathiot, and G. Durand, Impact of increasing antarctic glacial freshwater release on regional sea-ice cover in the Southern Ocean, Ocean Modelling, 121, 76-89, doi: 10.1016/j.ocemod.2017. 11.009, 2018.

Mo, K. C., and M. Ghil, Statistics and Dynamics of Persistent Anomalies, Journal of the Atmospheric Sciences, 44(5), 877-902, doi: 10.1175/1520-0469(1987)044<0877: SADOPA > 2.0.CO;2, 1987 .

Mo, K. C., and R. W. Higgins, The Pacific-South American Modes and Tropical Convection during the Southern Hemisphere Winter, Monthly Weather Review, 126(6), 1581-1596, doi: 10.1175/1520-0493(1998)126<1581:TPSAMA>2.0.CO;2, 1998.

Mo, K. C., and J. N. Paegle, The Pacific-South American modes and their downstream effects, International Journal of Climatology, 21(10), 1211-1229, doi: 10.1002/joc. 685, 2001. 
Mora, C., et al., The projected timing of climate departure from recent variability, $\mathrm{Na}$ ture, 502(7470), 183-187, doi: 10.1038/nature12540, 2013.

Mottram, R., et al., What is the Surface Mass Balance of Antarctica? An Intercomparison of Regional Climate Model Estimates, The Cryosphere Discussions, 2020, 1-42, doi: 10.5194/tc-2019-333, 2020.

Mueller, R. D., L. Padman, M. S. Dinniman, S. Y. Erofeeva, H. A. Fricker, and M. A. King, Impact of tide-topography interactions on basal melting of Larsen C Ice Shelf, Antarctica, Journal of Geophysical Research: Oceans, 117(C5), doi: 10.1029/2011JC007263, publisher: John Wiley \& Sons, Ltd, 2012.

Munneke, P. K., S. R. M. Ligtenberg, M. R. van den Broeke, J. H. van Angelen, and R. R. Forster, Explaining the presence of perennial liquid water bodies in the firn of the Greenland Ice Sheet, Geophysical Research Letters, 41(2), 476-483, doi: 10. 1002/2013GL058389, 2014.

Naithani, J., H. Gallée, and G. Schayes, Marine air intrusion into the Adelie Land sector of East Antarctica: A study using the regional climate model (MAR), Journal of Geophysical Research: Atmospheres, 107(D11), ACL 6-1-ACL 6-16, doi: 10.1029/ 2000JD000274, 2002.

Nash, D., D. Waliser, B. Guan, H. Ye, and F. M. Ralph, The Role of Atmospheric Rivers in Extratropical and Polar Hydroclimate, Journal of Geophysical Research: Atmospheres, 123(13), 6804-6821, doi: 10.1029/2017JD028130, 2018.

Nayak, M. A., G. Villarini, and D. A. Lavers, On the skill of numerical weather prediction models to forecast atmospheric rivers over the central United States, Geophysical Research Letters, 41(12), 4354-4362, doi: 10.1002/2014GL060299, publisher: John Wiley \& Sons, Ltd, 2014.

Neff, W., Atmospheric rivers melt Greenland, Nature Climate Change, 8(10), 857-858, doi: 10.1038/s41558-018-0297-4, 2018.

Neff, W., G. P. Compo, F. Martin Ralph, and M. D. Shupe, Continental heat anomalies and the extreme melting of the Greenland ice surface in 2012 and 1889: Melt- 
ing of Greenland in 1889 and 2012, Journal of Geophysical Research: Atmospheres, 119(11), 6520-6536, doi: 10.1002/2014JD021470, 2014.

Neiman, P. J., F. M. Ralph, G. A. Wick, Y.-H. Kuo, T.-K. Wee, Z. Ma, G. H. Taylor, and M. D. Dettinger, Diagnosis of an Intense Atmospheric River Impacting the Pacific Northwest: Storm Summary and Offshore Vertical Structure Observed with COSMIC Satellite Retrievals, Monthly Weather Review, 136(11), 4398-4420, doi: 10.1175/2008MWR2550.1, 2008a.

Neiman, P. J., F. M. Ralph, G. A. Wick, J. D. Lundquist, and M. D. Dettinger, Meteorological Characteristics and Overland Precipitation Impacts of Atmospheric Rivers Affecting the West Coast of North America Based on Eight Years of SSM/I Satellite Observations, Journal of Hydrometeorology, 9(1), 22-47, doi: 10.1175/2007JHM855. $1,2008 b$.

Neiman, P. J., F. M. Ralph, B. J. Moore, M. Hughes, K. M. Mahoney, J. M. Cordeira, and M. D. Dettinger, The Landfall and Inland Penetration of a Flood-Producing Atmospheric River in Arizona. Part I: Observed Synoptic-Scale, Orographic, and Hydrometeorological Characteristics, Journal of Hydrometeorology, 14(2), 460-484, doi: 10.1175/JHM-D-12-0101.1, 2013.

Neiman, P. J., B. J. Moore, A. B. White, G. A. Wick, J. Aikins, D. L. Jackson, J. R. Spackman, and F. M. Ralph, An Airborne and Ground-Based Study of a Long-Lived and Intense Atmospheric River with Mesoscale Frontal Waves Impacting California during CalWater-2014, Monthly Weather Review, 144(3), 1115-1144, doi: 10.1175/ MWR-D-15-0319.1, 2016.

Newell, R. E., N. E. Newell, Y. Zhu, and C. Scott, Tropospheric rivers? - A pilot study, Geophysical Research Letters, 19(24), 2401-2404, doi: 10.1029/92GL02916, publisher: John Wiley \& Sons, Ltd, 1992.

Nghiem, S. V., D. K. Hall, T. L. Mote, M. Tedesco, M. R. Albert, K. Keegan, C. A. Shuman, N. E. DiGirolamo, and G. Neumann, The extreme melt across the Greenland ice sheet in 2012, Geophysical Research Letters, 39(20), doi: 10.1029/2012GL053611, publisher: John Wiley \& Sons, Ltd, 2012. 
Nicolas, J. P., and D. H. Bromwich, Precipitation Changes in High Southern Latitudes from Global Reanalyses: A Cautionary Tale, Surveys in Geophysics, 32(4-5), 475494, doi: 10.1007/s10712-011-9114-6, 2011.

Nicolas, J. P., et al., January 2016 extensive summer melt in West Antarctica favoured by strong El Niño, Nature Communications, 8, 15,799, doi: 10.1038/ncomms15799, 2017.

Noone, D., and I. Simmonds, Implications for the interpretation of ice-core isotope data from analysis of modelled Antarctic precipitation, Annals of Glaciology, 27, 398-402, doi: 10.3189/1998AoG27-1-398-402, 1998.

O'Brien, T. A., et al., Increases in Future AR Count and Size: Overview of the ARTMIP Tier 2 CMIP5/6 Experiment, preprint, Climatology (Global Change), doi: 10.1002/ essoar.10504170.1, 2020.

O’Connor, W. P., D. H. Bromwich, and J. F. Carrasco, Cyclonically Forced Barrier Winds along the Transantarctic Mountains near Ross Island, Monthly Weather Review, 122(1), 137-150, doi: 10.1175/1520-0493(1994)122<0137:CFBWAT>2.0.CO; $2,1994$.

O'Reilly, C. H., Interdecadal variability of the ENSO teleconnection to the wintertime North Pacific, Climate Dynamics, 51(9), 3333-3350, doi: 10.1007/ s00382-018-4081-y, 2018.

Orr, A., G. J. Marshall, J. C. R. Hunt, J. Sommeria, C.-G. Wang, N. P. M. van Lipzig, D. Cresswell, and J. C. King, Characteristics of Summer Airflow over the Antarctic Peninsula in Response to Recent Strengthening of Westerly Circumpolar Winds, Journal of the Atmospheric Sciences, 65(4), 1396-1413, doi: 10.1175/2007JAS2498.1, 2008.

Palerme, C., C. Genthon, C. Claud, J. E. Kay, N. B. Wood, and T. L'Ecuyer, Evaluation of current and projected Antarctic precipitation in CMIP5 models, Climate Dynamics, 48(1-2), 225-239, doi: 10.1007/s00382-016-3071-1, 2017.

Pattyn, F., Sea-level response to melting of Antarctic ice shelves on multi-centennial 
timescales with the fast Elementary Thermomechanical Ice Sheet model (f.ETISh v1.0), The Cryosphere, 11(4), 1851-1878, doi: 10.5194/tc-11-1851-2017, 2017.

Payne, A. E., et al., Responses and impacts of atmospheric rivers to climate change, Nature Reviews Earth \& Environment, doi: 10.1038/s43017-020-0030-5, 2020.

Petit, J. R., et al., Climate and atmospheric history of the past 420,000 years from the Vostok ice core, Antarctica, Nature, 399(6735), 429-436, doi: 10.1038/20859, 1999.

Philander, S. G., and E. M. Rasmusson, The Southern Oscillation and El Niño, in Advances in Geophysics, vol. 28, pp. 197-215, Elsevier, doi: 10.1016/S0065-2687(08) 60224-1, 1985.

Philander, S. G. H., El Niño Southern Oscillation phenomena, Nature, 302(5906), 295301, doi: 10.1038/302295a0, 1983.

Picard, G., L. Arnaud, R. Caneill, E. Lefebvre, and M. Lamare, Observation of the process of snow accumulation on the Antarctic Plateau by time lapse laser scanning, The Cryosphere, 13(7), 1983-1999, doi: 10.5194/tc-13-1983-2019, 2019.

Priestley, M. D. K., D. Ackerley, J. L. Catto, K. I. Hodges, R. E. McDonald, and R. W. Lee, An Overview of the Extratropical Storm Tracks in CMIP6 Historical Simulations, Journal of Climate, 33(15), 6315-6343, doi: 10.1175/JCLI-D-19-0928.1, 2020.

Pritchard, H. D., S. R. M. Ligtenberg, H. A. Fricker, D. G. Vaughan, M. R. van den Broeke, and L. Padman, Antarctic ice-sheet loss driven by basal melting of ice shelves, Nature, 484(7395), 502-505, doi: 10.1038/nature10968, 2012.

Qiao, G., Y. Li, S. Guo, and W. Ye, Evolving Instability of the Scar Inlet Ice Shelf based on Sequential Landsat Images Spanning 2005-2018, Remote Sensing, 12(1), 36, doi: 10.3390/rs12010036, 2019.

Ralph, F. M., P. J. Neiman, and G. A. Wick, Satellite and CALJET Aircraft Observations of Atmospheric Rivers over the Eastern North Pacific Ocean during the Winter of 1997/98, Monthly Weather Review, 132(7), 1721-1745, doi: 10.1175/ 1520-0493(2004)132<1721:SACAOO>2.0.CO;2, 2004. 
Ralph, F. M., P. J. Neiman, and R. Rotunno, Dropsonde Observations in Low-Level Jets over the Northeastern Pacific Ocean from CALJET-1998 and PACJET-2001: Mean Vertical-Profile and Atmospheric-River Characteristics, Monthly Weather Review, 133(4), 889-910, doi: 10.1175/MWR2896.1, 2005.

Ralph, F. M., P. J. Neiman, G. N. Kiladis, K. Weickmann, and D. W. Reynolds, A Multiscale Observational Case Study of a Pacific Atmospheric River Exhibiting Tropical-Extratropical Connections and a Mesoscale Frontal Wave, Monthly Weather Review, 139(4), 1169-1189, doi: 10.1175/2010MWR3596.1, 2011.

Ralph, F. M., T. Coleman, P. J. Neiman, R. J. Zamora, and M. D. Dettinger, Observed Impacts of Duration and Seasonality of Atmospheric-River Landfalls on Soil Moisture and Runoff in Coastal Northern California, Journal of Hydrometeorology, 14(2), 443-459, doi: 10.1175/JHM-D-12-076.1, 2013.

Ralph, F. M., J. J. Rutz, J. M. Cordeira, M. Dettinger, M. Anderson, D. Reynolds, L. J. Schick, and C. Smallcomb, A Scale to Characterize the Strength and Impacts of Atmospheric Rivers, Bulletin of the American Meteorological Society, 100(2), 269289, doi: 10.1175/BAMS-D-18-0023.1, 2019.

Ralph, F. M., M. D. Dettinger, J. J. Rutz, and D. E. Waliser (Eds.), Atmospheric Rivers, Springer International Publishing, Cham, doi: 10.1007/978-3-030-28906-5, 2020.

Ralph, F. M., et al., Atmospheric Rivers Emerge as a Global Science and Applications Focus, Bulletin of the American Meteorological Society, 98(9), 1969-1973, doi: 10. 1175/BAMS-D-16-0262.1, 2017.

Rankl, M., J. J. Fürst, A. Humbert, and M. H. Braun, Dynamic changes on the Wilkins Ice Shelf during the 2006-2009 retreat derived from satellite observations, The Cryosphere, 11(3), 1199-1211, doi: 10.5194/tc-11-1199-2017, 2017.

Raphael, M. N., G. J. Marshall, J. Turner, R. L. Fogt, D. Schneider, D. A. Dixon, J. S. Hosking, J. M. Jones, and W. R. Hobbs, The Amundsen Sea Low: Variability, Change, and Impact on Antarctic Climate, Bulletin of the American Meteorological Society, 97(1), 111-121, doi: 10.1175/BAMS-D-14-00018.1, 2016. 
Reason, C. J. C., and M. Rouault, Links between the Antarctic Oscillation and winter rainfall over western South Africa: ANTARCTIC OSCILLATION, Geophysical Research Letters, 32(7), n/a-n/a, doi: 10.1029/2005GL022419, 2005.

Renwick, J. A., and M. J. Revell, Blocking over the South Pacific and Rossby Wave Propagation, Monthly Weather Review, 127(10), 2233-2247, doi: 10.1175/ 1520-0493(1999)127<2233:BOTSPA>2.0.CO;2, 1999.

Ridder, K. D., and G. Schayes, The IAGL Land Surface Model, Journal of Applied Meteorology, 36(2), 167-182, doi: 10.1175/1520-0450(1997)036<0167:TILSM>2.0.CO;2, 1997.

Rignot, E., J. Mouginot, B. Scheuchl, M. van den Broeke, M. J. van Wessem, and M. Morlighem, Four decades of Antarctic Ice Sheet mass balance from 1979-2017, Proceedings of the National Academy of Sciences, 116(4), 1095, doi: 10.1073/pnas. 1812883116, 2019.

Ritz, C., T. L. Edwards, G. Durand, A. J. Payne, V. Peyaud, and R. C. A. Hindmarsh, Potential sea-level rise from Antarctic ice-sheet instability constrained by observations, Nature, 528(7580), 115-118, doi: 10.1038/nature16147, 2015.

Robel, A. A., and A. F. Banwell, A Speed Limit on Ice Shelf Collapse Through Hydrofracture, Geophysical Research Letters, 46(21), 12,092-12,100, doi: 10.1029/ 2019GL084397, 2019.

Rogers, J. C., and H. van Loon, Spatial Variability of Sea Level Pressure and 500 mb Height Anomalies over the Southern Hemisphere, Monthly Weather Review, 110(10), 1375-1392, doi: 10.1175/1520-0493(1982)110<1375:SVOSLP>2.0.CO;2, 1982.

Rott, H., P. Skvarca, and T. Nagler, Rapid Collapse of Northern Larsen Ice Shelf, Antarctica, Science, 271(5250), 788-792, doi: 10.1126/science.271.5250.788, 1996.

Rott, H., W. Rack, T. Nagler, and P. Skvarca, Climatically induced retreat and collapse of northern Larsen Ice Shelf, Antarctic Peninsula, Annals of Glaciology, 27, 86-92, doi: 10.3189/S0260305500017262, 1998. 
Rott, H., W. Rack, P. Skvarca, and H. D. Angelis, Northern Larsen Ice Shelf, Antarctica: further retreat after collapse, Annals of Glaciology, 34, 277-282, doi: 10.3189/ $172756402781817716,2002$.

Roussel, M.-L., F. Lemonnier, C. Genthon, and G. Krinner, Brief communication: Evaluating Antarctic precipitation in ERA5 and CMIP6 against CloudSat observations, The Cryosphere, 14(8), 2715-2727, doi: 10.5194/tc-14-2715-2020, 2020.

Rutz, J. J., W. J. Steenburgh, and F. M. Ralph, Climatological Characteristics of Atmospheric Rivers and Their Inland Penetration over the Western United States, Monthly Weather Review, 142(2), 905-921, doi: 10.1175/MWR-D-13-00168.1, 2014.

Rutz, J. J., et al., The Atmospheric River Tracking Method Intercomparison Project (ARTMIP): Quantifying Uncertainties in Atmospheric River Climatology, Journal of Geophysical Research: Atmospheres, 124(24), 13,777-13,802, doi: 10.1029/ 2019JD030936, publisher: John Wiley \& Sons, Ltd, 2019.

Saha, S., et al., The NCEP Climate Forecast System Reanalysis, Bulletin of the American Meteorological Society, 91(8), 1015-1058, doi: 10.1175/2010BAMS3001.1, 2010.

Scambos, T., Images of Antarctic Ice Shelves, doi: 10.7265/N5NC5Z4N, type: dataset, 2001.

Scambos, T., H. A. Fricker, C.-C. Liu, J. Bohlander, J. Fastook, A. Sargent, R. Massom, and A.-M. Wu, Ice shelf disintegration by plate bending and hydro-fracture: Satellite observations and model results of the 2008 Wilkins ice shelf break-ups, Earth and Planetary Science Letters, 280(1-4), 51-60, doi: 10.1016/j.epsl.2008.12.027, 2009.

Scambos, T. A., Glacier acceleration and thinning after ice shelf collapse in the Larsen B embayment, Antarctica, Geophysical Research Letters, 31(18), doi: 10. 1029/2004GL020670, 2004.

Scambos, T. A., C. Hulbe, M. Fahnestock, and J. Bohlander, The link between climate warming and break-up of ice shelves in the Antarctic Peninsula, Journal of Glaciology, 46(154), 516-530, doi: 10.3189/172756500781833043, 2000. 
Scarchilli, C., M. Frezzotti, and P. M. Ruti, Snow precipitation at four ice core sites in East Antarctica: provenance, seasonality and blocking factors, Climate Dynamics, 37(9), 2107-2125, doi: 10.1007/s00382-010-0946-4, 2011.

Schlosser, E., K. W. Manning, J. G. Powers, M. G. Duda, G. Birnbaum, and K. Fujita, Characteristics of high-precipitation events in Dronning Maud Land, Antarctica, Journal of Geophysical Research, 115(D14), D14,107, doi: 10.1029/2009JD013410, 2010.

Schlosser, E., B. Stenni, M. Valt, A. Cagnati, J. G. Powers, K. W. Manning, M. Raphael, and M. G. Duda, Precipitation and synoptic regime in two extreme years 2009 and 2010 at Dome C, Antarctica - implications for ice core interpretation, Atmospheric Chemistry and Physics, 16(8), 4757-4770, doi: 10.5194/acp-16-4757-2016, 2016.

Schlosser, E., et al., The influence of the synoptic regime on stable water isotopes in precipitation at Dome C, East Antarctica, The Cryosphere, 11(5), 2345-2361, doi: 10.5194/tc-11-2345-2017, 2017.

Scott, R. C., J. P. Nicolas, D. H. Bromwich, J. R. Norris, and D. Lubin, Meteorological Drivers and Large-Scale Climate Forcing of West Antarctic Surface Melt, Journal of Climate, 32(3), 665-684, doi: 10.1175/JCLI-D-18-0233.1, 2019.

Seager, R., N. Harnik, Y. Kushnir, W. Robinson, and J. Miller, Mechanisms of Hemispherically Symmetric Climate Variability*, Journal of Climate, 16(18), 2960-2978, doi: 10.1175/1520-0442(2003)016<2960:MOHSCV>2.0.CO;2, 2003.

Seroussi, H., et al., ISMIP6 Antarctica: a multi-model ensemble of the Antarctic ice sheet evolution over the 21st century, The Cryosphere, 14(9), 3033-3070, doi: 10. 5194/tc-14-3033-2020, 2020.

Servettaz, A. P. M., et al., Snowfall and Water Stable Isotope Variability in East Antarctica Controlled by Warm Synoptic Events, Journal of Geophysical Research: Atmospheres, 125(17), e2020JD032,863, doi: 10.1029/2020JD032863, publisher: John Wiley \& Sons, Ltd, 2020.

Shields, C. A., and J. T. Kiehl, Atmospheric river landfall-latitude changes in future 
climate simulations, Geophysical Research Letters, 43(16), 8775-8782, doi: 10.1002/ 2016GL070470, publisher: John Wiley \& Sons, Ltd, 2016.

Shields, C. A., et al., Atmospheric River Tracking Method Intercomparison Project (ARTMIP): project goals and experimental design, Geoscientific Model Development, 11(6), 2455-2474, doi: 10.5194/gmd-11-2455-2018, 2018.

Shiotani, M., Low-frequency Variations of the Zonal Mean State of the Southern Hemisphere Troposphere, Journal of the Meteorological Society of Japan. Ser. II, 68(4), 461-471, doi: 10.2151/jmsj1965.68.4_461, 1990.

Shuang-Ye Wu, Brent Yarnal, and Ann Fisher, Vulnerability of coastal communities to sea-level rise: a case study of Cape May County, New Jersey, USA, Climate Research, 22(3), 255-270, 2002.

Shuman, C. A., E. Berthier, and T. A. Scambos, 2001-2009 elevation and mass losses in the Larsen A and B embayments, Antarctic Peninsula, Journal of Glaciology, 57(204), 737-754, doi: 10.3189/002214311797409811, 2011.

Siegert, M., et al., The Antarctic Peninsula Under a $1.5^{\circ} \mathrm{C}$ Global Warming Scenario, Frontiers in Environmental Science, 7, 102, doi: 10.3389/fenvs.2019.00102, 2019.

Silvestri, G. E., Antarctic Oscillation signal on precipitation anomalies over southeastern South America, Geophysical Research Letters, 30(21), doi: 10.1029/ 2003GL018277, 2003.

Simmonds, I., K. Keay, and E.-P. Lim, Synoptic Activity in the Seas around Antarctica, Monthly Weather Review, 131(2), 272-288, doi: 10.1175/1520-0493(2003)131<0272: SAITSA > 2.0.CO;2, 2003.

Skvarca, P., Fast recession of the northern Larsen Ice Shelf monitored by space images, Annals of Glaciology, 17, 317-321, doi: 10.3189/S0260305500013033, 1993.

Skvarca, P., Changes and surface features of the Larsen Ice Shelf, Antarctica, derived from Landsat and Kosmos mosaics, Annals of Glaciology, 20, 6-12, doi: 10.3189/ 1994AoG20-1-6-12, 1994. 
Skvarca, P., W. Rack, H. Rott, and T. I. Y Donángelo, Evidence of recent climatic warming on the eastern Antarctic Peninsula, Annals of Glaciology, 27, 628-632, doi: 10.3189/S0260305500018164, 1998.

Smith, B., et al., Pervasive ice sheet mass loss reflects competing ocean and atmosphere processes, Science, 368(6496), 1239, doi: 10.1126/science.aaz5845, 2020.

Sodemann, H., and A. Stohl, Moisture Origin and Meridional Transport in Atmospheric Rivers and Their Association with Multiple Cyclones, Monthly Weather Review, 141(8), 2850-2868, doi: 10.1175/MWR-D-12-00256.1, 2013.

Souverijns, N., A. Gossart, I. V. Gorodetskaya, S. Lhermitte, A. Mangold, Q. Laffineur, A. Delcloo, and N. P. M. van Lipzig, How does the ice sheet surface mass balance relate to snowfall? Insights from a ground-based precipitation radar in East Antarctica, The Cryosphere, 12(6), 1987-2003, doi: 10.5194/tc-12-1987-2018, 2018.

Spensberger, C., M. J. Reeder, T. Spengler, and M. Patterson, The Connection between the Southern Annular Mode and a Feature-Based Perspective on Southern Hemisphere Midlatitude Winter Variability, Journal of Climate, 33(1), 115-129, doi: 10.1175/JCLI-D-19-0224.1, 2020.

Stenni, B., et al., Three-year monitoring of stable isotopes of precipitation at ConcordiaStation, East Antarctica, The Cryosphere, 10(5), 2415-2428, doi: 10.5194/ tc-10-2415-2016, 2016.

Thomas, E. R., J. S. Hosking, R. R. Tuckwell, R. A. Warren, and E. C. Ludlow, Twentieth century increase in snowfall in coastal West Antarctica, Geophysical Research Letters, 42(21), 9387-9393, doi: 10.1002/2015GL065750, publisher: John Wiley \& Sons, Ltd, 2015.

Thompson, D. W. J., and J. M. Wallace, Annular Modes in the Extratropical Circulation. Part I: Month-to-Month Variability, Journal of Climate, 13(5), 1000-1016, doi: 10.1175/1520-0442(2000)013<1000:AMITEC>2.0.CO;2, 2000.

Thompson, D. W. J., and J. D. Woodworth, Barotropic and Baroclinic Annular Variability in the Southern Hemisphere, Journal of the Atmospheric Sciences, 71(4), 1480-1493, doi: 10.1175/JAS-D-13-0185.1, 2014. 
Trenberth, K. E., The Definition of El Niño, Bulletin of the American Meteorological Society, 78(12), 2771-2777, doi: 10.1175/1520-0477(1997)078<2771:TDOENO>2. $0 . \mathrm{CO} ; 2,1997$.

Tsuji, H., and Y. N. Takayabu, Precipitation Enhancement via the Interplay between Atmospheric Rivers and Cutoff Lows, Monthly Weather Review, 147(7), 2451-2466, doi: 10.1175/MWR-D-18-0358.1, 2019.

Turner, J., The El Niño-southern oscillation and Antarctica, International Journal of Climatology, 24(1), 1-31, doi: 10.1002/joc.965, 2004.

Turner, J., S. R. Colwell, G. J. Marshall, T. A. Lachlan-Cope, A. M. Carleton, P. D. Jones, V. Lagun, P. A. Reid, and S. Iagovkina, Antarctic climate change during the last 50 years, International Journal of Climatology, 25(3), 279-294, doi: 10.1002/joc.1130, 2005.

Turner, J., T. Phillips, J. S. Hosking, G. J. Marshall, and A. Orr, The Amundsen Sea low, International Journal of Climatology, 33(7), 1818-1829, doi: 10.1002/joc.3558, 2013.

Turner, J., et al., Absence of 21st century warming on Antarctic Peninsula consistent with natural variability, Nature, 535(7612), 411-415, doi: 10.1038/nature18645, 2016.

Turner, J., et al., The Dominant Role of Extreme Precipitation Events in Antarctic Snowfall Variability, Geophysical Research Letters, doi: 10.1029/2018GL081517, 2019.

Turton, J. V., A. Kirchgaessner, A. N. Ross, and J. C. King, The spatial distribution and temporal variability of föhn winds over the Larsen C ice shelf, Antarctica, Quarterly Journal of the Royal Meteorological Society, 144(713), 1169-1178, doi: 10.1002/qj. 3284, 2018.

Turton, J. V., A. Kirchgaessner, A. N. Ross, J. C. King, and P. Kuipers Munneke, The influence of föhn winds on annual and seasonal surface melt on the Larsen C Ice Shelf, Antarctica, The Cryosphere Discussions, 2020, 1-25, doi: 10.5194/tc-2020-72, 2020. 
Uotila, P., T. Vihma, and M. Tsukernik, Close interactions between the Antarctic cyclone budget and large-scale atmospheric circulation, Geophysical Research Letters, 40(12), 3237-3241, doi: 10.1002/grl.50560, 2013.

van den Broeke, M., Strong surface melting preceded collapse of Antarctic Peninsula ice shelf, Geophysical Research Letters, 32(12), L12,815, doi: 10.1029/ 2005GL023247, 2005.

van Wessem, J. M., C. R. Steger, N. Wever, and M. R. van den Broeke, Modelling perennial firn aquifers in the Antarctic Peninsula (1979-2016), The Cryosphere Discussions, 2020, 1-30, doi: 10.5194/tc-2020-148, 2020.

Vaughan, D. G., Recent Trends in Melting Conditions on the Antarctic Peninsula and Their Implications for Ice-sheet Mass Balance and Sea Level, Arctic, Antarctic, and Alpine Research, 38(1), 147-152, doi: 10.1657/1523-0430(2006)038[0147:RTIMCO] 2.0.CO;2, 2006.

Vaughan, D. G., and C. S. M. Doake, Recent atmospheric warming and retreat of ice shelves on the Antarctic Peninsula, Nature, 379(6563), 328-331, doi: 10.1038/ $379328 \mathrm{a} 0,1996$.

Vieli, A., A. Payne, A. Shepherd, and Z. Du, Causes of pre-collapse changes of the Larsen B ice shelf: Numerical modelling and assimilation of satellite observations, Earth and Planetary Science Letters, 259(3-4), 297-306, doi: 10.1016/j.epsl.2007.04. 050, 2007.

Vincent, D. G., The South Pacific Convergence Zone (SPCZ): A Review, Monthly Weather Review, 122(9), 1949-1970, doi: 10.1175/1520-0493(1994)122<1949: TSPCZA>2.0.CO;2, 1994.

Waliser, D., and B. Guan, Extreme winds and precipitation during landfall of atmospheric rivers, Nature Geoscience, 10(3), 179-183, doi: 10.1038/ngeo2894, 2017.

Walker, G. T., Correlation in Seasonal Variations of Weather - a Further Study of World Weather, Monthly Weather Review, 53(6), 252-254, doi: 10.1175/ 1520-0493(1925)53<252:CISVOW>2.0.CO;2, 1925. 
Wang, Y., et al., A Comparison of Antarctic Ice Sheet Surface Mass Balance from Atmospheric Climate Models and In Situ Observations, Journal of Climate, 29(14), 5317-5337, doi: 10.1175/JCLI-D-15-0642.1, 2016.

Wille, J. D., D. H. Bromwich, M. A. Nigro, J. J. Cassano, M. Mateling, M. A. Lazzara, and S.-H. Wang, Evaluation of the AMPS Boundary Layer Simulations on the Ross Ice Shelf with Tower Observations, Journal of Applied Meteorology and Climatology, 55(11), 2349-2367, doi: 10.1175/JAMC-D-16-0032.1, 2016.

Wille, J. D., V. Favier, A. Dufour, I. V. Gorodetskaya, J. Turner, C. Agosta, and F. Codron, West Antarctic surface melt triggered by atmospheric rivers, Nature Geoscience, 12(11), 911-916, doi: 10.1038/s41561-019-0460-1, 2019.

Wilson, A. B., Using the NCAR CAM 4 to Confirm SAM's Modulation of the ENSO Teleconnection to Antarctica and Assess Changes to this Interaction during Various ENSO Flavor Events, Ph.D. thesis, The Ohio State University, 2013.

Wuite, J., H. Rott, M. Hetzenecker, D. Floricioiu, J. De Rydt, G. H. Gudmundsson, T. Nagler, and M. Kern, Evolution of surface velocities and ice discharge of Larsen B outlet glaciers from 1995 to 2013, The Cryosphere, 9(3), 957-969, doi: 10.5194/ tc-9-957-2015, 2015.

Zhu, Y., and R. E. Newell, A Proposed Algorithm for Moisture Fluxes from Atmospheric Rivers, Monthly Weather Review, 126(3), 725-735, doi: 10.1175/ 1520-0493(1998)126<0725:APAFMF>2.0.CO;2, 1998.

Zou, X., D. H. Bromwich, J. P. Nicolas, A. Montenegro, and S. Wang, West Antarctic surface melt event of January 2016 facilitated by föhn warming, Quarterly Journal of the Royal Meteorological Society, doi: 10.1002/qj.3460, 2019. 
Appendices 



\section{Appendix A}

\section{Supplementary information and}

\section{figures to "West Antarctic surface melt triggered by atmospheric rivers"}

\section{A.1 Supplementary Text}

\section{Reanalysis comparison}

The multi-reanalysis study (Table 1) demonstrates a noteworthy relative agreement between data sources despite large disagreements between reanalysis precipitation (Bromwich et al. [2011a]; Nicolas and Bromwich [2011]) and to a lesser degree in moisture transport (Dufour et al. [2018]. The multi-reanalysis also demonstrates the impact of model physics and resolution when applying the detection algorithm. After acknowledging documented moisture biases (Agosta et al. [2015], the NCEP/DOE V2 and NCEP/NCAR V1 reanalyses had $\sim 3.0$ percentage points less AR activity than the more recent reanalyses (ERA-Interim, JRA-55, CFSR, and MERRA-2) around Antarctica when using an AR detection algorithm with the same continuity requirement (Supplementary Fig. A.2). Differences likely result from satellite derived atmospheric moisture content which is not assimilated in NCEP/NCAR and NCEP/DOE reanaly-

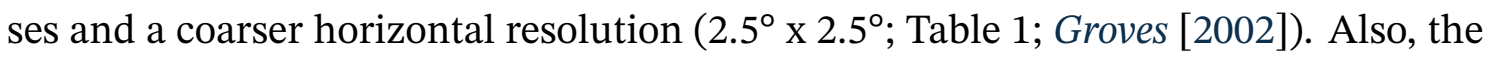


small difference in detection rates between the JRA-55 interpolated to a $2.5^{\circ} \times 2.5^{\circ}$ grid compared against the native $0.5^{\circ} \times 0.5^{\circ} \mathrm{JRA}-55$ shows that while the higher horizontal resolution reanalyzes have slightly higher AR detection rates, differences in model physics still introduce more variance agreeing with a similar experiment performed on a global AR detection algorithm and further studies backing this conclusion (Guan and Waliser [2017].

Within most of the reanalyses, there is a significant positive trend in ARs making landfall in the AP-Weddell and DML-PEL quadrants since the beginning of the 21st century (Table 1 and Supplementary Table A.1). The strongest positive trend is seen in MERRA-2 while ERA-Interim is the only reanalysis to show neutral and non-significant trends (Supplementary Table A.1). When the detection rates of all the reanalysis datasets are averaged together, a significant increasing trend appears in the DML-PEL, AP-Weddell, and WAIS quadrants (Supplementary Table A.1 and Supplementary Table A.2). Because the rate of ARs detected with ERA-Interim and MERRA-2 do not vary significantly along time, in particular after 1998 and 2001, the precipitation bias caused by an artifact related to the introduction of Advanced Microwave Sounding Unit (AMSU) radiances is likely not the cause of the present change in AR frequency (Bromwich et al. [2011a]). When using the AR detection algorithm with a less strict continuity there is a slight increase in the amount of detected ARs and slight increase in the positive trend in yearly AR occurrences. (Supplementary Table A.2 and Supplementary Fig. A.2).

When running the same AR detection algorithm using a less strict continuity requirement on all the reanalyses and comparing the results against the MAR meltwater magnitude, the percentage of melt attributed to ARs is generally quite similar. Amongst the other reanalyses with similar or higher resolutions than ERA-Interim (CFSR and JRA-55), the percentage of melt attributed to ARs over the Ross Ice Shelf/Marie Byrd Land during the melt season (December and Janaury) was similar to ERA-Interim despite those reanalyses having a slightly higher amount of detected ARs (Supplementary Fig. A.13). However, when the AR detection algorithm was applied to the $\mathrm{NCEP} / \mathrm{DOE} \mathrm{V} 2$ reanalysis, the percentage of surface melt attributed to AR activity across Marie Byrd Land (between 300 m - 1,500 m elevation) decreases by 20-40 percentage points compared to the other reanalyses (Supplementary Fig. A.13d). Over 
the AP during winter, the reanalyses have similar results with the NCEP/DOE V2 reanalysis showing around 10 percentage points less AR-related surface melt over the Larson B and C ice shelves (Supplementary Fig. A.13h). Despite detecting fewer ARs, the NCEP/DOE V2 and NCEP/NCAR V1 reanalyses are still detecting the most impactful ARs related to surface melt.

\section{Atmospheric river detection algorithm comparison}

Within the ARTMIP project, there is a large assortment of AR detection methods including many that use integrated vapor transport (IVT) in determining a threshold requirement for AR detection (Shields et al. [2018]. To examine the robustness of the IWV-based algorithm and the results presented in this study, we developed a separate AR detection algorithm that utilizes IVT defined as

$$
I \vec{V} T=-\frac{1}{g} \int_{900 h P a}^{300 h P a} q \vec{V} d p,
$$

where $q\left(\mathrm{~kg} \mathrm{~kg}^{-1}\right)$ is the specific humidity, $g\left(\mathrm{~m} \mathrm{~s}^{-2}\right)$ is the gravitational acceleration, and $p$ is the atmospheric pressure $(\mathrm{hPa})$, is the wind vector $\left(\mathrm{m} \mathrm{s}^{-1}\right)$. The IVT-based algorithm uses the same parameters as the IWV-based algorithm (i.e. 98th percentile of IVT, no discontinuities greater than 1 degree latitude, extends at least 20 degrees in the meridional direction, see Chapter 2). Over the Southern Ocean, the circulation pattern is dominated by the westerlies while poleward moisture advection from the mid-latitudes is dependent on the meridional component of the wind (King and Turner [2007]). When testing with a moisture transport term that includes both $\mathrm{U}$ and $\mathrm{V}$ components of the wind like used in a previous global AR detection algorithm tested over Antarctica (Guan and Waliser [2017]), our algorithm became biased towards intense extra-tropical cyclones with strong zonal moisture transport, but the high moisture filaments were often disconnected from the sub-tropics. Therefore, using an integrated q for IVT favors detecting ARs with a sub-tropical moisture connection.

The two algorithms have similar annual variability in AR detection occurrences, but the IVT-based algorithm has relative detection rate 0.6-0.8 percentage points higher than the IWV-based algorithm throughout all quadrants during the study period when run on an ERA-Interim dataset (Supplementary Fig. A.14). This 
agrees with previous studies comparing IVT and IWV-based detection methods over the Sierra Nevada in California (Huning et al. [2017]). Some of the AR shapes detected by the IVT-based algorithm exhibited strong meridional winds but lacked a clear moisture connection with the sub-tropics. Since our objective is to examine only definitive ARs and remove as many common potential extratropical cyclones as possible, we preferred the IWV-based detection algorithm detection.

When looking at the relationship between detected ARs and surface melting, the IWV-based algorithm shows that ARs account for a higher percentage of the total meltwater than the IVT-based algorithm (Supplementary Figs. A.15a and A.15b). However over the AP, the two algorithms have very similar meltwater percentages with the IVT-based algorithm showing slightly higher percentages over the Larsen C ice shelf (Supplementary Figs. A.15c and A.15d). This could be because over WAIS, downward longwave radiation from mixed phase clouds is most correlated with summer surface melt during AR events while the turbulent heat fluxes are smaller (Figs. $2 \mathrm{c}$ and $2 \mathrm{~d}$ ). Winter melting during ARs over the AP is still related to an increase in downward longwave radiation, however the sensible heat flux related to the foehn effect that is driven by the magnitude of the moisture transport becomes more important (Fig. 2e). As longwave radiation increases are correlated with increases in IWV and sensible heat flux increases are correlated with increases in IVT (Fig. 2), the two algorithms emphasize different physical mechanisms related to melting.

\section{Antarctic atmospheric rivers and rainfall}

As an extratropical cyclone travels across the Southern Ocean at the relatively warmer lower latitudes, the high moisture content within the AR can be related to tropical moisture export and typically is maintained through a continuous and vigorous moisture convergence in the cyclone's warm conveyor belt circulation and/or along the trailing cold front (Sodemann and Stohl [2013]; Boutle et al. [2011]; Bao et al. [2006]). As the cyclone travels southward, the evaporation along the AR path transitions to more moisture deposition over the cooler sea surface. Once an AR reaches a landmass, isentropic ascent within the warm conveyer belt combined with the orographic ascent of moisture leads to intense precipitation over the affected region (Neiman et al. [2008b]. Atmospheric rivers can persist over the domain through 
sequential cyclones under a conducive atmospheric circulation, meaning they can be distinct from a particular cyclone's warm conveyer belt (Sodemann and Stohl [2013])

While the presence of extratropical cyclones surrounding the Antarctic continent is common, most do not make landfall (Uotila et al. [2013]; Hoskins and Hodges [2005]). This dynamic also applies to ARs where they are associated with high precipitation events inland. For example, 4-5 atmospheric rivers contributed to $74-80 \%$ of the coastal Dronning Maud Land's surface mass balance (SMB) during 2009 and 2011 (Gorodetskaya et al. [2014]) - two years with anomalous surface mass balance within the past 60 years that compensated for the total Antarctic negative mass balance from 2009-2011 (Lenaerts et al. [2013]; Boening et al. [2012]; King et al. [2012]). Indeed, extratropical cyclones in concert with blocking high systems are responsible for directing strong moisture fluxes towards Antarctica and are the main source of precipitation along coastal and escarpment regions (Uotila et al. [2013]; Gorodetskaya et al. [2014]; Schlosser et al. [2017]; Gorodetskaya et al. [2013]; Souverijns et al. [2018]).

The high heat content associated with ARs frequently leads to rainfall rather than snowfall around the Amundsen Sea Embayment and the western AP ice shelves. According to MAR rainfall data from 1979-2017, 40-50\% of rainfall on the Pine Island and Thwaites Glacier region during summer (DJF; Supplementary Fig. 5a) and 30$50 \%$ of rainfall around the Larsen B, C, Wilkins, Bach, and George VI ice shelves during winter (March-October, Supplementary Fig. 5c) occurred during an AR landfall and within 24 hours after the landfall. In both regions, the ARs are responsible for over $100 \mathrm{~mm}$ of rainfall throughout the study period (Supplementary Figs. A.5b and A.5d). High AR-related summer rainfall percentages also are evident on the base of the Transantarctic Mountains and parts of the Siple Coast, but the rainfall magnitudes are small. Still, rain acts to decrease the albedo of the snow surface and increase surface meltwater, which can be an important contributor to melting events in summer. In regards to the Amundsen Sea Embayment, an increase in rainfall from ARs may increase the formation of meltwater ponds on the Pine Island and Thwaites Glaciers (Favier et al. [2014]; DeConto and Pollard [2016]; Bell et al. [2018]). 


\section{In depth case studies}

ARs were detected during three particularly intense melt events in WAIS and the AP (01/16, 05/16, and 03/15). Here we examine the various physical mechanisms related to melting that were associated with the ARs. From January 10-22, 2016, an historically large and prolonged melt event occurred over the western Ross Ice Shelf and Marie Byrd Land. ARs were detected from 1/10 18z - 1/11 12z, 1/12 12z $1 / 1312 z$, and $1 / 1400 z-1 / 1418 z$. During this period, a prolonged AR extending back to the sub-tropics persisted in the region through sequential cyclones directed by an intense blocking ridge over the South Pacific Ocean (Supplementary Figs A.6a and A.6b). Warm air advection and enhanced radiative forcing from mixed-phase clouds initiated surface melt and increased minimum temperatures which has been shown to reduce meltwater refreezing and decrease the surface albedo (Dufour et al. [2018]). Descending foehn winds originating from the coastal mountain ranges nearby the Amundsen Sea coast enhanced the surface sensible heat flux through isentropic drawdown in the leeward regions of Marie Byrd Land and Edward VII Peninsula (Supplementary Fig A.6g; Zou et al. [2019]). After the ARs ceased, residual high water content clouds (Supplementary Figs. A.6e and A.6f) continued to enhance the downward longwave radiation and continued the melt event for another week (Hu et al. [2019]). The high downward longwave radiation forcing was only partially compensated by a negative shortwave radiation flux at the surface (Supplementary Figs. A.6c and A.6d). At WAIS Divide Camp (elevation 1,800 m), observations indicated liquid-containing clouds along with drizzle while dark clouds with low bases were seen above the camp (Supplementary Fig. A.16; Nicolas et al. [2017]). Overall, this melt event was responsible for generating 40-70 mm of meltwater on the Ross Ice Shelf and the Siple Coast with smaller melt magnitudes extending up to around 1,500 m in Marie Byrd Land according to MAR (Supplementary Fig. A.8a).

The major melt event from May 25th-30th, 2016 that produced $71 \mathrm{~mm}$ of meltwater32 (50 mm of meltwater along the base of the AP mountains and edge of the Larsen C Ice Shelf according to MAR, Supplementary Fig. A.8b) was associated with an AR making landfall on the AP from 5/25 06z - 5/26 12z (Supplementary Fig. A.9; Kuipers Munneke et al. [2018]). A large blocking high-pressure ridge directed the AR to make landfall perpendicular to the AP (Supplementary Fig. A.9a). The IWV 
was orographically lifted over the mountains releasing latent heat aloft which was mechanically mixed towards the surface by a foehn wind leading to enhanced sensible heat fluxes over the Larsen $\mathrm{C}$ ice shelf that dominated the melt flux (Supplementary Fig. A.9d; Kuipers Munneke et al. [2018]). The AR brought clouds with high liquid and ice content to the AP and adjacent WAIS in the middle of winter creating high surface net radiative forcing (Supplementary Figs A.9c, A.9e, and A.9f) that combined with the foehn driven sensible heat flux bringing the surface skin temperature to near $0{ }^{\circ} \mathrm{C}$ on the AP (Supplementary Fig. A.9g).

Another large winter melt event on the AP, that produced 40-70 $\mathrm{mm}$ from March 22-28, 2015 according to MAR (Supplementary Fig. A.5c) and melt ponds on the Larsen A and B embayments, was associated with a documented AR (Bozkurt et al. [2018]). This AR that was detected 3/23 00z - 3/24 00z also led to an Antarctic-wide record maximum temperature of $17.5^{\circ} \mathrm{C}$ at Esperanza station on March 24th, 2015 (Bozkurt et al. [2018]). Similarly to the May 2016 melt event, a long narrow filament of high integrated water vapor that originated from the subtropics struck the western AP and generated a leeside foehn wind leading to increased sensible heat fluxes combining with net radiative surface warming (Supplementary Figs. A.10b, A.10c, and A.10d). Clouds with high liquid water paths were observed generally near the coastline while clouds with high ice water paths pushed further inland (Supplementary Figs. A.10e and A.10f). Sensible heat flux over the eastern AP shows a comparatively strong contribution for this case (Supplementary Fig. A.10d), which is in agreement with the previous study showing that an AR reinforced the foehn wind and associated surface warming in the eastern AP (Bozkurt et al. [2018]). However, the extent of the integrated moisture transport and surface melt is greater than the May 2016 melt event (Supplementary Figs. A.10a, A.8a, and A.8b). Our results demonstrate that both cases of winter surface melt on the eastern AP ice shelves (Supplementary Fig. A.9 and Supplementary Fig. A.10) involved a large blocking high-pressure ridge directing an AR to make landfall perpendicularly along the western AP and triggering a leeside foehn wind on the eastern AP creating large positive temperature anomalies and surface melt on the vulnerable34 ice shelves in that region (Alley et al. [2018]). 


\section{A.2 Supplementary figures and tables}

\begin{tabular}{|c|c|c|c|c|c|}
\hline Reanalysis Type & $\begin{array}{l}\text { Spatial } \\
\text { Resolution }\end{array}$ & $\begin{array}{l}\text { Sigma } \\
\text { Levels }\end{array}$ & $\begin{array}{l}\text { Data } \\
\text { Assimilation }\end{array}$ & $\begin{array}{l}\text { Percentage of days AR } \\
\text { landfall detected }\end{array}$ & $\begin{array}{l}\text { Relative change of AR } \\
\text { detection per decade } \\
\text { (\%) for AR landfalls }\end{array}$ \\
\hline CFSR & $0.5^{\circ} \times 0.5^{\circ}$ & 64 & 3D-Var + FOTO & $1.84 \%, 1.82 \%, 0.87 \%, 1.40 \%$ & $0.45,0.27,0.12,0.25$ \\
\hline JRA-55 & $0.5^{\circ} \times 0.5^{\circ}$ & 60 & 4D-Var & $2.11 \%, 2.08 \%, 0.93 \%, 1.34 \%$ & $0.47,0.18,0.11,0.24$ \\
\hline MERRA-2 & $0.5^{\circ} \times 0.625^{\circ}$ & 72 & $3 \mathrm{D}-\mathrm{Var}+\mathrm{IAU}$ & $2.03 \%, 1.68 \%, 0.97 \%, 1.39 \%$ & $0.53,0.32,0.34,0.30$ \\
\hline ERA-Interim & $0.75^{\circ} \times 0.75^{\circ}$ & 60 & 4D-Var & $1.68 \%, 1.75 \%, 0.96 \%, 1.24 \%$ & $0.25,-0.01,0.11,-0.01$ \\
\hline JRA-55 Low Res* & $2.5^{\circ} \times 2.5^{\circ}$ & 60 & 4D-Var & $2.27 \%, 2.08 \%, 1.05 \%, 1.54 \%$ & $\mathbf{0 . 4 9}, 0.23, \mathbf{0 . 1 5}, \mathbf{0 . 2 7}$ \\
\hline NCEP/DOE V2* & $2.5^{\circ} \times 2.5^{\circ}$ & 28 & 3D-Var & $1.24 \%, 0.80 \%, 0.70 \%, 1.03 \%$ & $0.41,0.19,0.17,0.22$ \\
\hline NCEP/NCAR V1* & $2.5^{\circ} \times 2.5^{\circ}$ & 28 & 3D-Var & $1.21 \%, 0.78 \%, 0.75 \%, 1.01 \%$ & $0.46,0.24,0.16,0.23$ \\
\hline Reanalysis Mean & & & & $1.78 \%, 1.58 \%, 0.89 \%, 1.29 \%$ & $\mathbf{0 . 4 5}, 0.19, \mathbf{0 . 1 7}, \mathbf{0 . 2 2}$ \\
\hline
\end{tabular}

Supplementary Table A.1: List of reanalyses utilized for the AR detection algorithm and statistics. Each reanalysis contains instantaneous fields analyzed at the same 6-hour frequency from 1979-2017 (except MERRA-2 and the reanalysis mean 19802017). For the detected ARs, the colors correspond to the DML-PEL, Wilkes Land, WAIS, and AP-Weddell quadrants respectively. Bold values correspond to significant trends ( $\mathrm{p}$-value $<0.025$ ). The asterisk represents the reanalysis datasets with a horizontal resolution too coarse for the AR detection algorithm, so the AR detection algorithm was run with an integrated water vapor continuity requirement of 3 degrees latitude instead of 1 degree. 


\begin{tabular}{|c|c|c|c|c|c|}
\hline Reanalysis Type & Spatial Resolution & $\begin{array}{l}\text { Sigma } \\
\text { Levels }\end{array}$ & Data Assimilation & $\begin{array}{l}\text { Percentage of days AR landfall } \\
\text { detected }\end{array}$ & $\begin{array}{l}\text { Relative change of AR } \\
\text { detection per decade } \\
\text { (\%) for AR landfalls }\end{array}$ \\
\hline CFSR & $0.5^{\circ} \times 0.5^{\circ}$ & 64 & 3D-Var + FОTO & $2.59 \%, 2.56 \%, 1.28 \%, 2.14 \%$ & $0.54,0.35,0.17,0.35$ \\
\hline JRA-55 & $0.5^{\circ} \times 0.5^{\circ}$ & 60 & $4 \mathrm{D}-\mathrm{Var}$ & $2.73 \%, 2.78 \%, 1.25 \%, 1.90 \%$ & $\mathbf{0 . 6 0}, 0.15, \mathbf{0 . 1 9}, \mathbf{0 . 2 7}$ \\
\hline MERRA-2 & $0.5^{\circ} \times 0.625^{\circ}$ & 72 & $3 D-V a r+I A U$ & $2.80 \%, 2.36 \%, 1.38 \%, 2.19 \%$ & $0.70,0.37,0.49,0.48$ \\
\hline ERA-Interim & $0.75^{\circ} \times 0.75^{\circ}$ & 60 & $4 \mathrm{D}-\mathrm{Var}$ & $2.22 \%, 2.43 \%, 1.30 \%, 1.79 \%$ & $0.26,-0.01,0.13,0.01$ \\
\hline JRA-55 Low Res & $2.5^{\circ} \times 2.5^{\circ}$ & 60 & 4D-Var & $2.27 \%, 2.08 \%, 1.05 \%, 1.54 \%$ & $\mathbf{0 . 4 9}, 0.23, \mathbf{0 . 1 5}, \mathbf{0 . 2 7}$ \\
\hline NCEP/DOE V2 & $2.5^{\circ} \times 2.5^{\circ}$ & 28 & 3D-Var & $1.24 \%, 0.80 \%, 0.70 \%, 1.03 \%$ & $0.41,0.19, \mathbf{0 . 1 7}, 0.22$ \\
\hline NCEP/NCAR V1 & $2.5^{\circ} \times 2.5^{\circ}$ & 28 & 3D-Var & $1.21 \%, 0.78 \%, 0.75 \%, 1.01 \%$ & $0.46,0.24,0.16,0.23$ \\
\hline Reanalysis Mean & & & & $2.16 \%, 1.99 \%, 1.11 \%, 1.67 \%$ & $0.51,0.20,0.21,0.27$ \\
\hline
\end{tabular}

Supplementary Table A.2: The percentage of detected ARs from a different configuration of the detection algorithm with a less strict continuity requirement ( 3 degrees latitude) applied to all reanalysis datasets, Trends of detected ARs making landfall and all detected ARs from 1979-2017 (except MERRA-2 and the reanalysis mean 19802017). For the detected ARs, the colors correspond to the DML-PEL, Wilkes Land, WAIS, and AP-Weddell quadrants respectively. Bold values correspond to significant trends ( $\mathrm{p}$-value $<0.025$ ). Instantaneous fields from all re-analyses are analyzed at the same 6-hour time steps. 

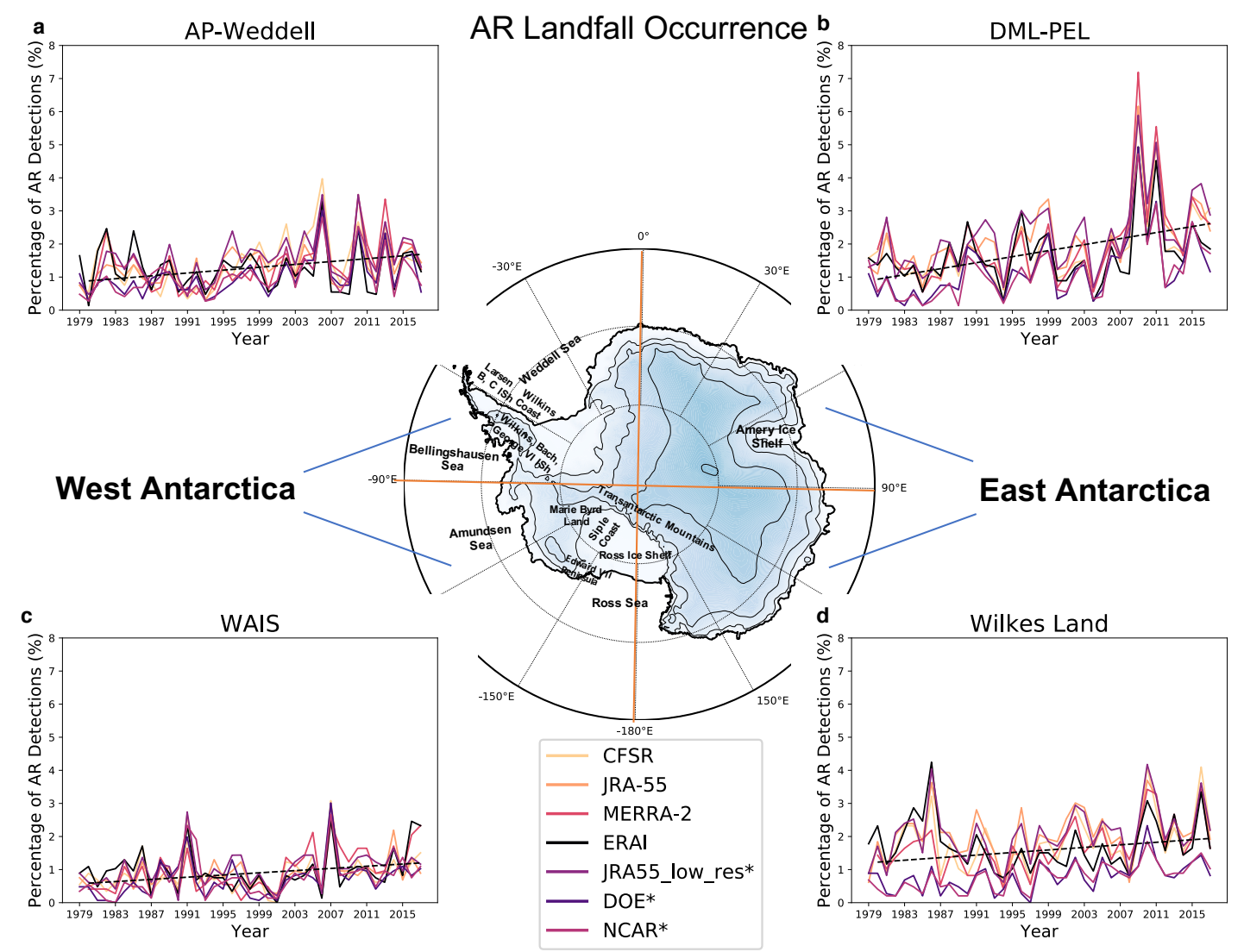

Supplementary Figure A.1: The yearly percentage of 6-hourly atmospheric river occurrences to make landfall detected in the multi-reanalysis dataset. Each box corresponds with a quadrant where the AR detection algorithm was run and accordingly labelled with the quadrant names used throughout the paper. The dashed line represents the linear regression of the mean AR landfall occurrence between all the reanalysis datasets. The asterisk represents the reanalysis datasets with a horizontal resolution too coarse for the AR detection algorithm, so the AR detection algorithm was run with an integrated water vapor continuity requirement of 3 degrees latitude instead of 1 degree. 

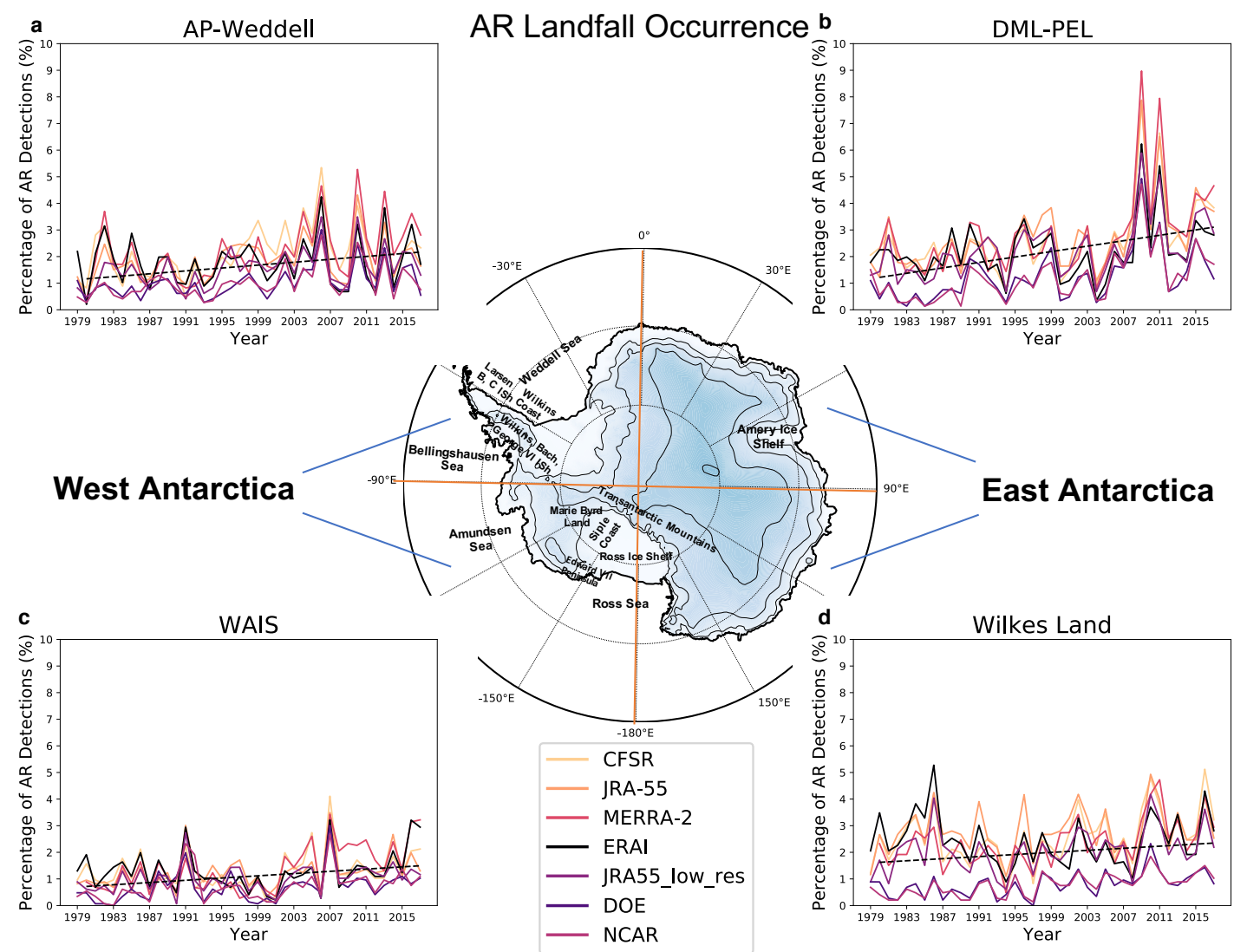

Supplementary Figure A.2: The yearly percentage of 6-hourly atmospheric river occurrences to make landfall detected in the multi-reanalysis dataset using a different configuration of the AR detection algorithm with a less strict integrated water vapor continuity requirement (3 degrees latitude) applied to all reanalysis datasets. The dashed line represents the linear regression of the mean AR landfall occurrence between all the reanalysis datasets. Each box corresponds with a quadrant where the AR detection algorithm was run and accordingly labelled with the quadrant names used throughout the paper. 

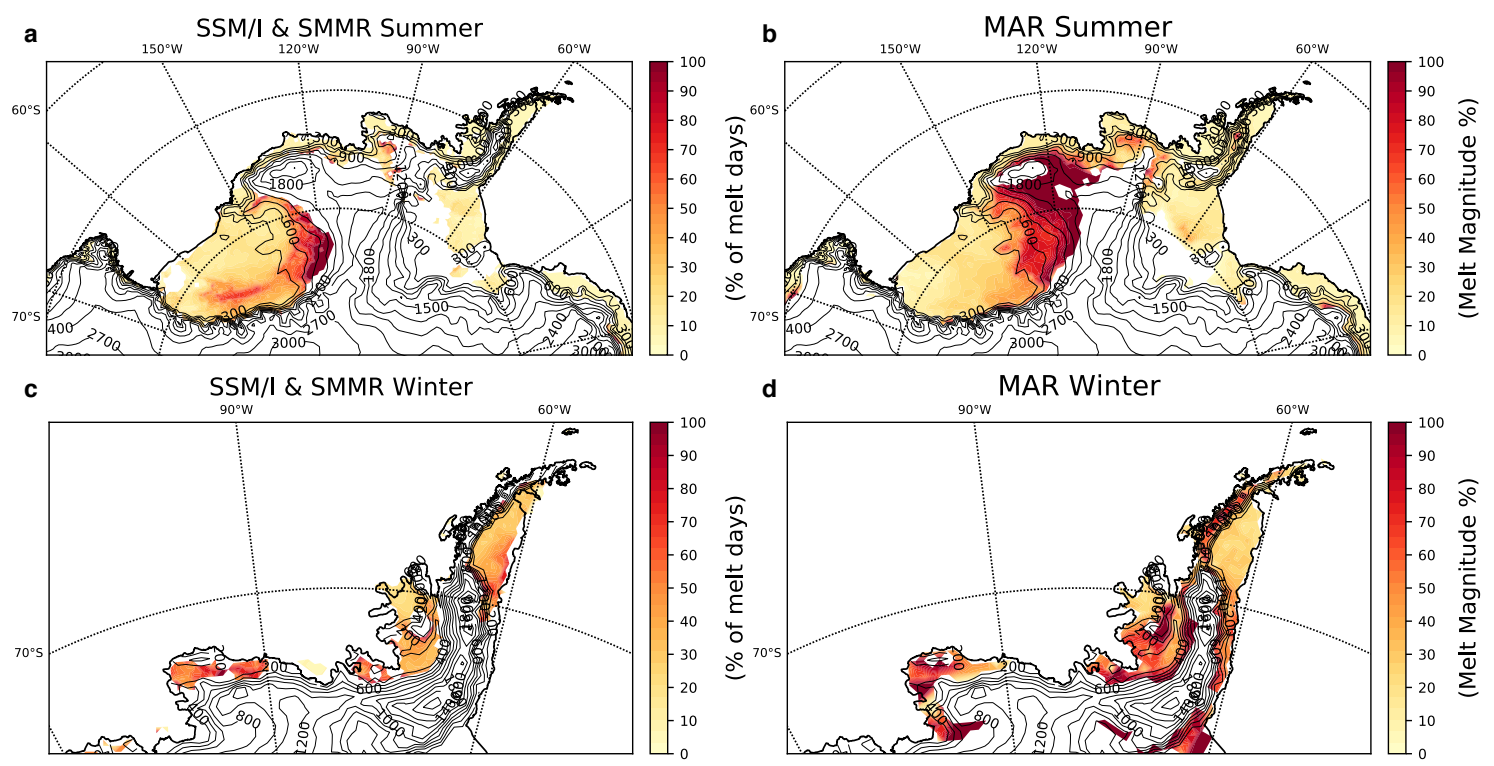

Supplementary Figure A.3: The percentage of total surface melt days from the SMMR and SSM/I observations (a and $\mathbf{c}$ ) and percentage of total surface meltwater according to MAR (b and $\mathbf{d}$ ) that occurred when an AR made landfall and within the 24 hours after landfall during December and January (a and b) and March-October (c and d) 1979-2017. The list of times indicating AR landfalls was provided by the detection algorithm using ERA-Interim data over West Antarctica (WAIS quadrant + AP-Weddell quadrant).

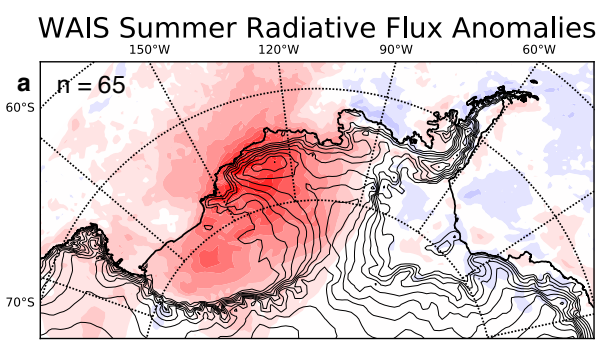

AP-Weddell Winter Radiative Flux Anomalies

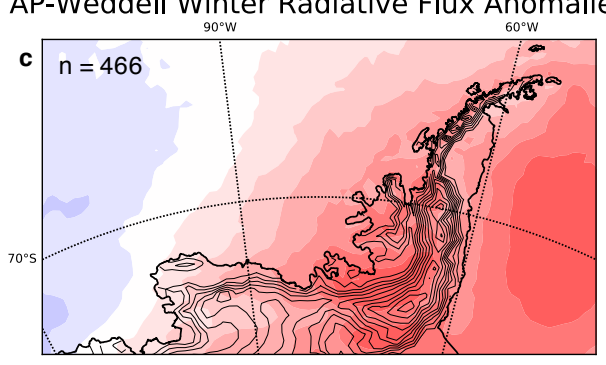

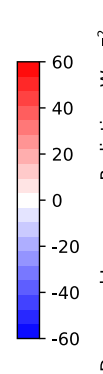

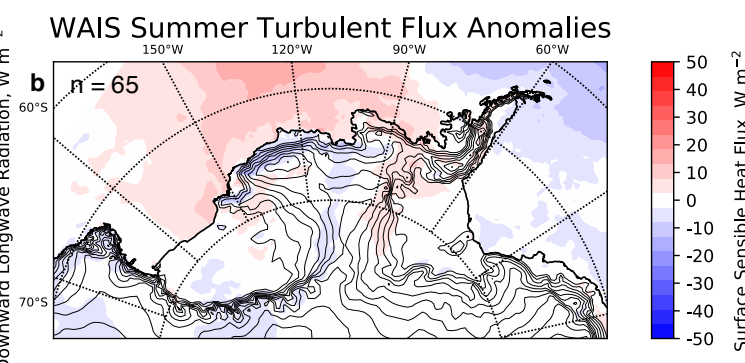

AP-Weddell Winter Turbulent Flux Anomalies

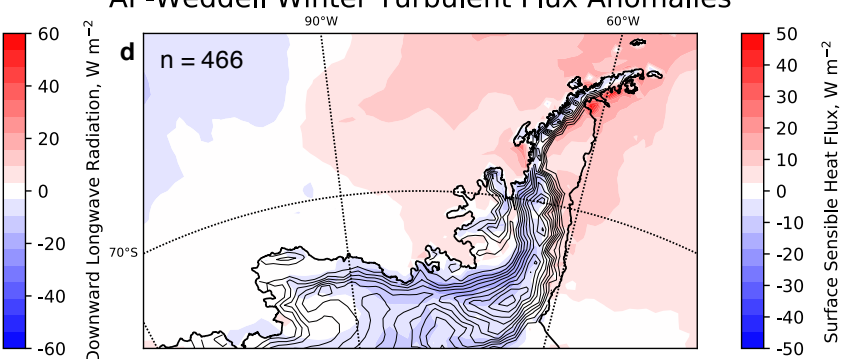

Supplementary Figure A.4: Composite of the MAR downward longwave radiation anomalies (a and c) and sensible heat flux anomalies (b and d) during ARs to make landfall in the WAIS (a and b) and AP-Weddell (c and d) quadrants during WAIS melt season (December and January) and winter (March-October) 1979-2017. 

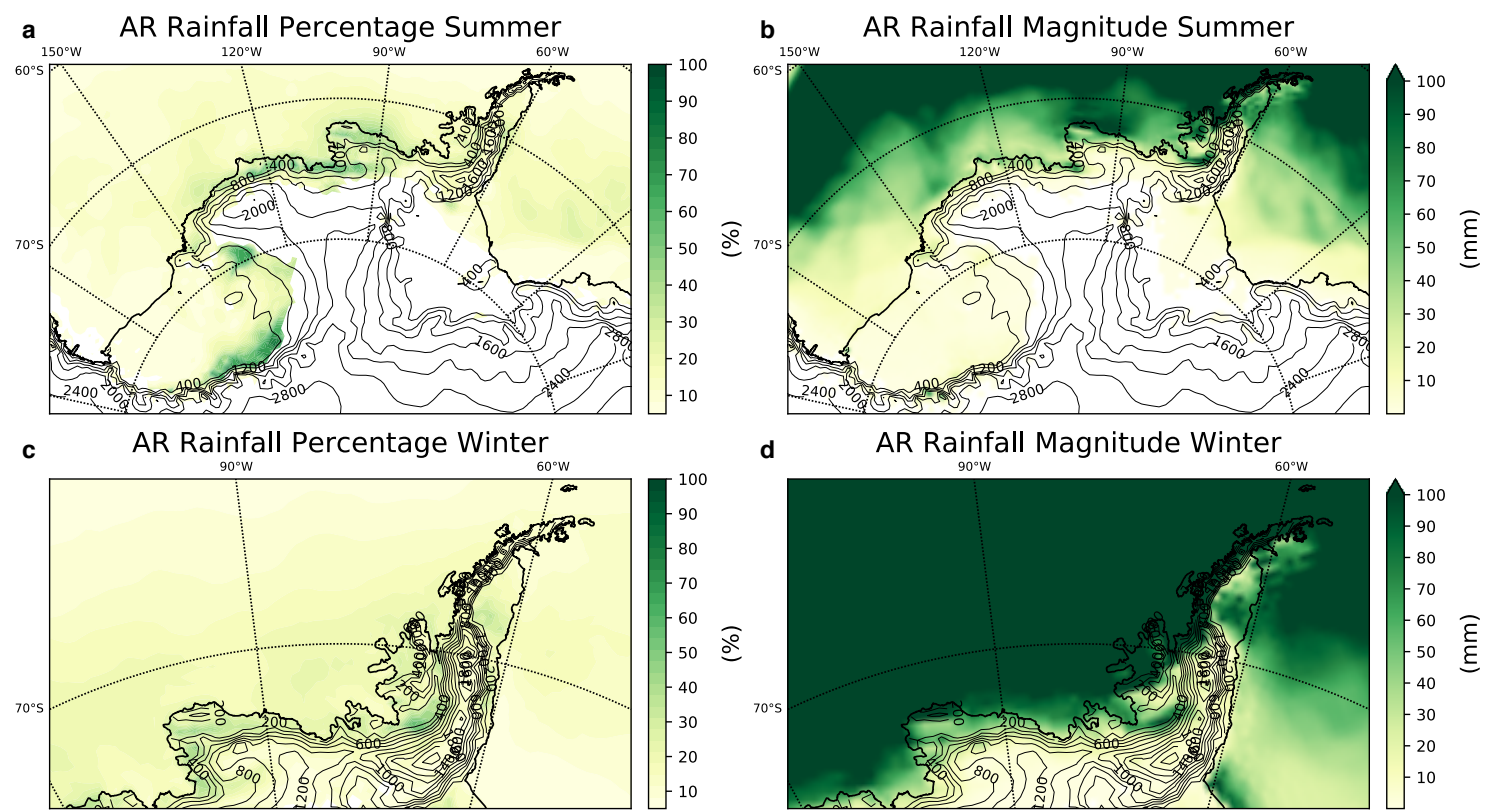

Supplementary Figure A.5: The percentage (a and $\mathbf{c}$ ) and magnitude (b and $\mathbf{d}$ ) of rainfall according to MAR that occurred when an AR made landfall and within the 24 hours after landfall during summer (December-February) (a and b) and winter (March-October) (c and d) from 1979-2017 according the to the AR detection algorithm when applied to ERA-Interim. The list of times indicating AR landfalls was provided by the detection algorithms using ERA-Interim data over West Antarctica (WAIS quadrant + AP-Weddell quadrant). 

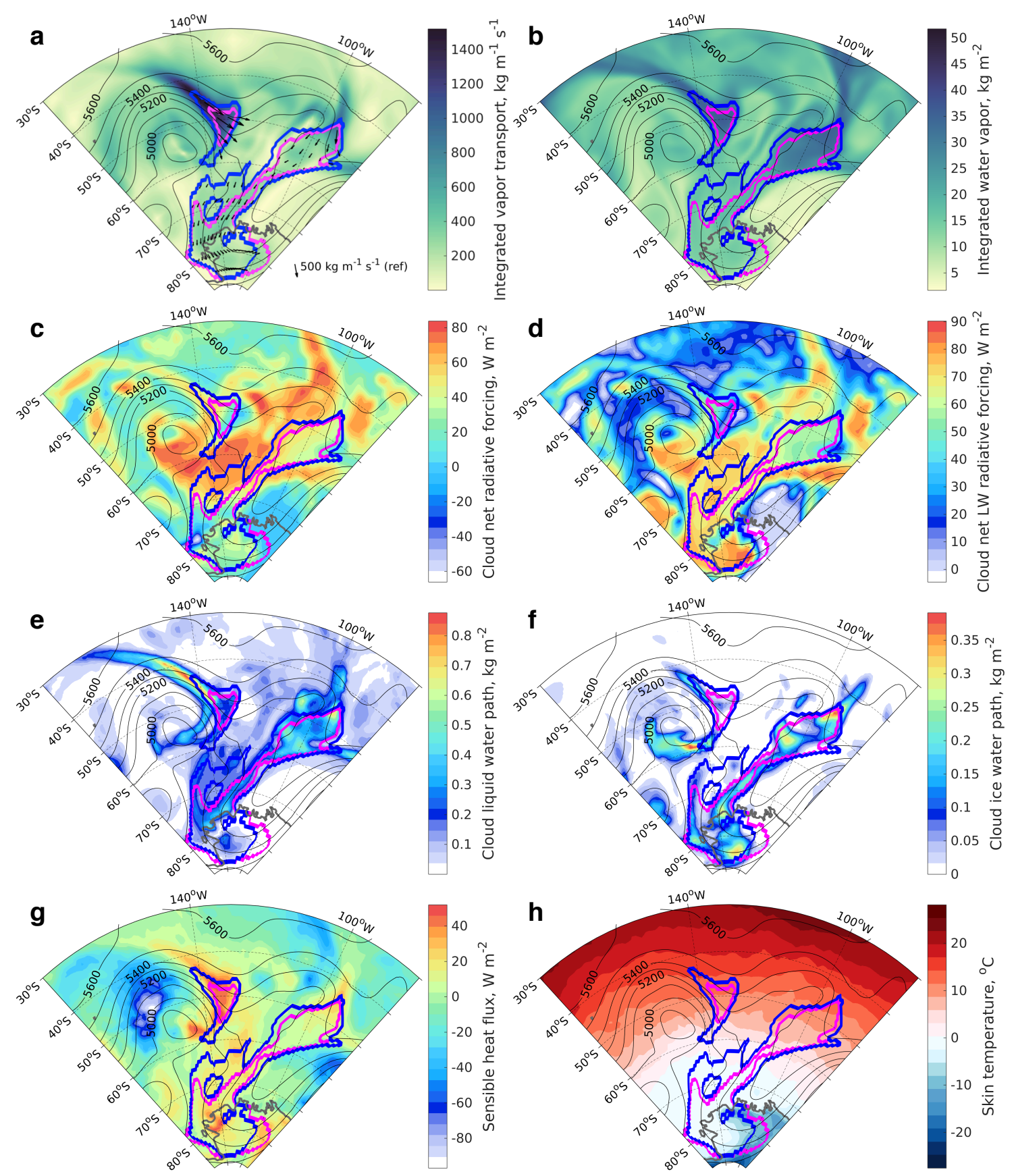

Supplementary Figure A.6: Atmospheric variables during an AR contributing to January 10 - 22, 2016 Ross Ice Shelf melt event. Purple contour shows the AR shape at the peak of the event on 12 UTC 11 January 2016 with spatial distribution of a integrated vapor transport (IVT), b integrated water vapor (IWV), c cloud net radiative forcing at the surface, $\mathbf{d}$ cloud net longwave radiative forcing, e cloud liquid water path, $\mathbf{f}$ cloud ice water path, $\mathbf{g}$ sensible heat flux, and $\mathbf{h}$ skin temperature all from ERAInterim. Contours represent the $500 \mathrm{hPa}$ geopotential height contours in meters and the dark blue contour and black arrows represents the AR shape and AR integrated vapor transport respectively according to the original Antarctic AR tracking algorithm (Gorodetskaya et al. [2014]. 

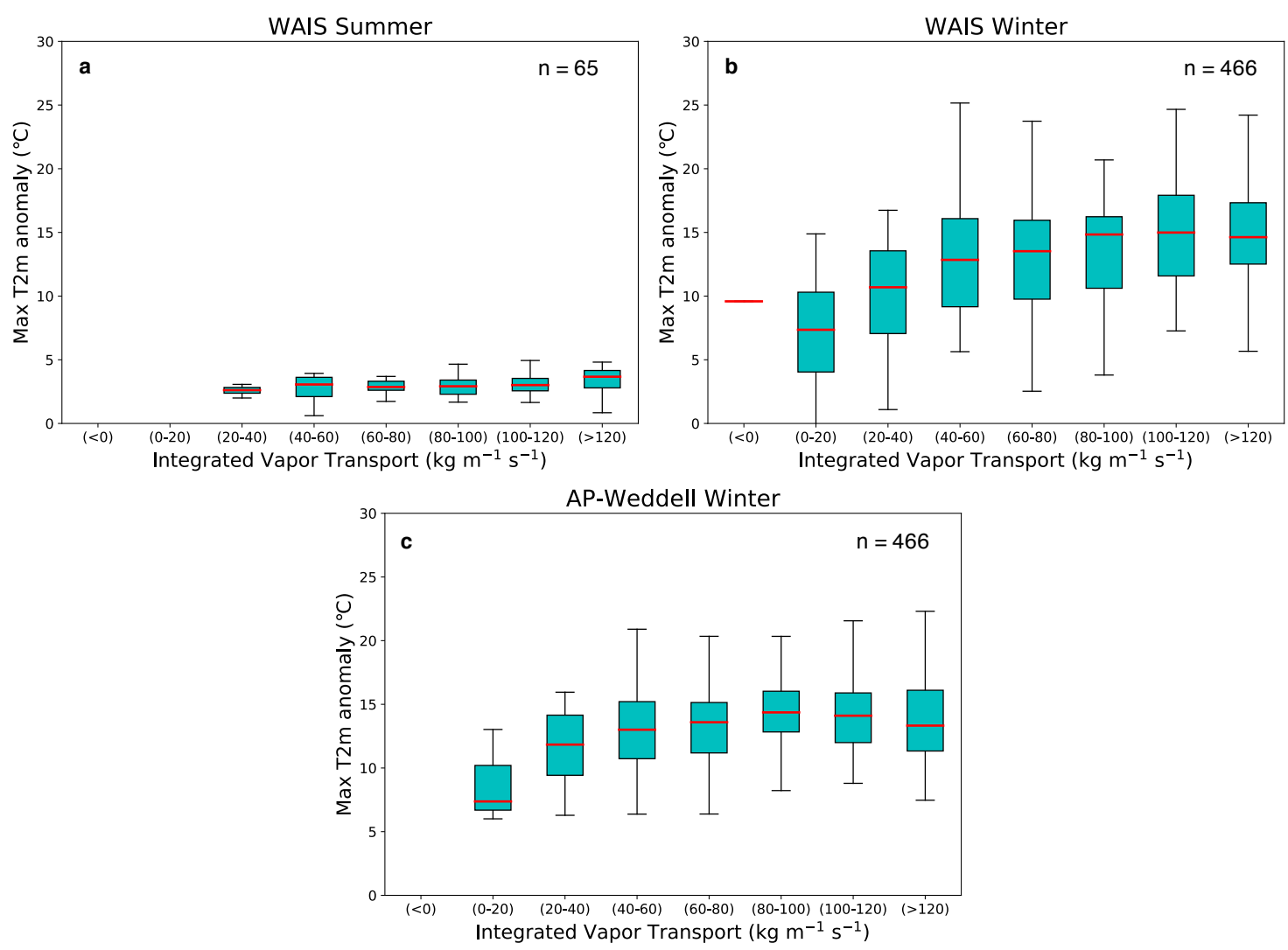

Supplementary Figure A.7: The maximum moisture transport upon landfall for each detected AR and associated maximum $2 \mathrm{~m}$ temperature anomaly along the coastline during a WAIS melt season (December and January), b WAIS winter (MarchOctober), and c AP-Weddell winter (March-October) using ERA-Interim from 19792017 over the WAIS quadrant (a and b) and the AP-Weddell quadrant (c). 


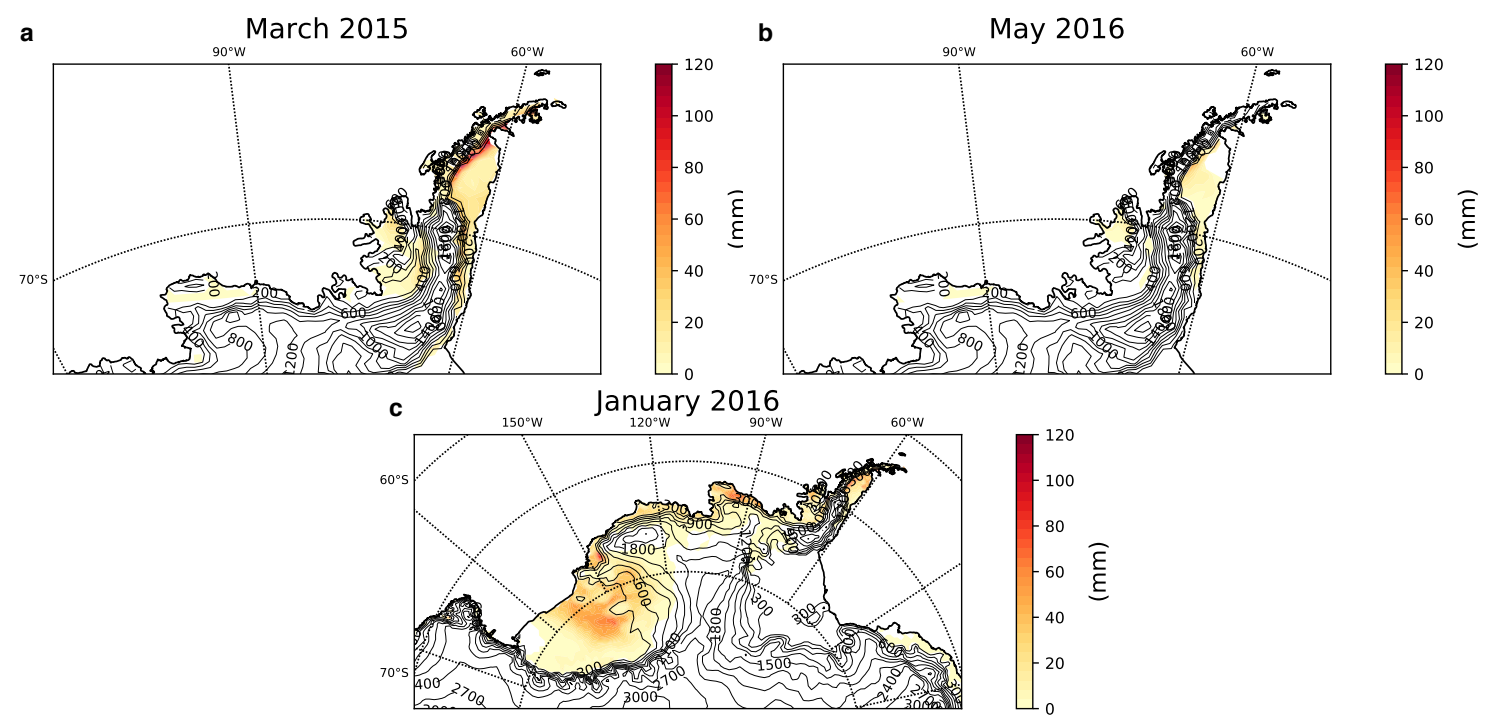

Supplementary Figure A.8: The cumulative melt magnitude for each melt event described in the study, a 22/03/15 - 28/03/15, b 23/05/16 - 31/05/16, c 10/01/16 $22 / 01 / 16$, as simulated by MAR. Surface melt is expressed in $\mathrm{mm}$. 

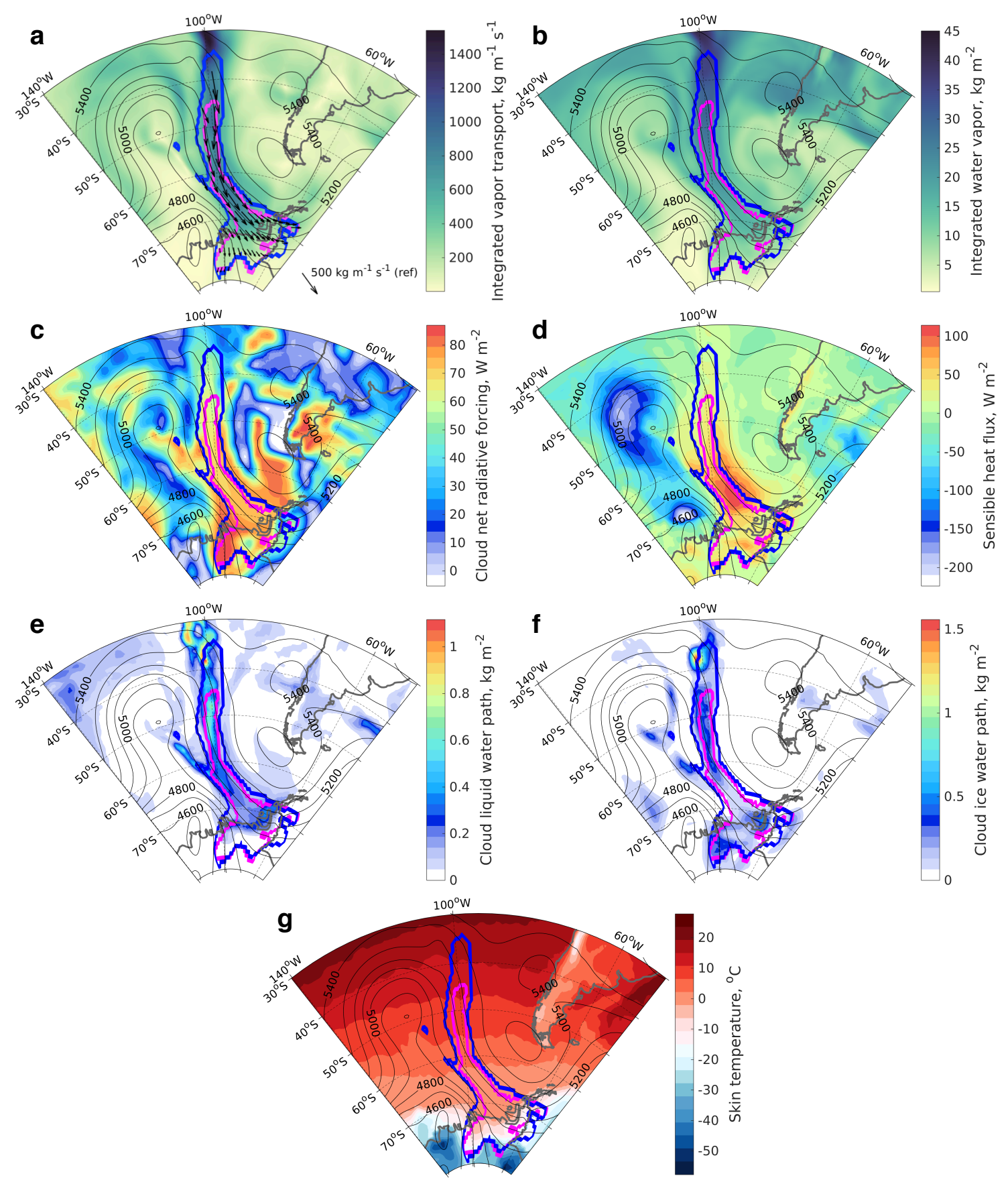

Supplementary Figure A.9: Atmospheric variables associated with an AR contributing to the May 25 - 30, 2016 melt event. Purple contour shows the AR shape at the peak of the event on 12 UTC 25 May 2016 with spatial distribution of a integrated vapor transport (IVT), b integrated water vapor (IWV), c cloud net radiative forcing at the surface, $\mathbf{d}$ sensible heat flux, e cloud liquid water path, $\mathbf{f}$ cloud ice water path, $\mathbf{g}$ sensible heat flux, and $\mathbf{h}$ skin temperature all from ERA-Interim. Contours represent the $500 \mathrm{hPa}$ geopotential height contours in meters and the dark blue contour and black arrows represents the AR shape and AR integrated vapor transport respectively according to the original Antarctic AR tracking algorithm (Gorodetskaya et al. [2014]. 


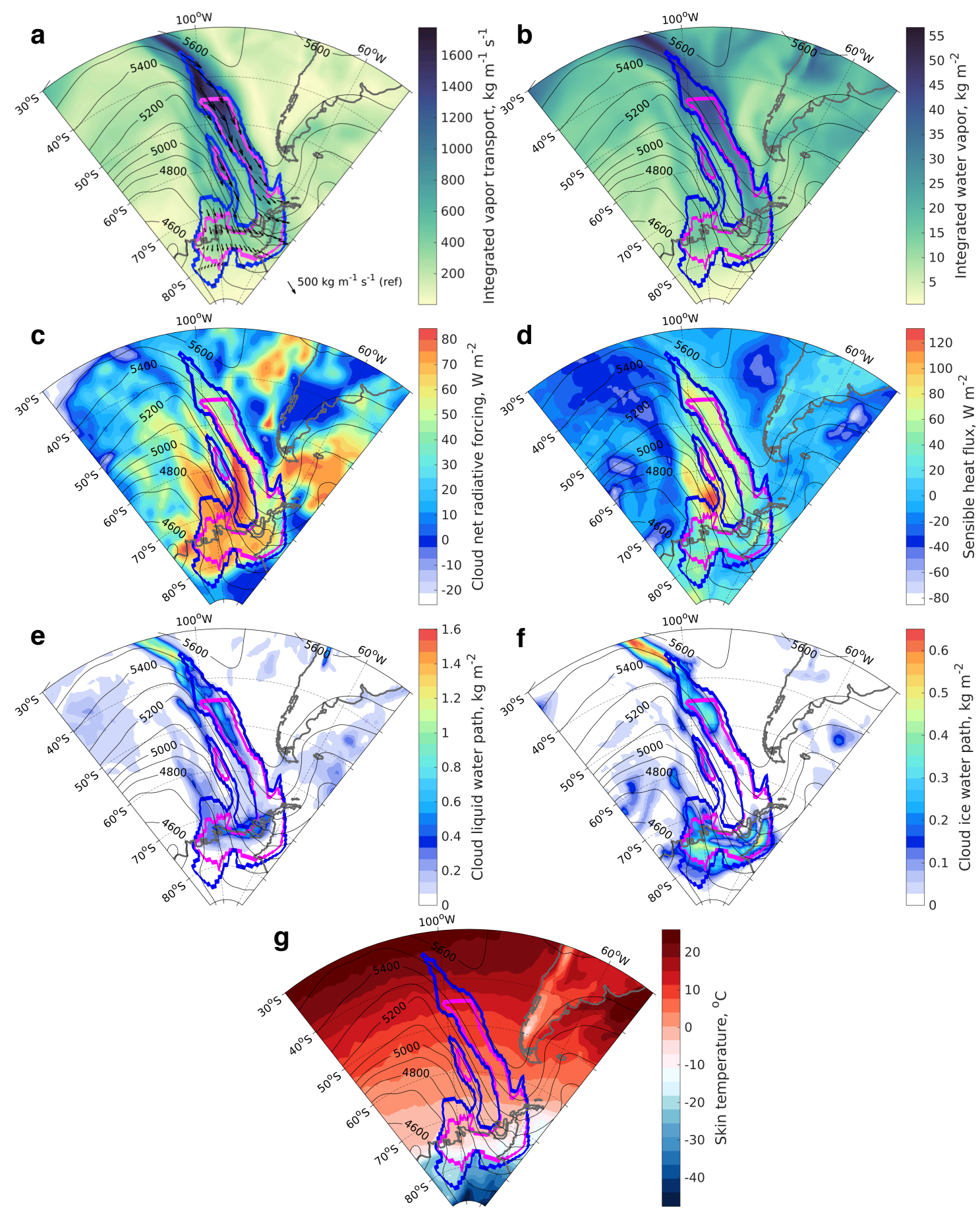

Supplementary Figure A.10: Atmospheric variables during an AR contributing to the March $22-28,2015$ melt event. Purple contour shows the AR shape at the peak of the event on 06 UTC 23 March 2015 with spatial distribution of a integrated vapor transport (IVT), b integrated water vapor (IWV), $\mathbf{c}$ cloud net radiative forcing at the surface, $\mathbf{d}$ sensible heat flux, e cloud liquid water path, $\mathbf{f}$ cloud ice water path, $\mathbf{g}$ sensible heat flux, and $\mathbf{h}$ skin temperature all from ERA-Interim. Contours represent the $500 \mathrm{hPa}$ geopotential height contours in meters and the dark blue contour and black arrows represents the AR shape and AR integrated vapor transport respectively according to the original Antarctic AR tracking algorithm18(Gorodetskaya et al. [2014]). 
a

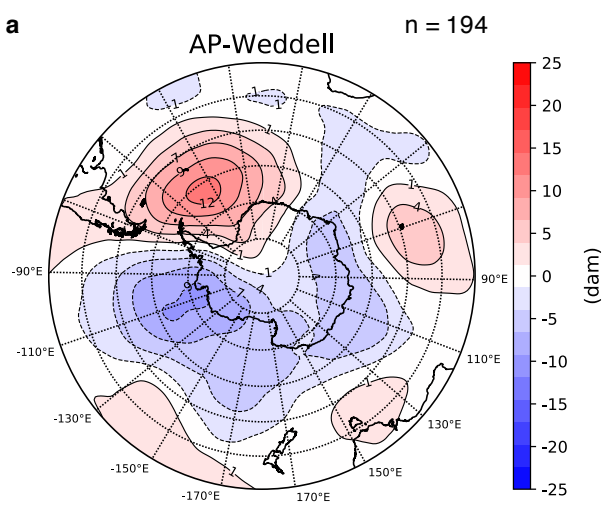

C

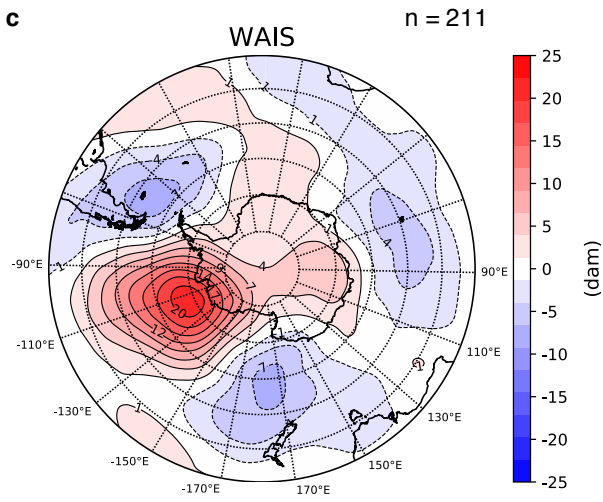

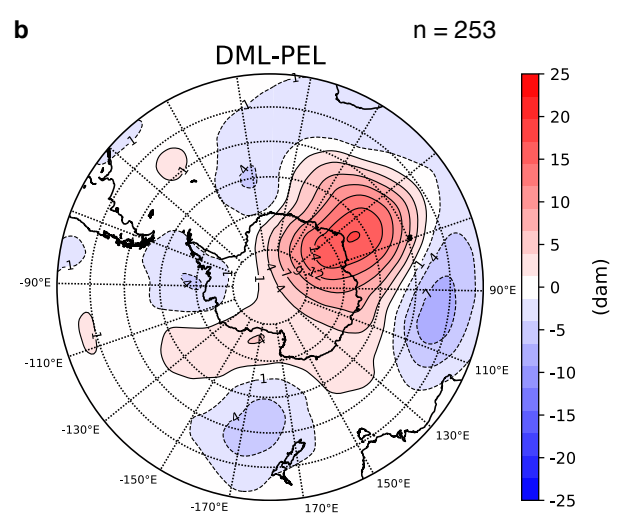

d

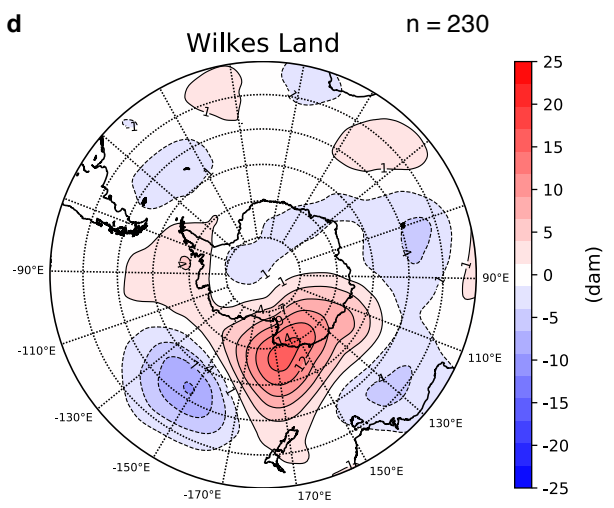

Supplementary Figure A.11: Composite of the $500 \mathrm{hPa}$ geopotential height anomalies during ARs to make landfall in the a AP-Weddell, $\mathbf{b}$ DML-PEL, $\mathbf{c}$ WAIS, and $\mathbf{d}$ Wilkes Land quadrants during AR landfalls for JJA using $6 \mathrm{hr}$ ERA-Interim data from 1979-2017. 


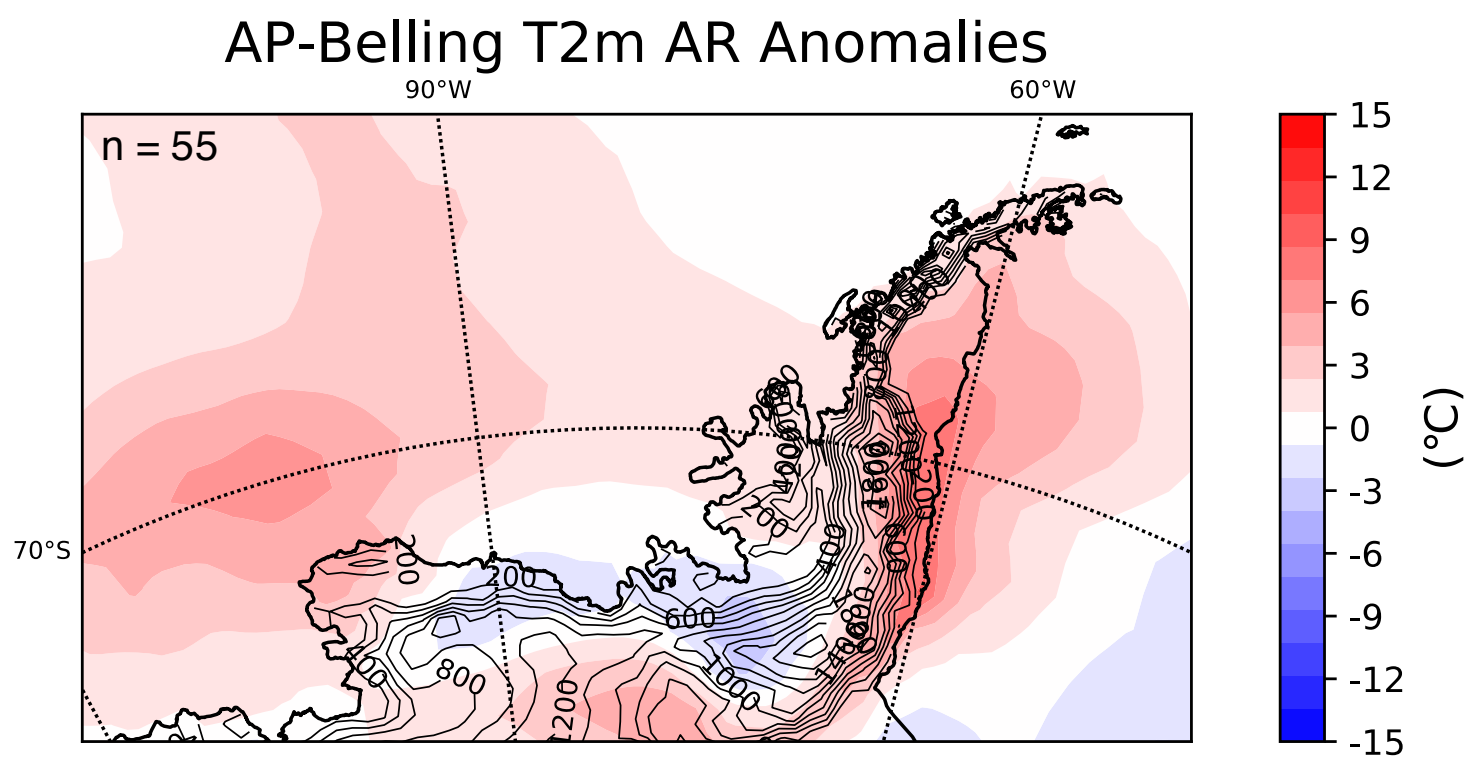

Supplementary Figure A.12: The difference in $2 \mathrm{~m}$ temperature anomalies associated with AP melting events (03/15, 05/16) and the composite ERA-Interim $2 \mathrm{~m}$ temperature anomalies during ARs to make landfall in the AP-Weddell quadrant for March and May from 1979-2017. 

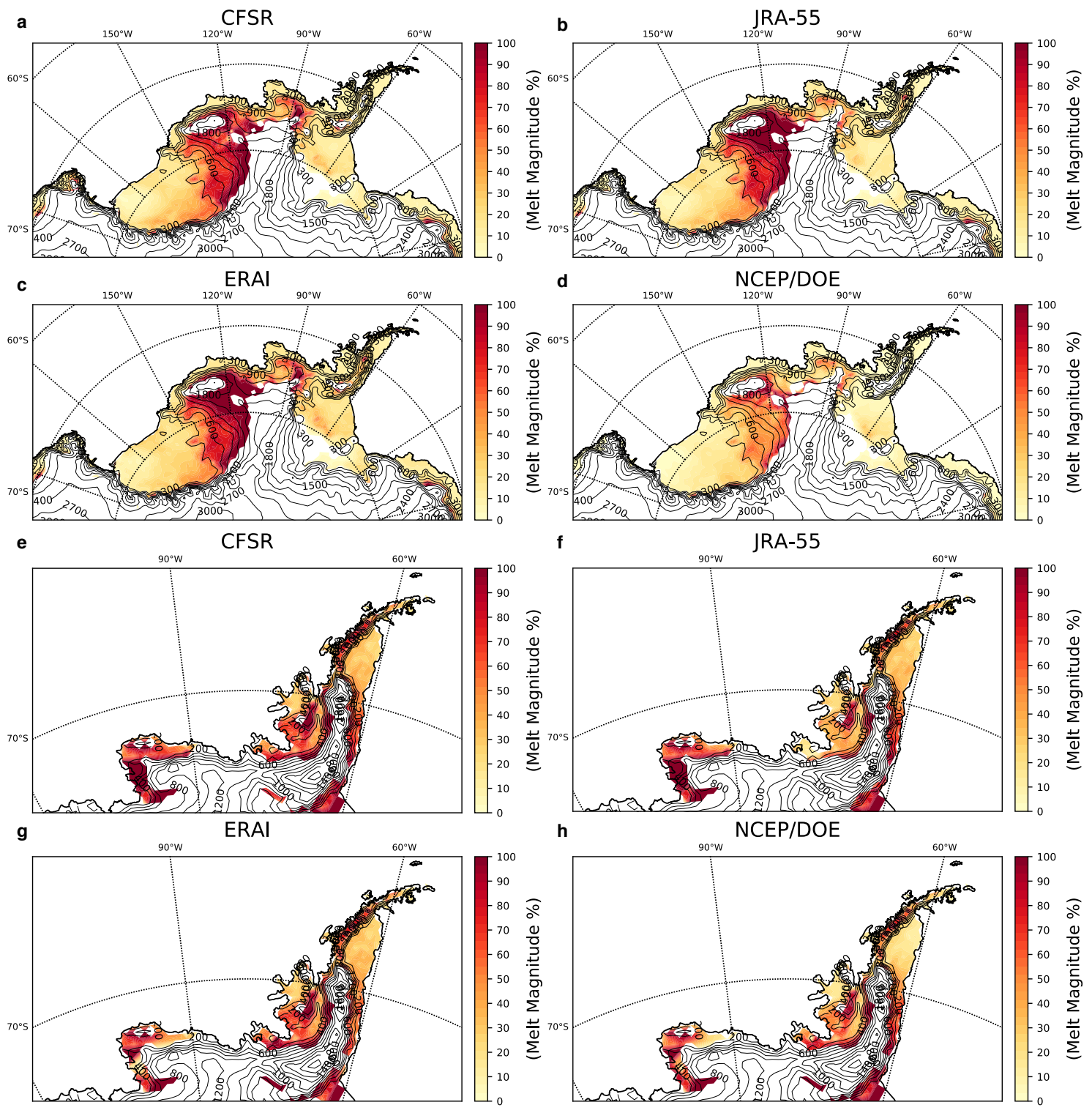

Supplementary Figure A.13: The percentage of total surface meltwater according to MAR that occurred when an AR made landfall and within the 24 hours after landfall during the melt season (December and January) and winter (March-October) from 1979-2017 according the to the AR detection algorithm when applied to the (a and e) CFSR, (b and f) JRA-55, (c and g) ERA-Interim, and (d and h) NCEP/DOE V2 reanalyses. The list of times indicating AR landfalls was provided by the detection algorithm using ERA-Interim data over West Antarctica (WAIS quadrant + AP-Weddell quadrant). 

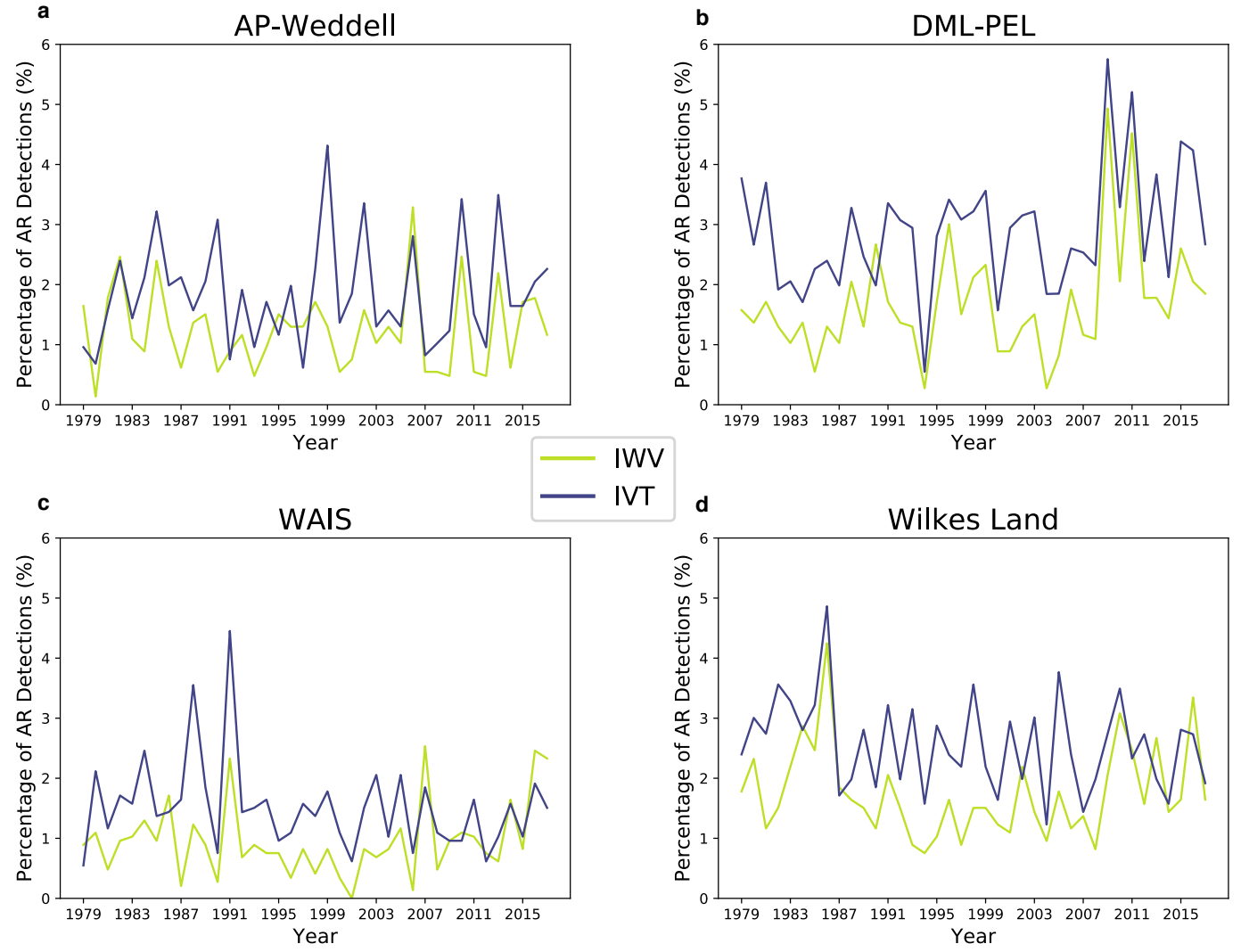

IWV

IVT d

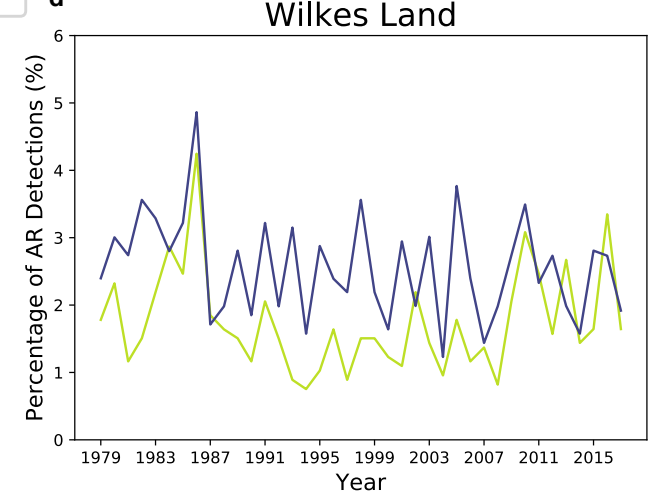

Supplementary Figure A.14: The yearly percentage of 6-hourly atmospheric river occurrences to make landfall detected using the IWV-based and IVT-based AR detection algorithms when applied to the ERA-Interim reanalysis for the AP-Weddell a, DML-PEL b, WAIS c, and Wilkes Land $\mathbf{d}$ quadrants. 

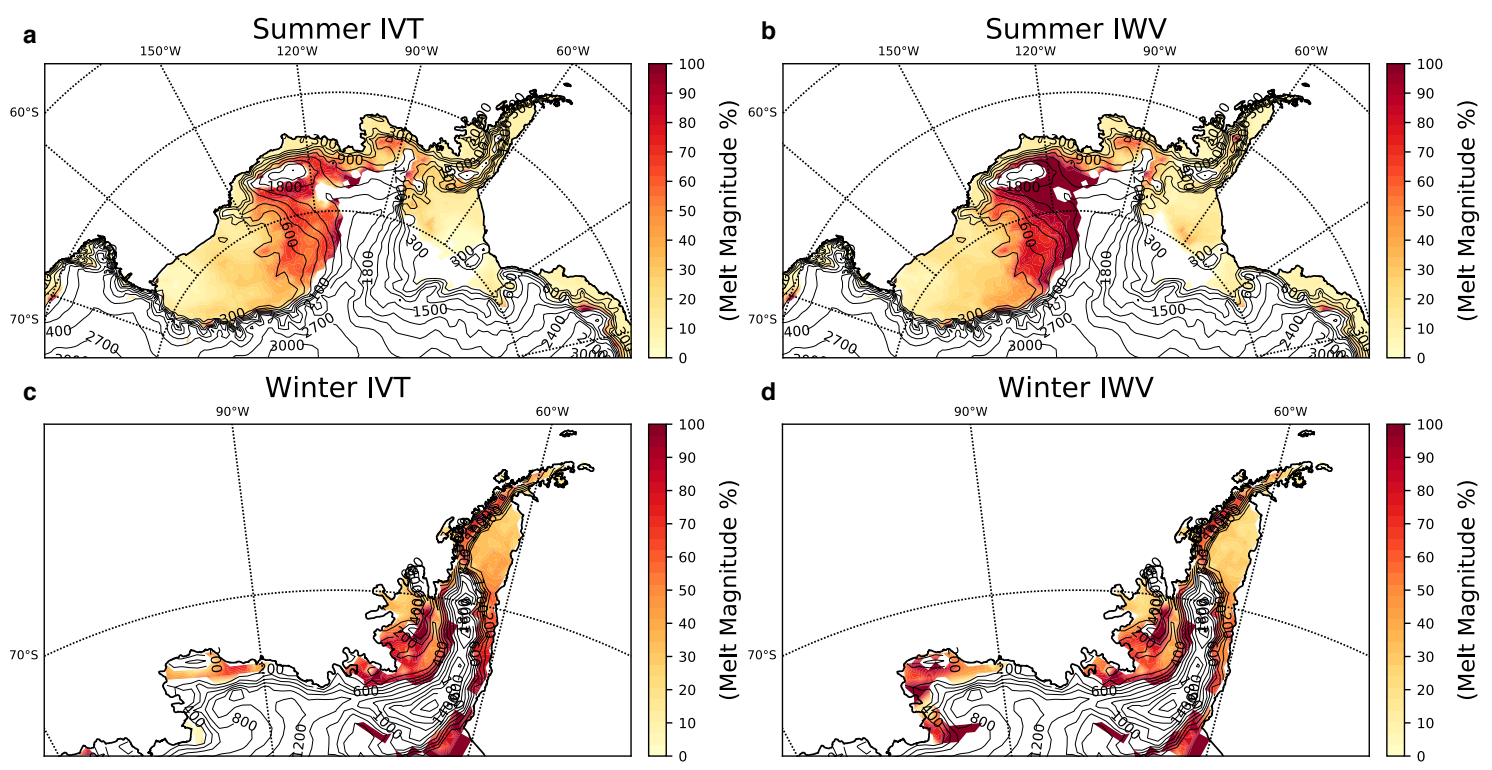

Supplementary Figure A.15: The percentage of total surface meltwater according to MAR that occurred when an AR made landfall and within the 24 hours after landfall during the melt season (December and January) and winter (March-October) from 1979-2017 according the to the IVT-based (a and c) and IWV-based (b and d) AR detection algorithms. The list of times indicating AR landfalls was provided by the detection algorithms using ERA-Interim data over West Antarctica (WAIS quadrant + AP-Weddell quadrant). 


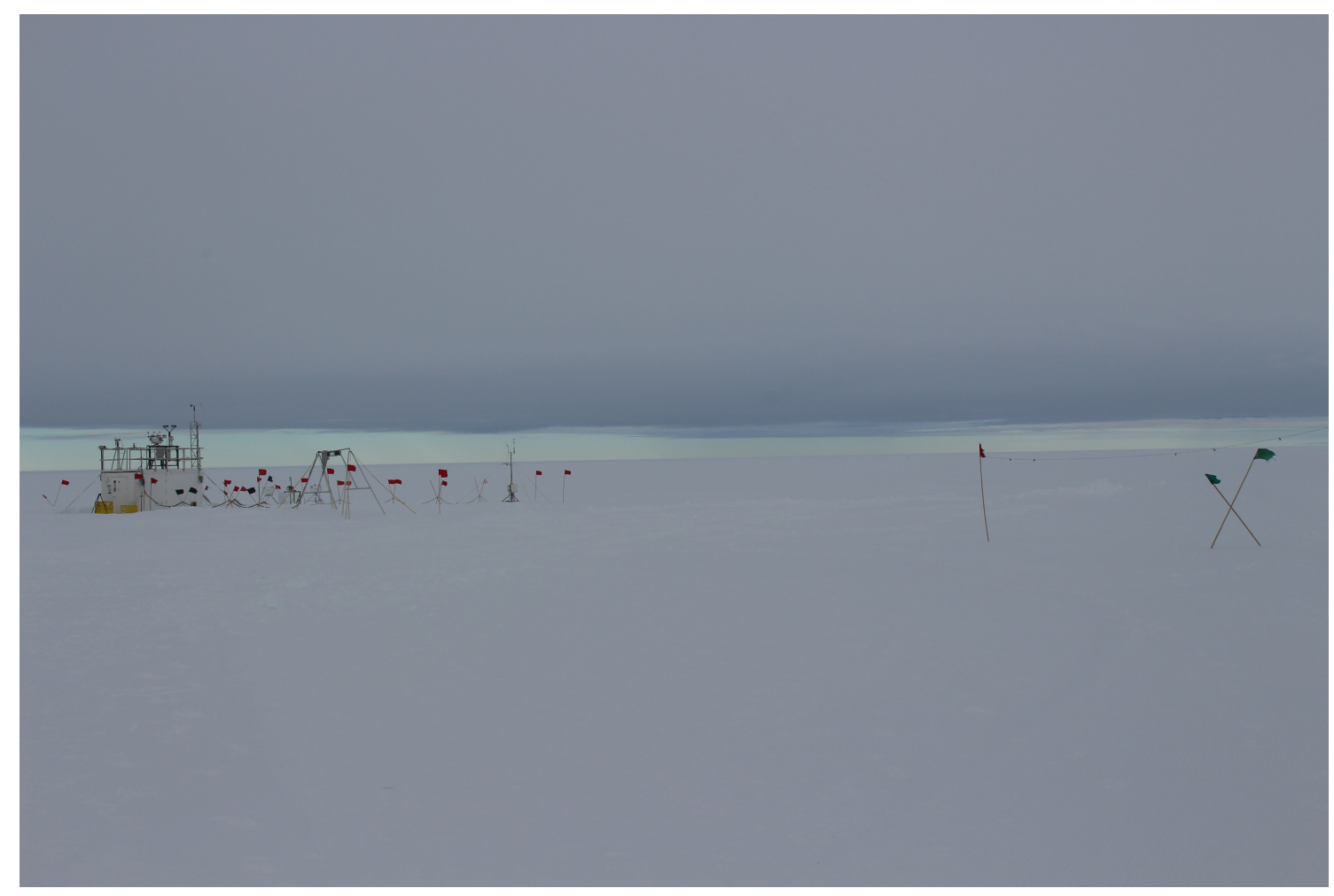

Supplementary Figure A.16: Photograph of stratus layer with high liquid water content taken at WAIS Divide Camp on January 10th, 2016. The instrumentation in the left of the photograph is from the Atmospheric Radiation Measurement West Antarctic Radiation Experiment (AWARE) and is described in detail in Nicolas et al. [2017]. Photograph taken by Jonathan Wille. 


\section{Appendix B}

\section{Supplementary information and}

\section{figures to "The atmospheric river}

\section{threat to Antarctic Peninsula}

\section{ice-shelf collapse"}

\section{B.1 Further discussion on ice-shelf disintegration events}

In our study, we examined 20 calving/collapse events on the Larsen iceshelves and linked 12 of those events to preceding atmospheric rivers (ARs). The eight calving events that did meet our criteria (i.e. an AR landfall according to the vIVT detection scheme at least five days prior to the calving/collapse event) happened under various circumstances. From these eight events, two calving events on February 8 and 23, 2002 occurred within five days of weak AR landfalls only detected by the IWV detection scheme while a third calving event on February 17 occurred with no prior AR detections from the vIVT or IWV schemes. This particular month was characterized by many calving events whose exact dates of occurrence were difficult to determine as the Larsen B was in a state of near continuous calving and collapse. However, the major final collapse on March 1-2 occurred after an AR landfall detected by the IVT scheme from February 25-27 (see supplementary Figure B.6) and is counted as one of the 12 linked to ARs. Two calving events on December 24th, 2001 and February 5th, 2008 were preceded by very intense ARs, but around 10 days prior. The calving event 
from November 29th, 2004 occurred after a long duration AR event, but also around 10 days prior. Only two calving events showed no relation with AR activity; a winter calving event on August 20th, 2002, and a calving event on January 29th, 2009. See the supplementary tables for more details on how the calving/collapse events were measured. Another interesting note not described in the main text is the majority of the 12 calving/collapse events since 2000 attributed to ARs occurred when cumulative IVT related with AR landfalls since November exceeded 13000-15000 $\mathrm{kg} \mathrm{m}^{-1} \mathrm{~s}^{-1}$ also including the collapse of the Larsen A in 1995. Although this result is rather specific to our approach of detecting ARs and measuring maximum IVT.

The Larsen ice-shelf collapses and their relationship to atmospheric rivers (ARs) were briefly described in the main text, so here we describe in greater detail the events surrounding these collapse events and others along the Antarctic Peninsula (AP).

\section{Larsen A Collapse 1995}

The spectacular, surprising collapse of the Larsen A in January 1995 was preceded by repeated retreats starting in the late 1980s (Skvarca [1993]; Rott et al. [1998]; Doake et al. [1998]; Scambos et al. [2000]). The record warm summers in 1986-1987 and 1992-1993 recorded at a nearby weather station were also summers of high AR frequency and likely preconditioned the ice shelf for collapse5 (Extended Data Fig. 4.4a). The literature on this collapse postulates these retreats pushed the Larsen A to a critical limit where a disturbance would initiate a final collapse (Rott et al. [1998]).

It appears that a historically intense AR (Max IVT $\sim 840 \mathrm{~kg} \mathrm{~m}^{-1} \mathrm{~s}^{-1}$, in the 99.7th intensity percentile) was the disturbance that triggered the final collapse. During the 5-day period surrounding the AR landfall on January 24th, the MAR simulated 6.5. Gt $(7.6 \mathrm{Gt})$ of runoff (meltwater) across the Larsen ice shelves while a roughly three-tenths reduction of sea ice concentration in the Larsen embayment occurred (Supplementary Fig. B.1). Highly anomalous positive $500 \mathrm{hPa}$ geopotential height anomalies during the AR landfall are indicative of a strong blocking ridge similar to the mean blocking patterns observed for all summer AR landfalls (Supplementary Fig. B.2a; Extended Data Fig. 4.3a). This AR landfall was associated with temperatures well above $0{ }^{\circ} \mathrm{C}$ aided by a very large sensible heat flux with very little mitiga- 
tion from the latent heat flux along with an elevated downward longwave radiative flux (Supplementary Fig. B.3). The combination of this very large runoff total, the absence of a regional sea ice cover allowing a swell-induced strain, along with the wind strain associated with the AR were likely the factors that led to the Larsen A ice shelf's dramatic demise (Massom et al. [2018]).

\section{Larsen B Collapse 2002}

The same AR that triggered the final collapse of the Larsen A also caused the calving of a large tabular iceberg $\left(\sim 1700 \mathrm{~km}^{2}\right)$ along with smaller icebergs $(\sim 550$ $\mathrm{km}^{2}$ ) from the front of the Larsen B, which had been growing in size until early 1995 (Scambos et al. [2000]. After the January 1995 AR, the Larsen B experienced a period of high melt years and above-average AR activity, especially in summer 1999/2000 (Leeson et al. [2017], that preconditioned the ice shelf for collapse (Fig. 4.3). Unlike the collapse of the Larsen A in 1995 where a single AR landfall could be linked with the final collapse, several AR landfalls preceded in the months before the final collapse of the Larsen B in late February 2002.

A small area of melt ponds was present on the Larsen B near the base of mountains on December 9th that expanded after an intense AR (Max IVT $~ 660 \mathrm{~kg}$ $\mathrm{m}^{-1} \mathrm{~s}^{-1}$, in the 98.2th intensity percentile) made landfall on December 13th (Supplementary Fig. B.4). The MODIS satellite imagery and AR detection algorithm reveal the structure of the AR extending from the Patagonia region of South America across the Drake Passage and striking the western AP (Supplementary Fig. B.4d and B.4e). A closer look of the AR as it makes landfall shows the thick clouds over the western AP transitioning to more scattered likely turbulent lenticular clouds over the Larsen B (Supplementary Fig. B.4b). This is indicative of a Foehn wind driving the sensible heat flux and cloud-clearance effect allowing shortwave radiation to reach the surface in between the clouds 8(Elvidge et al. [2020]). During the 5-day period surrounding the AR landfall on December 13th, the MAR simulates $1.0 \mathrm{Gt}(3.2 \mathrm{Gt})$ of runoff (meltwater) across the Larsen ice shelves (Supplementary Fig. B.4f). Afterwards, another intense long duration AR (IVT $~ 740 \mathrm{~kg} \mathrm{~m}^{-1} \mathrm{~s}^{-1}$, in the 99.2th intensity percentile) occurred from December 31 - January 2 (Supplementary Fig. B.5). This storm had a similar structure as the storm just two weeks earlier with a cloud band extending 
from east of South America to the AP (Supplementary Fig. B.5b). The melt ponds grew larger following this AR with increased iceberg calving from the ice-shelf front. A day after the AR passed, increased swells likely added strain to the ice-shelf margins in the absence of a sea ice cover (Supplementary Fig. B.5e; Massom et al. [2018]). During the 5-day period surrounding the AR landfall on January 1st, the MAR simulates 2.1 Gt (4.4 Gt) of runoff (meltwater) across the Larsen ice shelves (Supplementary Fig. B.5f). These two AR landfalls were associated with the two highest temperature peaks in December while the winds during the December 13th were particularly intense averaging $20 \mathrm{~m} \mathrm{~s}^{-1}$ (Supplementary Fig. B.6a)

Throughout February, the Larsen B was in the process of rapidly destabilizing with melt ponds and crevasses appearing more clearly while large icebergs were filling the embayment. Between the IWV and vIVT AR detection schemes, three distinct AR landfalls were detected (04/02, 18/02, and 25/02) although the two schemes did not agree on the first two events. This series of moderately intense ARs likely exacerbate the ongoing collapse with further melting and wind stress. The AR that preceded the major breakup of the Larsen B in the beginning March occurred from February 25-27 (in the 81.5th intensity percentile) and generated $2.4 \mathrm{Gt}(2.9 \mathrm{Gt})$ of runoff (meltwater) with a further southward melt extent then the previously documented AR landfalls that summer (Supplementary Fig. B.7). Like the previous AR landfalls, anonymously large swells were apparent along the ice-shelf margin (Supplementary Fig. B.7e; Massom et al. [2018]). Each of the three February AR landfalls were associated with temperatures above $0{ }^{\circ} \mathrm{C}$, high wind velocities, and elevated sensible heat and downward longwave radiative fluxes (Supplementary Fig. B.6b); all patterns that match previously documented winter AR landfalls on the AP9 (Wille et al. [2019]). The summer of 2001/2002 was characterized by persistent atmospheric blocking centered slightly northeast of the AP tip that led to a predominantly NE and NW flow advecting warm moist air masses and directing ARs towards the AP (Supplementary Fig. B.2b and B.2c; van den Broeke [2005]).

\section{Remnant Larsen B Calving}

Following the disintegration of the Larsen B in 2002, the shelf ice was replaced with land-fast ice and the glaciers that originally fed the Larsen B became 
tidewater glaciers with increased velocity (Scambos [2004]; Rott et al. [2002]). The remnants of the Larsen B, the Scar Inlet ice shelf, experienced a 2-3 fold increase in velocity from the loss of back stress after the Larsen B collapse (Wuite et al. [2015]. The land-fast ice in the Larsen B embayment buffers the Scar Inlet from swells )Qiao et al. [2019]), but as we observed, this ice is much more easily displaced than shelf ice. The front of the Scar Inlet ice shelf retreated significantly following two large calving events during the summers of 2005/2006 and 2007/2008 (Qiao et al. [2019]; Shuman et al. [2011]; Khazendar et al. [2015]). We found both these calving events were preceded by AR landfalls. In early February 2006, the Scar Inlet ice shelf retreated $20 \mathrm{~km}$ after a calving event15 (Shuman et al. [2011]). After an AR landfall on February 6th - 8th (IVT $~ 520 \mathrm{~kg} \mathrm{~m}^{-1} \mathrm{~s}^{-1}$, in the 91.0th intensity percentile), a newly calved iceberg and extensive melt ponds were observed (Supplementary Fig. B.8). In early February, another calving event led to a $11 \mathrm{~km}$ retreat of the eastern region of the Scar Inlet ice shelf(Qiao et al. [2019]). An historically intense AR (IVT $962 \mathrm{~kg} \mathrm{~m}^{-1} \mathrm{~s}^{-1}$, third highest intensity of all AR landfalls) from January 24th - 26th disintegrated and fragmented nearly all the land fast ice in the Larsen A and B embayments and generated $6.3 \mathrm{Gt}$ $(7.2 \mathrm{Gt})$ of runoff (meltwater) likely leading to the calving a week later (Supplementary Fig. B.9). This event actually was not considered an AR-related collapse in our analysis as the calving event happened more than five days after the AR event.

\section{Larsen C}

While the Larsen A and B have mostly disintegrated during the 21st century, the Larsen C remains in a stable configuration (Glasser et al. [2009]). Recently though, the calving of a large tabular iceberg $\left(\sim 6,000 \mathrm{~km}^{2}\right)$ on July 12th, 2017 brought the stability of the remaining Larsen C into question (Hogg and Gudmundsson [2017]). The crack leading to the calving, which had been growing over the course of many years, appears related to basal melting from subsurface melting19,20 (Holland et al. [2015]; Hutchinson et al. [2020]). The ice lost during the massive calving event is believed to be the passive shelf ice supposedly meaning no changes in the buttressing effect and ice-shelf velocity are anticipated (Fürst et al. [2016]). However, the ice-shelf front now displays a concave shape just as the Larsen A and B exhibited prior to their break-ups and any further calving could have a destabilizing effect (Fürst et al. [2016]; Skvarca 
[1994]). In addition, the Larsen $C$ is sensitive to the same AR-related mechanisms that drove the preconditioning and final collapses of the Larsen A and B (i.e. Foehn winds (Elvidge et al. [2020]; Turton et al. [2018]; Datta et al. [2019]; Turton et al. [2020], hydrofracturing (Lai et al. [2020]), swell-induced strain (Massom et al. [2018])). Even during winter temperatures above $10^{\circ} \mathrm{C}$ have been measured on the Larsen $\mathrm{C}$ during Foehn wind events27 (Jakobs et al. [2020]).

A few AR-related calving events have already been observed on the northern edges of the Larsen C. In early January 2005, an iceberg calved off the NE edge of the Larsen C after an AR landfall (Max IVT $\sim 460 \mathrm{~kg} \mathrm{~m}^{-1} \mathrm{~s}^{-1}$, in the 83.4th intensity percentile) on January 3rd. Melt pond formation was observed on the interior of the ice shelf near the base of the mountains and extensive runoff occurred throughout the Larsen C with a total 5-day runoff (meltwater) of $5.9 \mathrm{Gt}$ (6.8 Gt) (Supplementary Fig. B.10). The next month, a more intense AR (Max IVT $\sim 860 \mathrm{~kg} \mathrm{~m}^{-1} \mathrm{~s}^{-1}$, in the 99.7th intensity percentile) made landfall February 9th - 10th generating 4.5 Gt (5.0 Gt) of runoff (meltwater) (Supplementary Fig. B.11). The sea ice was blown away from the ice-shelf front and another iceberg calved off the ice-shelf front not far from the location of the previous calving. The $500 \mathrm{hPa}$ geopotential height anomalies during the AR show a blocking ridge centered on the northern extent of the AP in a similar position as the other AR events discussed in this section (Supplementary Fig. B.2d). The calving events on the Larsen C in 2005 and Scar Inlet in 2008 marked two years of very high detected AR activity, but after 2008, AR activity largely subsided along with occurrences of ice shelf calving on the AP (Fig. 4.3). However starting in 2015, AR activity began increasing again highlighted by two continental Antarctic temperature records subsequently set by ARs in March 2015 and February 2020 (Fig. 4.3c; Bozkurt et al. [2018]).

\section{Previous large calving events along the Larsen $B$}

ARs landfalls seem to have coincided with many other ice-shelf instability events described in the literature before 2000 (Scambos et al. [2000]). For instance, two ARs landfall on February 9-10 and February 13, 1998 may have generated large melt ponds observed on February 15, 1998 (Scambos [2001]). These melt ponds preceded the significant calving $\left(125 \mathrm{~km}^{2}\right)$ of the Larsen B in late February 1998 and the 
disruption of a compressive arch visible on March 23 leading to an increased rate of shelf retreat (Scambos et al. [2000]). Between January 10th and February 1st, 1999, a large calving event $\left(676 \mathrm{~km}^{2}\right)$ occurred (Scambos et al. [2000]), while two AR landfalls occurred on January 11 and January 24. However, due to the uncertainty in the timing of the calving events, we did not include these events in our analysis.

\section{Wilkins ice shelf}

The Wilkins ice shelf appears susceptible to many of the ice-shelf preconditioning processes described for the Larsen ice shelves. $60-80 \%$ of temperature occurrences and $40-60 \%$ of runoff rates in the 99.9th percentile on the Wilkins were related to AR activity (Fig. 4.2a and 4.2b). And like the Larsen ice shelves, AR landfalls are associated with high sensible heat fluxes near the mountain bases while the downward longwave radiative flux is elevated across the ice shelf. In addition, the Wilkins region receives notable rainfall $\left(>0.1 \mathrm{~cm} \mathrm{yr}^{-1}\right)$ on a yearly basis unlike the most parts of the Larsen with most of the rain related to AR activity (Extended Data Fig. 4.5a and 4.5c). The Wilkins ice shelf is vulnerable to swell-induced strain in the absence of sea-ice and there appears to be a relationship between AR occurrences and sea-ice decay west of the AP (Massom et al. [2018]), however this relationship is weaker than the AR/sea-ice relationship east of the AP tip. Still, the AR/swell height relationship is in fact stronger west of the AP given the west-east storm motions of the cyclones associated with ARs and this may be detrimental to the stability of the Wilkins ice shelf.

However, in regard to the calving and collapse events on the Wilkins ice shelf, the relationship with ARs is less clear. Using the criteria used to establish the co-occurrence of AR activity and ice-shelf collapse/calving for the Larsen ice shelves, we were not able to find major disintegration events on the Wilkins occurring within five days of an AR landfall. Observing calving events on the Wilkins ice shelf was more difficult, as clouds generally cover the western coast of the AP obscuring calving observations. Still, the documented major collapse events in late summer $1993\left(544 \mathrm{~km}^{2}\right.$; Lucchitta and Rosanova [1998]; Braun et al. [2009]), March 1998 (1100 km²; Scambos et al. [2000]; Lucchitta and Rosanova [1998]), and February-March 2008 (1220 km²; Braun et al. [2009]; Rankl et al. [2017]) occurred during a period warmer than average 
temperatures and high AR activity, especially in 1993 and 2008 when AR activity was particularly high (Fig. A.3). Since meltwater has been documented to precondition the Wilkins ice shelf for collapse via hydrofracturing (Scambos et al. [2009]), it is likely that ARs are driving many of the collapse events even if they are not actively present at the time of collapse. The prevalence of perennial firn aquifers on the Wilkins ice shelf may explain the disparity between AR occurrences and calving/collapse events (van Wessem et al. [2020]). These features where meltwater percolates in the snowpack and then remains buried under snow as a liquid before eventually draining into crevasses (Alley et al. [2018]), occur in areas with high snowfall accumulation like the Wilkins and can delay or reduce runoff (van Wessem et al. [2020]; Munneke et al. [2014]). Still more research is needed to properly understand their impact on Antarctic ice-shelf stability. Also, the June-July 2008 break-up of the Wilkins ice shelf was attributed to the redistribution of internal stress and brine infiltration highlighting the complexity of the ice-shelf system (Scambos et al. [2009]). 


\section{B.2 Supplementary figures}

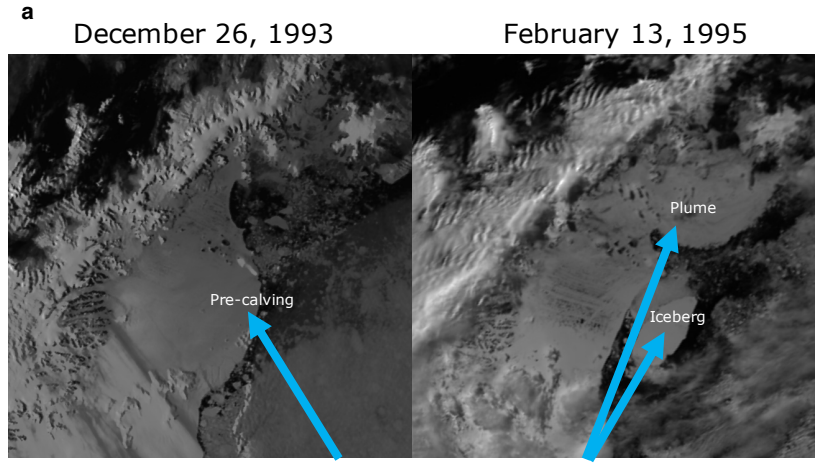

c
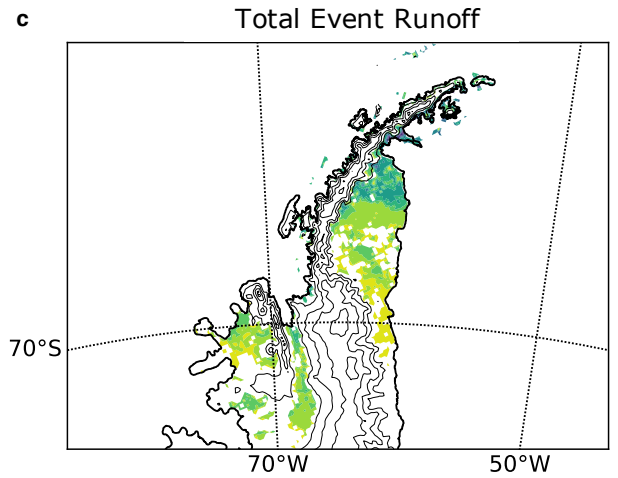

b Jan. 241995 AR Shape and Intensity

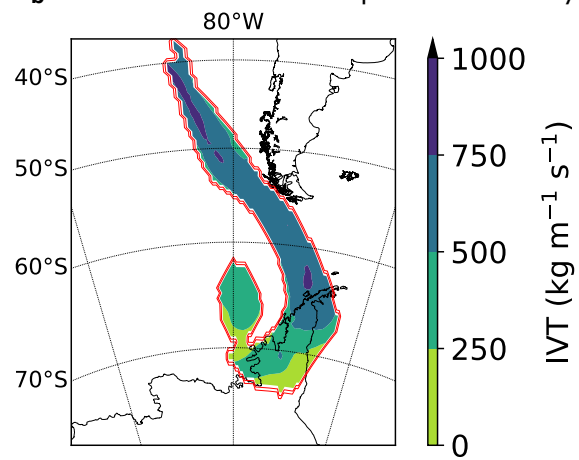

d

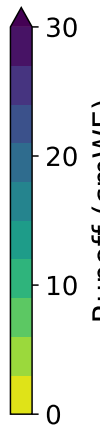

Two Day Sea Ice Change

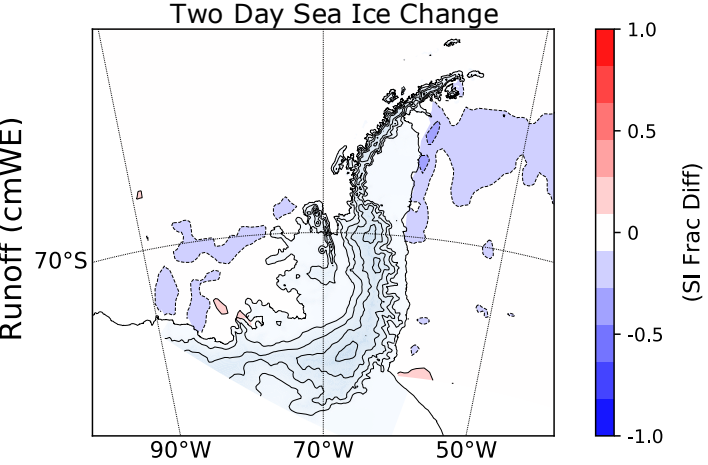

Supplementary Figure B.1: Overview of the Larsen A collapse in 1995. a AVHRR satellite imagery showing the state of the Larsen A before and after the collapse in late January 1995. b the shape and intensity of the detected AR believed to initiate the final collapse. $\mathbf{c}$ The total runoff that occurred from 23/01/95 00 UTC - 28/01/95 00 UTC. d The two day sea ice change centered on the AR occurrence from 24/01/95 00 UTC. 

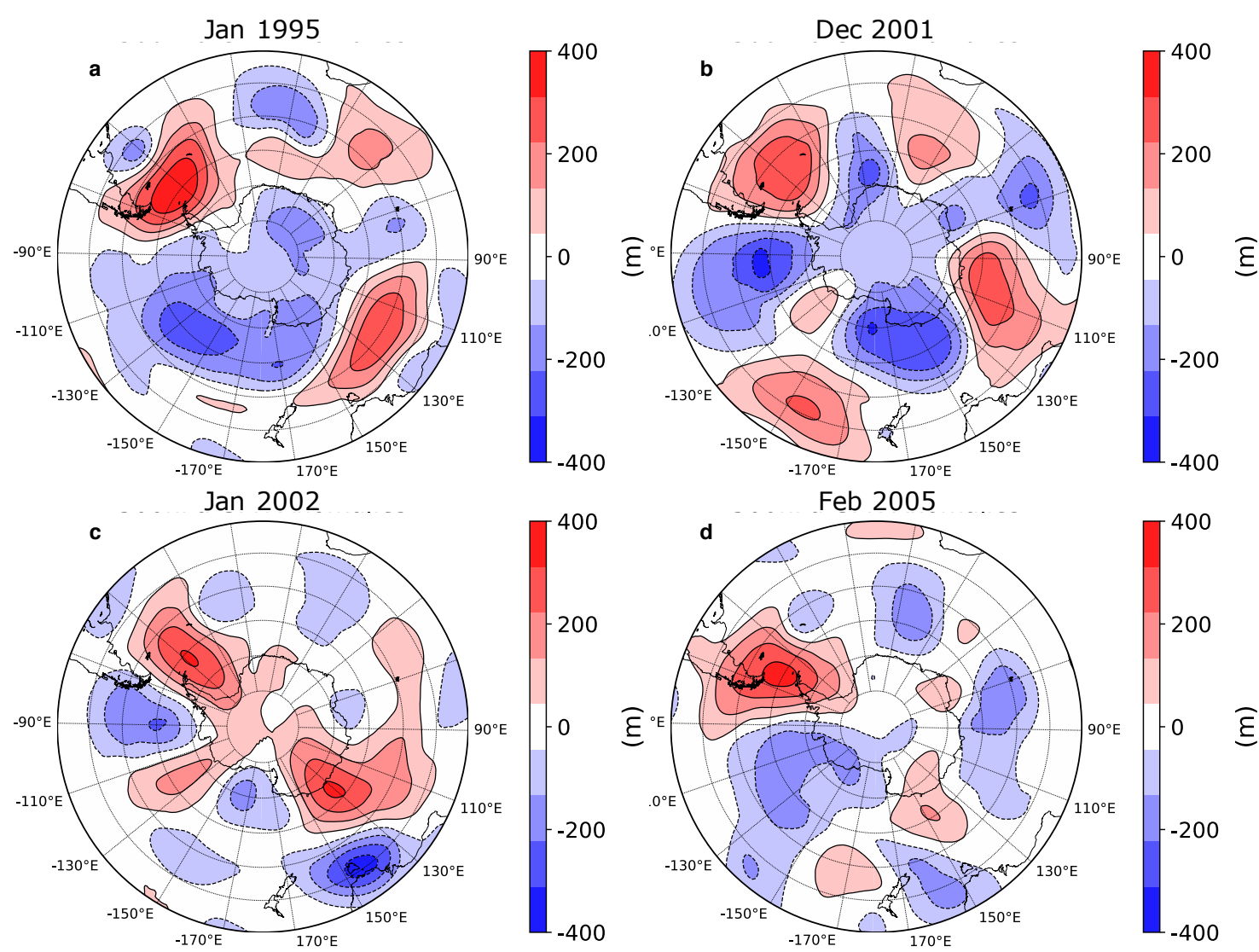

Supplementary Figure B.2: Composite MERRA-2 $500 \mathrm{hPa}$ geopotential height anomalies for a 24/01/95 12 UTC - 25/01/95 18 UTC, b 13/12/01 00 UTC - 14/12/01 00 UTC, c 01/01/02 00 UTC - 14/12/01 00 UTC, and d 09/02/05 18 UTC - 10/02/05 18 UTC. Monthly anomalies are with respect to the corresponding 1980-2018 monthly mean. 


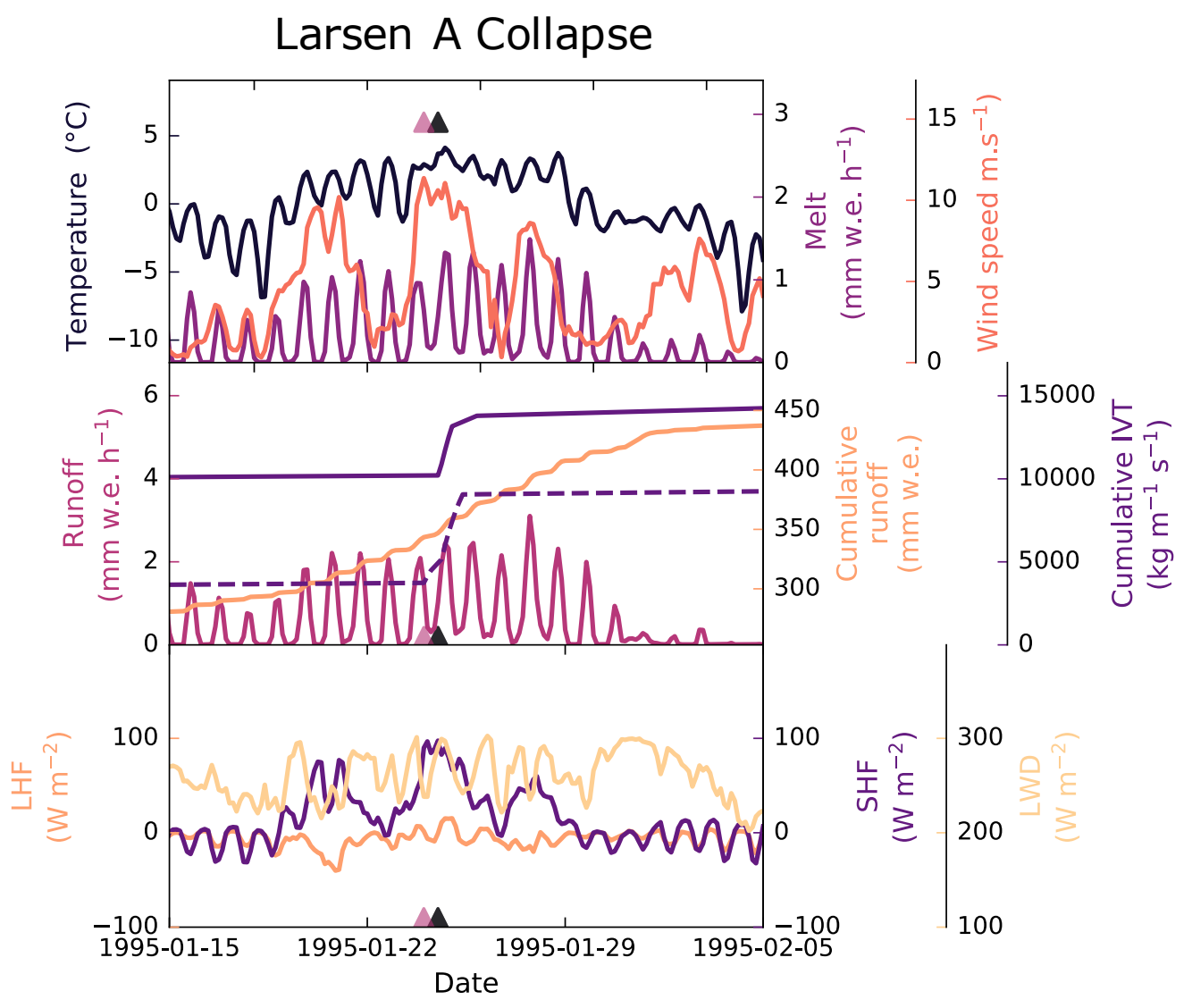

Supplementary Figure B.3: Variations of the main meteorological variables during the Larsen A collapses. The date of the first AR detection is displayed with black triangles (for the vIVT scheme) and purple triangles (IWV scheme). The color of the lines refers to the color of the axis of the same panel. LHF is surface turbulent latent heat flux, SHF is surface turbulent sensible heat flux, LWD is downward longwave radiation at the surface. Cumulative runoff and IVT are counted from the previous November. The location of the points used for this analysis is described in Extended Data Fig. 4.11 


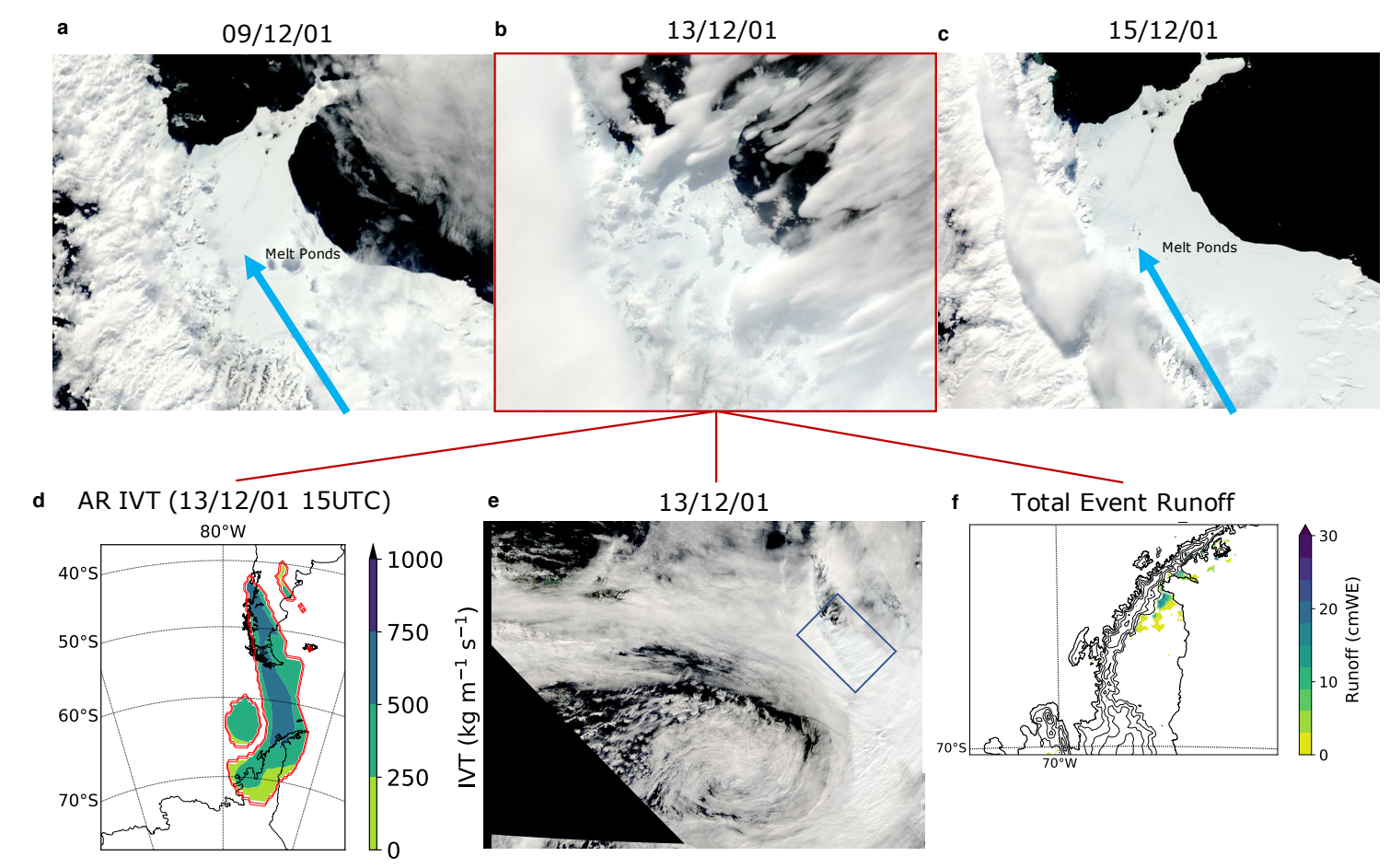

Supplementary Figure B.4: Overview of December 13th, 2001 AR over the Larsen B. MODIS satellite imagery from a 9/12/01, b 13/12/01, c 15/12/01 showing the enhanced melt ponds after the passing of an AR. $\mathbf{d}$ the shape and intensity of the detected AR on 13/12/01 15 UTC and seen in $\mathbf{b}$ and e. e A expanded satellite image demonstrating the structure of the AR landfall in 13/12/01. f The total runoff that occurred from 9/12/01 - 15/12/01. 


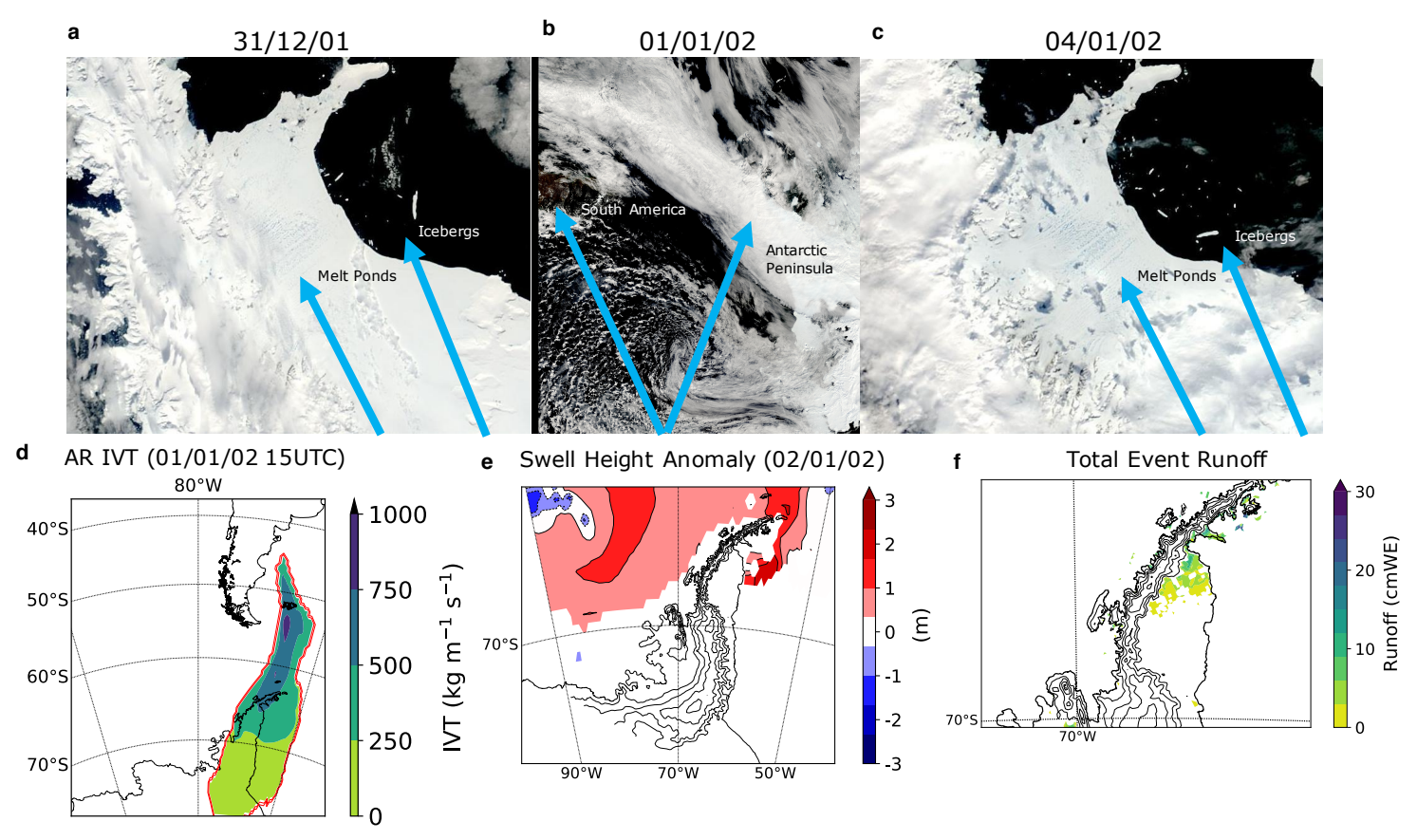

Supplementary Figure B.5: Overview of January 1st, 2001 AR over the Larsen B.

MODIS satellite imagery from a 31/12/01, b 01/01/02, c 04/01/02 showing the enhanced melt ponds after the passing of an AR. $\mathbf{d}$ the shape and intensity of the detected AR on 01/01/02 15 UTC and seen in b. e The swell height anomalies on 02/01/02 compared to the monthly climatological mean. $\mathbf{f}$ The total runoff that occurred from 31/12/01 - 04/01/01. 

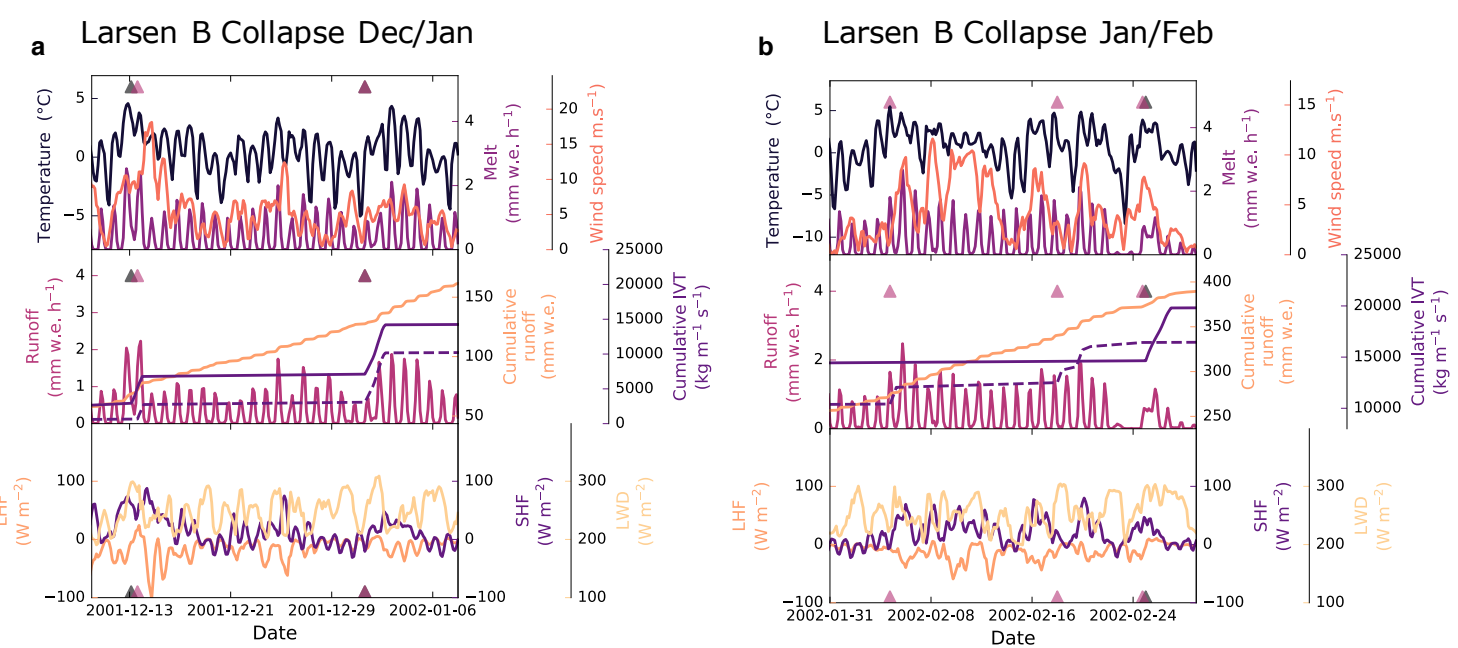

Supplementary Figure B.6: Variations of the main meteorological variables during the $\mathbf{a}$ Larsen A and $\mathbf{b}$ Larsen B collapses. The date of the first AR detection is displayed with black triangles (for the vIVT scheme) and purple triangles (IWV scheme). The color of the lines refers to the color of the axis of the same panel. LHF is surface turbulent latent heat flux, SHF is surface turbulent sensible heat flux, LWD is downward longwave radiation at the surface. Cumulative runoff and IVT are counted from the previous November. The location of the points used for this analysis is described in Extended Data Fig. 4.11 


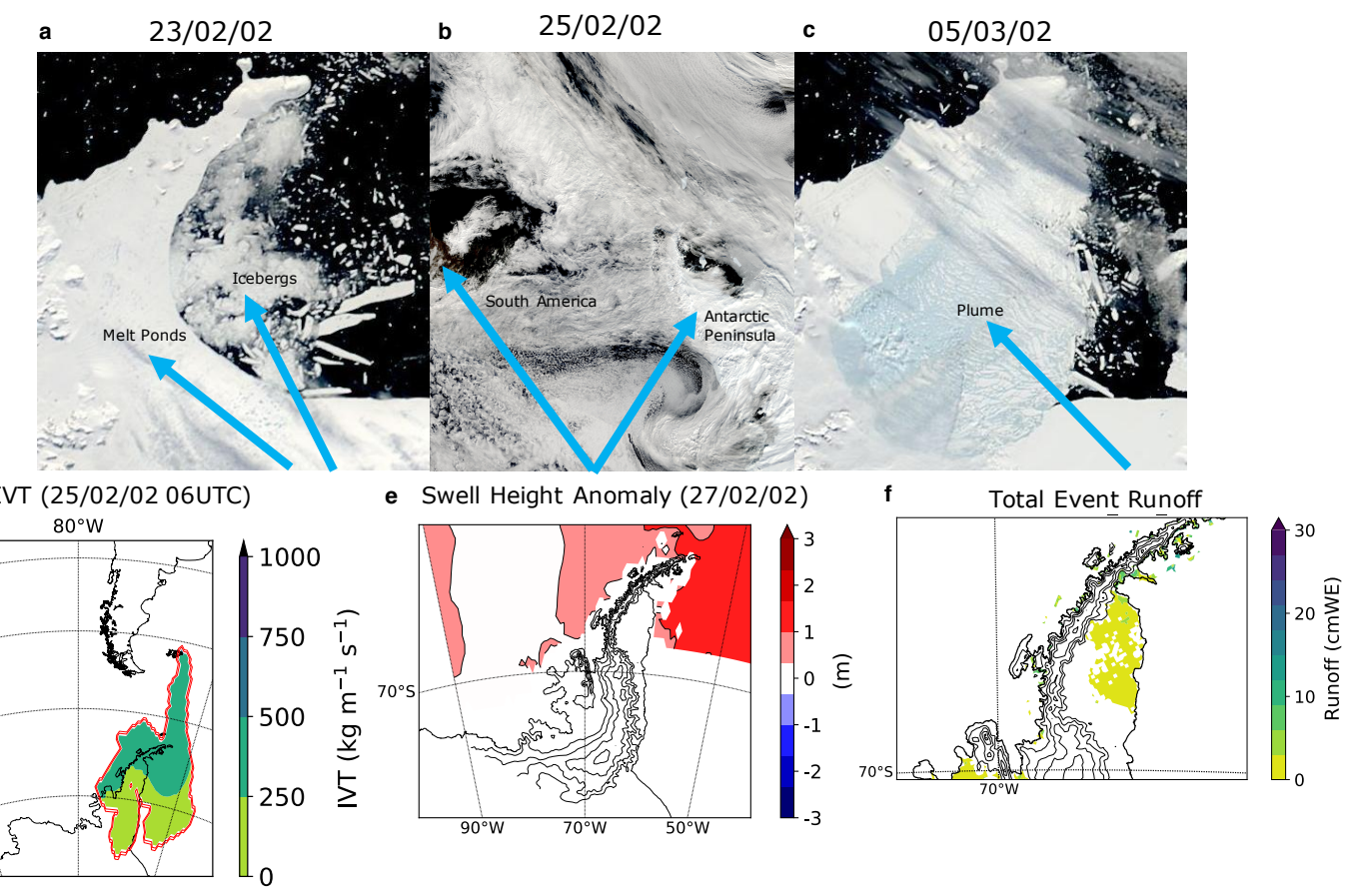

Supplementary Figure B.7: Overview of the Larsen B final collapse. MODIS satellite imagery from a 23/02/02, b 25/02/02, c 05/03/02 showing the enhanced melt ponds after the passing of an AR. $\mathbf{d}$ the shape and intensity of the detected AR on 25/02/02 06 UTC and seen in b. e The swell height anomalies on 27/02/02 compared to the monthly climatological mean. $\mathbf{f}$ The total runoff that occurred from 23/02/02 05/03/02.

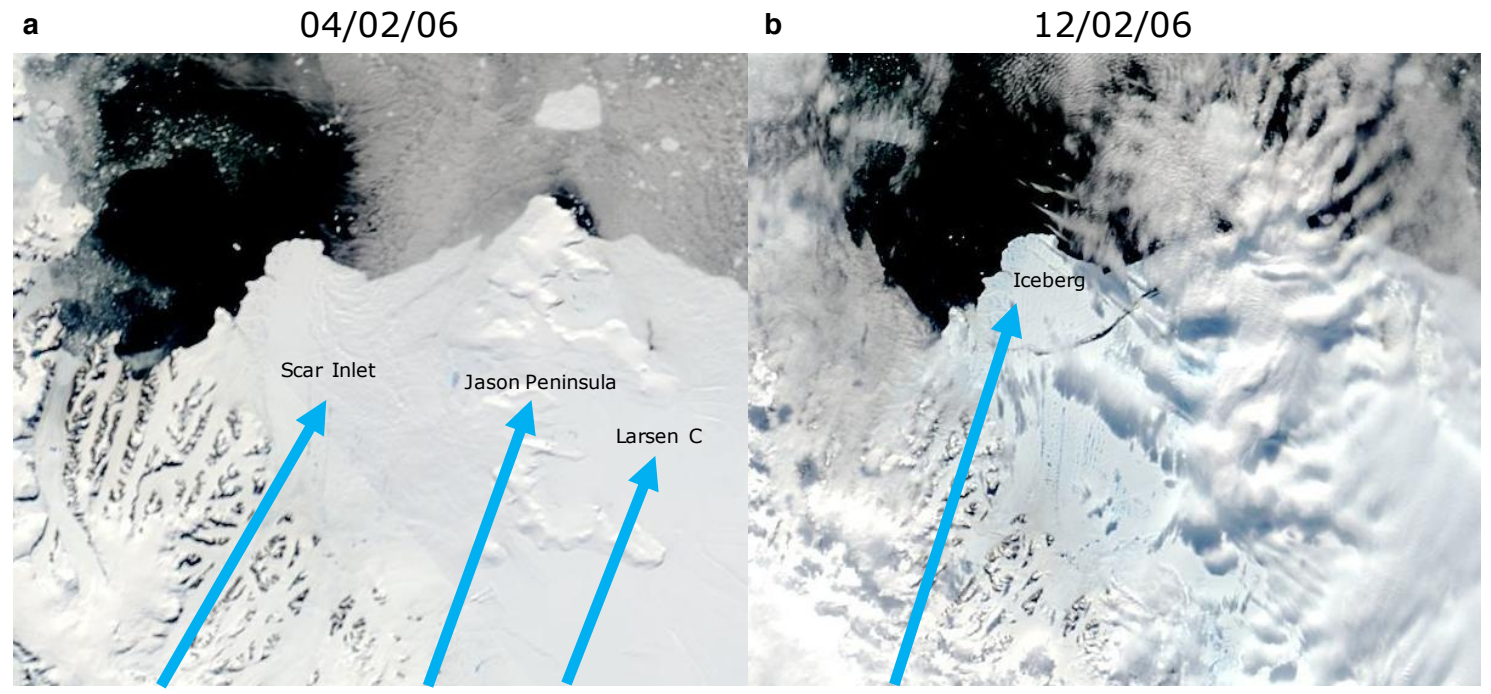

Supplementary Figure B.8: Overview of early February 2006 Scar Inlet ice shelf calving event. MODIS satellite imagery from a 04/02/06 and b 12/02/06 showing the iceberg calving and melt pond formation following an AR landfall February 6th - 8th. 


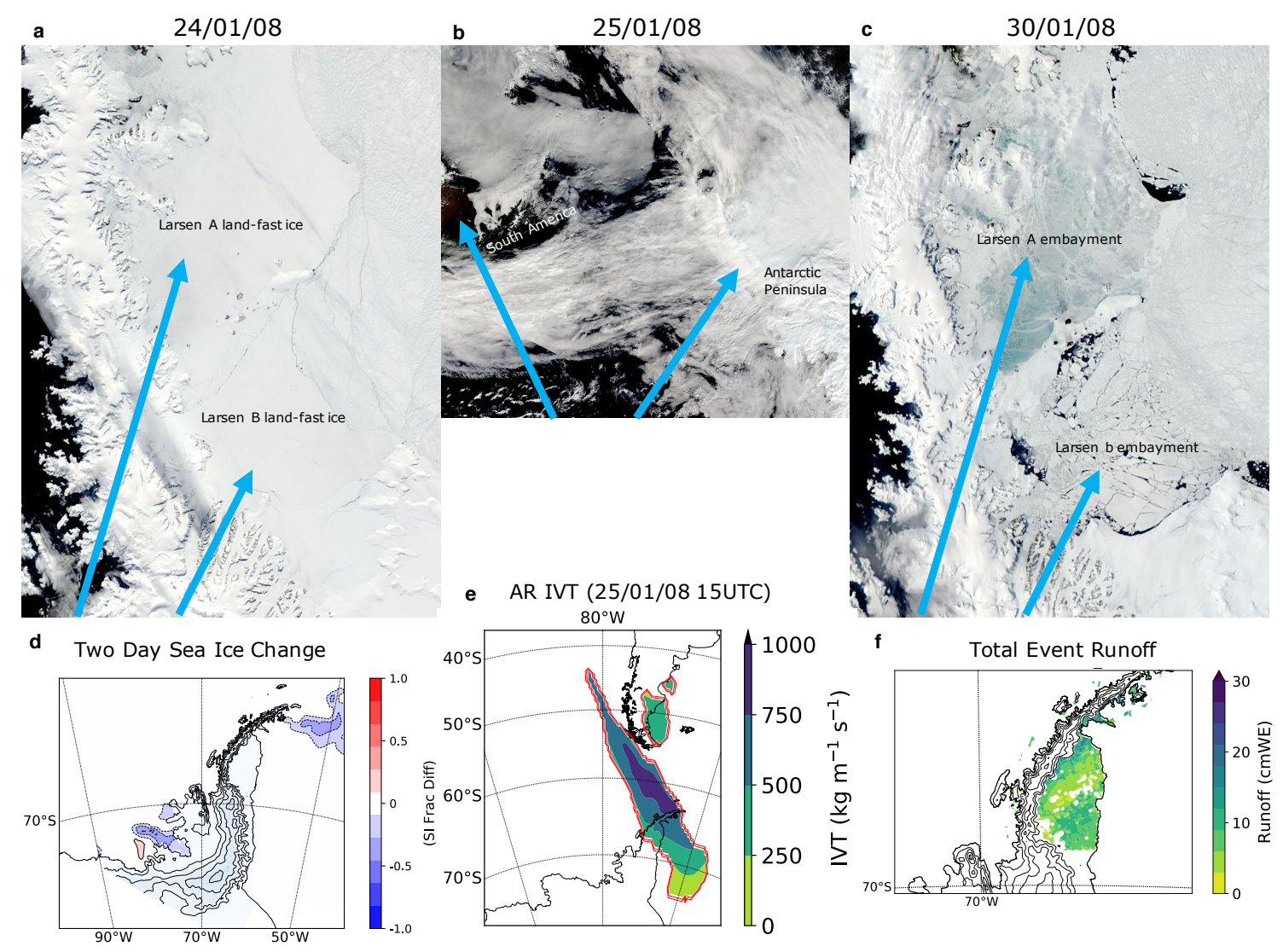

Supplementary Figure B.9: Overview of January 8th, 2008 AR over the AP. MODIS satellite imagery from a 24/01/08 and c 30/01/08 showing the land-fast ice and sea ice decay after the passing of an AR as seen in $\mathbf{b} 25 / 01 / 08$. $\mathbf{d}$ The two-day sea ice change centered on the AR occurrence from 25/01/08 00 UTC. e the shape and intensity of the detected AR on 25/01/08 15 UTC. f The total runoff that occurred from 25/01/08 $-30 / 01 / 08$. 


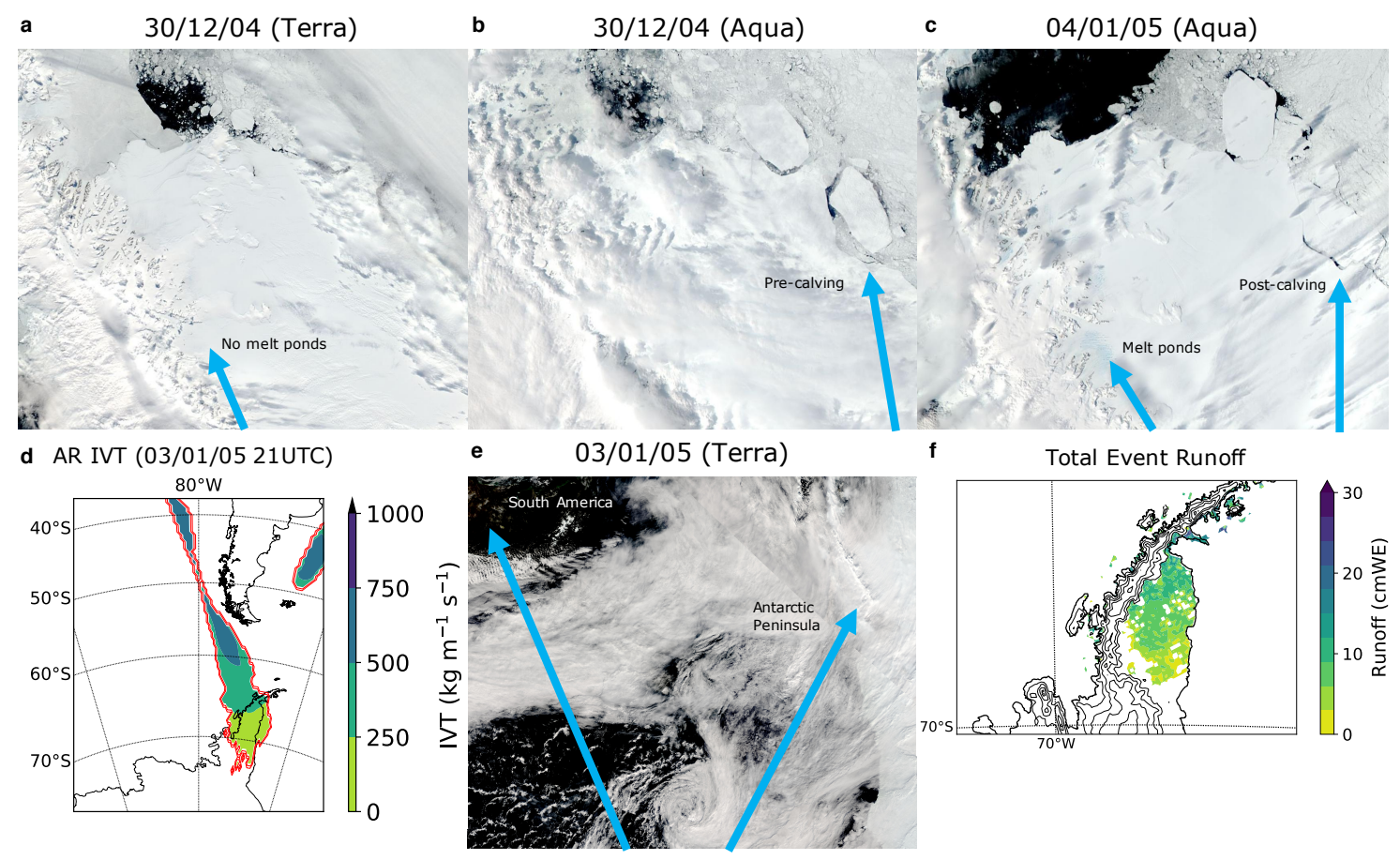

Supplementary Figure B.10: Overview of January 3rd, 2005 AR over the Larsen C. MODIS satellite imagery from a 30/12/04 (Terra), b 30/12/04 (Aqua), c 04/01/05 (Aqua) showing the enhanced melt ponds and calving after the passing of an AR as seen in e 03/01/05 (Terra). $\mathbf{d}$ the shape and intensity of the detected AR on 03/01/05 21 UTC. f The total runoff that occurred from 02/01/05 - 07/01/05. 


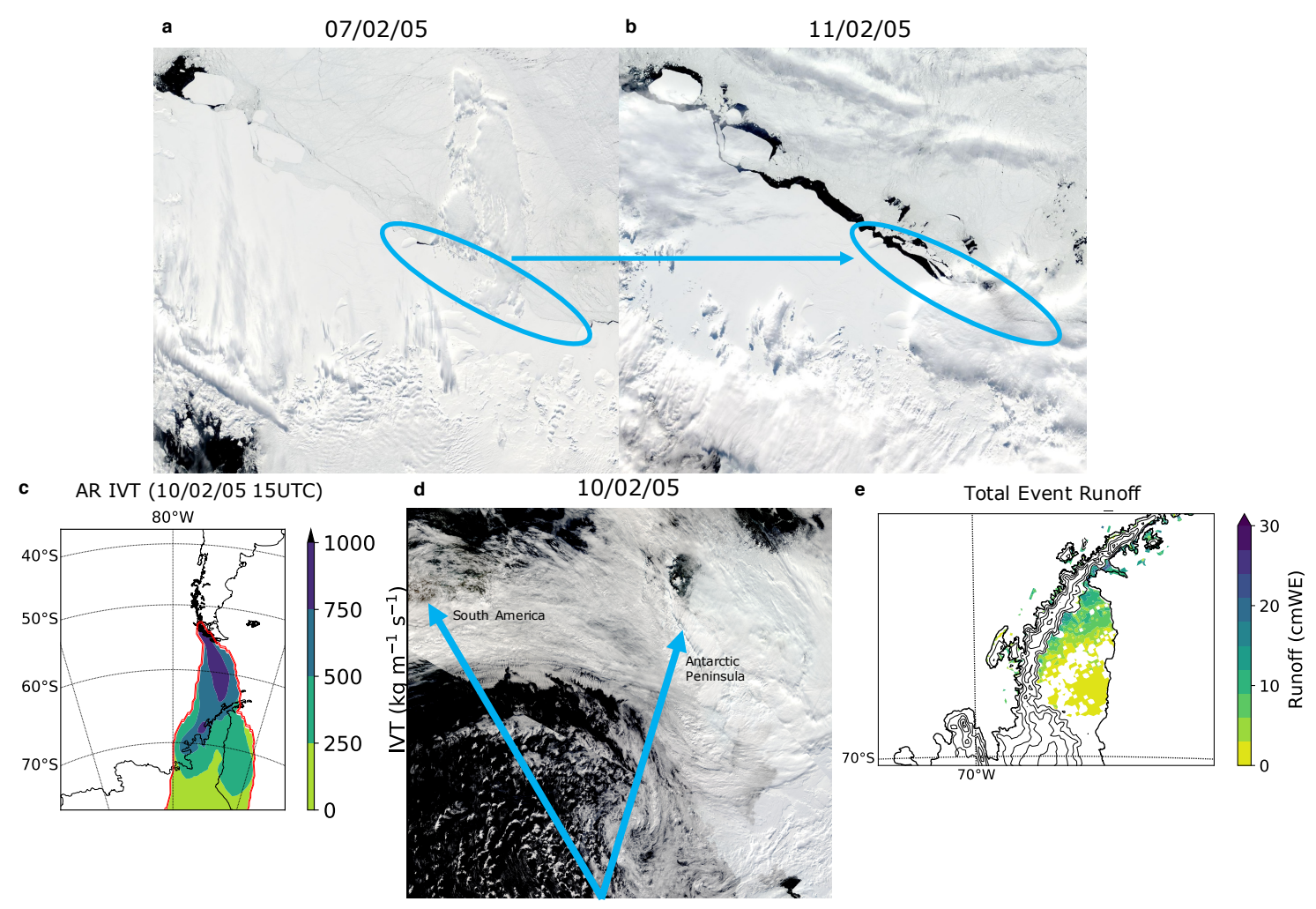

Supplementary Figure B.11: Overview of February 10th, 2005 AR over the Larsen C. MODIS satellite imagery from a 07/02/05 and b 11/02/05 showing the calving and sea ice displacement after the passing of an AR as seen in $\mathbf{d ~ 1 0 / 0 2 / 0 5}$. c the shape and intensity of the detected AR on 10/02/05 15 UTC. e The total runoff that occurred from 09/02/05 - 14/02/05.

\section{B.3 Supplementary Tables}

Tables containing the catalogue of ice shelf disintegration events for Fig. 4.3 in "The atmospheric river threat to Antarctic Peninsula ice-shelf collapse” 


\begin{tabular}{|c|c|}
\hline Index & Collapse date \\
\hline 1 & $2 / 27 / 2000$ \\
\hline 2 & $12 / 24 / 2001$ \\
\hline 3 & $1 / 6 / 2002$ \\
\hline 4 & $2 / 8 / 2002$ \\
\hline 5 & $2 / 17 / 2002$ \\
\hline 6 & $2 / 23 / 2002$ \\
\hline 7 & $3 / 2 / 2002$ \\
\hline 8 & $8 / 20 / 2002$ \\
\hline 9 & $1 / 18 / 2003$ \\
\hline 10 & $2 / 23 / 2003$ \\
\hline 11 & $4 / 18 / 2003$ \\
\hline 12 & $11 / 29 / 2004$ \\
\hline 13 & $1 / 3 / 2005$ \\
\hline 14 & $2 / 11 / 2005$ \\
\hline 15 & $1 / 1 / 2006$ \\
\hline 16 & $1 / 20 / 2006$ \\
\hline 17 & $2 / 11 / 2006$ \\
\hline 18 & $2 / 5 / 2008$ \\
\hline 19 & $11 / 30 / 2008$ \\
\hline 20 & $1 / 29 / 2009$ \\
\hline
\end{tabular}

Table B.1: List of the collapse and calving events retrieved with MODIS images and used in Figure 4.3. 


\begin{tabular}{|c|c|c|c|c|c|}
\hline $\begin{array}{l}\text { Collapse } \\
\text { date/period }\end{array}$ & $\begin{array}{l}\text { Attributed date } \\
\text { in Figure } 1\end{array}$ & $\begin{array}{l}\text { Area in figure } 1 \\
\text { (after calving) }\end{array}$ & Area in ref. 1 & Loss & Reference \\
\hline & 1 Jan. 1980 & 11512 & 12190 & & \\
\hline 25 Jan. 1995 & 25 Jan. 1995 & 11512 & 12190 & & 2,3 \\
\hline 30 Jan. 1995 & 30 Jan. 1995 & 9192 & & 2320 & 2 \\
\hline 25 Apr. 1998 & 25 Apr. 1998 & 9022 & & 170 & 2 \\
\hline 18 Nov. 1998 & 18 Nov. 1998 & 7829 & & 1193 & 2 \\
\hline 5 Aug. 1999 & 5 Aug. 1999 & 7198 & 8299 & 631 & 2 \\
\hline 6 Oct. 2000 & 6 Oct. 2000 & 6831 & & 2367 & 2 \\
\hline 12 Dec. 2001 & 12 Dec. 2001 & 6829 & & 2 & 2 \\
\hline 4 Feb. 2002 & 4 Feb. 2002 & 6664 & & 165 & 2 \\
\hline 4/27/28 Feb.2002 & 24 Feb. 2002 & 5942 & & 722 & 2 \\
\hline 5 Mar. 2002 & 5 Mar. 2002 & 4052 & & 1890 & 2 \\
\hline 7 Mar. 2002 & 7 Mar. 2002 & 3541 & & 346 & 2 \\
\hline 18 Mar. 2002 & 18 Mar. 2002 & 3463 & & 78 & 2 \\
\hline 3 Nov. 2002 & 3 Nov. 2002 & 3327 & 4429 & 136 & 2 \\
\hline 19 Mar. 2003 & 19 Mar. 2003 & 2678 & & 649 & 2 \\
\hline 23 Apr. 2003 & 23 Apr. 2003 & 2667 & & 11 & 2 \\
\hline 19 Feb. 2006* & 19 Feb. 2006* & 2167 & & 650 & 4 \\
\hline Feb. $92008^{* *}$ & 9 Feb. $2008^{* *}$ & 1977 & 2407 & 140 & 4 \\
\hline
\end{tabular}

Table B.2: Extent of Larsen B ice shelf along time, as used in Figure 4.3. *MODIS images the 3 Feb. and 20 Feb. 2006 available on the NSIDC website ** MODIS images the 30 Jan. and 10 Feb. 2008 available on the NSIDC website 


\begin{tabular}{llllll}
\hline $\begin{array}{l}\text { Collapse } \\
\text { date/period }\end{array}$ & $\begin{array}{l}\text { Attributed date } \\
\text { in Figure 1 }\end{array}$ & $\begin{array}{l}\text { Area in figure 1 } \\
\text { (after calving) }\end{array}$ & Area in ref. 1 & Loss & Reference \\
\hline & 1 Jan. 1980 & & $3394^{*}$ & & 1 \\
1986 & 1 Mar. 1986 & 3394 & & 0 & $1,3,5$ \\
$1986 / 1992$ & 2 Jul. 1992 & 3244 & & $150^{* *}$ & 3,5 \\
1993 & 26 Aug. 1993 & 3027 & $2168^{* * *}$ & $1,3,5$ & $1,3,5$ \\
1995 & 25 Jan. 1995 & 859 & 638 & $288^{* * * *}$ & 1 \\
1998 & 8 Dec. 1998 & 571 & 397 & $241^{* * * * *}$ & 1 \\
2004 & 15 Nov. 2004 & 330 & & 217 & 3,5 \\
\hline
\end{tabular}

Table B.3: Extent of Larsen A ice shelf along time, as used in Figure 4.3.

* Ref. 5 proposes an area of $2488 \mathrm{~km}^{2}$

**Ref. 5 proposes a loss of $244 \mathrm{~km}^{2}$

*** Ref. 5 proposes a loss of $926 \mathrm{~km}^{2}$ between the 25 Jan. 1995 and 30 Jan. 1995

****Computed using areas from ref. 1, occurrence was determined approximately

using AVHRR image from 12 Dec. 1998 (available on the NSIDC website)

***** Computed using areas from ref. 1, occurrence was determined approximately using MODIS images from 15 Nov. 2004 and 29 Nov. 2004 (available on the NSIDC website) 


\begin{tabular}{|c|c|c|c|c|c|}
\hline $\begin{array}{l}\text { Collapse } \\
\text { date/period }\end{array}$ & $\begin{array}{l}\text { Attributed date } \\
\text { in Figure } 1\end{array}$ & $\begin{array}{l}\text { Area in figure } 1 \\
\text { (after calving) }\end{array}$ & Area in ref. 1 & Loss & $\begin{array}{l}\text { Reference } \\
1\end{array}$ \\
\hline & 1 Jan. 1980 & 16577 & 16577 & 0 & 6 \\
\hline $1986-1990$ & 1 Mar. 1986 & 16480 & & 97 & 6 \\
\hline $1990-91$ & 1 Mar. 1991 & 15768 & 15986 & 712 & 6 \\
\hline $1991-92$ & 1 Mar. 1992 & 15768 & & 0 & 6 \\
\hline $1992-93$ & 1 Mar. 1993 & 15224 & & 544 & 6 \\
\hline 1993-98 & 1 Mar. 1998 & 15224 & & 0 & 6 \\
\hline 1998-99 & 1 Mar. 1999 & 14104 & 14694 & 1120 & 6 \\
\hline $1999-2000$ & 1 Mar. 2000 & 14017 & & 87 & 6 \\
\hline $2000-01$ & 1 Mar. 2001 & 14017 & & 0 & 6 \\
\hline 2001-03 & 1 Mar. 2003 & 13964 & & 53 & 6 \\
\hline 2003-04 & 1 Mar. 2004 & 13717 & 13663 & $51\left(+196^{*}\right)$ & 6 \\
\hline 2004-07 & 1 Mar. 2007 & $13717^{* *}$ & & 0 & 6 \\
\hline 2008 & 28-29 Feb. 2008 & 13265 & & 452 & 7,8 \\
\hline 2008 & 30-31 May 2008 & 13105 & & 160 & 7,8 \\
\hline 2008 & 1 Jul. 2008 & 11885 & & 1220 & 7,9 \\
\hline 2009 & 6 Apr. 2009 & 11021 & 11144 & $790+\left(74^{*}\right)$ & $6,9,10$ \\
\hline 2013 & 23 Mar. $2013^{* * *}$ & 10150 & 10150 & $938 * * * *$ & 9 \\
\hline
\end{tabular}

Table B.4: Extent of Wilkins ice shelf along time, as used in Figure 4.3.

*loss over the Southern Wilkins ice shelf between 1986-2004 and 2004-2010 (given in ref.6)

**13680 $\mathrm{km}^{2}$ before March 2008 according to Ref. 8

*** Date from https://earthobservatory.nasa.gov/images/81174/breakup-continues-

on-the-wilkins-ice-shelf

****This value corresponds to the difference between the area in 2015 (ref 9) and from the 2010s in ref 1. 


\section{Table References:}

1. Cook, A. J. Vaughan, D. G. Overview of areal changes of the ice shelves on the Antarctic Peninsula over the past 50 years. The Cryosphere 4, 77-98 (2010).

2. Rack, W. Rott, H. Pattern of retreat and disintegration of the Larsen B ice shelf, Antarctic Peninsula. Ann. Glaciol. 39, 505-510 (2004).

3. Scambos, T. A., Hulbe, C., Fahnestock, M. Bohlander, J. The link between climate warming and break-up of ice shelves in the Antarctic Peninsula. J. Glaciol. 46, 516-530 (2000).

4. Qiao, G., Li, Y., Guo, S. Ye, W. Evolving Instability of the Scar Inlet Ice Shelf based on Sequential Landsat Images Spanning 2005-2018. Remote Sens. 12, 36 (2020).

5. Rott, H., Skvarca, P. Nagler, T. Rapid Collapse of Northern Larsen Ice Shelf, Antarctica. Science 271, 788-792 (1996).

6. Lemos, A., Arigony-Neto, J., Mendes-Júnior, C. W. Costi, J. A comparative analysis between variations in wet snow zone and the main break-up and disintegration events in WILKINS ice shelf, Antarctic peninsula. Glob. Planet. Change 177, 39-44 (2019).

7. Braun, M., Humbert, A. Moll, A. Changes of Wilkins Ice Shelf over the past 15 years and inferences on its stability. The Cryosphere 3, 41-56 (2009).

8. Scambos, T. et al. Ice shelf disintegration by plate bending and hydro-fracture: Satellite observations and model results of the 2008 Wilkins ice shelf break-ups. Earth Planet. Sci. Lett. 280, 51-60 (2009).

9. Rankl, M., Fürst, J. J., Humbert, A. Braun, M. H. Dynamic changes on the Wilkins Ice Shelf during the 2006-2009 retreat derived from satellite observations. The Cryosphere 11, 1199-1211 (2017).

10. Humbert, A. et al. Deformation and failure of the ice bridge on the Wilkins Ice Shelf, Antarctica. Ann. Glaciol. 51, 49-55. 


$$
202
$$




\section{Appendix C}

Supplementary figures to "Antarctic atmospheric river climatology and precipitation impacts" 


\section{Supplementary figures}

a)

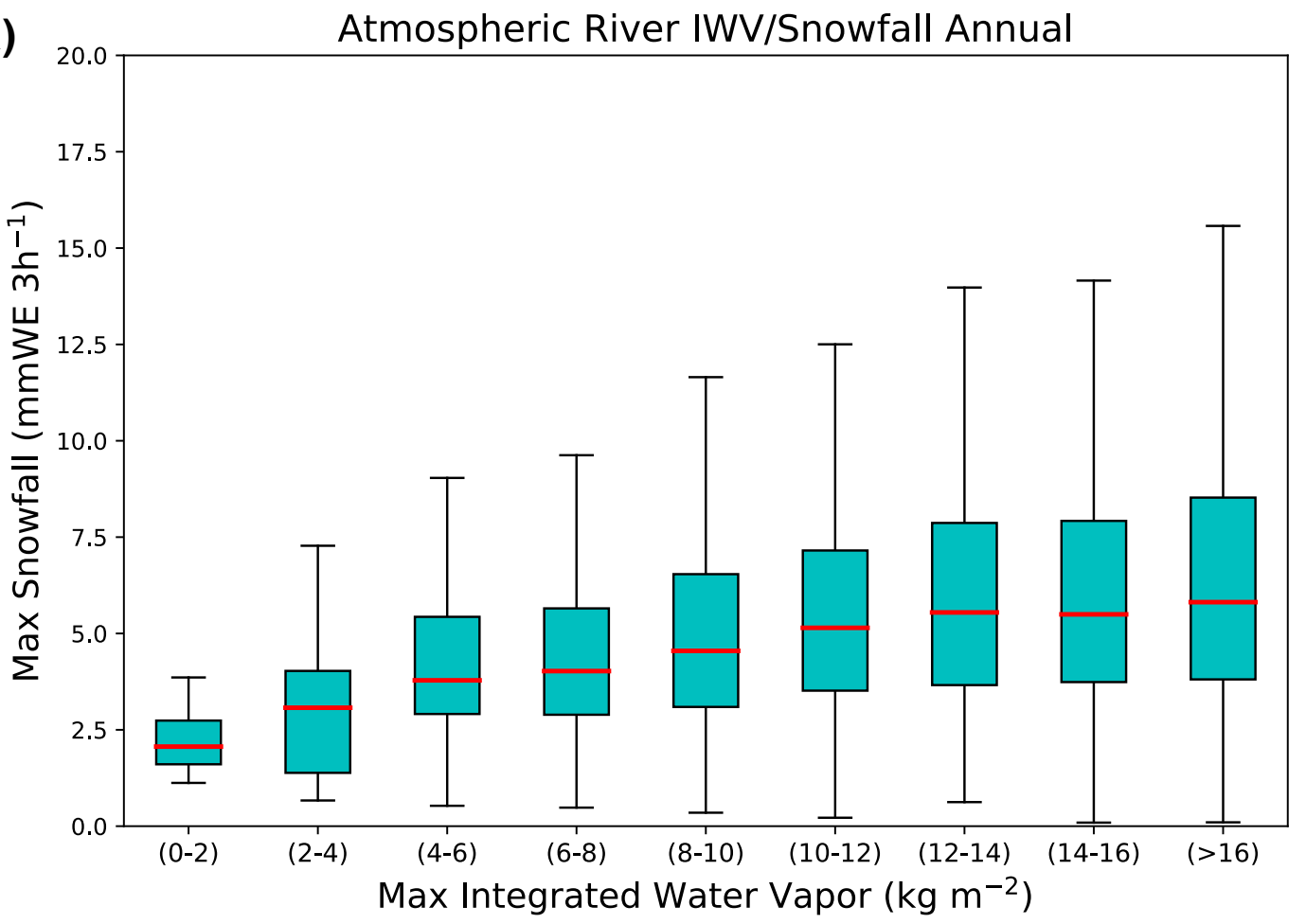

b)

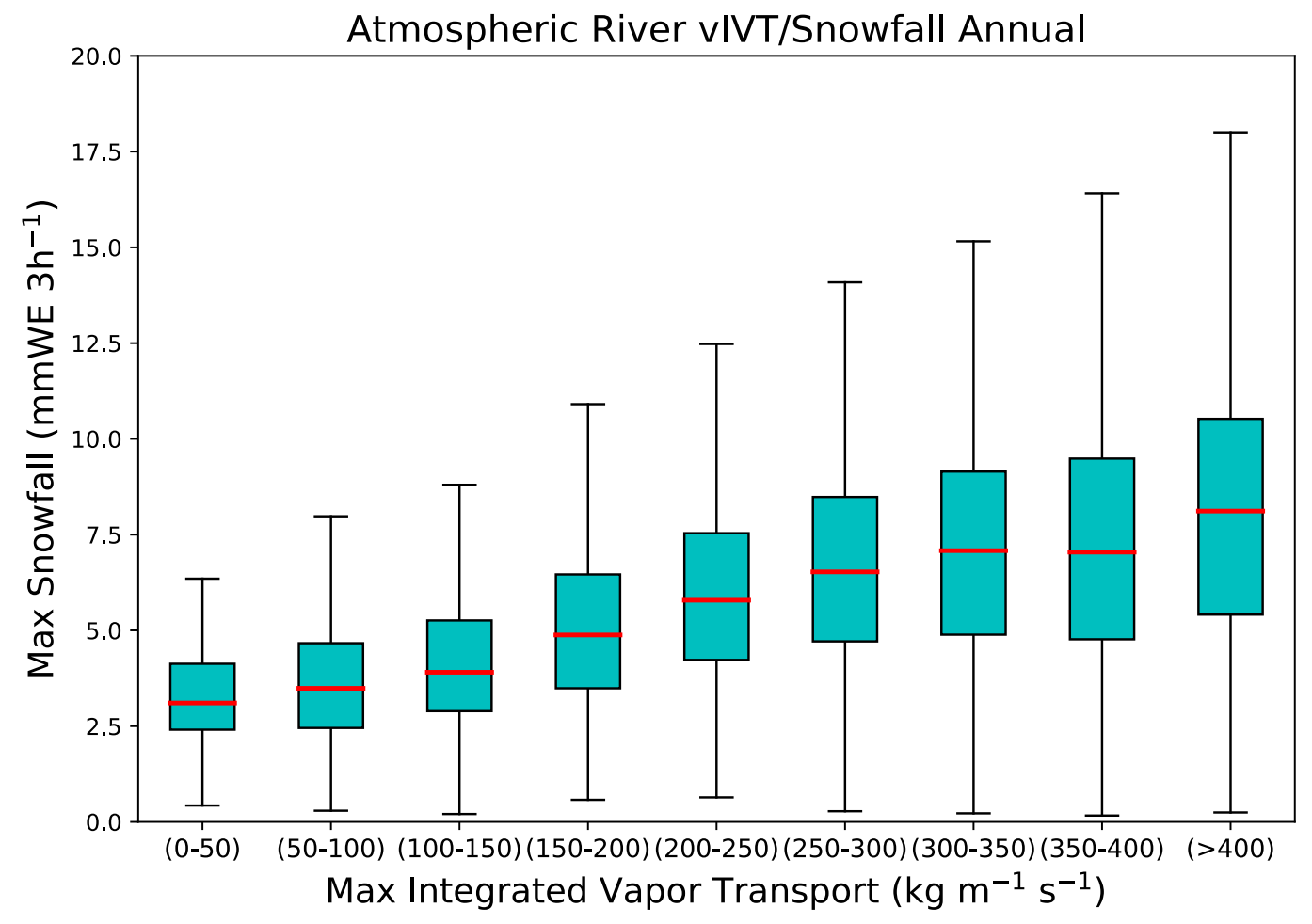

Supplementary Figure C.1: The maximum snowfall rate at every AR landfall in Antarctica from 1980-2018 compared against the a) maximum integrated vapor vapor (IWV) and b) maximum integrated vapor transport (vIVT). The AR landfalls in a) were provided by the IWV based detection scheme and in b) by the vIVT based detection scheme. 


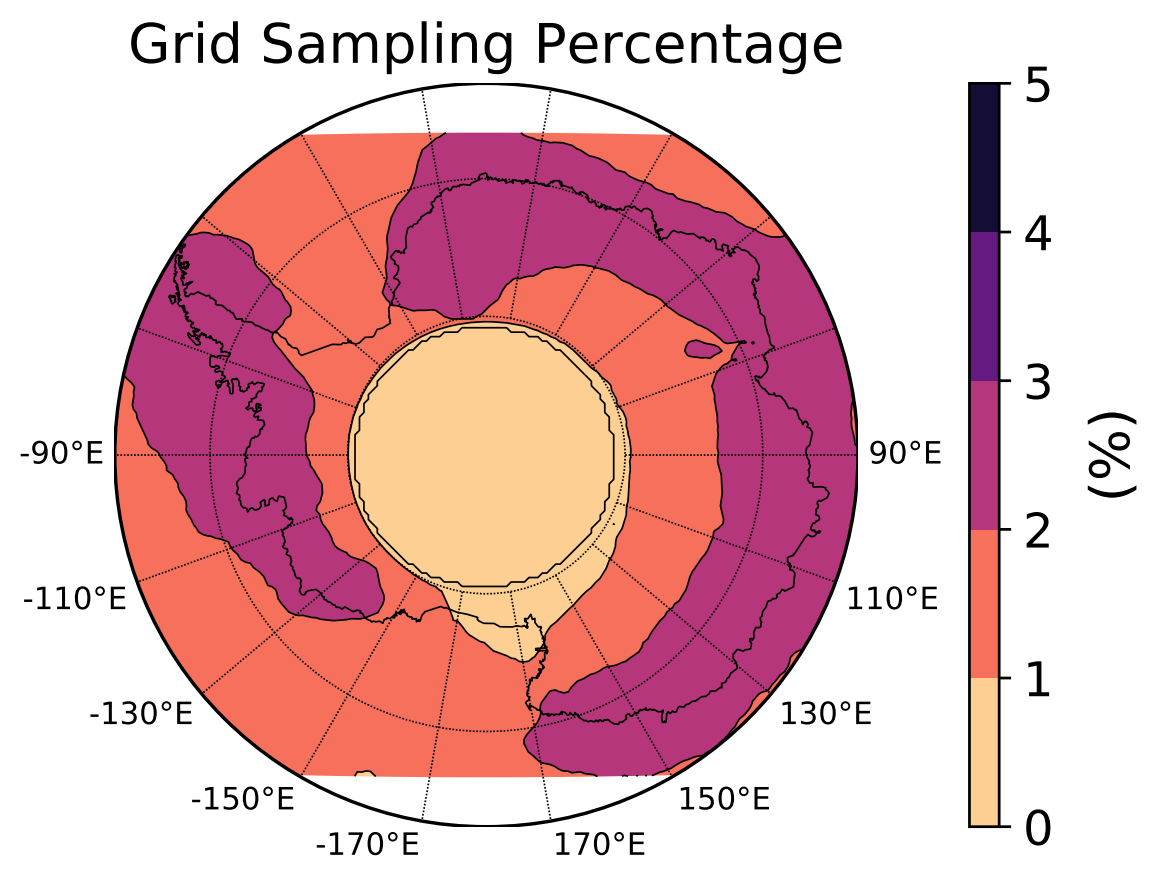

Supplementary Figure C.2: The sampling frequency in the study domain from applying the AR precipitation attribution method and counting the timesteps during and within 24 hours after an AR landfall on the Antarctic continent. 

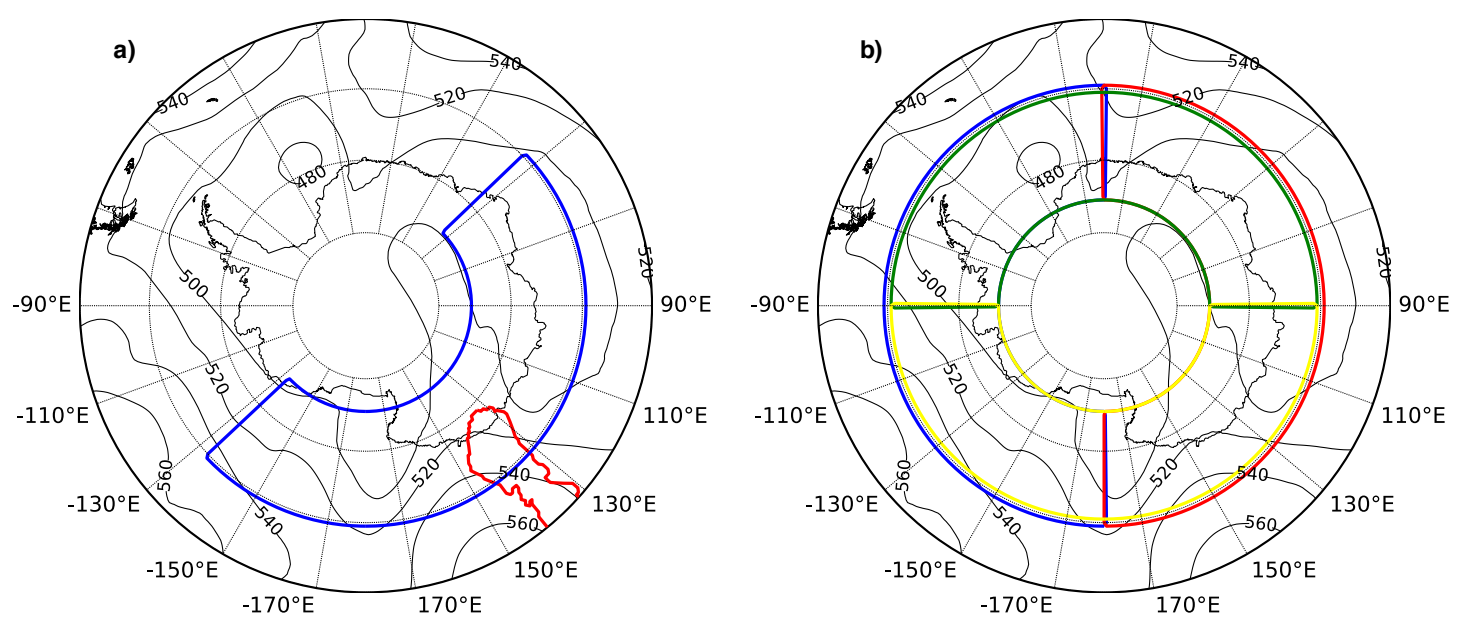

Supplementary Figure C.3: a) An example of the $180^{\circ}$ azimuth centered around an AR landfall where the blocking index described in section 2.4 is calculated. The blocking index is calculated by taking the difference between the maximum and minimum monthly $500 \mathrm{hPa}$ geopotential heigh anomaly in the blue highlighted region. b) The four $180^{\circ}$ azimuths where the blocking index is calculated for non-AR timesteps. The azimuth with the greatest blocking index becomes the value used to compare the blocking indices of AR timesteps against non-AR timesteps. 


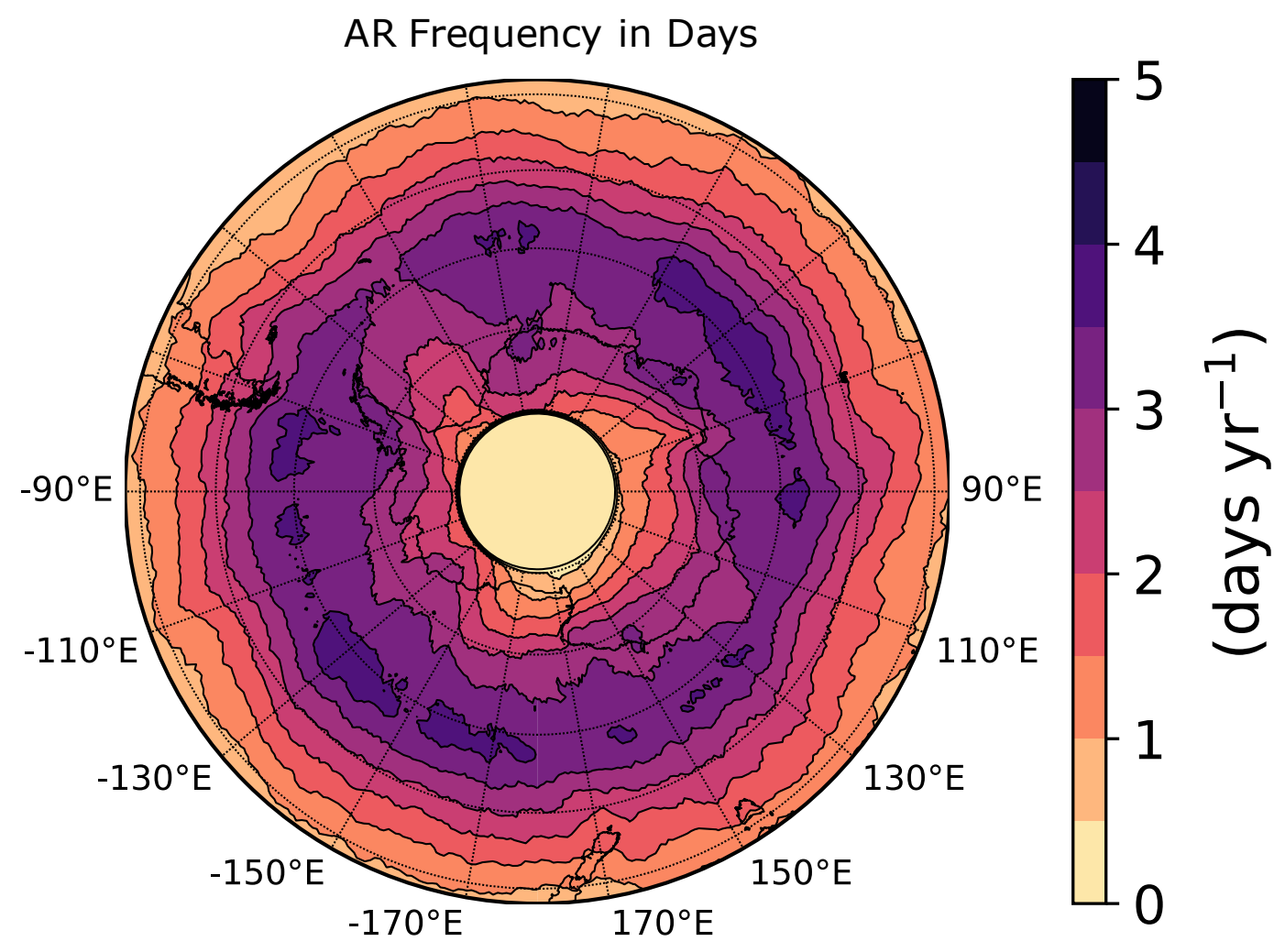

Supplementary Figure C.4: AR frequency from the vIVT scheme of the AR detection algorithm for 1980-2018 expressed in days per year. 


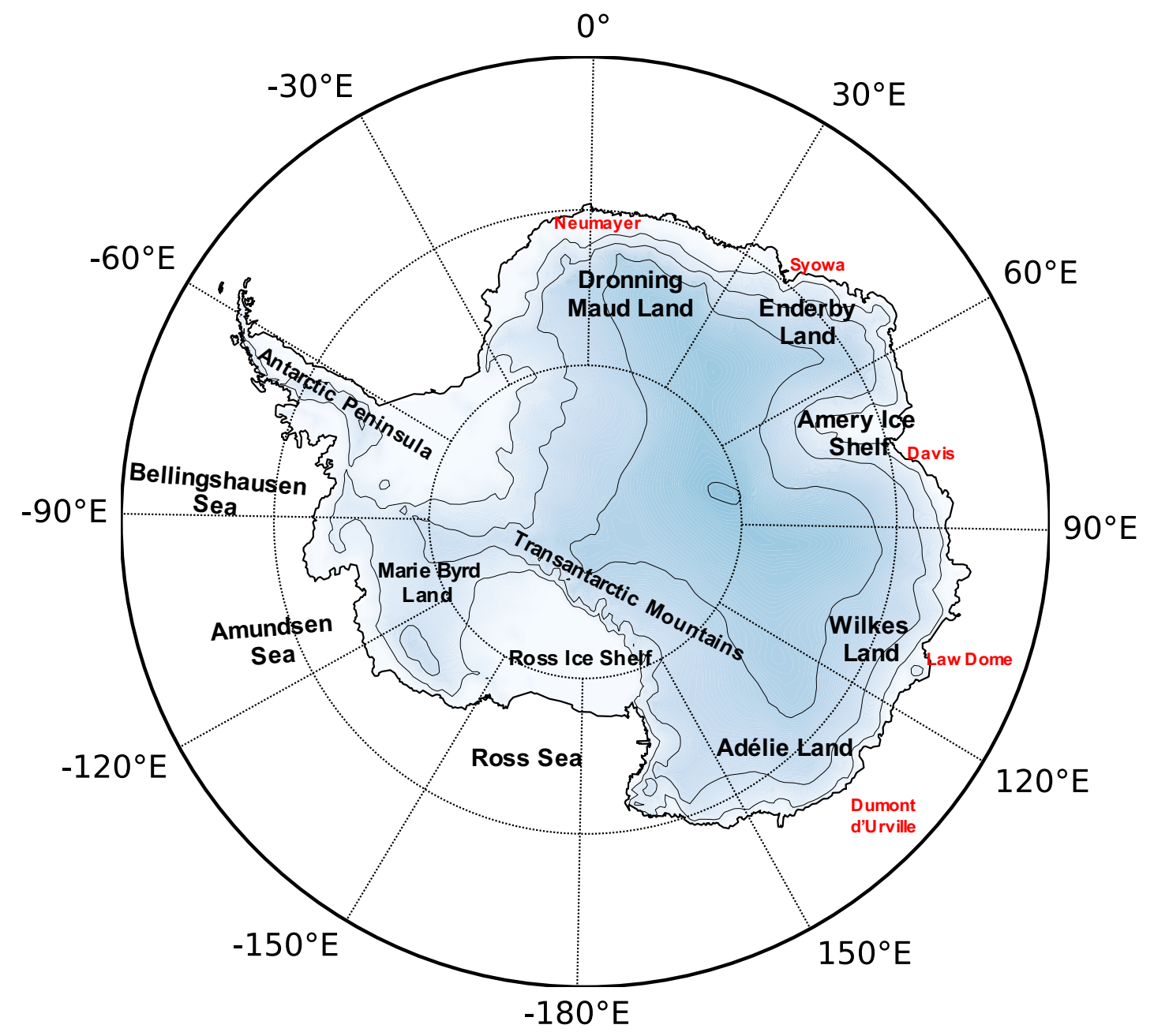

Supplementary Figure C.5: Locations of frequently mentioned regions and stations. 


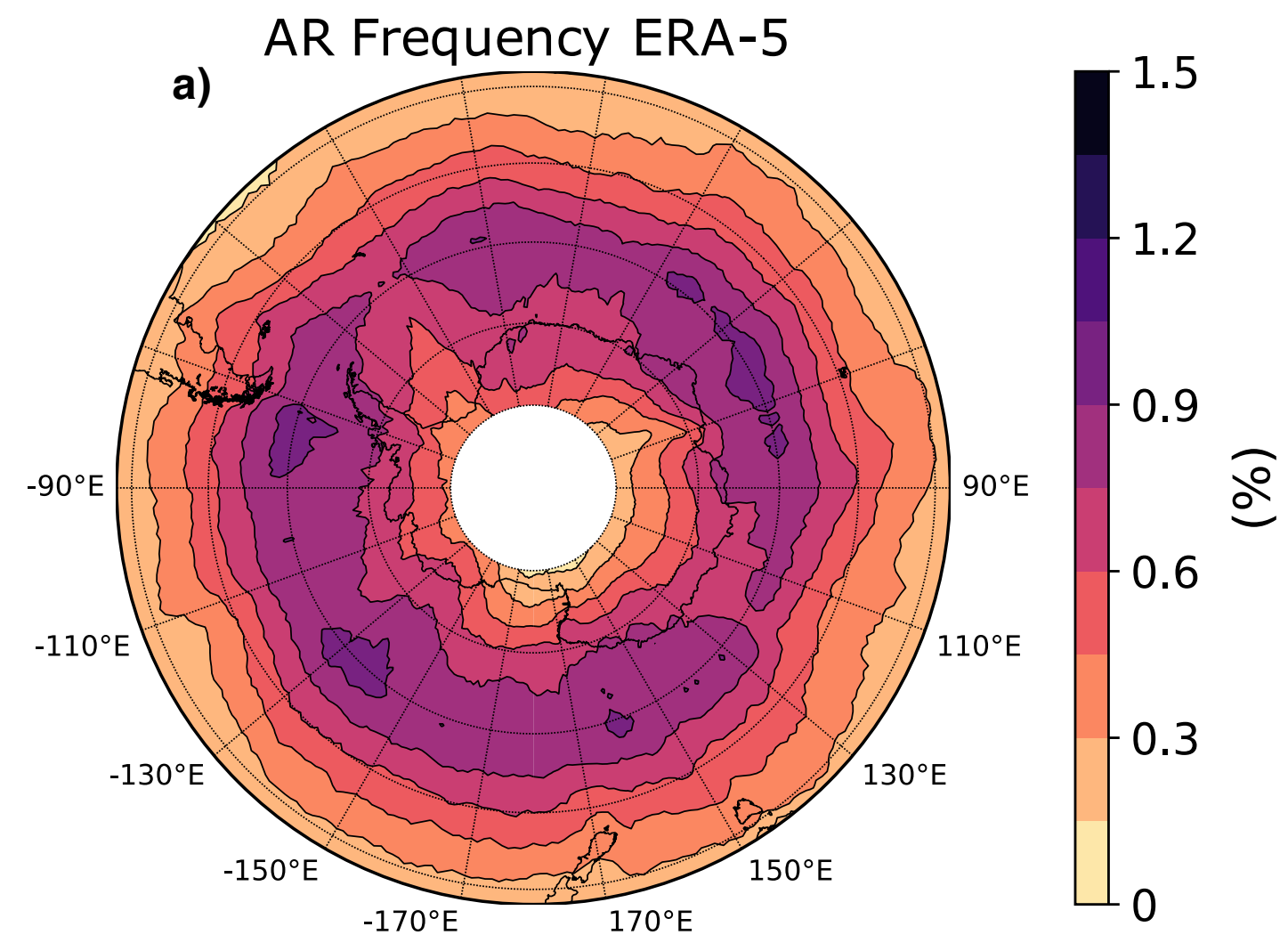

\section{AR Frequency Difference}

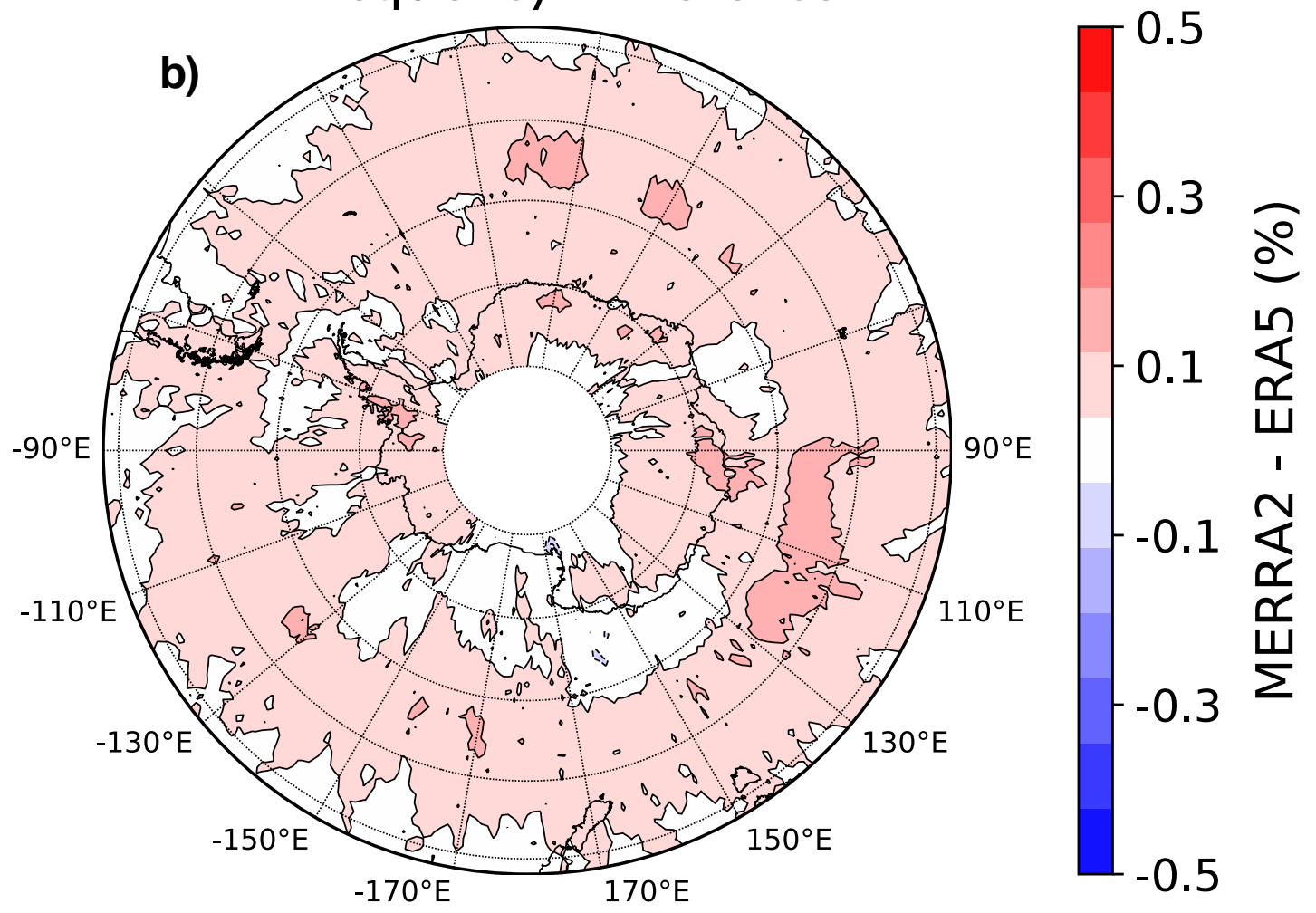

Supplementary Figure C.6: a) AR frequency from the vIVT scheme of the AR detection algorithm using the ERA-5 AR catalog for 1980-2018 and b) the AR frequency difference between MERRA-2 and ERA-5. 

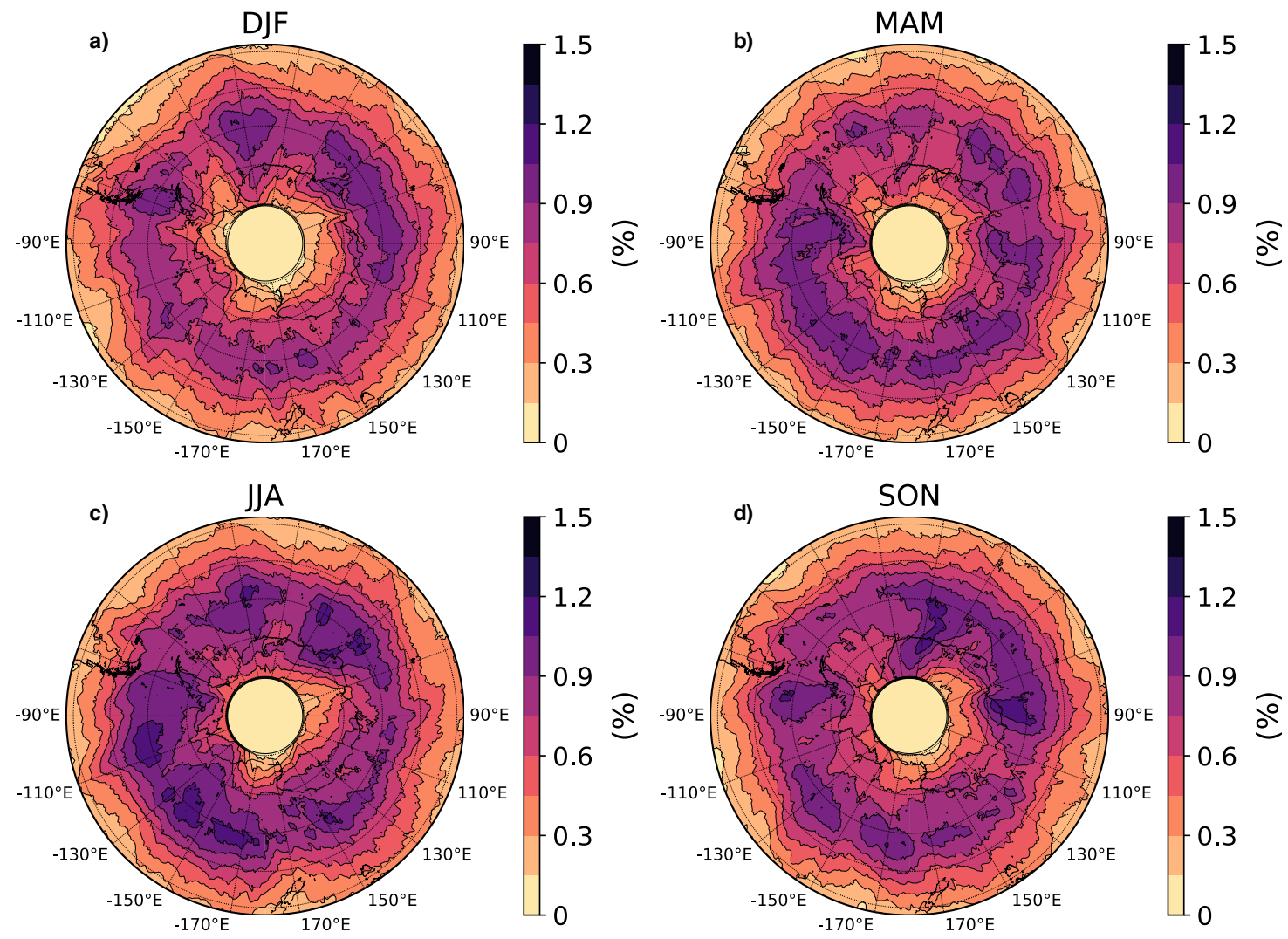

Supplementary Figure C.7: AR frequency from the vIVT scheme of the AR detection algorithm for a) summer (DJF), b) fall (MAM), c) winter (JJA), d) spring (SON) 1980-2018. 

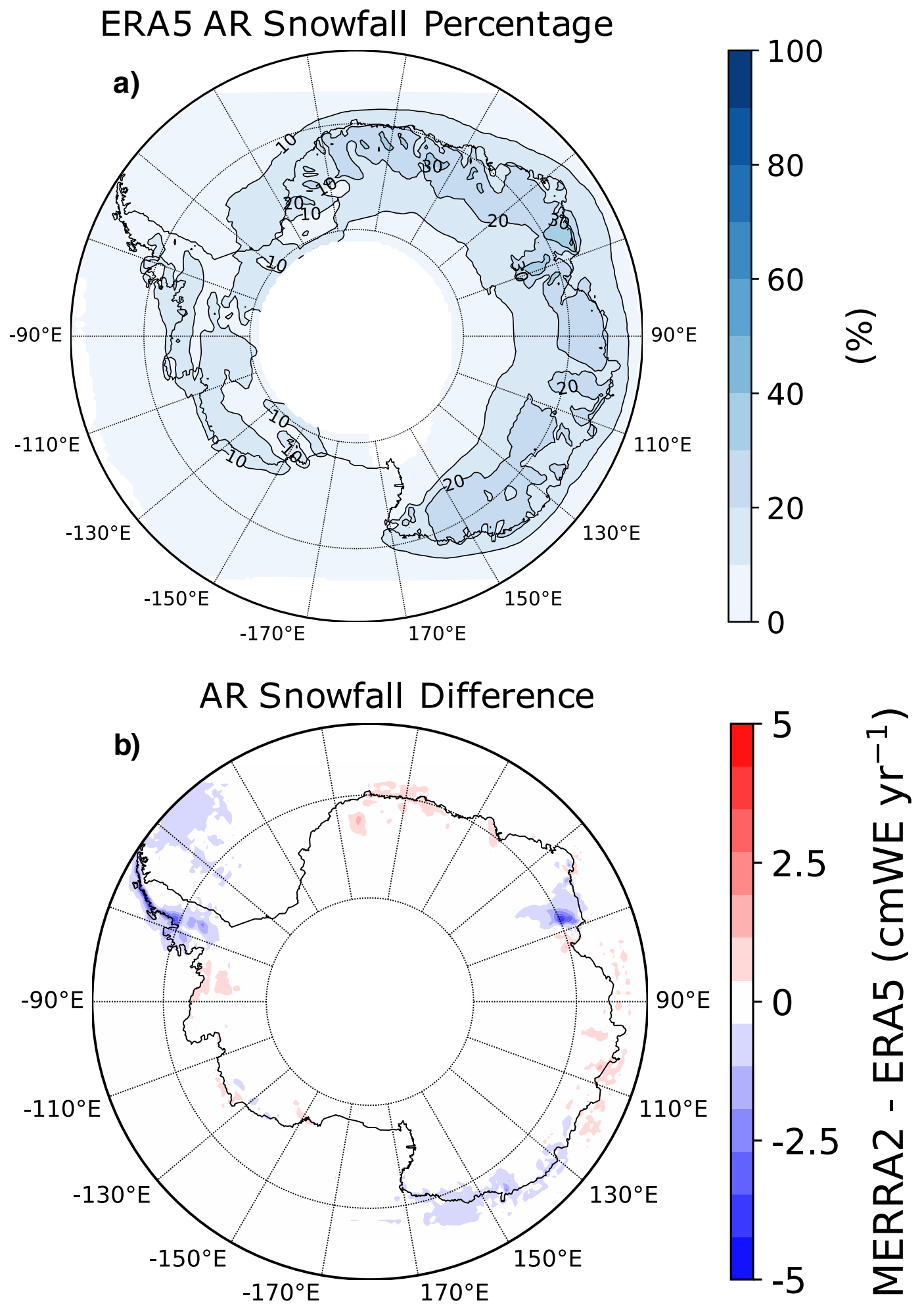

Supplementary Figure C.8: a) The percentage of the total snowfall attributed to AR landfalls using the precipitation attribution method with the ERA-5 AR catalog for 1980-2018 and b) the difference in year AR-related snowfall between the MERRA-2 and ERA-5 AR catalogs. 

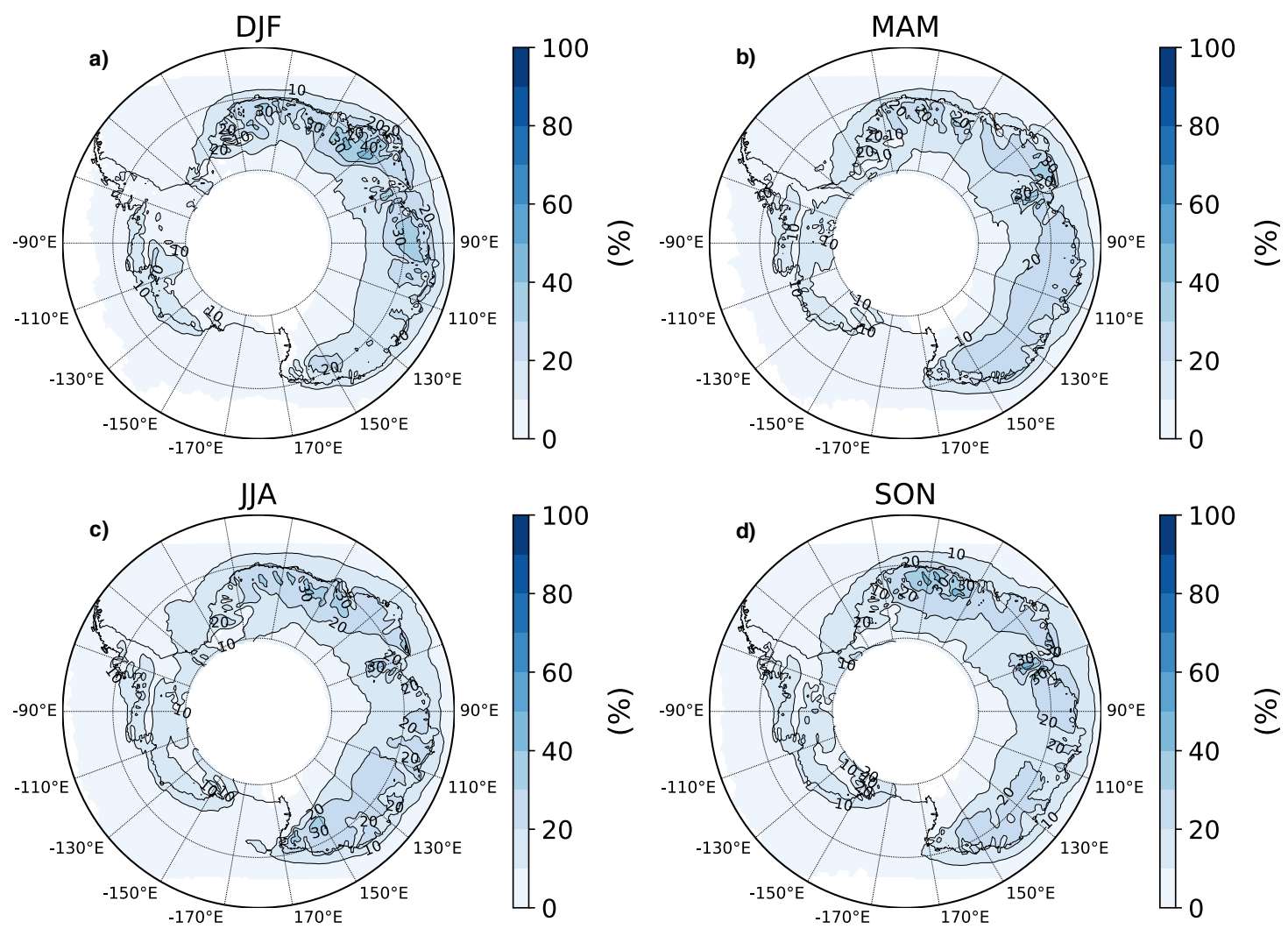

Supplementary Figure C.9: The percentage of the total snowfall that can be attributed to AR landfalls using the precipitation attribution method for a) DJF, b) MAM, c) JJA, and d) SON 1980-2018. 

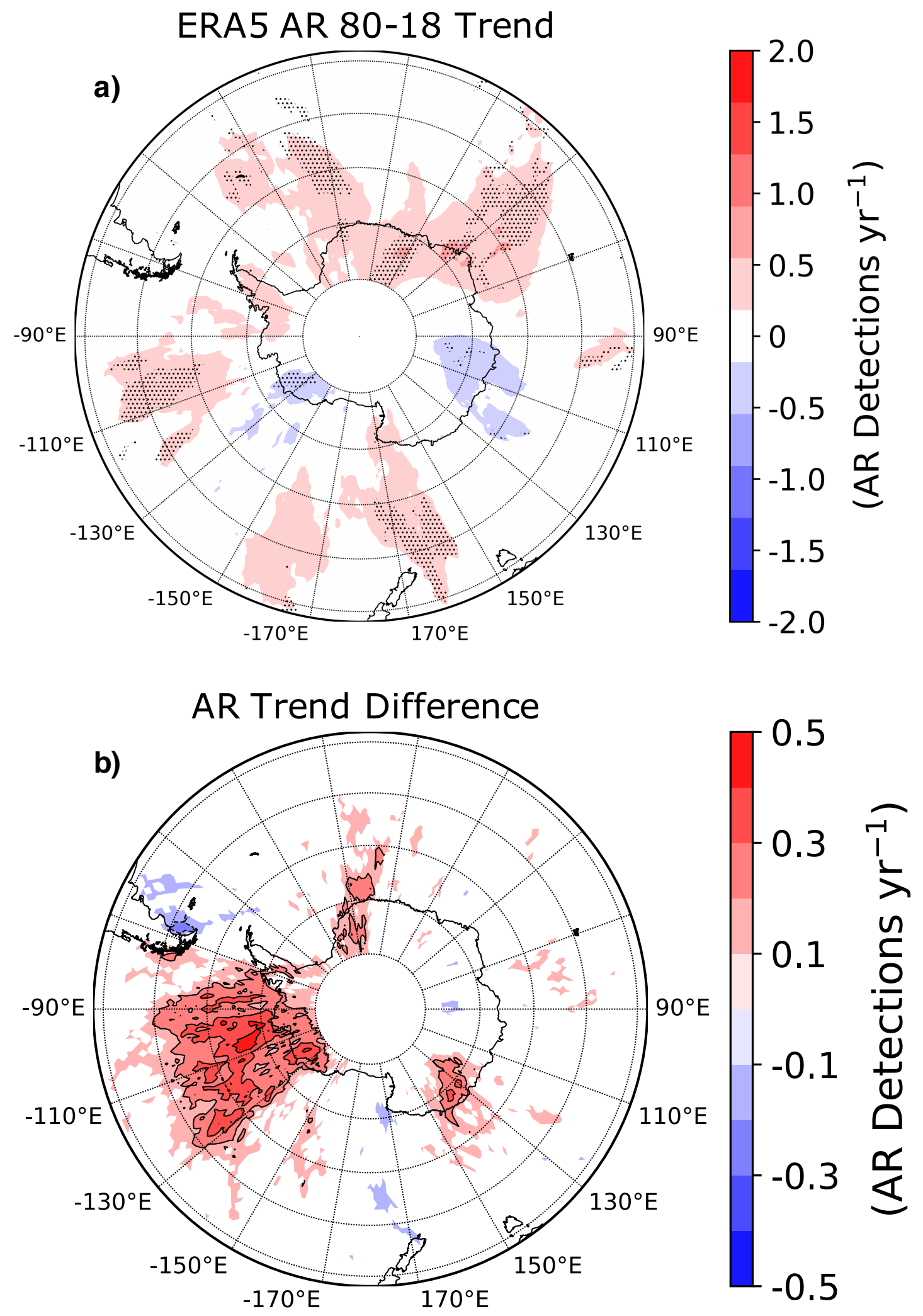

Supplementary Figure C.10: a) The trends in annual AR frequency measured by detections per year for 1980-2018 when using the ERA-5 AR catalog. Black circles represent areas of significant trends (p-value $<0.025)$. b) The difference in the annual AR frequency trend between the MERRA-2 and ERA-5 AR catalogs. 

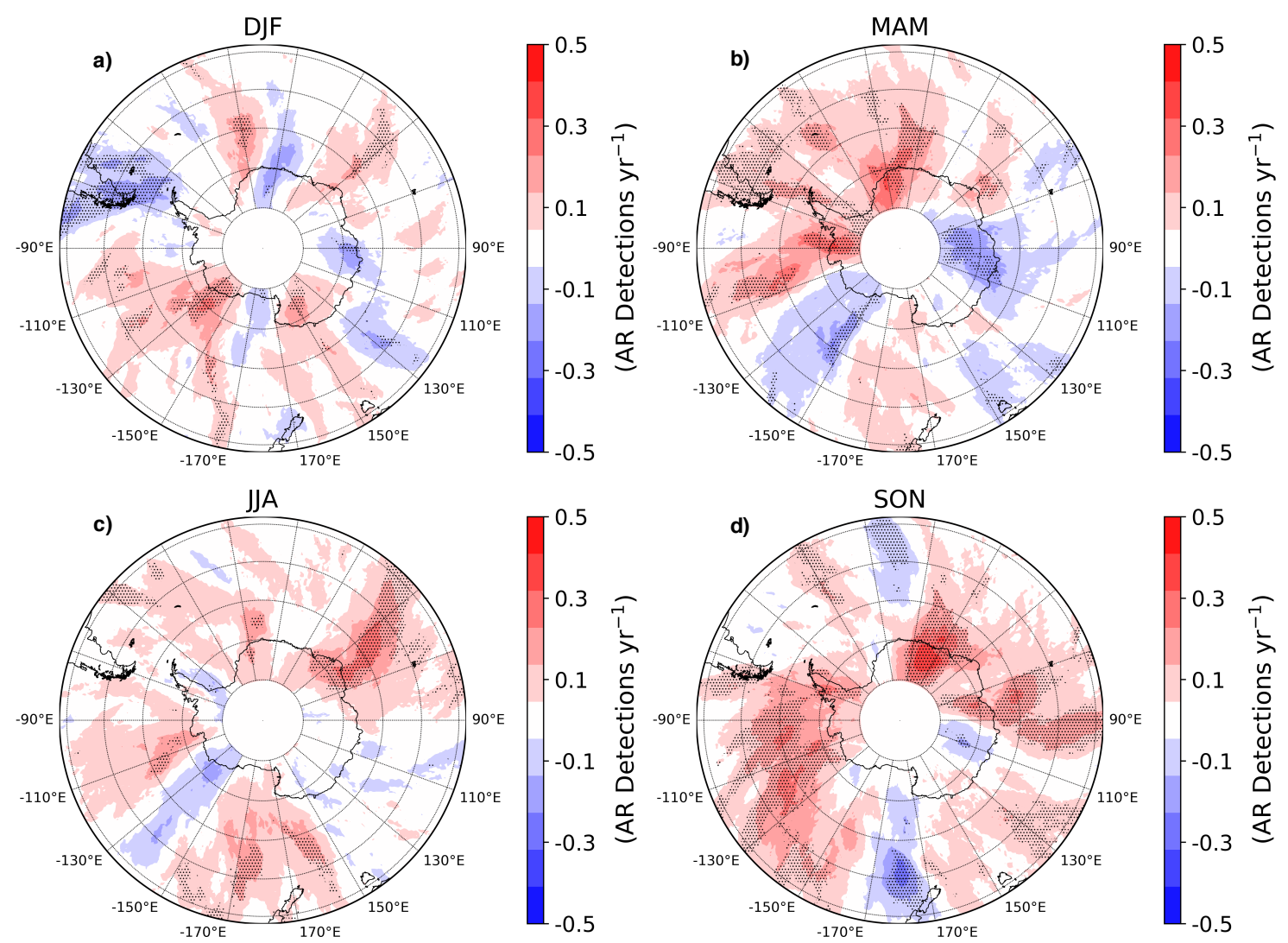

Supplementary Figure C.11: The trends in seasonal AR frequency measured by detections per season for a) DJF, b) MAM, c) JJA, and d) SON 1980-2018. Black circles represent areas of significant trends ( $\mathrm{p}$-value $<0.025)$. 

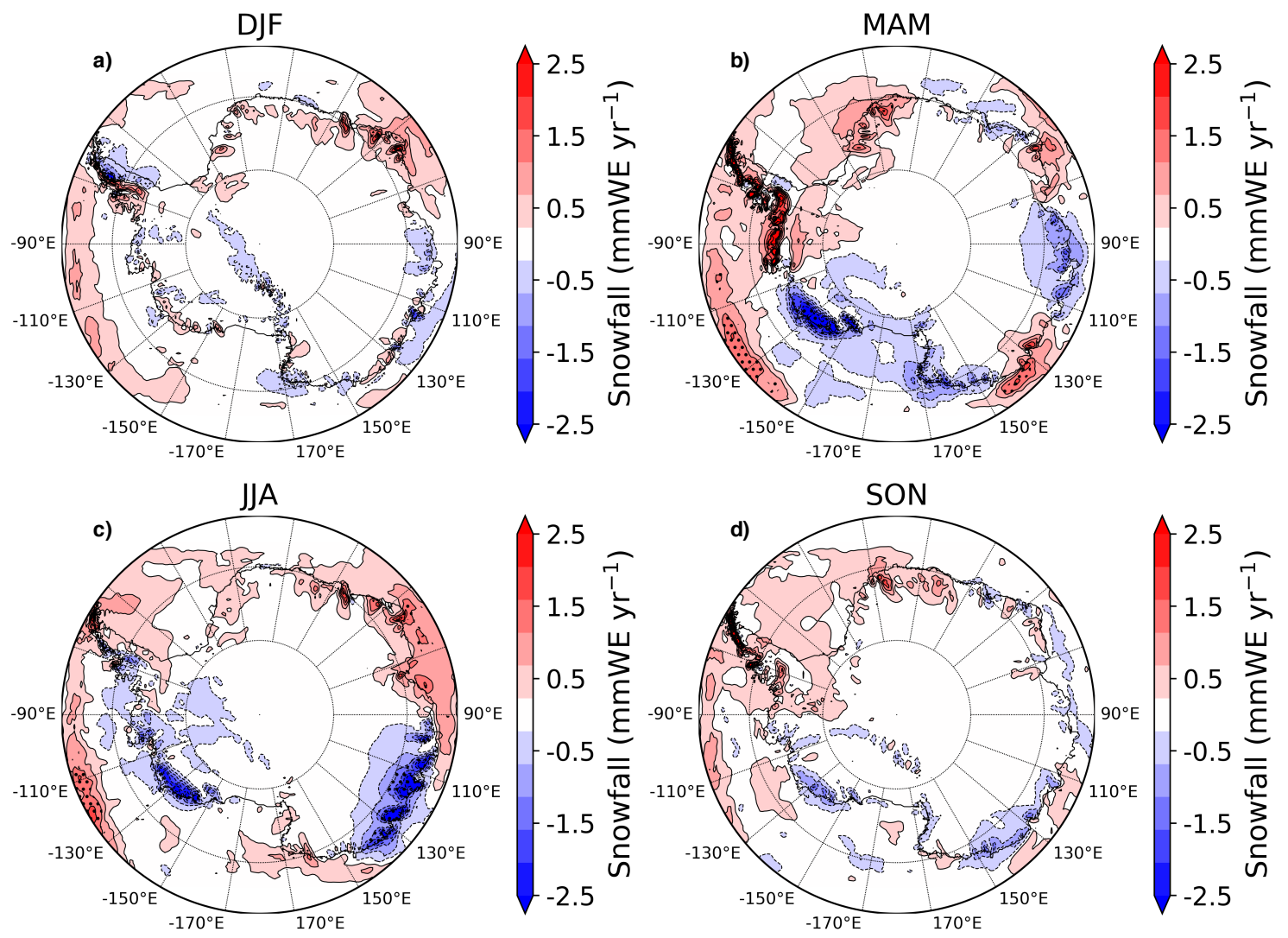

Supplementary Figure C.12: The trends in seasonal accumulated snowfall by MAR for a) DJF, b) MAM, c) JJA, and d) SON 1980-2018. Black circles represent areas of significant trends ( $\mathrm{p}$-value $<0.025$ ) 

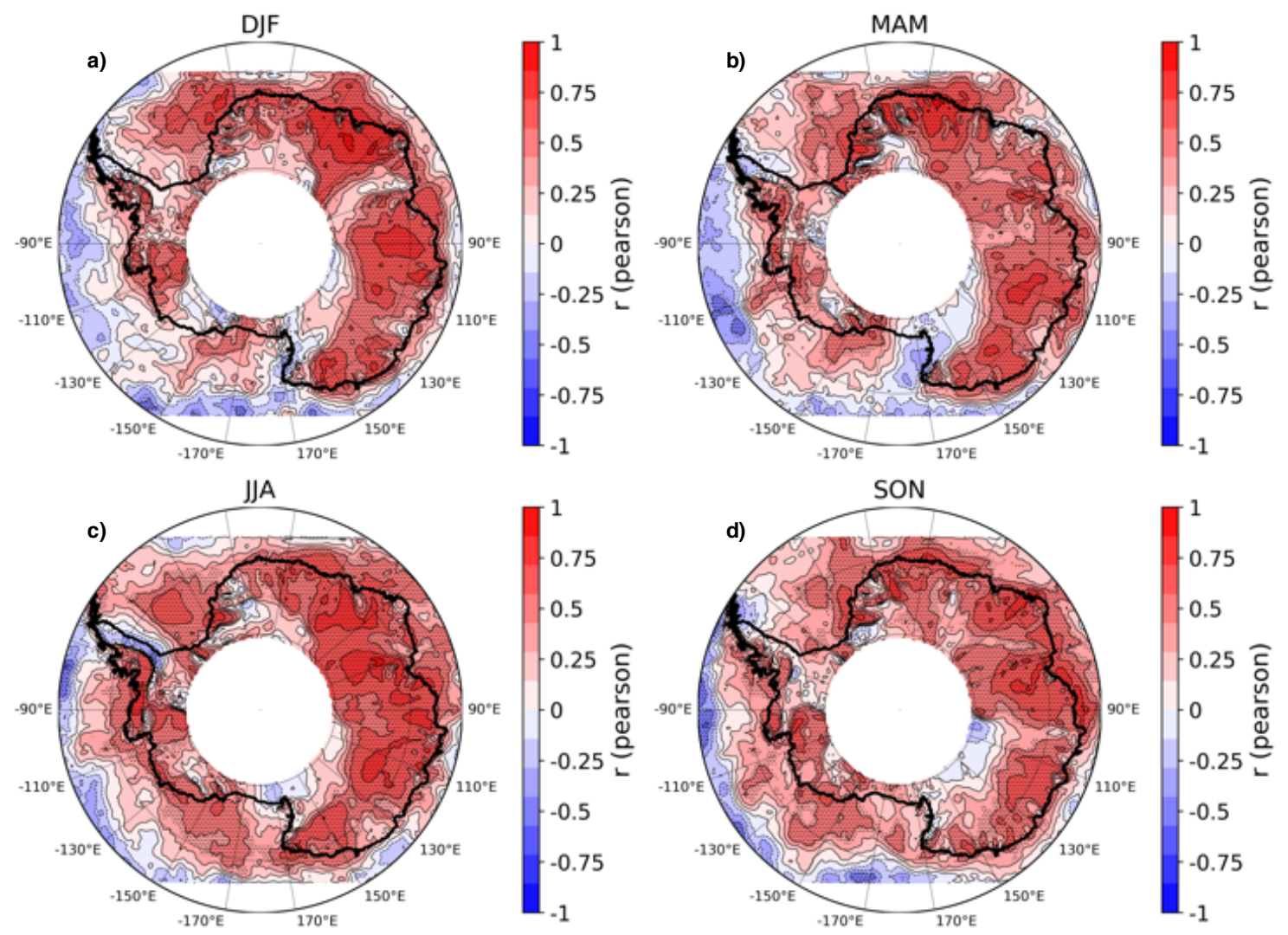

Supplementary Figure C.13: The Pearson's correlation coefficient (r-values) between seasonal AR frequency and seasonal snowfall accumulation from MAR for a) DJF, b) MAM, c) JJA, and d) SON 1980-2018. Black circles represent areas of significant correlations ( $\mathrm{p}$-value $<0.025$ ) and both datasets are detrended. 

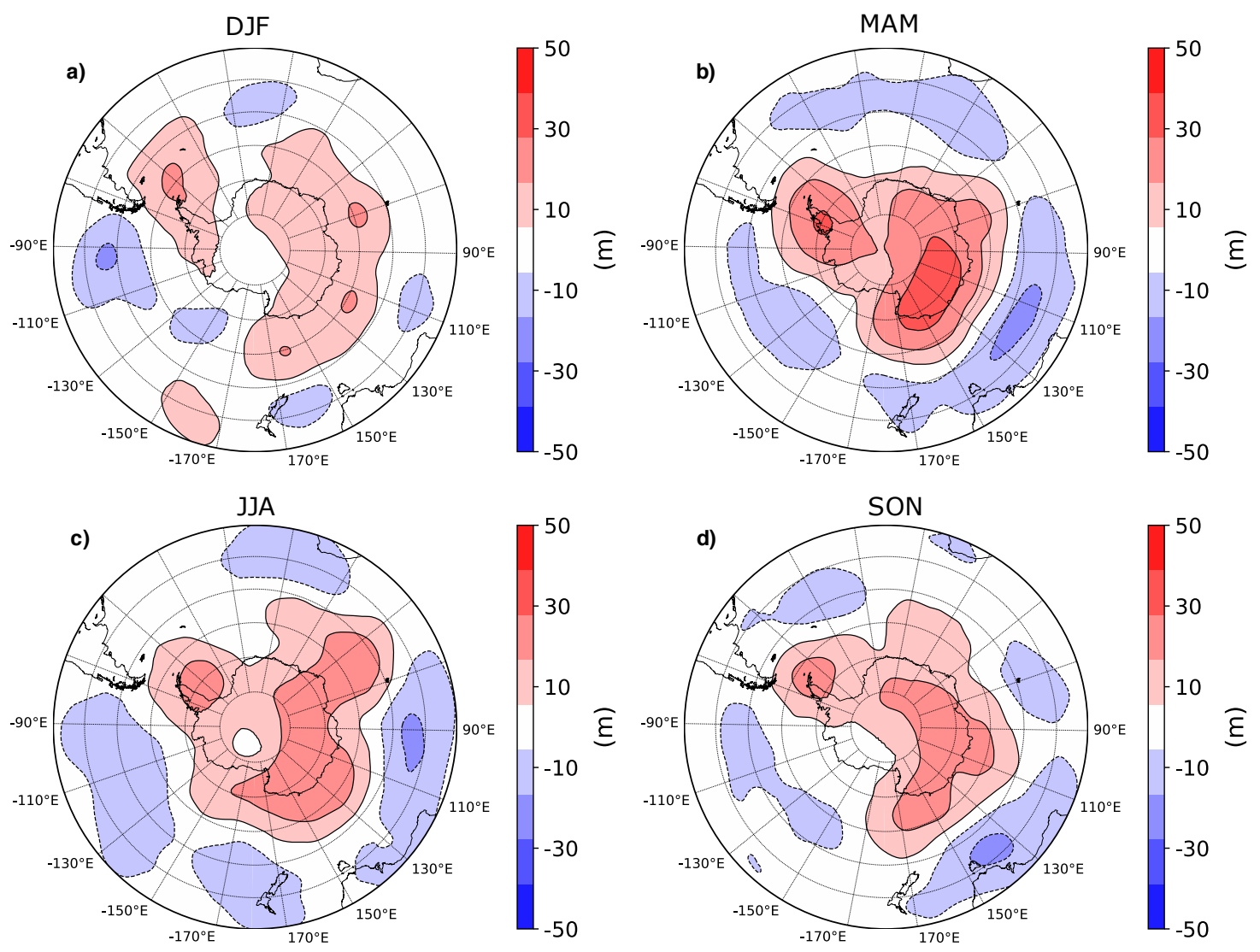

Supplementary Figure C.14: Composite MERRA-2 $500 \mathrm{hPa}$ geopotential height anomalies for AR landfalls during a) DJF, b) MAM, c) JJA, and d) SON 1980-2018. 


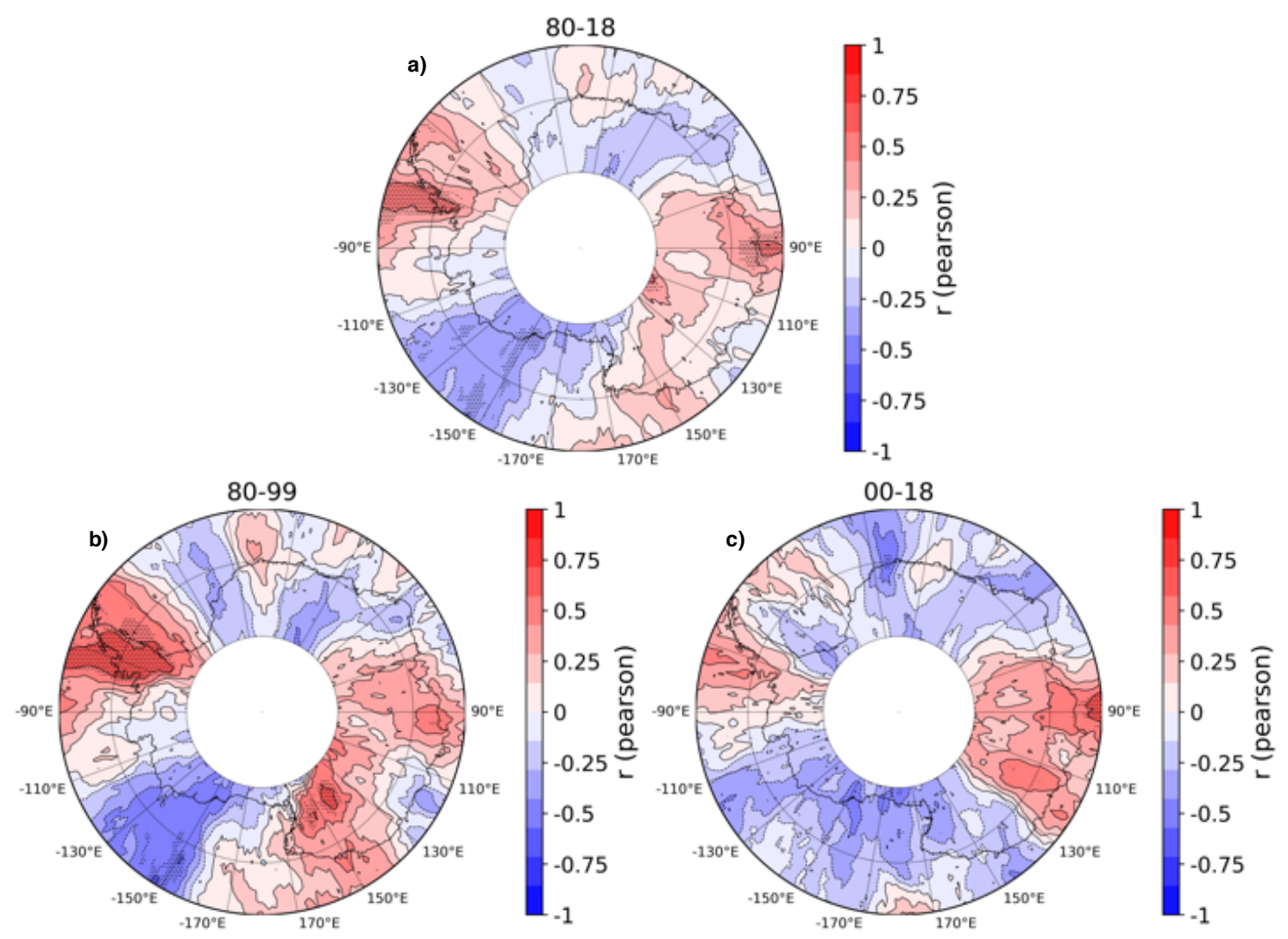

Supplementary Figure C.15: The Pearson's correlation coefficent (r-values) between annual AR frequency using the ERA-5 AR catalog and annually averaged Marshall SAM index for a) 1980-1999, b) 2000-2018, and c) 1980-2018. Black circles represent areas of significant correlations $(p$-value $<0.025)$ and both datasets are detrended. 

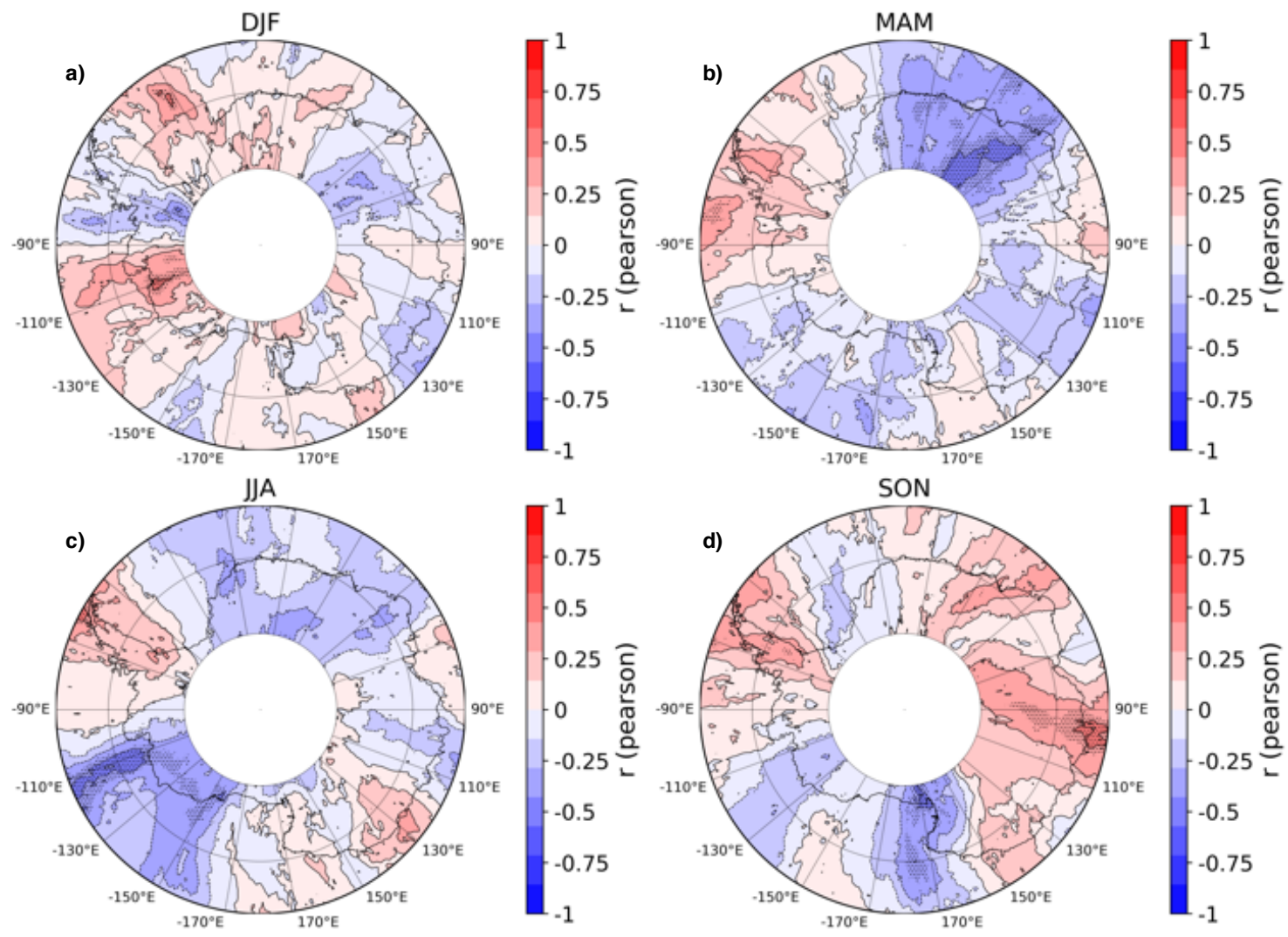

Supplementary Figure C.16: The Pearson's correlation coefficent (r-values) between seasonal AR frequency and seasonally averaged Marshall SAM index for a) DJF, b) MAM, c) JJA, and d) SON 1980-2018. Black circles represent areas of significant correlations ( $\mathrm{p}$-value $<0.025$ ) and both datasets are detrended. 

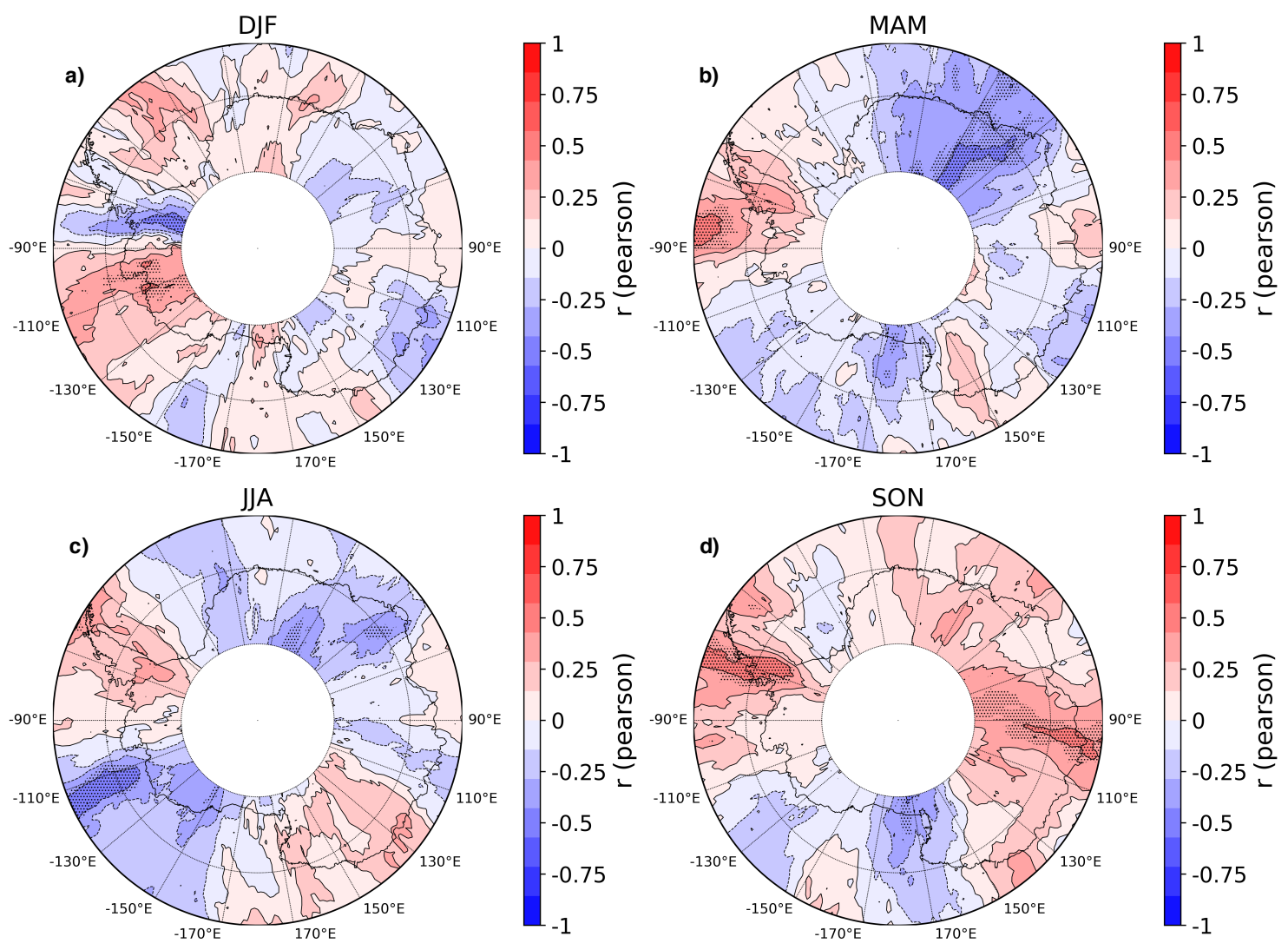

Supplementary Figure C.17: The Pearson's correlation coefficent (r-values) between seasonal AR frequency using the ERA-5 AR catalog and seasonally averaged Marshall SAM index for a) DJF, b) MAM, c) JJA, and d) SON 1980-2018. Black circles represent areas of significant correlations ( $\mathrm{p}$-value $<0.025)$ and both datasets are detrended. 


\section{Appendix D}

Code for atmospheric river detection algorithm: Wille_v1 
\#Atmospheric river detection algorithm using IWV. Version 1.0 .1

\#Note: After Wille et al. (2019) was accepted, a small error was discovered on line 101

\#0riginally "if lat_mask[coast_idx[x2_idx[i]]] >= y_idx[i]:" was "if Tat_mask[coast_idx[x2[i]]] >=y_idx[i]: \#The error correction slightly increases the amount of detected AR landfalls, but does not significantly impact the results.

from netCDF4 import Dataset

import numpy as np

import matplotlib.pyplot as plt

import shapefile

import netCDF4 as nc

import cartopy

from pylab import *

from scipy. interpolate import griddata

import io

from matplotlib import animation

import sys

import operator

import glob, os

import pickle

import csv

\#import pdb; pdb.set_trace()

\#Define the boundaries of the quadrants and halves in relation to reanalysis dataset

\#There are three different lines where the quadrant/half names are inputed

\#Line 43

\#Line 57

\#Line 58

\#Also the AR time index output files have to be changed based on the quadrant/half used

EAIS = slice $(0,120)$ \#The DML-PEL quadrant

DDU = slice $(120,240)$ \#The Wilkes Land quadrant

WAIS $=$ slice $(240,360)$ \#The WAIS quadrant

wed $=\operatorname{slice}(360,480)$ \# The AP-Weddell quadrant

EAIS_DDU $=\operatorname{slice}(0,240)$ \# East Antarctica half

WAIS_wed $=\operatorname{slice}(240,480)$ \# West Antarctica half

\#Read in the 12 files containing the monthly precipitable 
water values from 1979-2017

os. chdir("/media/willej/storage1/data/ERAI/pwat/month/

79 1 $\left.17^{\prime \prime \prime}\right)$

datevar list $=[]$ \#empty list later used to store the AR dates

mon =

['01', '02', '03', '04', '05 ', '06 ', '07', '08 ', '09 ', '10 ', '11', '12 ']

file2 = "/media/willej/storage1/data/ERAI/land_sea.nc"

\#Land/sea mask file

fh2 $=$ Dataset $\left(f i l e 2, \operatorname{mode}={ }^{\prime} r\right.$ ', format $\left.={ }^{\prime N E T C D F 4 " ~}\right)$

lsm = fh2. variables[' $\left.{ }^{\prime} \mathrm{sm}^{1}\right][0,::-1$,WAIS_wed] \#Reverse the

land mask looking from the $90 \mathrm{~S}$ to north

lat_mask = fh2. variables ['latitude'] [:: -1$]$

\#The minimum latitude that equals 0 (ocean) for each

longitude value

coast_idx $=$ np.argmin( $(\mathrm{sm}, \operatorname{axis}=0)$

$b=0$ \#counter for the month

for file in sorted(glob.glob("*")):

print (file)

\#Read in data

fh1 = Dataset (file, $\operatorname{mode}={ }^{\prime} r$ " , format $=$ "NETCDF4" $)$

lat = fh1.variables ["lat'][20:67] \#The latitude range

of consideration is from -45 to -79.5

lon $=$ fh1.variables [" lon'] [WAIS_wed]

pwat $=$ fh1. variables ['pwat'] [: ,20:67,WAIS_wed]

time2=fh1.variables ["time"] [: ]

units=fh1.variables ['time']. units

\#Extract the date information

try:

cal = fh1.variables ['time'], calendar

except AttributeError :

\# Attribute doesnt exist

$\mathrm{cal}=$ 'standard'

datevar=( nc . num2date (time2, units=units, calendar=cal) )

fh1. close ( )

\#Begin the algorithm

pwat_per = np.percentile(pwat, 98, axis=0) \#Calc the 
98th percentile of pwat at all points

\#Create indicies where the pwat exceeds the 98th percentile

indices $=n p \cdot$ where (pwat $>$ pwat_per) \#Create indicies

where the pwat exceeds the 98th percentile

time $=$ indices [0] \#The time indices

$y=$ lat [indices[1] ] \#The latitude numbers

$x=$ lon[indices[2] ] \#The longitude numbers

x2 = indices[2] \#The longitude indices

timesteps = unique(time) \# unique timesteps, avoids if(timestep != prev_timestep) loop

river_idx = [] \#This list will store all AR detections

landfäll_idx = [] \#This list will store AR landfalls only

for timestep in timesteps: \#Cycle through the timesteps in each monthly file

timestep_idx = np. where(timestep == time) [0]

\#organize the indices by time

$y_{-} i d x=y[$ timestep_idx]

$x \_i d x=x[$ timestep_idx $]$

$x \overline{2} \_i d x=x 2$ [timestep_idx]

if not (y_idx[:-1] - y_idx[1:] > 1) any(): \# checks

the difference between successor/predecessor latitudes at

the array level (no loop)

if $y_{-} i d x, \max ()-y_{-} i d x, \min ()>20$ : \#The

difference between the minimum and maximum latitude river_idx.append(timestep) \#Attach the

timestep to the all AR list

$$
\begin{aligned}
i & =n p \cdot \operatorname{argmin}\left(y_{-} i d x\right) \\
t & =n p \cdot \operatorname{argmax}\left(y_{-} i d x\right)
\end{aligned}
$$

if lat mask[coast idx[x2 idx[i]] ] >=

y_idx[i]: \#If the minimum latitude is at or below the

latitude of the coastline

AR is considered a landfall

landfall_idx.append(timestep) \#Then the

datevar_list.append(datevar[landfall_idx])

\#\#\#\#\#\#\#\#\#\#\#\#\#\#\#\#\#\#\#\#\#\#\#\#\#\#\#\#\#\#\#\#\# Creation fichiers textes

\#Create two text files: One for the AR time indices for all rivers and one for ARs that make landfall 
with open('/home/willej/Documents/data/ERAI/'+mon [b] +' 79_17_WAIS_wed_all_idx_v1.dat', 'W') as file:

file.write( '\n'.join(str(idx) for idx in river_idx))

with open( '/home/willej/Documents/data/ERAI/ '+mon [b]

+" 7917 WAIS wed landfall idx v1.dat', "W') as file:

file.write (" $\backslash n^{\prime}$. join $(\operatorname{str}(i d x)$ for idx in

landfall_idx))

print(mon[b]) \#output the month to check if the file matches the correct month

$\mathrm{b}=\mathrm{b}+1$

\#0utput the list of AR landfall dates

datevar_list $=$ np. asarray (datevar_list)

with open('/home/willej/data/ERAI/ar_dates/

WAIS_wed_ar_dates.dat', 'W') as file:

file.write('\n'.join(str(idx) for idx in datevar_list))

print (datevar_list) 


\section{Appendix E}

\section{Code for atmospheric river detection}

\section{algorithm: Wille_v2}

\section{Code summary}

The process the algorithm goes for each timestep through can be summarized as follows: (1) Scan the grid cells that are within the 98th percentile in the meridional direction and split the shapes into separate arrays if there is a discontinuity. (2) Save the array with the highest length. (3) If that array is greater than $20^{\circ}$ latitude in length, save the array and then rearrange the array to be scanned in the longitudinal direction. (4) Split the array into separate arrays anywhere a discontinuity in the longitudinal direction greater than $20^{\circ}$ occurs. (5) Rearrange all the arrays again to be scanned in the meridional direction. (6) Take each remaining array and split them if there is a discontinuity in the meridional direction. (7) If any of the elements from the split array are greater than $20^{\circ}$ latitude in length, then it is a proper discrete AR shape and the coordinates are saved to a final, master array. 
\#from mpl_toolkits.basemap import Basemap

from netCDF4 import Dataset

import numpy as np

import matplotlib.pyplot as plt

import shapefile

import netCDF4 as nc

import cartopy

from pylab import *

\#from mpl_toolkits.basemap import Basemap, maskoceans, addcyclic, shiftgrid

from scipy. interpolate import griddata

import io

from matplotlib import animation

import sys

import operator

import glob, os

import pickle

import cSV

np. set_printoptions (threshold=sys : maxsize)

\#import pdb; pdb.set_trace()

\#This script will run the atmospheric river detection algorithm using VIVT data. This script is configured for MERRA-2 data

\#Create the array and coordinates settings that will be used to store the output of the detection algorithm

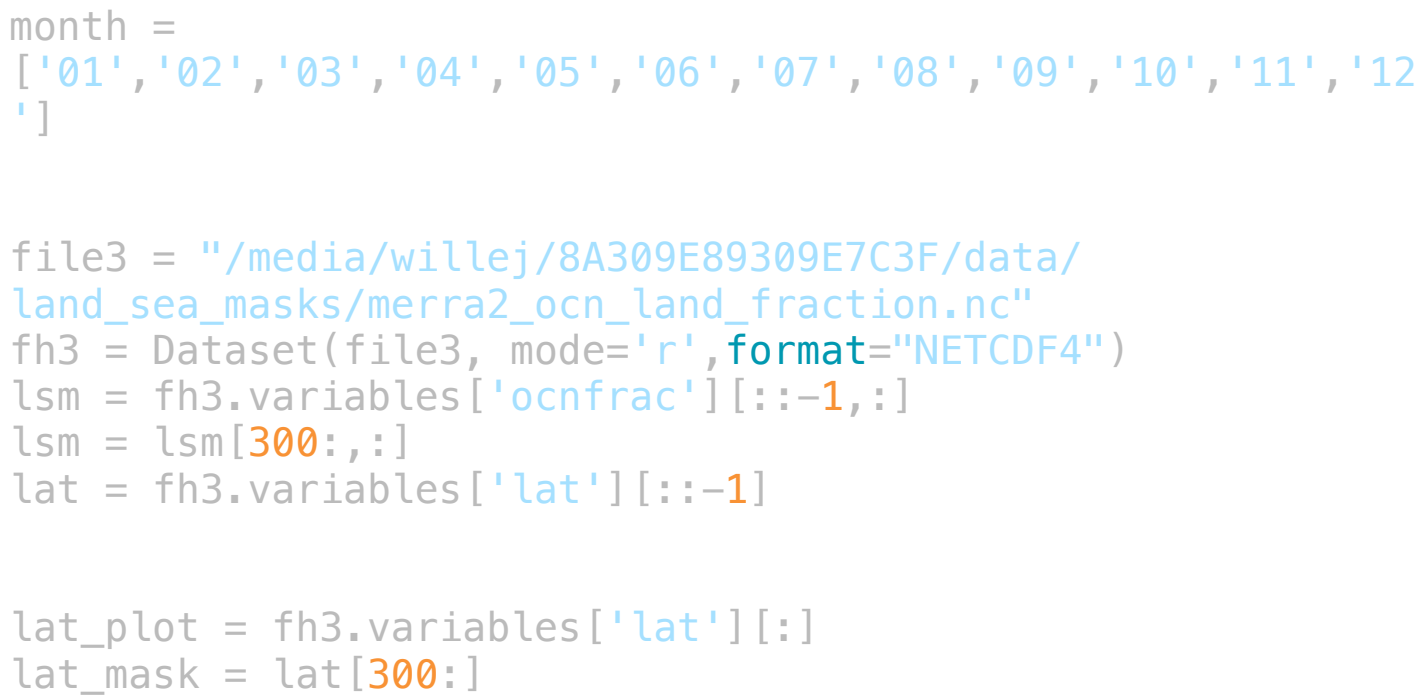




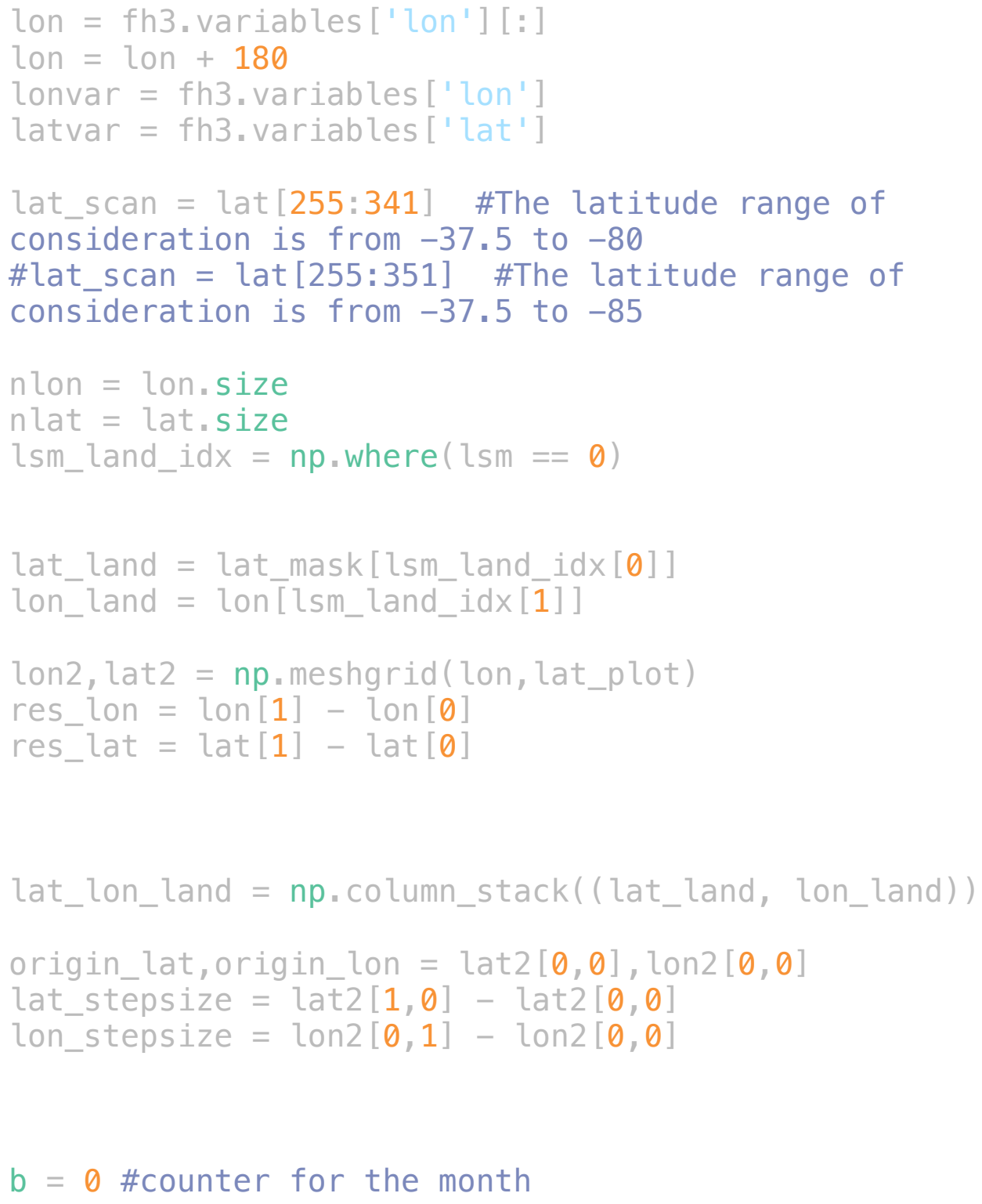

\#Read in the monthly vIVT files

for mon in month: \#loop through the files; the MAR melting data and the AR indicies print (mon)

file1 = "/media/willej/8A309E89309E7C3F/data/VIVT_IWV/ MERRA2/80_19/ivt/1_hourly/ant_merra2_1980_2019_"+mon+ " nc"

$\operatorname{print}(f i l e 1)$ 


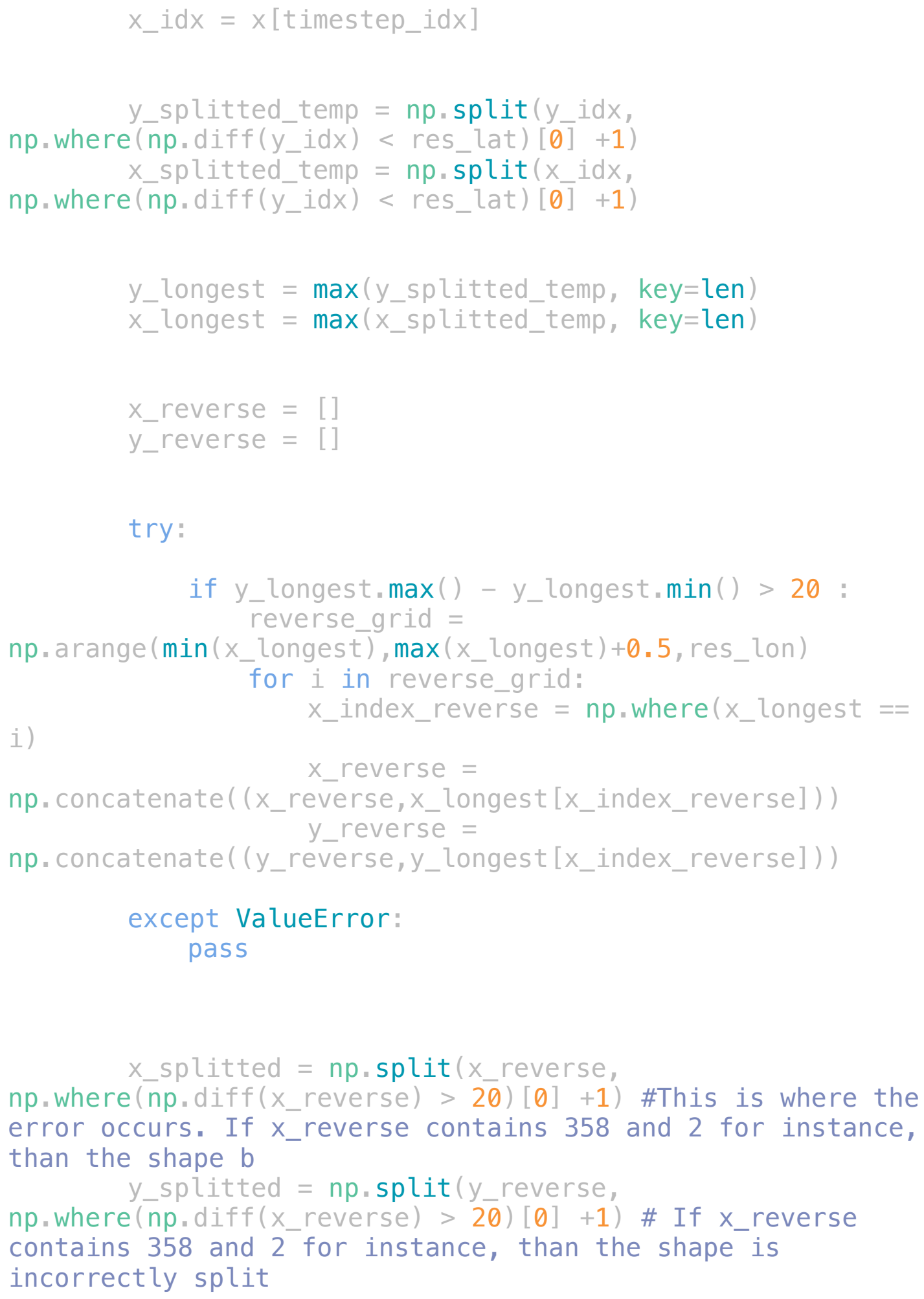


try:

20:

if x_splitted[0][0]+360 - x_splitted [-1][-1] <

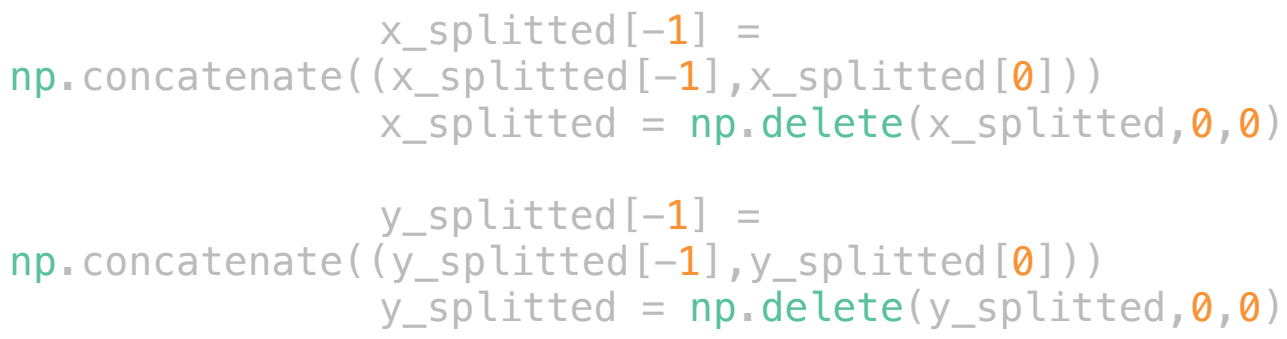

try:

reverse_grid2 $=$

np. arange (max (y_splitted [i]), min(y_splitted [i])-0.5, res_lat )

for $j$ in reverse_grid2:

np. where (y_splitted $[\bar{i}]==\bar{j}$ )

$$
y_{\text {__index_reverse2 }=}
$$

$$
\text { x_reverse2 = }
$$

np. concatenate( (x_reverse2, $x$ _splitted [i]

[y_index_reverse2]) )

y_reverse2 =

$\mathrm{np}$. concatenate( (y_reverse2,y_splitted [i]

[y_index_reverse2]))

except ValueError: 
pass

try:

y_splitted_final $=$ np.split $\left(y \_r e v e r s e 2\right.$, np. where (np.diff(y_reverse2) < res_lat) [0] +1)

x_splitted_final $=$ np.split $\left(x_{\text {_ }}\right.$ reverse2, np. where (np.diff(y_reverse2) < res_lat)[0] +1)

for $z$ in $\operatorname{range}(0$, len(y_splitted_final)): if y_splitted_final[z]. $\max ()-$ y_splitted_final[z],min() > 20: y_splitted_final[z])) x_splitted_final[z]))

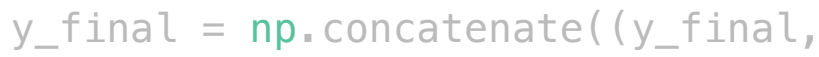
x_final = np. concatenate ( $\left(x \_f i n a l\right.$,

$x$ _shape $=n p \cdot$ concatenate $\left(\left(x \_\right.\right.$shape, $x \_f$ inal $\left.)\right)$

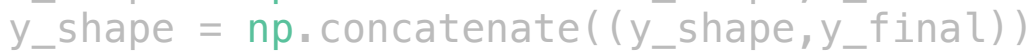

except ValueError:

pass

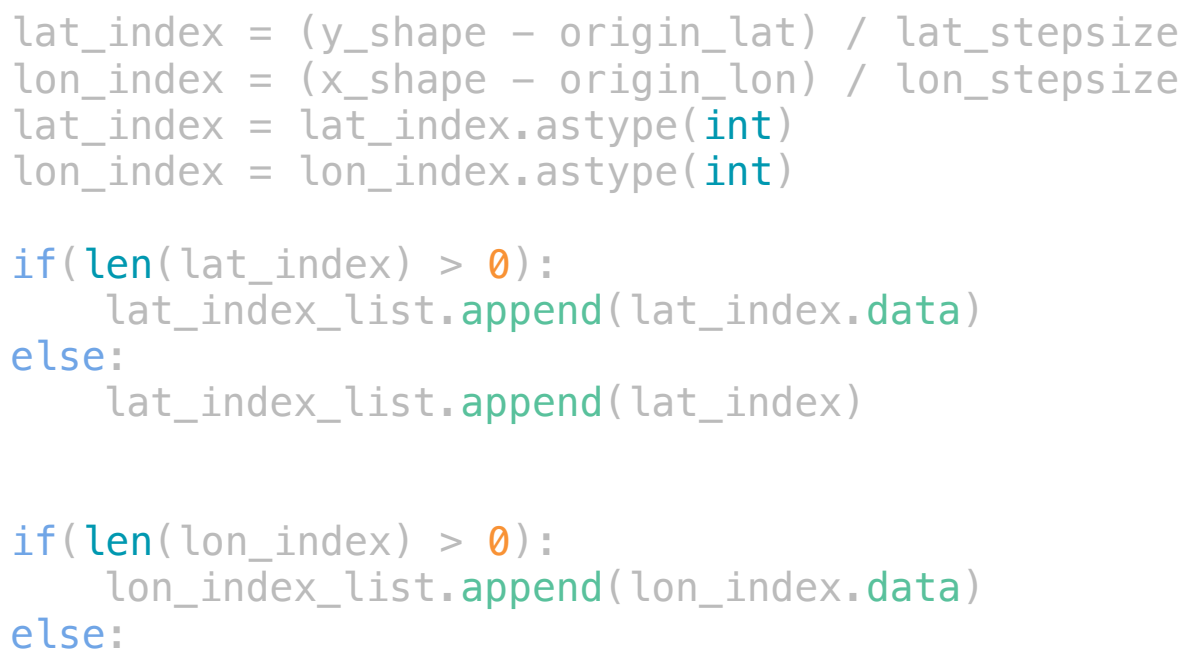




\section{lon_index_list.append( lon_index)}

\#Save the latitude and longitude indices of where AR shapes are detected

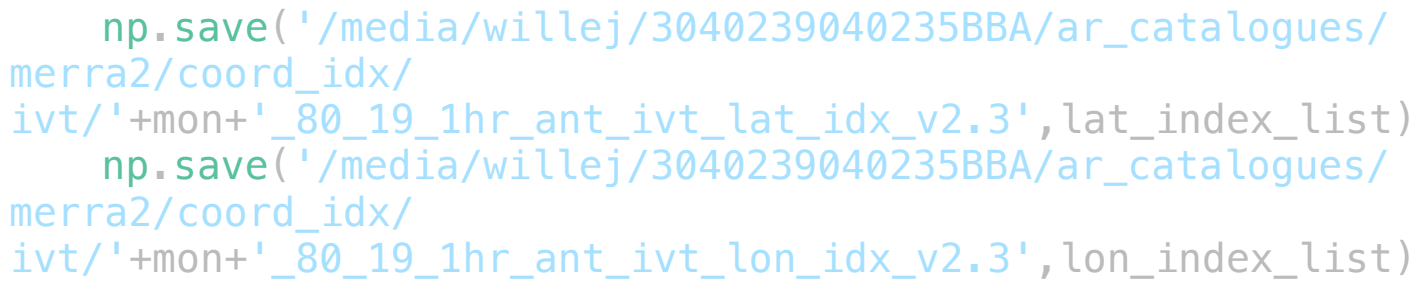


Appendix E. Code for atmospheric river detection algorithm: Wille_v2 